\title{
Foreign Language Learning Motivation in Higher Education: A Longitudinal Study on Motivational Changes and their Causes
}

\author{
Vera Busse, \\ Pembroke College
}

Department of Education, University of Oxford

Thesis submitted to the University of Oxford for the degree of Doctor of Philosophy. Michaelmas Term, 2010.

Word Count: 95000 (approx.) 


\section{Acknowledgments}

Working on a doctoral thesis about motivational changes is not without irony, as one inevitably ends up critically analysing one's own motivational ups and downs during its long gestation period. This thesis derives from my intrinsic interest in the topic; the finished product, however, is certainly a tribute to those people who helped me to maintain my enthusiasm over the last three and a half years. I would therefore like to express my heartfelt gratitude to all those who supported me during this challenging time.

First of all, I am indebted to my two supervisors, Dr Lynn Erler and Dr Catherine Walter. Thank you Lynn, you helped me through the difficult time of conceptualising the study in its present form; thank you also for staying in touch with me after your retirement. Thank you, Catherine, for helping me to make sense of the intimidating mass of data generated by this longitudinal project; thank you also for your thoughtful comments on the (very many) drafts of my chapters. A big thank you also to all the students who participated in the project, and, of course, thank you to my assistant Vicky.

Thank you, too, to Prof. Zoltán Dörnyei, for receiving me in Nottingham and for introducing me to my friend and fellow researcher, Florentina Taylor. Thanks, Florentina, for discussions, feedback and encouragement! Thanks a lot also to Dr Bob Vanderplank, dear Bob, thanks a lot for providing me with the proximal goals of writing book reviews for System; your encouraging feedback proves the power of verbal persuasion on self-efficacy beliefs. My warmest thanks also go to my fellow graduate students, in particular to John, thanks for your invaluable advice regarding stats questions, and Margot, thanks for moral support!

My gratitude also goes to all my other dear friends. Thanks, Claudia for ongoing support and in particular for believing in me at a time when everyone else thought that with a job and two little children there was little point in even attempting to do a D.Phil. project. Thanks also to you, Sally, for making me see the power of imagination and the importance of 
nourishing our ideal self visions from a literary perspective. And thank you, too, to Nicole and family, for food supply and layout advice in the final spurt towards completion.

Last but not least, my gratitude goes to my family: to Gudrun and Norbert who passed on to me a sound basis of stubbornness (quite necessary for long-term projects), to my mother-in-law, Estela (without your help and your dedication to the boys I could have never found the time to engage with the project, thank you so much); to my husband and friend Sebastian (thank you for staying up with me at night to make sense of Cohen's cryptic work on statistical power analysis; thank you for giving me the opportunity of discussing my work with you - there is certainly nothing like standing up against the scrutiny of a theoretical physicist); and to my children, Julian and Nicolas. You two have taught me a great deal about the value of self-determination theory; although it is sometimes hard to live with two very headstrong little boys who dress themselves in red jackets with pink shirts and green trousers, I will do my very best to foster your growing sense of autonomy. 


\begin{abstract}
L2 motivational research may be described as an ongoing quest to identify motivational attributes underlying motivated language learning behaviour. This study employs a novel theoretical and methodological focus in this endeavour: firstly, it applies theories of the self to a motivational exploration of L2 motivation involving first-year students studying towards German degree courses at two major UK universities. Secondly, the study explicitly addresses the time- and context-sensitive nature of motivational attributes. While the majority of L2 motivational studies treat motivational attributes as static and rely heavily on one-off surveys, this study uses a longitudinal mixed-methods approach. Questionnaires were administered at the beginning and at the end of the academic year, and students were interviewed five times over the course of the academic year. Results suggest that the concept of integrative orientation in its traditional sense plays a minor role for these students. The concepts of the ideal L2 self and intrinsic motivation are better suited to capture these students' motivation for studying German, and together with self-efficacy beliefs they offer a good basis for understanding students' motivated engagement with language learning throughout the year. However, the data also reveal that considerable changes take place during the course of the year. Importantly, students' intrinsic motivation significantly decreases and so do self-efficacy beliefs for speaking and listening, a trend concomitant with decreasing effort to engage with language learning. The qualitative data shed light on the motivational changes observed, and provide a detailed and rich picture of the interplay between motivation and contextual factors. Based on the empirical insights gained, a theoretical framework is proposed which links the motivational attributes examined and situates them within multilayered contextual spheres. The thesis concludes by outlining pedagogical suggestions how to counteract decreasing motivation during the first year at university.
\end{abstract}




\section{Table of Contents}

1 INTRODUCTION AND BACKGROUND 8

$\begin{array}{lll}1.1 & \text { Rationale } & 10\end{array}$

$\begin{array}{lll}\text { 1.1.1 Why is a study on motivation for learning German at university level of interest? } & 10\end{array}$

$\begin{array}{ll}\text { 1.1.2 Why is studying the first year at university important? } & 11\end{array}$

$\begin{array}{ll}\text { 1.1.3 What does motivational research offer? } & 13\end{array}$

$\begin{array}{ll}\text { 1.1.4 What contribution does the study make to the field? } & 17\end{array}$

$\begin{array}{llr}1.2 & \text { Organisation of the thesis } & 18\end{array}$

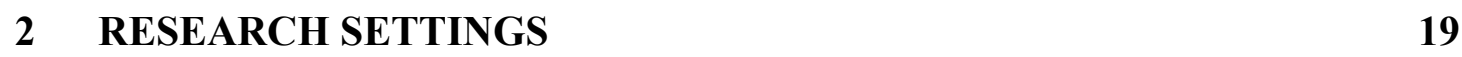

$\begin{array}{llr}2.1 & \text { University A } & 19\end{array}$

$\begin{array}{llr}2.2 & \text { University B } & 23\end{array}$

3 LITERATURE REVIEW $\quad 28$

$\begin{array}{llr}3.1 & \text { Introduction } & 28\end{array}$

$\begin{array}{ll}3.2 & 29\end{array}$

3.3 Influential Theories in Mainstream Motivational Research $\quad 29$

$\begin{array}{lll}\text { 3.3.1 Goal Theories, Value-Expectancy Theory and Attributions } & 31\end{array}$

$\begin{array}{llr}3.4 & 35\end{array}$

$\begin{array}{lll}3.4 .1 & \text { Self-Determination Theory } & 36\end{array}$

$\begin{array}{lll}3.4 .2 & \text { Self-Efficacy } & 41\end{array}$

$\begin{array}{lll}3.4 .3 & \text { Possible Selves } & 49\end{array}$

3.5 Motivation to Learn Languages $\quad 55$

$\begin{array}{lll}3.5 .1 & \text { The Early Days } & 56\end{array}$

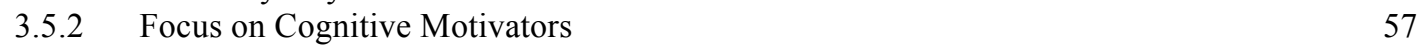

$\begin{array}{lll}3.5 .3 & \text { Motivation and Time } & 63\end{array}$

$\begin{array}{ll}\text { 3.5.4 Self-Concepts in L2 Motivational Research } & 72\end{array}$

\begin{tabular}{|rr} 
3.6 Implications for the Current Approach to Motivation & 88
\end{tabular}

$\begin{array}{lll}3.7 & \text { Defined Research Aims } & 90\end{array}$

4 METHODOLOGY AND PROCEDURES 92

4.1 Considerations on the nature of the research aims: towards a combined use of
qualitative and quantitative methods

4.1.1 Conceptual Implications of the Chosen Approach 94

$\begin{array}{lll}\text { 4.1.2 } & \text { Epistemological Beliefs } & 97\end{array}$

4.2 Considerations on the nature of the research aims: towards a longitudinal design 99

$\begin{array}{lll}4.2 .1 & \text { Practical Implications of Chosen Approach } & 100\end{array}$

$\begin{array}{llr}4.3 & \text { Participants and Setting } & 101\end{array}$

$\begin{array}{ll}\text { 4.3.1 Sampling for Questionnaire } & 102\end{array}$

$\begin{array}{ll}\text { 4.3.2 Sampling for Interviews } & 104\end{array}$ 
4.4 Instruments $\quad 105$

4.4.1 Questionnaire 105

$\begin{array}{ll}4.4 .2 & \text { Interviews } \\ \end{array}$

$\begin{array}{lll}4.5 & \text { Procedures } & 111\end{array}$

4.5.1 Questionnaire 112

$\begin{array}{ll}\text { 4.5.2 Interviews } & 115\end{array}$

$\begin{array}{ll}\text { 4.6 Data Analysis } & 116\end{array}$

4.6.1 Questionnaire 116

$\begin{array}{ll}4.6 .2 & \text { Interviews } \\ \end{array}$

4.7 Ethical Considerations 119

4.7.1 Quality Criteria and Limitations of Chosen Approach 122

\section{WHY GERMAN? - STUDENTS' MOTIVATION TO STUDY GERMAN AT UNIVERSITY LEVEL AT THE BEGINNING OF THE ACADEMIC YEAR 125}

5.1 Questionnaire Results $\quad 125$

$\begin{array}{lll}5.1 .1 & \text { Distribution of the six motivational variables } & 125\end{array}$

$\begin{array}{ll}\text { 5.1.2 The perceived role of six motivational variables } & 126\end{array}$

5.1.3 Wish for Language Proficiency 130

$\begin{array}{lll}\text { 5.1.4 Integrative Reasons } & 131\end{array}$

$\begin{array}{ll}\text { 5.1.5 Relationship between variables } & 132\end{array}$

5.2 Interview Results 134

5.2.1 Enjoyment of the Language Learning as Reason for Studying German 136

$\begin{array}{lll}5.2 .2 & \text { School experience } & 137\end{array}$

$\begin{array}{ll}\text { 5.2.3 Wish for Language Proficiency } & 141\end{array}$

$\begin{array}{lll}5.2 .4 & \text { Ideal L2 self } & 142\end{array}$

$\begin{array}{lll}\text { 5.2.5 Instrumental Reasons for Studying } & 144\end{array}$

$\begin{array}{lll}\text { 5.2.6 Integrative Reasons for Studying } & 145\end{array}$

$\begin{array}{lll}\text { 5.2.7 External Pressure } & 147\end{array}$

$\begin{array}{llr}5.3 & \text { Summary } & 149\end{array}$

6 THE MOTIVATIONAL ROLLERCOASTER: STUDENTS' MOTIVATIONAL CHANGES OVER THE COURSE OF THE FIRST ACADEMIC YEAR 153

$\begin{array}{llr}\text { 6.1 } & \mathbf{1 5 4}\end{array}$

6.1.1 Time Point 2 Results in Comparison with Time Point 1 Results 155

$\begin{array}{llr}\text { 6.2 Interviews } & \mathbf{1 6 2}\end{array}$

6.2.1 Continued Enjoyment of Learning German 166

6.2.2 Wish for Language Proficiency as Reasons for Continuing to Study German 202

$\begin{array}{lll}6.2 .3 & \text { Ideal L2 Self } & 206\end{array}$

$\begin{array}{lll}\text { 6.2.4 Instrumental Reasons for Studying } & 213\end{array}$

$\begin{array}{lll}\text { 6.2.5 } & \text { Integrative Reasons for Studying } & 218\end{array}$

$\begin{array}{lll}\text { 6.2.6 External pressure } & 221\end{array}$

$\begin{array}{llr}6.3 & \text { Summary } & 224\end{array}$

$7 \quad$ EXPLORING EFFORT AND EFFICACY 227

$\begin{array}{lll}7.1 & \text { Questionnaire Results } & 227\end{array}$

7.1.1 Exploring Effort and Self-Efficacy: Results of Principal Component Analysis 228

7.1.2 Exploring Effort: Perceived level of Effort at Time Point 1 and Time Point $2 \quad 232$

7.1.3 Relationship between Effort and Students' Motivations for Studying German 235 
7.1.6 Relationship between Self-efficacy and Students' Motivations for Studying German 243

$\begin{array}{lll}\text { 7.1.7 Relationship between Effort and Self-Efficacy } & 248\end{array}$

$\begin{array}{lll}7.1 .8 & \text { Summary } & 250\end{array}$

8 DISCUSSION $\quad 252$

8.1 What Contribution does the Study make to the Field? 252

8.1.1 Exploring the Concept of the Ideal L2 Self and the Ought-to L2 Self in the
English-speaking context

$\begin{array}{ll}\text { 8.1.2 Exploring Students' Intrinsic Motivation } & 259\end{array}$

$\begin{array}{lll}\text { 8.1.3 Exploring Students' Self-Efficacy Beliefs } & 262\end{array}$

8.1.4 Exploring Motivational Change and the Role of Context 264

8.1.5 Towards an Expanded L2 Motivational Self System 266

$\begin{array}{lll}\text { 8.2 Pedagogical Implications for Universities } & \mathbf{2 7 0}\end{array}$

8.2.1 Addressing the Exo-Level: Content and Language Integrated Learning 273

8.2.2 Addressing the Exo-Level: Supporting Autonomous Forms of Language Learning 281

8.2.3 Addressing the Micro- and Meso-Levels 286

$\begin{array}{lll}\text { 8.2.4 Final Reflection: Adjusting Students' Expectations } & 290\end{array}$

REFERENCES

APPENDICES $\quad 312$

\section{List of Tables}

Table 1 Overview of similarities and differences between University A and B 27

$\begin{array}{lr}\text { Table } 2 \text { Overview of participants } & 103\end{array}$

Table 3 Overview of gender and school background at Time Point $1 \quad 104$

Table 4 Overview of gender and school background at Time Point 2 104

$\begin{array}{ll}\text { Table } 5 \text { Overview of interviewees } & 105\end{array}$

Table 6 Questionnaire scales $\quad 109$

Table 7 Aggregated means of the six motivational variables at Time Point $1 \quad 127$

Table 8 Paired samples t-test between the six motivational variables at TimePoint $1 \quad 128$

Table 9 Correlation matrix for the six motivational variables at Time Point $1 \quad 132$

Table 10 Condensed overview of students' reasons for studying 135

Table 11 Aggregted means of the six motivational variables at Time Point $1 \quad 154$

Table 12 Paired Samples t-test between the six motivational variables at Time Point 1 and $2 \quad 156$

Table 13 Correlation matrix for the six motivational variables at Time Point $2 \quad 161$

Table 14 Coefficient R for the six motivational variables 162

Table 15 Overview of interviewees' self-perceived motivation $\quad 165$

Table 16 Correlation matrix for the six motivational variables and effort at Time Point $1 \quad 236$

Table 17 Correlation matrix for the six motivational variables and effort at Time Point $2 \quad 236$

Table 18 Correlation matrix of the six motivational variables and self-efficacy at Time Point 1244

Table 19 Correlation matrix of the six motivational variables and self-efficacy at Time Point 2244

Table 20 Correlation matrix of self-efficacy and effort at Time Point $1 \quad 248$

$\begin{array}{ll}\text { Table } 21 \text { Correlation matrix of self-efficacy and effort at Time Point } 2 & 248\end{array}$

Table 22 Overview of motivational impact of proposed approaches 273 


\section{Introduction and Background}

This study is the result of my long-standing interest in factors that may motivate or demotivate students to learn a foreign language. It is also an expression of my belief that motivational research is important, as motivation has a lot to say in whether or not students will persist in the long-drawn-out process of learning a foreign language. In the English school context, learning a language beyond GCSE level is not compulsory. Motivation therefore decides whether the learner continues learning a language at A-level. It further influences whether the learner keeps up learning this language after school by studying it either in his spare time, in language institutions, or even at university. The lifelong process of language learning is not possible without sustained motivation.

This thesis focuses on students' motivation(s) for studying German as a foreign language in higher education; in particular, it explores students' motivation for studying German at university level, the changes in students' motivation over the course of the first year at university, and the interplay between students' motivation and the learning environment. My interest in this project was initially triggered by my own personal and professional experience. Before undertaking a D.Phil. course in the Department of Education, I had been working as a language lecturer at an English university for two years. I will call this university University A for confidentiality reasons, as it is also one of the two research sites where my doctoral project was carried out. Although University A traditionally attracts academically strong and highly motivated students, the first year of students here appeared to be characterised by strong motivational changes, an impression echoed in the accounts of other lecturers involved in teaching foreign languages to first-year students at this university (Kemp and Lang, 2005) as well as at other universities (Bavendiek, 2008). 
In 2007, I took a Diploma Course on Learning and Teaching in Higher Education (DipLATHE). As part of the diploma course, a colleague and I conducted a small-scale study which involved interviews with second and fourth year students at University A about their experiences with studying German (Busse and MeyerBeining, 2007). Although the focus of the study was on students' retrospective perception of a particular language class and its form of assessment, students also touched upon the topic of motivational change experienced during the first year and provided me with some preliminary insights into some of the challenges of the first year.

This thesis represents my endeavour to pursue the issues raised by this incidental evidence and to gain an in-depth understanding of students' first year experience at University A by systematically investigating it from a motivational perspective. The value of this study is supported by the high prestige of the university, which has one of the largest German departments in the United Kingdom. The purpose of the study is to seek in-depth insights into a particular cohort of students rather than providing a panoramic overview over first year students in general. However, in order to better evaluate the insights gained from University A, a comparison university was chosen for the project. In Chapter 2, I will elaborate on selection criteria in more detail, but it should be pointed out here that the comparison university is a more recently established university which features a similarly strong and large German department. It will be called University B for ethical reasons from now on.

As a language educator working in higher education, my ultimate goal is to reach a better understanding of motivation and motivational change from the students' perspectives in order to learn how contextual factors can better support first year students' learning processes throughout the year. This concern has influenced the 
design of the present research project. On the basis of the results obtained, pedagogical implications for what the university environment and in particular the language-based course elements could do to help students during this difficult year are discussed.

\subsection{Rationale}

Exploring the first year at university from a motivational perspective with a focus on the learning of German as a foreign language is important for various reasons. I will address the rationales that have led to designing the study in its current form below.

\subsubsection{Why is a study on motivation for learning German at university level of interest?}

In recent years, falling student numbers in modern foreign languages such as French and German at GCSE and A-level in the UK have generated much debate. The fall in numbers comes as little surprise to language teachers. Enthusiasm for modern foreign languages in secondary schools is all too often short-lived. Researchers have been aware of this motivational decline for some time (Chambers, 1999), and differing views on the root of the problem have been put forward (Coleman, 2009, Coleman, Galaczi and Astruc, 2007, Macaro, 2008a), based both on the macro-, i.e. societal, as well as the micro-, i.e. school and classroom, levels of language learning.

However, while existing research has generated insights into the factors that cause students to turn away from language learning at school level, little is known about those that contribute to their sustained involvement. Students' motivations for learning German at university level have received comparatively little attention, with only a few exceptions (Coleman, 1996).

This is all the more surprising as modern foreign languages - with the exception of Spanish - face severe challenges in higher education, and the decrease in applications for subjects such as German has given universities ample cause for 
concern. The Languages, Linguistics, Area Studies (LLAS) report for the Arts and Humanities Research Council (2006) gives evidence for the declining attractiveness of modern foreign languages among students, which appears to be linked to an unfavourable image of language learning as too challenging. It also highlights the wider implications resulting in the closure of language departments, and reductions in language provision. Press responses to the latter developments indicate that these issues have slowly become a matter of wider concern in English society (The Guardian, 11 June 2009, 13 March 2007) and that not only academics are alarmed by the closure of German departments in particular (The Guardian, 22 September 2009).

More extensive reviews of the media coverage is given elsewhere (Godsland, 2010); the point here is to show that in the light of the above challenges, the research fills a current need: much insight can be gained from the motivational profiles of students who manage to sustain their motivation all the way through school to university level. Knowing students' reasons for studying German at university provides schools with information about factors that have successfully led these students to continue their language studies beyond school. It also provides universities with the background knowledge necessary to respond to the particular motivational profiles of their students.

\subsubsection{Why is studying the first year at university important?}

In the introductory section I pointed out that students appear to undergo particularly strong motivational changes during the first year. This observation was surprising as well as worrying: it is surprising if one assumes that only highly motivated students set out to study a language such as German at university level. It is worrying, as literature on the transition from school into Higher Education has shown that the first year at university is already very demanding, posing serious challenges for students.

The general importance of the first year at university for subsequent academic 
development is well documented, as academic failure and student attrition are most likely to occur during the first year of university, a trend observed not only universally but also in the particular learning context of the UK (Yorke, 2001, Yorke and Longden, 2008). This makes the first year not only a crucial but also a precarious stage in the learner's higher education experience, as documented by a wealth of literature. A recent literature overview (Harvey, Drew and Smith, 2006) identified $750^{1}$ studies dealing with the first year experience in higher education, which are further supplemented by a substantial amount of "grey" literature. The majority of studies explore the relationship between transition, adjustment and student drop-out.

A common denominator in these studies may be called the focus on collective deficiencies of first-year students, while the individual level has received little attention. That is, individual strengths and learner needs have been rather neglected. Also absent from this substantial body of research are studies looking at students' first year experience from the angle of motivational research, as well as longitudinal studies that explore students' experiences during the year in a time-sensitive manner. This is all the more surprising as the potential of longitudinal inquiries for exploring the first year experience (McInnis, 2001), and the role of motivation in students' higher education learning experience (Erl, Hayward, Wright, Edwards, Lunt, Mills, $\mathrm{Yu}, 2008)$ is well recognised. I would argue that a systematic reflection over time from the angle of motivational research on the interplay between first year students' motivation(s) and contextual factors in the university learning environment is essential if the teaching and learning infrastructure in higher education institutions is to take first year students' individual needs better into account. I would also argue that paying attention to the first year in particular is important given its crucial role for academic development, and that declining student numbers in modern foreign languages such as

\footnotetext{
${ }^{1}$ Note, however, that in this overview all studies on first-year students were taken into account, that is, students in their first year at undergraduate as well as postgraduate level.
} 
German make student attrition especially undesirable.

\subsubsection{What does motivational research offer?}

Motivational research provides insights into the variables influencing human behaviour. The substantial body of motivational literature offers the theoretical framework needed to systematically explore students' experiences during the first year at university from a motivational perspective.

Through the small exploratory study conducted within the framework of the DipLATHE programme, I had already gained some insight into students' experience of the first year at university. Interviewees implied that, in retrospect, the first year had been extremely challenging. They were also quite critical of the set-up of the degree course. My colleague and I (Busse and Meyer-Beining, 2007) pointed towards the division between language and literature study in the degree programme at University A as a source of dissatisfaction. It appeared that the lack of integration of language tuition into literature study led towards a downgrading of language study as a less important side of the degree and led to less engagement in language learning; this impression was echoed by other lecturers (Kemp and Lang, 2005). There were also other teaching issues that merited attention: in particular, I explored an apparent lack of alignment between learning aims, course content and assessment of a first-year oral/ writing course I was teaching, while my colleague explored different approaches to teaching academic writing and possible implications for this particular course.

However, these factors appeared to be only components of a more complex picture characterised by some interviewees' professed wish to gain language proficiency on the one hand and reported low engagement in pursuing this aim on the other; other individuals with surprising resilience displayed unexpected motivational turns. The educational potential of motivational theories to gain in-depth insights into the factors underlying students' learning behaviour, to explore the interaction between 
motivation and learning environment, and to use these insights to inform and improve foreign language teaching in a research-based manner is demonstrated both in the literature review (Chapter 3) and in the discussion chapter (Chapter 8).

Special attention is paid to the recently developed L2 Motivational Self System (Dörnyei, 2005, 2009b), as it offers not only a useful framework for exploring students' motivation to learn a foreign language such as German but also provides empirical insights on foreign language learning motivation that my research could build on. What is more, some of the data gained by the DipLATHE enquiry seemed to be tapping precisely into the core concept of the system, the ideal L2 self. One of the students I interviewed explained his passion for studying languages in the following terms:

Yes, I think as an English native-speaker; you don't really have to know another language, yet I have this idea of myself as someone who is fluent in different languages - that keeps me going. I also study French: it's an educational thing.

This statement was all the more interesting as I had known this student for quite some time; as a self-taught Scottish student, he was not only younger than his peers but also had only a very basic command of German when he started his studies. His first year at university had been characterised by strong motivational turbulence and varying effort to become proficient in the two languages, but he later persisted to graduate successfully in both German and French. It was obvious that emotional identification with German-speaking people - an important factor according to the socialpsychological tradition which dominated early motivational research on language learning - had little to say in explaining his motivation for studying German. Rather, Branan, ${ }^{2}$ a Scotsman to the tips of his fingers as he stressed, had not even travelled to any German-speaking country prior to studying German, but his idea of becoming a

\footnotetext{
${ }^{2}$ Note that all names used in this thesis are pseudonyms chosen by participants themselves.
} 
multilingual intellectual seemed to have been one component that made him choose and continue to study German.

The literature review explores the L2 Motivational Self System and its empirical contributions in more depth. It also discusses its theoretical underpinnings in detail, i.e. theories of possible selves in mainstream psychology. The results chapters (5-7) shows that the ideal L2 self indeed offered a good conceptual basis for understanding not only these students' reasons for studying German but also their sustained motivation for continuing to engage with German.

However, the following statement by a DipLATHE interviewee who had just embarked on the second year illustrated the need to explore the interaction between motivational factors which sustain motivation in the long term, and the various factors that negatively affect students' immediate motivation and lead to lack of engagement with language learning:

I started to study because I love and enjoy learning German - I still love it, I really want to be able to speak German. Then, I just don't feel very motivated to study the language as it is, right now, I mean, I did not spend much time on language learning last year.

The L2 Motivation Self System in its current form has limitations in this respect. I will elaborate on these in the literature review in more depth, but it may be pointed out here that the nature of the relationship between the students' ideal / ought-to L2 selves and the learning environment is under-theorised and that the L2 Motivational Self System excludes the beliefs held about the actual self.

For a better understanding of the ups-and-downs of students' motivation during the year, I additionally drew on motivation theories such as self-determination theory and its concept of intrinsic motivation (Deci and Moller, 2005, Deci and Ryan, 1985, Deci and Ryan, 2008, Ryan and Deci, 2000, Vallerand, 1997) as well as self-efficacy theory (Bandura, 1969, 1986, 1995, 1997); to a lesser degree other strands of 
motivational research have further amplified and fed into my theoretical thinking, as acknowledged and elaborated in the literature review.

My theoretical interest in these two theories in particular was again guided by some of the findings of the DipLATHE interviews. Firstly, as the quotation above showed, students stated that they had enjoyed learning German at school, but complained that their enjoyment of learning German suffered during the first year at university. The doctoral project endeavours to find out about what "to enjoy" meant for these students, and to gain insights into the factors that stimulate or hinder their enjoyment of learning German, which guided me to literature on self-determination. The exploration of the concept of intrinsic motivation in particular has not only helped me to gain a better understanding of various facets of students' enjoyment of learning German but has also proved useful for investigating the intricate relationship between motivation and learning environment.

The data from the DipLATHE interviews also suggested a link between motivational change and declining confidence. This impression tied in with another exploratory enquiry into first-year students studying German (Bavendiek, 2008). However, on the grounds of the DipLATHE data and my teaching experience, it seemed to be of little use to explore confidence in an all-encompassing, broad sense, as students' confidence for specific university tasks appeared to be more revealing for interpreting their engagement with specific aspects of the course. As an interviewee in her fourth year stressed:

[In the first year] I hated grammar [...] Now I feel much more confident but back then I didn't really know where to start. So I just brushed it under the carpet [...] I feel much more serious about it now, I am enjoying more because I am feeling more able as well.

The need to explore the relationship between students' confidence and motivational change in a contextually situated fashion then guided my attention to literature on self- 
efficacy beliefs. The present study explores the role of task-based confidence and suggests that it is an important factor for understanding not only motivational change but also the formation and elaboration of students' ideal selves.

I have here outlined in very broad strokes some of the impulses that led me to turn to motivational literature in general and to the theories mentioned in particular. The important insights that can be gained from approaching these students' first year experience from a motivational angle will be elaborated on further in the literature review and are evidenced in the results chapters.

\subsubsection{What contribution does the study make to the field?}

While motivational research has much to offer in exploring this particular research context, the study also fills a gap in the theoretical development of language learning motivational research itself. This gap will be described in detail in the literature review in Chapter 3, but I will here highlight the three main points.

Firstly, this research is guided by a thorough scrutiny of recent theoretical and empirical contributions in the field of language learning motivation. It explores motivation by drawing on these insights, but at the same time it amplifies existing theoretical thinking, in particular by suggesting ways of refining the L2 Motivational Self System.

Secondly, the empirical data from the study is important, as recent studies looking at students' motivation for learning foreign languages are dominated by a focus on the learning of English. More research is needed on the motivations for studying other languages than English.

Thirdly, the study responds to a paucity of exiting studies looking at students' language learning motivation over time. This longitudinal element not only fills an existing empirical gap but also ties in with recent theoretical thinking on motivation. 
The results are therefore significant in gaining a better understanding of the relationship between motivation and time.

\subsection{Organisation of the thesis}

This thesis is organised around three broad research objectives:

- to explore students' motivation for studying German at university level

- to explore changes in students' motivation over the course of the first year

- to explore the interplay between students' motivation and the learning environment.

After providing the general context to the present study, the rest of the thesis is organised into the following chapters: Chapter 2 introduces the research environments chosen to carry out the study. Chapter 3 presents a critical review of the relevant literature as well as the key definitions and concepts. It shows how the literature has informed the present study and refines the three broad research aims into several more closely-defined research aims. The nature of my research aims led me to adopt a longitudinal mixed-methods approach, which will be discussed in the methodology section in Chapter 4. This chapter also provides information on the sample and the research instruments used, i.e. questionnaire design and interview guide. Chapter 5-7 present the findings of the data. Chapter 5 addresses students' motivation for studying German at the beginning of the academic year. Chapter 6 explores the changes in students' motivation over the year and tries to unravel links between motivational change and the learning environment. Chapter 7 explores the relationship between students' motivations, their motivated behaviour, and their task-based confidence. Chapter 8 then discusses research findings and places them into the wider context of motivational research, along with recommendations for future research. The thesis concludes by outlining some pedagogical implications of the study. 


\section{Research Settings}

The research settings chosen have intrinsic value, as both universities feature German departments which are amongst the largest and strongest in the country. I will show below that both departments are comparable in many respects. Both universities have strong academic reputations and the undergraduate German courses focus both on German literature and German language. As is the case in most English universities, the language of instruction for literature classes and classes on the linguistic aspects of German is English at both institutions. Only language tuition is imparted to some extent in German. The universities are also comparable in that first year students receive a similar amount of language tuition per week, i.e. around 3 hours weekly. However, there are also some fine differences which make the comparison between University A and University B interesting for a motivational enquiry. I will here look at the two research settings in more detail by describing the language departments and the course structures.

\subsection{University $A$}

University A has an excellent academic reputation both nationally and internationally and is traditionally rated highly in Research Assessment Exercises. It is a well established university, with its historical roots dating back to medieval times. The subfaculty of German is therefore one of the oldest in the country. It is also one of the largest departments with a student intake of around $80^{3}$ undergraduates per academic year and 19 full-time members of department. In the Research Assessment Exercise (RAE) 2008 results, the German department fared well and the research output in particular received high ratings.

\footnotetext{
${ }^{3}$ Note that the official website states a higher number (120), but the actual number of first-year students has been much lower in the last two years.
} 
University A differs from most other universities in its collegiate system, which means that students of German are not only part of the larger university, but also of a smaller, interdisciplinary, academic college community. Students also receive tutorials in their respective subjects in their colleges. Tutorials may be called intensive and personal teaching sessions, as they consist of an hour-long meeting between one to three students and their tutor. In general, undergraduate students usually have a strong sense of belonging to their college, and the collegiate system and its tutorials (2005, Moore, 1968, Palfreyman, 2001, Rose and Ziman, 1964, Tapper and Palfreyman, 2000), and more recently students' differing conceptions of the tutorial (Ashwin, 2005), have been linked to teaching success.

German in University A is studied either on its own, or in combination with other subjects: German can be studied in combination with another modern language such as for instance French (Modern Languages degree), or in combination with subjects like English, philosophy, classics or history (a joint degree). The main components of the German degree course are language and literature. According to the official website, these are equally distributed, it is stated:

Language is the keystone of the [...] course. Language papers form about $50 \%$ of the Preliminary (First-year) and Final Examination. [From official website]

It should be noted, however, that University A traditionally sets a stronger focus on literature. In this respect it also needs to be highlighted that literature is mainly taught within the collegiate framework, i.e. by students' college tutors through the traditional tutorial system, while language is mainly taught at a departmental level or by groups of colleges, usually by language lecturers on fixed-term contracts, and this may tend to give more status to the literature teaching.

According to the modern languages prospectus (2009/2010:3), the language aims of modern languages courses at University A are 
achieving spoken fluency in colloquial and more formal situations, the ability to write essays in the foreign language, and the ability to translate into and out of the foreign language with accuracy and sensitivity to a range of vocabulary, styles and registers. [From modern foreign language prospectus]

Note that the order of language skills mentioned gives a slight emphasis to achieving oral proficiency. The website further states that modern foreign languages students will attend oral classes and courses on the grammatical structure of the studied language(s), translation into and out of the language(s) and, in some of the languages, comprehension (mentioned in the order here reported). With regard to the first year in particular, the modern foreign languages prospectus (2009/2010: 6) states:

Your first year is closely structured [...] you will attend oral classes and courses on the grammatical structure of both languages, translation into and out of both languages, and, in some of the languages, comprehension. You will also attend introductory lecture courses and participate in seminars and/or tutorials on literature. [From modern foreign language prospectus]

In practice, first year students of German normally have three hours of language tuition per week: a grammar class, a translation class, and a combined oral/writing class. During the first term only, students also attend four lectures in German and four additional oral classes related to the themes of the lectures. Students are additionally expected to work through exercises through Computer Assisted Language Learning (CALL).

The exact number of hours of teaching each student receives at University A may vary somewhat. Students who score highly in the admissions grammar test are exempt from grammar classes, while students who score low on the admissions test have an additional hour of grammar class per week.

Grammar classes are normally taught in four groups with approximately 20 students in each. Classes are taught in English at a departmental level. The four additional oral classes are usually taught in groups of around ten students, also at a departmental level. Translation classes are taught at college level; they may be taught 
by college tutors or temporary lecturers depending on the college. Group size for translation and oral/ writing classes may vary widely between colleges; there are usually between three and eight students per class. Translation classes comprise translations of prose texts from German into English and English into German and are either held in English or German. Often, translation into English is taught by the college German tutor, while translation into German is taught by temporary lecturers, many of them native German speakers who also teach the oral/ writing classes. The third hour of language teaching, described as an oral/ writing class, is of a somewhat complicated nature. The class is officially labelled an oral class and therefore counts as oral practice in the overall distribution of language tuition. However, the class is aimed at preparing students for a written exam, Paper I, which is taken at the end of the first year. A close scrutiny of the difficulties caused by the conflict between the official status of the class and the requirement that it prepares students for Paper I have been elaborated on in detail elsewhere (Busse and Meyer-Beining, 2007). The oral class is therefore in practice a combined oral/ writing class, where German is largely used as a means of instruction and where students are supposed to interact with teachers in German, but which focuses mainly on the improvement of writing skills.

The language work of students is assessed at the end of the first year by means of two language papers. Paper I consists of a reading comprehension exercise (to be answered in German) and one essay in German. Paper II is a translation into German of a prose passage and a translation from German of a prose passage, both passages in a modern literary register.

It is worth noting that the language papers, Papers I and II, carry equal weight with the literature papers (III and IV). Thus, a failure to pass Papers I and II would probably make the student fail the whole course, although there is a possibility that papers can compensate for each other, e.g. when Paper I is passed but Paper II is 
failed. The importance of two language assessments within the overall assessment of the degree is thus firmly established; however, there is no oral examination at the end of the first year, which reflects the limited oral tuition during that year.

\subsection{University $B$}

In contrast to University A, University B is a more recently established university with a German department founded in 1970 . However, University B enjoys a similarly high academic reputation: it is currently ranked among the 5 best in the Times League Table of Universities (The Times, 27 May 2010), with the department of German Studies ranked in the top ten of the Times League table of German Departments in the UK (The Times, 27 May 2005). The two universities have very comparable Research Assessment Exercise (RAE) results (2008), with University A scoring slightly higher in category four (publications with international impact), and with University B scoring slightly higher in the Teaching Quality Assessment. University B also houses one of the largest centres for the study of modern German language and culture in the UK. The student intake per year is around 60 students and the department has ten fulltime members of staff.

As in University A, students can study German either as a single subject or in combination with another language or another subject. Along with the traditional combinations, there is also the possibility of studying German and Business Studies or German with International Studies.

The course structure differs from that of University A, in that German is studied in a modular system in which a differing emphasis on the study of German can be placed: German can either be studied in the form of German and a subject or German with a subject. Studying German and another subject means that the German modules on German language, politics and culture form one half of the degree course with the other half made up of modules from the other chosen subject. Studying 
German with a subject means that the modules for the other subject form only one quarter of the degree course. Students who study German as a single subject have a full German degree with modules on German language, politics and culture which account for three quarters of the components studied, but, in addition, a further quarter made up of modules in a chosen subject, which can be another language such as, for instance, Italian.

The University B website broadly describes the language aims of the degrees as designed to maximise language skills. In the language prospectus (2009/2010:2) it states:

Our aim is that when you graduate you will have acquired a very high level of expertise in written and spoken German as well as an in-depth understanding of German culture and society from both a historical and a contemporary perspective. [From modern foreign language prospectus]

Note that the order of language skills mentioned gives a slight emphasis to written German. It further specifies with regard to the first year (2009/2010:7):

In the first year we place particular emphasis on grammar work [...] we will also help you develop your language skills, including speaking in German, translating from and into German, and writing in German [...] we will give you training in how to use a range of elearning resources for language learning [From modern foreign language prospectus]

Thus, a focus on the development of grammar knowledge is established, which is concurrent with the de facto focus of the first year set at University A.

In practice, all students take one complete module in German language in the first year, consisting of three hours of language work weekly. The three weekly classes consist of a large language class, a small language class and an oral class. ${ }^{4}$ The official website classifies the large language class as focusing on translation and the small language class as focusing on grammar. However, these boundaries are not clear-cut.

\footnotetext{
${ }^{4}$ Note that at the time of writing, the German department is considering a structural change of the existing language classes.
} 
Large language classes cover translation from and into German as well as grammar tuition, while small language classes focus on grammar, but also work on translations. Writing practice is also incorporated into both language classes.

The large language class has a lecture format, with about 20 students per class. Classes are taught in English. The small language class usually consists of about eight to nine students. Classes are also mainly taught in English. The oral class is taught in German and focuses on conversation. There are about 8 students in each oral class.

Within the framework of university teaching, students from University B therefore have similar contact time in German language study as students from University A, i.e. normally three hours a week. The set-up of the language tuition differs in that students at University A have grammar classes, translation classes and oral/writing classes while students at University B have large language classes, small language classes and oral classes. The classes' content is comparable in that students at both universities receive grammar and translation tuition as well as writing practice. Students at University B have somewhat more oral practice, as they have a full oral class per week focusing on solely conversation, while students at University A only have one combined oral/ writing class per week; however, there are four additional oral lessons during the first term at University A. The group size is comparable for grammar classes and large language classes, which each have around 20 students. Small language classes at University B have around eight students and may therefore be on average slightly larger than translation classes at University A ranging from three to eight students. The oral classes at University B have around eight students, while the oral/ writing classes at University A have around four to eight students; the four additional oral classes have around ten students.

In contrast to University A, language tuition at University B is provided at the department level by both permanent and temporary language lecturers. As at 
University A, students are additionally expected to work through exercises in Computer Assisted Language Learning (CALL). In contrast to University A, students at University B also undertake student-led project work. In the first year German language project (Media project), students work in pairs or groups on a written German language topic. The project is guided by the oral language class tutor and contributes to the end-of-year mark in spoken German.

Similarly to University A, language work is assessed by two language papers at the end of the year. The written examination tests translation skills, essay writing skills and reading comprehension. Students who fail the exam are required to take a departmental test at the beginning of the subsequent year. In contrast to University A, there is also an oral examination at the end of the year. 
Table 1 Overview of Main Similarities and Differences between University A and B

\begin{tabular}{|c|c|c|}
\hline Main Similarities & Main Differences & \\
\hline & University A & University B \\
\hline $\begin{array}{l}\text { Both universities are amongst the } \\
\text { largest and strongest in the country } \\
\text { and have strong academic } \\
\text { reputations. }\end{array}$ & $\begin{array}{l}\text { University } \mathrm{A} \text { is a } \\
\text { historical university } \\
\text { and has a collegiate } \\
\text { and a departmental } \\
\text { teaching system. }\end{array}$ & $\begin{array}{l}\text { University B was } \\
\text { established in the } \\
1970 \text { s and has a } \\
\text { departmental } \\
\text { teaching system. }\end{array}$ \\
\hline $\begin{array}{l}\text { At both universities English is the } \\
\text { language of instruction for } \\
\text { literature classes and classes on the } \\
\text { linguistic aspects of German; } \\
\text { German can be studied either on } \\
\text { its own, or in combination with } \\
\text { other subjects. }\end{array}$ & $\begin{array}{l}\text { At University A, } \\
\text { literature is taught } \\
\text { within the collegiate } \\
\text { framework and } \\
\text { language is taught at } \\
\text { a departmental level } \\
\text { or by groups of } \\
\text { colleges, usually by } \\
\text { language lecturers on } \\
\text { fixed-term contracts. }\end{array}$ & $\begin{array}{l}\text { At University B, } \\
\text { literature and } \\
\text { language tuition is } \\
\text { provided at a } \\
\text { department level by } \\
\text { both permanent and } \\
\text { temporary language } \\
\text { lecturers. }\end{array}$ \\
\hline $\begin{array}{l}\text { At both universities, students } \\
\text { receive a similar amount of } \\
\text { language tuition per week (around } \\
3 \text { hours weekly); students receive } \\
\text { translation, writing and grammar } \\
\text { tuition; the focus in the first year is } \\
\text { on the development of } \\
\text { grammatical knowledge; students } \\
\text { are expected to work } \\
\text { independently on CALL exercises; } \\
\text { the written examinations at the end } \\
\text { of the year test translation skills, } \\
\text { essay writing skills and reading } \\
\text { comprehension. }\end{array}$ & $\begin{array}{l}\text { At University A, } \\
\text { students have a } \\
\text { combined oral/ } \\
\text { writing class in the } \\
\text { first year and there is } \\
\text { no oral examination } \\
\text { at the end of the year. }\end{array}$ & $\begin{array}{l}\text { At University B, } \\
\text { students receive a full } \\
\text { oral class per week } \\
\text { and there is an oral } \\
\text { examination at the } \\
\text { end of the year. There } \\
\text { is a language project } \\
\text { to supplement } \\
\text { language tuition, } \\
\text { which contributes to } \\
\text { the end-of-year mark } \\
\text { in spoken German. }\end{array}$ \\
\hline
\end{tabular}




\section{Literature Review}

This chapter provides an overview of important motivational research strands that have influenced the development of research into L2 motivation before turning to an in-depth review of research conducted on L2 language learning motivation. It stresses the importance of a self perspective for the general motivation to learn as well as for L2 learning, and argues for a closer scrutiny of the interaction between self and context.

\subsection{Introduction}

The focus of this literature review is to provide an overview of the theoretical and empirical insights gained by motivational research conducted in the area of language learning (L2) ${ }^{5}$ which have shaped and framed the present research project. Firstly, a general definition of the word motivation is provided as a point of reference for the reader. This is followed by an overview of the wider field of motivational research, as existing theoretical constructs in L2 motivational research draw on mainstream motivational research in the areas of psychology and education. Given the broad scope of motivational research, the literature review focuses on those theories that have been most influential in L2 motivational research. Thirdly, a brief historical outline of the development of L2 motivation theories is given, followed by a closer scrutiny of empirical studies that have informed this research. Fourthly, the implications of the literature reviewed for the conceptualisation of motivation in the present research project are discussed and a working definition is provided. Lastly, the broad research aims are further refined into several more closely-defined research aims.

\footnotetext{
${ }^{5}$ In the following, L2 motivational research will be used to refer to research on language learning motivation in general. It is important, however, to distinguish at times between second language learning motivational research and foreign language (FL) learning motivational research. In these instances, I will refer explicitly to FL motivational research.
} 


\subsection{What is motivation?}

While motivation is talked about virtually all the time in everyday contexts, the word poses some considerable difficulties as a research concept, as its definition and the variables included differ according to the theoretical framework being used. Although opinions differ with regard to the composition of the complex motivational construct involved in human behaviour, a simple definition many researchers would agree to could be that motivation, a word which derives from the Latin verb movere, concerns what moves a person to the choice of a particular action, what moves him or her to expend effort on this action and to persist with this action (Dörnyei, 2001).

While early motivational research paid much attention to the factors involved in triggering human action, contemporary motivational research has come to focus more on those factors involved in persisting and continuing to engage with a chosen activity. Pursuant to the research interest of this study as explained in Chapter 1, the theories with potential to shed light on the interaction between students' motivation, time and context will be explored; that is, the focus is on exploring those theories that may provide insights into the factors that motivate students to learn German as a foreign language and to sustain their effort over time, and on those that may shed light on the interaction between individual motivation and the learning environment of the university. I will argue in this vein that research on the self as a motivational concept is a promising area which has much educational potential.

\subsection{Influential Theories in Mainstream Motivational Research}

It has been noted that there is very little consensus among researchers with regard to the exact properties of motivation. The focus of this thesis excludes an in-depth discussion of early motivational theories as covered elsewhere (Owens, 1981, Schunk, Pintrich and Meece, 2008, Weiner, 1990, 1992), but in order to understand recent developments in motivational theories, it may be important to note that early 
motivational theories were dominated by quite a mechanistic view of motivation; the changing emphasis on either the instinctive or reflexive side of human behaviour is vividly depicted through the "man as a machine" metaphor in Weiner's Human Motivation (1992). The metaphor stresses the responsive role that is being ascribed to humans when motivation is attributed to inner forces - needs in Hullian terms (Hull, 1951), Triebe / drives in Freudian terms (Freud, 1934) - or to outside stimuli and reinforcement in behaviourist terms (e.g. Watson, 1913). Such a deterministic view of human behaviour left many researchers unsatisfied, especially in the field of learning (Atkinson, 1964, Koch, 1956, Rotter, 1966, Weiner, 1969).

Around 1960 and in line with the general Zeitgeist in psychology, theories turned to a cognitive view of motivation in which humans are seen as proactive rather than responsive (an overview is provided by Bandura, 1986, Deci and Ryan, 1985, Weiner, 1990). Most researchers conceded that actions are not always under direct motivational control, i.e. that they can be unconscious; but cognitive psychology started to focus more on conscious thought processes and purposeful rather than on elicited behaviour. Hand in hand with this change in mainstream motivational research underwent a gradual theoretical narrowing down process and today there is no longer any grand theory dominating the field:

There has been a general shift from the creation of all-encompassing, broad theories to a focus on narrower, more bounded "mini-theories" and the analysis of specific aspects of motivated behaviour (Graham and Weiner, 1996: 64)

Particular attention has been paid to the process of setting goals for oneself, of planning courses of action to reach valued outcomes or to avoid unwanted ones and of interpreting positive and negative outcomes of an action. These cognitive motivators have found theoretical framing in three very influential groups of theories, i.e. goal theories (Locke and Latham, 1990, Schunk et al., 2008), expectancy-value theory 
(Atkinson, 1964, Rotter, 1966) and attribution theory (Heider, 1958, Weiner, 1985, 1992, 2005), all of which have directly or indirectly influenced L2 motivational theories. An in-depth review of these theories lies outside the scope of the present research; they will, however, be briefly outlined, as they have shaped thinking on L2 motivation particularly during the 1990s. I will then discuss three self-concept theories that are particularly germane to the present study and to a more recent development in L2 motivational theories.

\subsubsection{Goal Theories, Value-Expectancy Theory and Attributions}

According to goal theories, humans exercise self-influence through setting themselves challenging goals, a process that serves as a cognitive mechanism of motivation and self-directedness. One distinguishes goal setting and goal-orientation theories. In goal setting theory (Locke and Latham, 1990), goals are considered as immediate regulators of behaviour. The theory suggests that the way individuals set themselves goals is a crucial predictor of their work performance. Specific and difficult goals are linked to better performance than easy and non-specific goals. Locke and Latham provide evidence that goal setting is strongly related to expenditure of effort and that individuals with specific and challenging goals persist longer at a task than individuals with easy and vague goals provided the goals are attainable (Latham and Locke, 2006, 2007); effect sizes in meta-analyses ranged from .42 to .80 . (an overview of early research is provided by Locke, 1996, Locke and Latham, 1990). In the context of the present study it may also be worth pointing out that goal-setting combined with feedback appears to enhance performance (Bandura and Cervone, 1986, Becker, 1978, Erez, 1977).

Goal-orientation theory has a slightly different focus, as it deals especially with the quality of an individual's goal orientation. In contrast to goal-setting theory, it deals with the questions why an individual may want to engage in a task and how 
he/she will approach the task. Contemporary achievement goal theory distinguishes between mastery and performance goal orientations (Pintrich, 2000a, 2000b). The former refers to the pursuit of "mastery goals" with the focus on learning content, and the latter to the pursuit of "performance goals" with the focus on getting good grades, outdoing other students or demonstrating abilities (Ames, 1992, Ames and Archer, 1988). Sometimes further distinctions are drawn between intrinsic, mastery, and taskinvolved orientations on the one hand and extrinsic, performance, and ego-involved orientations on the other (Ames, 1992, Dweck and Leggett, 1988, for a definition of intrinsic and extrinsic motivation also see section 3.3.1). In mainstream motivational research, there are numerous studies exploring the relationship between goalorientations and motivated engagement (e.g. Anderman and Wolters, 2006, e.g. Diener and Dweck, 1978, Diener and Dweck, 1980, Pintrich and Garcia, 1991, Pintrich and Schrauben, 1992, Wolters and Yu, 1996). In L2 motivation theories, the interest in goal theories increased in the 1990s; existing theoretical frameworks were expanded and attention was paid to the importance of learner goals for motivational processes (3.3.3).

Expectancy-value theory principally addresses the initial phase of motivation as it aims to explain the incentive to pursue a particular action by an individual's expectancy of success and the value that the individual attaches to this success (Atkinson, 1964). In addition, the locus of control - that is, whether a person perceives that the outcome of an event lies outside or within his control - further influences expectancies (Rotter, 1966). This construct of locus of control can also be found in attribution theory (see below) in the dimension of perceived causality.

Although there is no direct equivalent in L2 motivational models, the influence of expectancy-value theory can be traced in the socio-psychological framework (3.3.1), which places great emphasis on the value that learners attach to the language, 
or on the attitude that they have towards the language and the country. Newer approaches within mainstream motivational theories have already attempted to connect expectancy-value theory to research on the self and identity via the value component (Brophy, 2009), a line of thought which could be particularly interestingly pursued in the educational context, but which has not yet found an echo in recent conceptualisations of L2 motivation.

Attribution theory originated in the work of Heider (1958), but its most significant proponent has been Weiner (Weiner, 1985, 1992, 2005). The underlying tenet of attribution theory is that individuals always evaluate why a particular outcome occurred, and that in the process they make causal attributions, based on which they make decisions. In his early writings, Weiner (Weiner, Russell and Lerman, 1979) focused on four main causes to which people attribute success and failure: ability, effort, task difficulty and luck. Later, other attributions were added and, importantly, two new qualities of attributions were conceived: locus of causality and stability. Locus of causality refers to the perceived location of a cause as internal or external to the learner, whereas stability refers to the potential changeability of a cause over time. A further, later added dimension concerned the extent to which an event or outcome is under the control of the learner or participant. Causes can thus be perceived to be internal or external, stable or unstable, controllable or uncontrollable. Expectancy of succeeding in a task depends on the individual's interpretation of causality in previous achievement situations: e.g. if a person repeatedly fails an examination having assiduously studied for it, and others have passed it, according to Weiner it is likely that he or she will attribute his/ her failure to lack of ability.

Since the 1990s, attention has also been paid to attributions in the field of L2 motivation (3.4.2). McDonough (1986: 155) states that attribution to stable causes such as aptitude are most common in language learning: 
In the case of language learners, one of the most frequent attributions to a stable factor outside their control is to aptitudes such as an ear for languages. Thus a language learner may easily save face by ascribing failure to a physical disposition: "I'm no mug but I've got no ear for languages".

The differing findings from existing studies, however, do not reflect this conclusion (McQuillan, 2000, Tse, 2000, Ushioda, 1996b, Williams and Burden, 1999, Williams, Burden and Al-Baharna, 2001, Williams, Burden, Poulet and Maun, 2004). For instance, a small-scale study by Williams and Burden (1999) revealed a tendency amongst primary and secondary students in the UK to identify internal effort as the main reason for success in learning a foreign language, together with help from others and a growing sense of competence. By contrast, external factors such as distraction by others, difficulty of work and poor teaching were most often cited as reasons for failure. A study on French students' motivation in relation to cognitive thought process (Ushioda, 1996b) showed that university students who experienced negative outcomes during their course of study and still displayed high motivation did not attribute these negative course outcomes to ability, but instead stressed that it could be overcome by effort, and hard work. Tse (2000) found that American university students $(\mathrm{N}=51)$ attributed success to the teacher, the environment, the community and personal motivation, and failure to lack of effort, the teacher and the course. A study into the attributions of students in Bahrain for their success and failure in learning English (Williams et al., 2001) revealed that practice, support from family and teachers, exposure to the language and a positive attitude were the most frequently cited reasons for success by these students. By contrast, inadequate teaching methods, lack of support from family and teachers, poor comprehension and a negative attitude were the most commonly cited reasons for failure. Another study set in the US (McQuillan, 2000) identified motivation, the pace of the lesson, quality of teacher, ability, time and effort, level and atmosphere as the most common explanations of success by 81 university 
students of foreign languages. On the other hand, lack of time and effort, poor study strategies and atmosphere were most frequently cited for failure. The study by Williams et al. (2004) suggests that in England secondary schools students of German attribute their failure more to lack of effort than do students of French or Spanish. Note that different research instruments were used, which makes direct comparison difficult: McQuillan's quantitative study used a questionnaire that had already specified attribution categories, while the other studies cited above are set in a qualitative paradigm and attribution categories emerged from interviews (Ushioda, 1996b, Williams and Burden, 1999), questionnaires with open-ended questions (Williams et al., 2004) or a combination of both (Williams et al., 2001), or FL autobiographies (Tse, 2000). However, findings seem to indicate that attributions for success and failure may depend on the language being studied and on the cultural background of the students.

While attribution theory can undoubtedly make a valuable contribution to researchers' understanding of language learning motivation, the attempt to explore students' attributions for success and failure through the quantitative research instrument was not successful, as the attribution scale failed to reach sufficient reliability in the pilot phase of the study.

\subsection{Motivation and the Self}

The brief sketch of motivational theories above does not intend to reflect the plethora of theoretical frameworks in the wider motivational landscape. Rather, three theories have been singled out due to their influence in both mainstream and L2 motivational research. I would now like to draw special attention to an interesting development in motivational research, which may be described as the rise of the self as a motivational concept, which, in Pajares and Schunk's words, appears to be "on the verge of dominating research and theory on academic motivation" (2002:17); a trend also perceivable in recent developments in L2 motivational research. 
In mainstream motivational research, there are a great many studies looking at the relation between motivation and the self, although these are theoretically founded on different strands of motivational research, among them self-worth theory (Covington, 1976, 1992, 1998) and research on the self as a concept (Marsh, 1986, 1987, 2006, Marsh, Kong and Hau, 2000, Marsh, Seaton, Trautwein, Lüdtke, Hau, O'Mara and Craven, 2008). Here, I will discuss self-determination theory (Deci and Moller, 2005, Deci and Ryan, 1985, Deci and Ryan, 2008, Ryan and Deci, 2000, Vallerand, 1997), self-efficacy theory (Bandura, 1969, 1986, 1995, 1997), and possible selves theory (Dunkel and Kerpelman, 2006, Markus and Nurius, 1986, Markus and Nurius, 1987, Markus and Ruvolo, 1989) in more detail, as they have most strongly influenced the theoretical thinking of this study.

\subsubsection{Self-Determination Theory}

Self-determination theory has not only been highly influential in mainstream psychological theory but has also increasingly guided research on language learning. Its influence can be traced to the field of language learning autonomy and to the Canadian motivational language learning research context, the latter of which will be discussed in detail in section 3.3.4.1. The present section will provide an overview of self-determination theory as developed by Deci and Ryan and their colleagues (Deci and Moller, 2005, Deci and Ryan, 1985, Deci and Ryan, 2008, Ryan and Deci, 2000, Vallerand, 1997) and will highlight some empirical studies that may shed light on the findings of the present enquiry. Note that self-determination theory has generated a wealth of empirical studies, but the main bulk of research has been conducted in the US.

According to self-determination theory, human motivation is shaped by three basic human needs: the need for self-determination, or autonomy, the need for competence, and the need for interrelatedness, i.e. the need to be part of a social 
world. The first two in particular have received much attention in mainstream motivation research.

The need for self-determination is reflected in people's need to act autonomously and to feel in control of their own actions. When people act out of free choice, they act in a self-determined manner. It is important to note that although selfdetermination is seen as a basic human need, the environment exerts influence on it:

Although we define self-determination as a quality of human functioning, we also emphasize that it can be either supported or hindered by environmental forces $[\ldots]$ when the environment supports self-determination, the person will be more self-determining. (Deci and Ryan, 1985:38-39)

The need for self-determination is integral to intrinsic motivation, a concept which has strongly shaped the motivational research landscape. Intrinsic motivation refers to the motivation that arises from the pleasure an activity produces in itself. While early mechanistic theories could not explain motivations for behaviour such as exploration and play, intrinsic motivation can account for such behaviour as it seen as an explorative force to engage with an activity and to learn out of interest and enjoyment (Deci and Moller, 2005). Intrinsic motivation is internally regulated. Choice seems to play an important part in intrinsically motivated behaviour (e.g. Deci and Ryan, 1985, e.g. Deci and Ryan, 2008, Moller, Deci and Ryan, 2006, Zuckerman, Porac, Lathin and Deci, 1978), and so does conquering challenges (e.g. Csikszentmihalyi and Nakamura, 1989, Danner and Lonky, 1981, Deci and Ryan, 1985, Harter, 1974, Shapira, 1976).

For instance, a by now well-known experimental study with 80 US undergraduate university students showed that participants had significantly higher levels of intrinsic motivation when allowed to choose which puzzles to work on and to freely allot their time during the process of problem solving (Zuckerman et al., 1978). Another study involving 60 college students in the US found that students prefer to 
work on challenging puzzles unless they were promised extrinsic rewards, in which case students preferred the easy ones (Shapira, 1976). Experimental studies involving children similarly showed that children who could freely choose an activity would usually opt for one that provided a challenge (Danner and Lonky, 1981); in addition, children would report greater pleasure when engaging with moderately difficult tasks than with easy or difficult ones (Harter, 1974). More recent experimental studies have refined these early findings by suggesting that providing an initial choice to select one particular task does not in itself enhance intrinsic motivation: rather, ongoing choices in work methods, pace and effort are needed to sustain intrinsic motivation (Thomas and Oldfather, 1997). Note, for instance, that the early study by Zuckerman et al. (1978) allowed initial choice but also allowed for freedom with regard to time management in the process of problem solving, which may have been important factor in the positive effect observed. As Reeve, Nix and Hamm (2003) conclude on the basis of another experimental study involving 60 undergraduate students from a US university, task choice between teacher-chosen activities does not necessarily have an effect on intrinsic motivation unless it is embedded within a larger autonomysupportive environment and classroom climate.

Intrinsic motivation is not only anchored in people's need to be selfdetermined, but also in their need to be competent: when people feel competent and self-determined, they are more likely to enjoy an activity and to continue to engage in it. Although intrinsically motivated behaviour is seen as part of human nature, a sense of competence is necessary to sustain it.

It is worth pointing out in this respect that one's needs to master challenging tasks are linked to one's needs for competence: when activities are perceived to be unmasterable, perceived incompetence occurs. Self-determination theory therefore stresses that for sustained intrinsic motivation, choice and an optimal level of 
challenge is needed, the latter being defined as a challenge that is slightly harder than one's skill level (Deci and Ryan, 1985). The close relationship between intrinsic motivation, task challenge and perceived competence has been revealed by a variety of experimental as well as questionnaire studies (e.g. Boggiano, Main and Katz, 1988, Csikszentmihalyi and Nakamura, 1989, Czsikszentmihalyi, Rathunde and Whalen, 1993, Danner and Lonky, 1981, Harter, 1974, Hunt, 1966, 1975, Shapira, 1976); indications are that tasks that are too challenging have a detrimental effect on intrinsic motivation and result in perceived incompetence. Note, however, that tasks that are too easy may be similarly detrimental as they fail to engage the person and may result in boredom.

Perceived incompetence, however, may not only derive from failing to perform overly challenging tasks. The influence of feedback in this respect has generated a great deal of research (e.g. Anderson, Manoogian and Reznick, 1976, Deci, 1971, Fisher, 1978, Koestner, Ryan, Bernieri and Holt, 1984, Reeve and Jang, 2006, Reeve, Jang, Carrell, Jeon and Barch, 2004, Ryan, 1982). It appears that feedback which is controlling is detrimental to intrinsic motivation while feedback which is informational is beneficial. Feedback which is controlling prescribes thinking and behaving in a specified way, while informational feedback enables the learner to engage with the activity more effectively without undermining the need for autonomy. For instance, in an experimental study by Ryan (1982), 64 students received informational feedback and the other 64 received controlling feedback while solving a puzzle. Informational feedback consisted of a short information about students' performance, controlling feedback provided the same information combined with information how students should be doing (e.g. "good, you're doing as you should"). Findings showed that students who received controlling feedback did not only rate their level of intrinsic motivation lower in the self-report questionnaire subsequently 
administered, but they also performed significantly worse on the puzzle tasks and ceased to engage with them when free to choose whether to continue. An insightful recent experimental study involving 20 teachers used a longitudinal approach to explore the impact of feedback in the school context (Reeve et al., 2004). The experimental group consisting of 10 teachers was trained to give autonomy-supporting feedback to students, which made a perceptible impact on students and significantly improved students' intrinsic motivation and engagement in the tasks over time.

There is also evidence to show that monetary rewards, and other rewards such as tokens etc. often used in schools, are detrimental for intrinsic motivation, as they tend to be experienced as controlling and thereby undermine people's need for selfdetermination (e.g. Deci, 1971, Deci, 1972, for a metaanalysis of experiments see Deci, Koestner and Ryan, 1999).

Extrinsically motivated behaviour is sometimes mistaken for the antagonistic counterpart of intrinsic motivation. It is important to note, however, that extrinsic motivation is not just the opposite of intrinsic motivation. It is true that externally regulated behaviour is felt to be alienating as it undermines people's sense of selfdetermination, yet Deci and Ryan (2000) define extrinsic motivation on a continuum: behaviour can either be completely externally regulated (initiated by external rewards or punishment), or somewhat externally regulated (by exerting self-control, for instance, in order to comply with expected norms), or somewhat internally motivated (when people attribute personal importance to an activity), to the point where external motivation becomes internally regulated and fully synthesised with the self, in which case it may co-exist harmoniously with intrinsic regulation of motivation. While the continuum outlined above does not suggest that extrinsically motivated activities necessarily become internalised, it is possible that extrinsically motivated behaviour may become internalised over time. It is hypothesised that significant others who 
model or value certain behaviour can play a part in this process (Deci and Ryan, 1985, Ryan and Deci, 2000).

\subsubsection{Self-Efficacy}

Similarly to self-determination theory, self-efficacy theory has been very influential in mainstream psychology, in particular in the field of educational psychology. In their review of motivational research, Graham and Weiner (1996) find that self-efficacy constructs predict behaviour and behavioural change more consistently than any other motivational construct. Self-efficacy beliefs have also shown to influence a wide range of other motivational beliefs, such as, for instance, expectancy beliefs, or the value someone places on an activity (Bandura, 1997, see also value-expectancy theory 3.2.1).

The general importance of self-efficacy beliefs for motivated engagement in learning has been well-researched in the school context (see, for instance, Schunk et al., 2008) as well as in the higher education context (see, for instance, Lent, Brown and Larkin, 1984, Shell and Husman, 2008). Also, the significance of self-efficacy beliefs for the adjustment of first-year students to higher education has been documented (Chemers, Hu and Garcia, 2001).

However, in the field of L2 motivation self-efficacy beliefs have been considerably less influential, although there have been some attempts to include them in motivational frameworks (see 3.3.2). I will argue that the dimension of perceived competence is important to understanding motivation, yet research evidence for the importance of self-efficacy beliefs for language learning motivation is somewhat sparse and marred by methodological difficulties, which is why the existing studies will be discussed in a separate section below (3.2.4.2).

The present section will provide an overview of self-efficacy theory as developed and popularized by Albert Bandura $(1986,1995,1997)$ and point out some 
empirical studies that are of interest for the purpose of the present enquiry. Note that self-efficacy theory has generated a large body of empirical studies, not only in the US but also in different cultural contexts and across different disciplines (e.g. Bassi, Steca, Fave and Caprara, 2007, Garcia and De Caso, 2006, Graham, 2007, Magogwe and Oliver, 2007, Matsui, Matsui and Ohnishi, 1990, Schwarzer, Bäßler, Kwiatek, Schröder and Zhang, 1997, Speier and Frese, 1997).

Bandura's reflections on self-efficacy are rooted in a social cognitive view of human functioning. From a social cognitive perspective, humans are seen as proactive and self-regulating rather than merely reactive to inner drives or environmental influences. Human functioning is seen as the product of a dynamic interplay of cognitive and other personal factors, environmental events, and behaviour, an idea which is expressed in Bandura's model of triadic reciprocality:

In the social cognitive view people are neither driven by inner forces nor automatically shaped and controlled by external stimuli. Rather, human functioning is explained in terms of a model of triadic reciprocity in which behavior, cognitive and other personal factors, and environmental events all operate as interacting determinants of each other (Bandura, 1986: 18)

At the heart of the theory is the view that individuals are agents of their behaviour who actively engage in their own development; individuals possess a differentiated set of self-beliefs, which enable them to exercise a measure of control over their thoughts, feelings and actions (Bandura, 1997). Among the mechanisms that help humans to measure control, Bandura ascribes an eminent role to self-reflection. Individuals evaluate the adequacy of their thoughts and behaviour, and alter their thinking and subsequent behaviour according to this self-reflective evaluation. Of vital importance to this process of self-reflection are self-efficacy beliefs, which shape motivation, human behaviour, affective and physiological states. 
According to Bandura, perceived self-efficacy refers to human capability beliefs, i.e. people's perceptions of their ability to perform well on a given task. It is important to note that people's sense of efficacy is based on their beliefs about their capability (which does not necessarily mean that these are objectively true). As Bandura states: "Perceived self-efficacy is an important contributor to performance accomplishments, whatever the underlying skills might be" (1997: 37). There is wideranging evidence from diverse areas to support Bandura's claim that self-efficacy beliefs are better predictors of behaviour than the real capability of people (e.g. Barling and Abel, 1983, Barling and Beattie, 1983, Godding and Glasgow, 1985, Manning and Wright, 1983, an overview of the academic context is provided by Pajares, 1994). There have also been various studies conducted in the institutional learning context suggesting that self-efficacy beliefs affect achievement (a metaanalysis of studies conducted before 1990 is provided by Multon, Brown and Lent, 1991), predict performance even when controlling for previous performance (Eccles, Adler, Futterman, Goff, Kaczala, Meece and Midgley, 1983, Meece, Wigfield and Eccles, 1990) influence task choice, learners' persistence and engagement (Pajares and Schunk, 2002, Schunk and Pajares, 2005, Zimmerman and Kitsantas, 2007) and the use of self-regulation strategies (Linnenbrink and Pintrich, 2000, Pintrich and DeGroot, 1990, Shell and Husman, 2008).

Bandura (1997) further argues that particularly in higher education, where students are expected to become more and more autonomous in their learning, selfefficacy beliefs are a prerequisite for success. In this vein, a recent investigation by Kitsantas and Zimmerman (2009) may be of interest: the study explores the relationship between self-efficacy beliefs, homework and achievement of 223 American college students via path analyses. Results suggest that self-efficacy beliefs strongly influence the effort students expend on home assignments, which, in turn, 
proves to have a significant impact on the final examination performance. Another particularly insightful study for the present research context is provided by Chemers, $\mathrm{Hu}$ and Garcia (2001), who take a longitudinal look at first-year university students at a Californian university. Data was elicited by administering questionnaires at two time points; the sample in the first questionnaire was based on 373 students, while the second sample was based on 256 students from the original sample. Structural equation modelling was used for the analysis. The data provided strong support for the thesis that initial self-efficacy has predictive value for students' subsequent academic performance and their adjustment to higher education. Interestingly, the study also revealed that students with a higher level of initial self-efficacy were also more likely to evaluate the new learning environment as challenging, while less self-efficacious individuals felt it to be more threatening, and this was associated with perceived stress. While it needs to be pointed out that the sample included a larger proportion of female than male students (79\% female students at Time Point 1 and $82 \%$ at Time Point 2$)$, a factor which may influence the generalisability of the results, the longitudinal data seem to support Bandura's (1997) proposition that people with a high sense of selfefficacy achieve better results because they approach challenges in a different way than individuals with a low sense of self-efficacy: according to Bandura, selfefficacious individuals approach tasks with the intention and anticipation of mastery; they intensify their efforts in the face of adversities and persist longer in the tasks.

However, Bandura (1997) points out that self-efficacy beliefs are not stable. He distinguishes four factors which are hypothesised to be both sources of existing selfefficacy beliefs and sources of possible change: 
enactive mastery experiences that serve as indicators of capability

vicarious experiences that alter efficacy beliefs through transmission of competencies and comparison with the attainment of others

verbal persuasion and allied types of social influences that one possesses certain capabilities

physiological and affective states from which people partly judge their capability and strength

The term mastery experiences refers to the positive effect of prior successful performances, which according to self-efficacy theory have the strongest impact on capability beliefs. Performance success generally raises the sense of personal efficacy, while failure lowers it. Individuals develop their capability beliefs on the basis of their interpretation of performance in a task.

The second source, vicarious experience, also influences self-efficacy beliefs, although not as strongly as mastery experiences. Seeing other people who are similar to oneself succeed in a task can lead the person to believe that a task is manageable and that he or she might possess similar capabilities of succeeding. Conversely, observation of failure on the part of other people one judges to resemble oneself can lower one's perception of competence. In a similar vein, surpassing associates or competitors raises self-efficacy beliefs, whereas being outperformed lowers them. Referential comparison is especially important when comparison to others is the only way of judging one's success in a task.

The third source of influence is verbal persuasion, or other people's judgements of one's ability to accomplish a task. Although this source is seen as weaker than the previous two, verbal persuasion, such as encouragement in overcoming obstacles, can provide specific information about personal competence and can act as a source of efficacy information. Encouragement by significant others can heighten one's sense of competence while negative persuasions can weaken perceptions of competence and 
hinder the development of a strengthened sense of self-efficacy: "It is easier to sustain a sense of efficacy, especially when struggling with difficulties, if significant others express faith in one's capabilities than if they convey doubts" (Bandura, 1997: 101). However, self-efficacy theory places less importance on verbal persuasion than does research on self-concept, which relies heavily on influence by significant others (Pajares and Schunk, 2002, see section 3.4.2.1).

The fourth source comprises the affective dimension; it refers to somatic information from which people partly judge their capabilities yet according to Bandura (1997) self-efficacy beliefs can, in turn, also influence physiological states themselves.

The four sources of self-efficacy hypothesised by Bandura have been tested across different disciplines; early findings are synthesised in Bandura (1997). It is worth pointing out, however, that the most convincing evidence has been found for the influence of mastery experience on self-efficacy beliefs (e.g. Fantuzoo and McWayne, 2002, Hampton, 1998, Klassen, 2004, Lent, Brown, Gover and Nijer, 1996). For instance, a study on 163 Japanese first-year students found that all four hypothesised sources of self-efficacy beliefs were significantly correlated with self-efficacy but only verbal persuasion and mastery experience were strongly correlated with self-efficacy (Matsui et al., 1990). Britner and Pajares (2006) similarly found significant correlations between self-efficacy and vicarious experiences, social persuasion, physiological arousal and mastery experience in a study on 319 school student designed to investigate the four hypothesised sources of self-efficacy. However, only mastery experience significantly predicted self-efficacy. In a recent critical review of existing literature, Usher and Pajares (2008) summarise a substantial body of evidence stating that mastery experiences appear indeed to be the best predictor for self-efficacy beliefs; however, contextual variables, among them gender, ethnicity and academic ability or domain, 
seem to play an important role in determining the strength and influence of the four different sources.

The notion that one's mastery experiences are the most influential source of selfefficacy information has important pedagogical implications in the context of institutionalised learning. Opposed to self-enhancement models of academic achievement, which try to alter students' beliefs of self-worth or competence mainly by verbal persuasion, social cognitive theorists hold that one should primarily try to enhance competence and confidence through successful experience in a performance, that is, through authentic mastery experiences. If verbal persuasion is employed, persuaders must try to cultivate students' beliefs in their capabilities while at the same time ensuring that the envisioned success is attainable (Bandura, 1986). In this respect, the importance of performance feedback which informs learners of goal progress is suggested as a way of persuading students of their capabilities. Bandura (1995) also points out that care must be taken as it is easier to weaken self-beliefs through verbal persuasion than to strengthen them; this is instructive with regard to findings suggesting that competence beliefs decline as students advance through school (Eccles, 1984, Eccles, Wigfield, Flanagan, Miller, Reuman and Yee, 1989, Harter, 1990, Marsh, 1989, Wigfield, Eccles and Pintrich, 1996, Wigfield, Eccles and Rodriguez, 1998).

It is worth pointing out that there is an interface between self-determination and self-efficacy theory in that both theories acknowledge the importance of perceived competence for motivated engagement. Both theories also show that motivated behaviour is influenced by context. Further, it is interesting to note that both theories stress the importance of feedback received through task engagement apart from verbal persuasion: self-efficacy theory stresses the importance of mastery experience when engaging with activities for people's competence beliefs; and in a similar vein, selfdetermination theory underlines the importance of mastering tasks, while stressing, 
however, that in order to master tasks and to derive pleasure from this, tasks have to be optimally challenging.

\section{Self-Efficacy vs. Self-Concept}

In the motivational literature, there seems to be a lack of agreement with regard to the differences between self-efficacy and self-concept; sometimes the terms are even used synonymously in the literature, and this makes some theoretical clarification necessary.

Although self-efficacy and self-concept are both concerned with the individual's perceptions of competence, there are some important differences which deserve attention, as they have guided the construction of the research instrument used in this study (Chapter 4): to begin with, self-efficacy beliefs, as noted above, are dynamic, while research on self-concept usually views the self as stable. This is an important point, as self-efficacy beliefs may therefore better serve to shed light on motivational processes as explored in this study.

Also, self-efficacy is more task- and situation-specific than self-concept (Bandura, 1997, Schunk et al., 2008). One's self-concept has traditionally been a more general view of oneself, although in recent years domain-specific elements of the self, e.g. someone's self-concept for mathematics, has received increasing attention (e.g. Marsh, 1986). While self-efficacy is mainly concerned with judgments of capabilities, self-concept is a self-descriptive judgment including the feelings of self-worth that accompany competence beliefs (Pajares and Schunk, 2002). Also, self-efficacy beliefs are measured differently from self-concept: while self-efficacy does not compare with others and focuses on a specific ability to accomplish a task, self-concept items focus on social comparison (Marsh, 1993), including items such as "compared to others in my class I am good at [...]". Self-efficacy items, on the other hand, are worded in terms of can, a judgment of capability. (Bandura, 1997, Mills, 2004, Pajares and Schunk, 2002). 


\subsubsection{Possible Selves}

It has already been pointed out that the self concept is traditionally seen as relatively stable. During the past two decades, however, interest in the less stable aspects of the self has increased, and much attention has been paid to the domain of possible selves, an interest that has found a strong echo in a recent motivational theory in the field of L2 learning (3.4.4.2).

Markus and Nurius were the first to call the future-oriented parts of the self concept possible selves, explaining that "possible selves represent those selves the person could become, would like to become, or is afraid of becoming" (Markus and Nurius, 1986:954). Possible selves are seen as important for stimulating motivated behaviour as individuals try to bridge the perceived discrepancy between the current state and the desired state, a notion that can be traced back to earlier research linking images of future with plans to behaviour directed to attain this imagined future (Miller, Galanter and Pribram, 1960), a point that has been further developed in Higgins' selfdiscrepancy theory (Higgins, 1987).

Although research on possible selves is admittedly still in the early stages of its development, the motivational impact of desirable (or undesirable) selves has been documented in several studies. Note, however, that research has mainly been confined to the US (Anderman, Anderman and Griesinger, 1999, Beal and Crockett, 2010, Cross and Markus, 1991, Dunkel and Anthis, 2001, Markus and Nurius, 1987, Markus and Ruvolo, 1989, Oyserman and Markus, 1990, Ruvolo and Markus, 1992, Strauss and Goldberg, 1999, Wurf and Markus, 1991).

For instance, after an in-depth qualitative enquiry to elicit information about individuals' possible selves, Markus and Nurius (1986) conducted a questionnaire study involving 136 US students to quantitatively explore the link between possible 
selves and motivational and affective states. Stepwise regression analysis revealed that the likely-to-be self made consistent and unique contributions to motivated behaviour.

In another study, Oyserman and Markus (1990) explored hoped for, expected and feared selves in 238 adolescents between 13-16 years of age via open and closedended questionnaires. It was interesting to see that delinquents' expected selves were not only more negative than those of their non-delinquent peers but also very similar to their feared self (becoming a criminal, murderer), a factor which was, in turn, significantly correlated with their official involvement with delinquency. The authors suggest that delinquent adolescents were lacking a positive expected self to counterbalance the feared self and to initiate motivated, non-delinquent behaviour. The motivational stimulus of possible selves for adolescence is also underlined by a questionnaire study involving 350 seventh-grade students by Anderman et al. (1999). The empirical data indicated that positive present and future academic selves were related to better grades; when multiple regression was used, present and future selves both significantly predicted grade point average.

In an exploratory study investigating possible selves across different age groups, Cross and Markus (1991) used open-ended questionnaire to elicit information about 173 participants' possible selves. The study provided rich descriptive data of the varying visions people have at different stages in their lives. The data elicited suggested that individuals' possible self visions serve as motivational stimulus across the lifespan. It also indicates that the number of feared and hoped-for selves generated by individuals seems to decrease with age. Note, however, that the inherent drawbacks of a cross-sectional approach have to be taken into account when interpreting these tentative results.

In this vein, a particularly insightful approach is the recent longitudinal study by Beal and Crockett (2010), which explores 312 adolescents' future aspirations and 
expectations regarding work and education. (Note that Beal and Crockett do not draw on possible self terminology although they relate their study to possible selves research). Open-ended questionnaires were administered at three different time points; at time points 1 and 2 (one year apart) adolescents were still at high-school; time point 3 was seven years later when participants were around 21-27 years old. Multiple regression analysis supported the view that students' thoughts about their future are important for their development; they seem to influence not only current behaviour and attainments but also adult educational attainment. Note that although sample loss was experienced between time point 2 and 3 , over $60 \%$ of the sample participated in the young adult follow-up. Apart from illustrating the motivational long-term impact of future-oriented thoughts, the study generated two other important insights: firstly, the data suggest that even within a one-year period students' future-oriented thinking may change, e.g. more students expected to complete education at time point 2 . Secondly, there seems to be a bidirectional effect between future vision and learning environment, e.g. extracurricular activities seem to have a positive impact on students, as they appear to increase occupational expectations over time.

In the context of the present study it may be worth mentioning that beliefs about who one might become in the future may be particularly important in phases of drastic change, such as the transition from school to university. When individuals contemplate change, they generate various possible selves, which can serve as important guidance to students to pursue or, alternatively, abandon the chosen path (Kerpelman, 2006). An insightful longitudinal study to explore the role of possible selves in situations of life transition has recently been carried out by Manzi, Vignoles and Regalia (2010). The first phase of the study involved 229 young adults in Italy and the UK; 86 were in the transition from school to university; and 143 were in the transition to parenthood. The second point of data collection was eight months after 
time point 2. Participant attrition was stronger in the first group (response rate 44\%) than in the second group (response rate 58.3\%). The personalised follow-up questionnaire included a list of possible selves participants had described before the transition. The data suggest that possible selves structures played an important role in forming post-transition identity. It also appeared that participants who achieved their desired possible selves and incorporated them into post-transition identity had higher emotional wellbeing.

It is important to point out, however, that not all possible selves will serve as long-term motivators. Whether people can actually vividly imagine their future, and therefore whether or not the vision stimulates behaviour, has to do with whether an individual perceives a possible self to be attainable. In other words, unless a vision is likely to some extent, behaviour is not triggered. As Oyserman and James stress (2009:375),

Possible selves that are remote in their likelihood [...] make for pleasant dreams or sleepless nights, but these possible selves are unlikely to change behaviour unless [...] the perceived likelihood of their potential reality increases.

In the educational context, this point must be taken into consideration. Oyserman (2008) points out that behaviour depends on the perception of future as either close or distant, a point which is related to the previous one: a learner who sees the future as distant (as in life begins after graduation from school) is not likely to exert effort on a task merely because the task may be beneficial for his future possible self. If, however, the present is perceived as paving the way for a very possible future which one is approaching step-by-step, possible selves may become effective regulators of behaviour. Students, therefore, have to become convinced that present action matters and that this action has relevance for the attainment of possible selves (Oyserman, 2008). 
Moreover, students also have to perceive that they have some control over outcome. By drawing on the concept of locus of control as explained in valueexpectancy theory (3.2.1), Oyserman and James (2009) hypothesise that only if students feel they have some control of a situation will they expend effort on it. The belief, for instance, that intelligence is malleable and that stronger effort can shape one's intelligence may play a role in how hard students' try to solve a problem (Dweck, 2000). Only under these conditions can possible selves allow the individual to initiate the necessary steps and strategies for accomplishing a goal.

Lastly (and this point is crucial) hypothetical images of oneself in the future can only unfold their motivation potential if the vision is felt to be to "real", that is if imagination is lively enough to "see" and "feel" the picture (Markus and Nurius, 1986). Only if a possible self vision is brought to mind vividly can it be a powerful motivator and improve performance (Ruvolo and Markus, 1992), a fact that has attracted attention in the area of sports psychology, where the motivational potential of imagery and image enhancement techniques are explored (Beauchamp, Bray and Albinson, 2002, Cumming, 2008, Cumming and Hall, 2002, Cumming, Hall, Harwood and Gammage, 2002, Gould, Damarjian and Greenleaf, 2002, Gregg and Hall, 2006, Hall, Munroe-Chandler, Cumming, Law, Ramsey and Murphy, 2009, Short, Tenute and Feltz, 2005, Wesch, Milne, Burke and Hall, 2006).

For instance, a cross-sectional three phase study by Gregg and Hall (2006) involving 994 sports students revealed that athletes at a competitive level find it easier to conjure up positive imagery scenarios connected to their discipline than athletes at recreational level. Athletes at competitive level also reported that they had more control over the image, and that they felt stronger emotion while picturing these situations. Given that self-efficacy beliefs have shown to influence motivated behaviour in various contexts (3.4.2) and that possible selves have to be perceived as 
likely in order to be pursued, it may not be surprising that many of the cited studies have further revealed a stable relationship between imagery use and self-efficacy: for instance, a study conducted with 51 varsity golfers just before a championship found significant correlations between imagery use, self-efficacy beliefs and golf performance (Beauchamp et al., 2002). It seems plausible to argue that higher levels of self-efficacy make the attainment of visions more likely and thereby increase the power of the individual's imagery use. Indications are, however, that the relationship is bidirectional, although caution has to be taken when inferring cause-and-effect relationships. For example, in a study involving 122 football players, imagery use was a significant predictor of both self-confidence and self-efficacy when regression analysis was used (Munroe-Chandler, Hall and Fishburne, 2008). Similarly, in another investigation involving 162 exercisers from such different areas as aerobics and martial arts, appearance-health imagery significantly predicted exercise behaviour and technique imagery significantly predicted task efficacy when regression analysis was used (Cumming, 2008).

Given the focus of the present study, it is further worth underlining that Markus and Nurius (1986) stress the fragile nature of possible self beliefs and the importance of the environment for the development of possible self beliefs. Empirical evidence includes, for instance, an insightful interventional longitudinal study by Oyserman, Bybee and Terry (2006). The study aimed to explore the relationship between academic success and academic possible selves and involved 141 school students. Findings indicate that the intervention was successful in enhancing academic possible self beliefs, and in the two-year follow-up, students showed better grades and less misbehaviour in class. Note that just like individuals themselves, possible selves are socially situated, and people's relations with each other play a part in the process of generating possible selves. The effect of influential others in particular should 
therefore not be underestimated, as both real people and fictional characters can serve as inspirations for possible selves. Influential others can also help individuals realise their future vision, or, conversely, convince them to abandon them. (Harter, 1999, Kerpelman, 2006, Kerpelman, Eryigit and Stephens, 2008, Kerpelman and Pittman, 2001).

For instance, a laboratory study by Kerpelman and Pittman (2001) involving 76 young adults and their peer partners illustrates how easily participants' possible selves are influenced by feedback received from peers. Interestingly, it was particularly highly valued possible selves that were most susceptible to influence. Another insightful questionnaire study on 374 African-American students showed that both self-efficacy and parental support, in particular support from mothers, had a significant effect on how students visualised their educational future (Kerpelman et al., 2008).

To summarise, possible selves are socially contingent, the environment plays an important role in stimulating them but also influences whether they flourish: for possible selves to become more than escapist fantasies and to unfold their motivational potential, individuals need to feel able to attain their future vision and to believe that their action will make an impact on getting closer to the desired vision. These beliefs can either be nourished or undermined by the environment.

\subsection{Motivation to Learn Languages}

Research on L2 learning motivation is - rather similarly to main-stream motivational research - a field of differing theories and approaches. It falls beyond the scope of this study to cover them all in detail, but an outline of the historical development of the field is important to understand the recent developments which are germane to the present research. The overview is divided into four sub-sections. Starting with early motivational research shaped by the social-psychological framework of language 
learning, it moves to the $1990 \mathrm{~s}$, which were characterised by an increasing interest in cognitive motivators. The third section is an outline of the subsequent interest in motivational change, followed by a fourth section which describes self perspectives on motivation, which have particularly shaped the current research.

\subsubsection{The Early Days}

In what way does language learning motivation differ from general motivation to learn? The first to address this question and to develop a L2 motivational theory were the Canadian social psychologists Gardner and Lambert (1972). By acknowledging that motivation, not just aptitude, plays an important role in language learning, the researchers provided the foundation stone of the field as it is today. It was further stated that language learning is qualitatively different from other kinds of learning, as it is embedded in a mediating process between the learners' identity and the culture of the target language.

Second languages, unlike virtually any other curriculum topic, must be viewed as a central social psychological phenomenon. [...] In the acquisition of a second language, the student is faced with the task of not simply learning new information (vocabulary, grammar, pronunciation, etc.) which is part of his own culture but rather of acquiring symbolic elements of a different ethnolinguistic community. [...] Furthermore, the student is not being asked to learn about them; he is being asked to acquire them, to make them part of his own language reservoir. This involves imposing elements of another culture into one's own lifespace. As a result [...] his willingness or ability to identify with other cultural communities become important considerations in the process of second language acquisition. (Gardner, 1979: 193-194)

In Gardner and Lambert's original framework (Gardner and Lambert, 1972), motivation was defined in terms of the interplay between the desire to achieve a goal, the effort expended on it, and the pleasure associated with it. Of crucial influence on these factors were the learners' attitudes towards the speakers and the culture of the target language, which led to development of the well-known distinction between integrative and instrumental orientations. Orientations in general are clusters of 
reasons for studying an L2; an integrative orientation refers to a positive attitude towards and a genuine interest in the speakers and the culture of the target language, while an instrumental orientation is shaped by considerations of the practical purposes and other advantages that the learning of the language might bring about. It was postulated that an integrative orientation is superior to an instrumental orientation and would lead to higher achievement. Gardner has stressed in his later work that integrative and instrumental orientations should not be interpreted as dichotomous (Tremblay and Gardner, 1995); the original ideas have also undergone some modifications over the years (see Gardner, 2001). I will not trace these developments in detail; what is important to retain is that the social-psychological view, and with it the idea of integrativeness, has had a prevailing influence on L2 learning motivation theory and research.

\subsubsection{Focus on Cognitive Motivators}

In the 1990 s, early motivational theories were criticised for various reasons. One of the complaints was that the theories did not seem to be generalisable to many foreign language (FL) learning situations. In the context of FL learning, where students have little contact with the target language - or where the language is almost a global property as in the case of English - the distinction between integrative and instrumental orientations did not prove to be very useful. Researchers rightly pointed out that the model was developed within a Canadian environment, where anglophone and francophone communities live closely together, a fact that shapes students' learning experience in a unique way. Another concern was that the model did not take account of insights from mainstream motivational research, as discussed earlier in this chapter.

During the past 20 years there has been a growing concern with the theoretical content of [the concept of integrativeness], partly because it did not offer any obvious links with the new cognitive motivational 
concepts that had been emerging in motivational psychology (such as goal theories or self-determination theory) and partly because the label "integrative" was rather limiting, and quite frankly, did not make too much sense in many language learning environments.(Dörnyei, 2009b:9-10)

Finally, the increasing focus on cognitive theories of motivation was due to researchers' increasing interest in investigating pedagogical issues in the "real world" situation of the classroom: although the original socio-psychological model had been expanded into a socio-educational model (Gardner, 2001), the main tenets remained virtually the same, and failed to satisfy those interested in the role of motivation in the complex process of foreign language teaching: even if attitudes towards a specific language/ culture initially play a role in motivating a person to enrol in a language course, these attitudes may not be sufficient to predict sustained involvement during the learning process (Dörnyei and Skehan, 2003).

According to Gardner "the source of motivation impetus is relatively unimportant, provided that motivation is aroused" (1985: 169), a statement which was to ignite heated debate. L2 motivational researchers came to challenge this view by pointing out that it is of vital importance for any teacher or institution that wants to promote language learning to know more about the factors that arouse motivation, or, as Oxford and Shearin (1994: 15) phrased it: "without knowing where the roots of motivation lie, how can teacher water these roots?" Prompted by an influential article by Crookes and Schmidt (1991) which called for a reopening of the research agenda, other researchers followed suit (Oxford, 1994, Oxford and Shearin, 1994, Skehan, 1991) leading to a lively debate among key scholars (a detailed overview is provided by Dörnyei, 1998) and to a surge of differing approaches to L2 motivation, also embracing cognitive factors such as goals, attributions and self-efficacy beliefs (see Crookes and Schmidt, 1991, Dörnyei, 1994a, Oxford, 1996, Ushioda, 1997, 1998, Williams and Burden, 1997). I will describe two of the resulting motivational models 
in more detail as they have particularly influenced recent conceptualisations of motivation. I will also explore the state of research on language learning motivation and self-efficacy to date.

\subsubsection{Dörnyei's 1994 framework}

Dörnyei’s 1994 framework for structuring L2 motivation in the educational context is important, as the recently developed L2 Motivational Self System (3.4.4.2) draws on this early motivational model. In this early framework, L2 motivation is situated on three different levels; the language level, the learner level and the learning situation level. The language level encompasses components that draw on the socio-educational framework and includes the integrative vs. instrumental distinction. The learner level then involves the individual characteristics that the learners bring to the learning process, such as need for achievement, perceived L2 competence, causal attributions, self-efficacy, self-confidence and language use anxiety.

These constructs draw on cognitive theories, except for the last two. The concept of self-confidence bears a resemblance to self-efficacy beliefs; however, it relates to the work of Clément (1980), who has proposed that self-confidence is an important determinant of the motivation to learn a L2. The source of self-confidence, according to Clément, lies in the frequency and quality of the contact with the target community, and is therefore situated in the social-psychological tradition. In addition, the concept of linguistic self-confidence is broader and not as task-specific as selfefficacy beliefs. Self-confidence may be best described as the positive counterpart of language anxiety, the role of which has received much attention (MacIntyre, 1995, MacIntyre, Baker, Clément and Donovan, 2002a, 2002b, MacIntyre, Clément, Dörnyei and Noels, 1998, MacIntyre and Gardner, 1994).

The third level of the framework, the learning situation level, relates specifically to the L2 learning classroom, in that it comprises course-specific 
motivational components, teacher-specific motivational components and groupspecific motivational components. Course-specific motivational components include interest (in the course), relevance (of the course to one's needs) expectancy of success and satisfaction. Teacher-specific components include the authority type of the teacher and modelling processes, feedback and task presentation. Group-specific motivational components include goal-orientedness, the norm and reward system in place, group cohesiveness and classroom goal structure. Dörnyei (2001) points out that this early motivational model only clusters key variables concerned with L2 motivation, and does not elaborate on the relationship between them. In other words, the question arises of how the factors situated on the learner, language, and learning situation levels relate to each other.

In short, this early motivational framework offered an important step towards widening the motivational framework in L2 motivational research; it provided little insight, however, into the relationship between the three motivational levels outlined.

\subsubsection{Williams and Burden's Social Constructivist Framework}

Williams and Burden's (1997) model was particularly forward-looking, as it not only drew on insights gained from mainstream motivational research, but also explicitly addressed a) the interactive relationship between context and individual and b) the temporal nature of motivation.

Williams and Burden (1997) take a social constructivist position, in which it is assumed that each person is motivated differently and that choice plays an important part in an individual's motivation. They include a wide range of cognitive factors in their model, such as the distinction between intrinsic and extrinsic motivation, perceived value of the activity, learners' beliefs about themselves, such as selfefficacy beliefs, their sense of agency including locus of control and causality, attributions as well as goals. Yet they contend that a purely cognitive approach has 
shortcomings, as it fails to take account of the influence of affective factors, emotions, and social and contextual influences, which also form part of the interrelated motivational framework. The authors also point out that motivational theories have to acknowledge the temporal dimension of motivation, which becomes particularly important in such a long-drawn-out process as language learning:

The literature has tended not to differentiate clearly between what initiates motivation, i.e. turns someone on to an activity and what sustains the involvement in the activity and what keeps them interested in pursuing a particular goal. There are a multitude of reasons why learners may well be highly motivated to begin learning a foreign language, but it is quite another matter to sustain that motivation (Williams and Burden, 1997: 141)

On the basis of this reasoning, the model distinguishes between a) the decision to do something b) the reasons for doing something and c) sustaining the effort or persisting, while all three aspects are connected in an interactive fashion and influenced by the social context.

Williams's and Burden's model might be seen as the starting point of a gradually evolving interest in the relationship between motivation and time, which characterises the present state of motivational research.

\subsubsection{Self-Efficacy in Language Learning}

The importance of self-efficacy beliefs in mainstream motivational theories has already been pointed out (3.3.2). It is interesting to note, however, that despite attempts in the 1990s to include self-efficacy in L2 motivational frameworks, as shown above, there are to date few studies on self-efficacy in relation to motivation (Cheng, 2002, Ehrman, 1996, Mills, Pajares and Herron, 2007, Mori, 2002, Tremblay and Gardner, 1995 being exceptions). Also, methodological difficulties are not uncommon among the few existing self-efficacy investigations - as will be outlined in more detail below - which may explain why recent re-conceptualisations have somewhat neglected the importance of students' capability beliefs for their motivated 
engagement. This paucity of studies, however, seems counterproductive: self-efficacy theory has great potential to shed light on motivational change (3.3.2), particularly in educational contexts where continuous exposure to persuasion by others (student and teacher feedback) and varying success when dealing with learning tasks can affect mastery experience, and strengthen or, conversely, undermine self-efficacy beliefs.

On the basis of the literature reviewed, it therefore seems evident that an exploration of motivational change should not ignore students' self-efficacy beliefs. There are, however, few studies to guide the present research: Bandura (1997) states that self-efficacy has to be measured in a situationally sensitive fashion and at a microanalytic level, for instance, self-efficacy for special academic problems, yet L2 studies tend to measure self-efficacy in such a broad manner that they cannot capture any task-specific beliefs about capability. For instance, if self-efficacy for writing is measured by one item asking students to rate their English writing ability on a 5-point Likert scale (Cheng, 2002), then the insight is very limited, as Mills (2004) points out. One's perceived writing capability may in fact differ from genre to genre; a person might feel very efficacious in writing a personal letter, but not in academic writing. Also, efficacy items are often combined with other measures of value e.g. "I liked reading classes at junior and senior high schools" (Mori, 2002). In a similar vein, MacIntyre, MacMaster and Baker (2001) measure self-efficacy beliefs by a one-item judgment about one's ability to complete a language course as ("I expect to do well in this class"). Such crude measures ignore the fact that a student might, for instance, expect to do well in the written examination, but not in the oral examination. In addition, the item measures more this person's expectations of success than his/her perceived self-efficacy. Note that according to Bandura (1997) outcome expectancies are only partly governed by beliefs of efficacy.

A similar concern may be raised with regard to the study conducted by 
Tremblay and Gardner (1995). ${ }^{6}$ Although the scales used in Tremblay and Gardner's study include task-specific items, it is problematic that self-efficacy is measured in terms of anticipated proficiency in French, e.g. "I could by the end of my French course understand French well enough to teach a French course", "I could by the end of my French course write a French novel". Further note that the items would not have been suitable for the current study because most of them are much wider in scope than the ones designed for this study.

Task/ situational sensitivity is crucial if beliefs of self-efficacy are to be measured. This distinction, however, is not always clearly drawn: note for instance, that Ehrman (1996: 92), measures self-efficacy "by rather simple statements of selfconfidence in one's learning ability" such as "How do you rate your own ability to learn foreign languages relative to other Americans in general? How do you rate your own ability to learn foreign languages relative to other Foreign Service Institute students you have known? How well do you think you will do on the course?"

Following the discussion on self-concept vs. self-efficacy above, self-efficacy beliefs are usually not well measured by items enquiring about future intentions ("will" statements); in addition, unlike items for measuring self-concept or the L2 concept of self-confidence, they do not include a dimension of social comparison. By asking generally about an individual's perceived competence in the four language skills with one item for each skill (How well can you read/ write/ speak listen in the foreign language?), one may actually measure more generalised personality attributes than competence beliefs in the exact area.

\subsubsection{Motivation and Time}

It has already been pointed out in the discussion of Williams and Burden's framework

\footnotetext{
${ }^{6}$ Note that measures of self-efficacy items were not included in the Tremblay and Gardner study. I therefore contacted Tremblay and Gardner and obtained the scales used in the study.
} 
(3.4.2.2) that motivation may not be viewed as a simple and static phenomenon. Given that language learning is a lengthy process, sustained motivation is needed in order to accomplish it. This explains why researchers have become increasingly interested in the temporal aspect of motivation and have started to pay closer attention to motivational processes. In recent years, this interest has mainly been propelled by two motivational researchers, Zoltan Dörnyei and Ema Ushioda. I will first turn to their early motivational thinking before exploring their current approaches.

\subsubsection{Dörnyei and Ottó's Process Model of L2 Motivation}

Driven by the desire to find a theoretical framework which can take the temporal aspect of motivation into account, Dörnyei and Ottó developed a Process Model of L2 Motivation (1998). The model draws on various motivational theories, most importantly on goal theories and attribution theory. It describes motivation as a sequence of three discrete stages of action; the preactional, actional and postactional stages. The first stage refers to the choices people make in setting goals. Their wishes and hopes influence their goal setting behaviour, which leads to formation of intention, which then serves as an initiator of action, or action-launching impulses.

The actional stage deals with how motivation is maintained and efforts are sustained in the pursuit of goals. It is characterised by a dynamic appraisal process: learners constantly evaluate the input they receive from the environment, they evaluate the progress they make towards the desired outcome and compare the actual events with the predicted ones. Self-regulatory strategies, such as goal-setting strategies, learning and self-motivating strategies, function as control mechanisms at the actional stage.

The postactional stage describes the period after the goal has been achieved or the action ended and involves the individuals's evaluation of the particular tasks. By drawing on attribution theory (3.2.1), causal attributions are seen as particularly 
relevant to whether action is renewed, thus reinitiating the motivational cycle.

Williams and Burden's (1997) framework suggested that motivational research may need to distinguish between three motivational stages: students' decision to do something, their reasons for doing something, and the factors influencing their sustained effort - an insight specified and illustrated by the process model. The process model poses problems, however, if its insights are to be transferred to the educational context; firstly, in the educational context it is difficult to draw clear-cut boundaries between the three different stages, as it is not quite clear where an activity starts and where it ends. In addition, learners are usually involved in many parallel tasks, and different goals may be competing with each other; these problems are raised by the author himself (Dörnyei, 2005). Nevertheless, the process model marks another important step towards a better understanding of the unstable nature of motivation, by acknowledging the complexity of motivational actions, which do not occur in isolation but have both antecedents and consequences. Dörnyei (2009d, 2010) himself highlights the drawbacks of approaching motivation as a series of linear cause-effect relations, and has recently turned to a dynamic system perspective on motivation (3.5.3.3).

\subsubsection{Motivational Processes from a Qualitative Perspective}

The increasing interest in the temporal dimension of motivation is also apparent in the early approach to motivation of motivational researcher Ushioda (1996a, 1997, 2001), which was innovative in that it not only acknowledged the temporal dimension of motivation but also decidedly distanced itself from the socio-psychological research tradition in both its theoretical and its methodological focus. Ushioda's work has been a precursor to more use of qualitative methods in a field that had largely been dominated by a quantitative research paradigm. Her early motivational thinking was influenced by a qualitative study on university students' motivation for studying a 
modern foreign language; it will be outlined here, as it has influenced the methodological approach to motivation in the current study.

Ushioda conducted a two-phase qualitative study with 20 undergraduate learners of French as a foreign language in Ireland, ten of whom were in their first year and ten in their second year, in order to explore motivational thinking in foreign language learning. By drawing on motivational theories such as goal theories and attribution theory, she identified causal and teleological dimensions to people's motivation to learn a foreign language. The causal dimension draws on attribution theory and emphasises the role of the individuals' evaluation of past experience in the formation of current motivation while the teleological dimension draws on goal theories and focuses on future-directed behaviour. Her data suggested that the L2learning-related experience is relevant in forming students' first wish to engage with a foreign language at university level. Future goals may not be immediately be important for students but appear to become more relevant over time, especially in the face of difficulties, e.g. failure in examinations. What remains unclear from the study is whether the development towards stronger goal-orientation took place in first or second year students, a point that is of interest to the present study. Importantly, though, Ushioda's research showed that future studies needed to pay attention to emergent and changing pattern of students' motivation, and that qualitative studies may be particularly suited to doing so. Ushioda's insights also illustrate the point that more longitudinal approaches to motivation are needed to uncover the evolving nature of students' motivation. Although the potential of longitudinal studies for motivational research has been stressed elsewhere as well (Dörnyei, 2007), it has yet to inspire a sound body of research. A problem that is inherent in longitudinal studies is participant attrition, which also affected Ushioda's study in that it reduced the student number in interviews to 14 learners, as students were either unavailable for a second 
interview or had withdrawn from the course. One may conclude that patterns of effective motivational thinking as identified by Ushioda in her study on French undergraduate students are characteristic of those highly motivated students who managed to sustain their motivation over the course of the year.

Although longitudinal studies are still a rarity in L2 motivational research, there is supporting evidence for Ushioda's assertion that goals tend to become more specific when people enter university: Shoaib and Dörnyei (2005) report on a study where participants were asked to reflect on the changes their motivation underwent during their life-long language motivation process. A drawback of this study is that it relied on retrospective data, where there was a considerable time difference between the interview conducted and the events recalled. This raises the question of whether participants remembered accurately the time at which this specification took place, a problem called the telescope effect, which will be discussed in Chapter 4 (4.2).

\subsubsection{A Dynamic Systems Approach}

The process-oriented model by Dörnyei and Ottó as described above (3.4.3.1) depicted motivation as a series of linear cause-effect relations. More recently, Dörnyei (2009d, 2010) has questioned such an approach to motivation. He points out:

In retrospective [...] I can see that the model I was proposing had multiple, parallel, and interacting cause-effect relationships, accompanied by several circular feedback loops, making the validity of the overall linear nature highly questionable [...] and therefore a more radical reformulation was needed (2009d:196-197)

He acknowledges this complex nature of motivation by turning to dynamic systems theory (DST), a theory which has become increasingly influential in the wider field of second language acquisition (Larsen-Freeman, 1997, Larsen-Freeman and Cameron, 2008). While an in-depth scrutiny of DST would go beyond the scope of this thesis, it should be pointed out that a dynamic and non-linear view of motivation takes into account that the very factors that exert influence on motivated behaviour also undergo 
change over time. A good example of the difficulty of capturing the complexity of motivational dynamics is that of self-efficacy beliefs (3.3.2): self-efficacy has consistently been shown to be linked with a variety of motivational factors as discussed previously, e.g. I pointed out that they appear to exert influence on the value someone places on an activity and on the expectancy beliefs an individual holds, factors which, in turn, influence motivated behaviour. Yet self-efficacy beliefs undergo changes over time, thereby influencing changes in the other motivational factors as well. This dynamic nature of the very factors involved in motivational processes triggering and sustaining motivated action therefore make it difficult to predict motivated behaviour in terms of cause-and-effect thinking.

However, past research, which mainly relies on correlation-based studies, has shown consistent relationships between certain motivational factors and motivated behaviour. In order to reconcile these fairly consistent results with DST theory, Dörnyei turns to research on personality, development and the notion of attractors (Nowak, Vallacher and Zochowski, 2005). He postulates the existence of various and overlapping attractors, forming attractor states: "Attractor states are preferred states towards which the system gravitates" (Dörnyei, 2009d:198). Accordingly, a person with a high level of self-efficacy may not undergo as strong a motivational change even when encountering difficulties as a person with a low level of self-efficacy, because a person's sense of self-efficacy serves as an attractor state.

Using DST to illustrate the complexity of the interlinked and evolving factors involved in human behaviour is certainly useful, but caution needs to be exercised in transferring and making use of a theory developed specifically to predict and uncover physical laws to explore human behaviour: in the natural sciences, DST serves to calculate mathematically a certain trajectory, and the initial values of all variables involved at a starting point have to be known (Luenberg, 1979). Transferring the 
underlying tenet of DST to human motivation would imply that once all motivational factors and their "initial values" are known, an individual motivational trajectory could be fully predicted, a somewhat presumptuous implication reminiscent of early mechanistic views of human motivation. Given the impossibility of knowing all factors involved in initiating and sustaining human motivation, the practical value of DST in motivational research is quite limited, which may explain the lack of empirical research on this front in the L2 motivational field to date.

Nevertheless, the recent turn to a DST perspective has propelled further the useful process of rethinking the methodological approaches traditionally used in motivational research: experiments or large-scale surveys carried out on isolated variables to predict motivated behaviour make little sense in such a complex systems paradigm. SLA researchers Larsen-Freeman and Cameron (2008) suggest a process of retrodiction instead of prediction where the researcher examines the system somewhat after the fact, to try to make sense of what has already occurred, while Dörnyei (2009d) points towards the potential of longitudinal case studies in particular to uncover the complexity of motivational processes and describe the sub-systems at work in an individual's motivated behaviour.

\subsubsection{A Person-in-Context relational view of motivation}

The overviews provided above show that the temporal dimension is an important factor when looking at motivation. At the same time, the discussion foreshadows the empirical challenges posed when motivation is not seen as a static state but as a dynamic phenomenon. Approaching motivation becomes even more complex if the dynamics between individual, learning context and motivation are examined in more detail.

Similarly to mainstream motivation, L2 motivational research has traditionally tried to identify individual differences which predict motivated behaviour, e.g. large- 
scale surveys testing whether a given characteristic of a group - e.g. a strong integrative orientation - leads to more engagement with or higher achievement in language learning. The influence of the context was thus only acknowledged insofar as socio-cultural factors were reflected in the individual's attitude (e.g. an integrative orientation) towards learning.

If the insights gained so far from the exploration of motivation over time are followed, motivation must be conceptualized as a dynamic state of arousal which is situated within an individual and guided by a complex interplay of motivational processes, some of which may even be triggered by the unconscious (see 3.1). Motivation therefore cannot simply be induced by a given environment: for the present research this means that motivated learners cannot simply be seen as the outcome of a motivation-instilling environment. However, neither is it true that motivation can be seen as separate from the context. As the literature review has also shown, some motivational thought processes can indeed be constructed or constrained by the environment, that is, motivation is also a contextually-bound phenomenon: mainstream motivational psychology highlights the influence of the learning environment on individuals' thought processes: I discussed in my review of selfdetermination theory how an individual's need for self-determination and his/her intrinsic motivation can be nourished or undermined by the learning environment; in particular I pointed out the importance of feedback. I also highlighted how the environment plays a role in forming self-efficacy beliefs, and discussed sources such as mastery experience and verbal persuasion that can increase or lower perceived competence. Also, the role of the environment for shaping and encouraging future selves was pointed out.

However, the relationship between motivation and context does not go in one direction only. Across disciplines ranging from cognitive psychology through 
mainstream motivational research to cross-cultural psychology, investigations focusing on learning and motivation increasingly focus on the interaction between students' motivational beliefs and the learning environment, a so-called person-incontext perspective on learning and motivation (Volet, 2001). Aligned to those strands in educational psychology stressing the interdependent and mutually influential relationship between context and individual (Järvelä, 2001, Järvelä, Volet and Järvenoja, 2010, Turner, 2001, Volet, 2001, Volet, Vauras and Salonen, 2009), and reflecting the broader turn towards the influence of social context in SLA research (Lafford, 2007), motivational researcher Ushioda (2009) has recently argued for a person-in context relational view of motivation in language learning.

Ushioda criticises the fact that L2 motivation research still tends to view the learning context as stable, as a background variable which exerts influence on student motivation yet remains unaffected by it. She stresses that learner and context variables interact with each other, in that the learner and the learning environment mutually influence and shape each other. Therefore motivation is seen as a process that emerges from this interaction over time. She argues:

My argument is that we need to take a relational (rather than linear) view of these multiple contextual elements, and view motivation as an organic process that emerges through the complex system of interrelations. (Ushioda, 2009:220)

In a similar manner to the implications of the dynamic system approach in L2 motivation (Dörnyei, 2009d, 2010) outlined above, Ushioda's recent approach calls into question dominant linear approaches to motivation. The author stresses explicitly that the latter lead to cause-and-effect thinking, oversimplifying the complex relationship between learner and context. She argues for paying more attention to the individual learner as situated in context - the broader social context and the particular learning environment - and for viewing this learner as a real person, rather than an 
abstract collection of characteristics.

If motivation is thus no longer seen in terms of (collective) individual differences, but as a phenomenon which emerges from the interaction between the learner and the learning environment, the shortcomings of traditional methodological approaches to motivation become obvious, and the limitations of cross-sectional quantitative studies in particular are evident.

However, the methodological challenges of doing justice to the approach developed by Ushioda and of viewing motivation in a relational manner go even further: they are similar to the challenges posed by the line of thought initiated by the dynamic systems approach to motivation (3.4.3.3). In essence, traditional cause-andeffect models would have to be abandoned completely, and qualitative longitudinal studies would have to try to unravel the intertwined relations that constitute emergent motivation. This may explain why empirical studies have not yet pursued Ushioda's line of thought either.

\subsubsection{Self-Concepts in L2 Motivational Research}

In the early days, research on second language learning motivation particularly emphasised the importance of the link between learning and identity. In the 1990s, researchers pointed out the difference between learning a second language and learning a foreign language, the latter of which is usually characterised by limited contact with L2 speakers or opportunities for practice. Researchers still agreed, however, that there was a qualitative difference between language learning and the learning of other kinds of tasks. Echoing Gardner and Lambert (1972), Williams (1994:77) points out: 
The learning of a foreign language involves far more than simply learning skills, or a system of rules, or a grammar; it involves an alteration in self-image, the adoption of new social and cultural behaviours and ways of being.

L2 motivational researchers' quest, therefore, was to find a theory to acknowledge the link between language learning and the student's self, and which was not defined within the narrow constraints of second language learning situations. Self theories in mainstream motivational research seemed to offer a way forward to free motivational theories of the constraints involved in second language learning. I will first turn to the influence of self-determination theory in the field of L2 motivation. I will then turn to the influence of possible selves theories in L2 motivational research as evidenced in Dörnyei’s (2005, 2009c) L2 Motivational Self System. Being especially relevant for the present research, and having engendered several noteworthy studies, special attention will be paid to the L2 Motivational Self System and those studies seeking to validate the model empirically.

\subsubsection{Self-Determination in Language Learning}

It has already been pointed out that self-determination theory has not only been influential in mainstream motivational psychology, but has also exerted considerable influence on L2 motivational research. The value of self-determination theory for language learning motivation has been acknowledged for some time (e.g. Brown, $1981,1990,1994)$ in particular by researchers interested in learner autonomy (Benson, 2000, Ushioda, 1996b, 1997). It has found a particularly strong echo in recent motivational research conducted in the Canadian context by Noels and her colleagues (McIntosh, Cameron and Noels, 2004, Noels, 2001b, 2009, Noels, Clément and Pelletier, 1999, Noels, Pelletier, Clément and Vallerand, 2000). Although the smallscale nature and the particular research context have to be taken into account when interpreting existing studies, findings suggest that intrinsic motivation is an important 
variable when exploring students' motivated engagement with language learning. For instance, a quantitative study conducted on teachers' communicative style (Noels et al., 1999) involving 78 students on a French immersion course revealed moderate correlations between intrinsic motivation and students' motivational intensity (.39) and their intention to continue to study (.49). The study also tentatively suggests that students' intrinsic motivation is lower the more controlling and the less informative students perceived the teacher to be. Although observed correlations were only weak (.28), this finding is in line with the predictions of self-determination theory that an autonomy-supporting environment leads to higher levels of intrinsic motivation, while a controlling environment lowers the level of intrinsic motivation (Deci and Ryan, 1985). In another study on 159 students' motivations for learning an L2, Noels et al. (2000) found that intention to continue was moderately correlated with all three different intrinsic motivation scales used, knowledge (.49), accomplishment (.46) and stimulation (.34).

Although there are, to my knowledge, no large scale studies to corroborate the importance of intrinsic motivation for engagement in the language learning process, it appears that intrinsic motivation is a useful concept for exploring students' motivation to engage with language learning. Less convincing, I would argue, is the attempt to match self-determination theory to the socio-psychological perspective.

It is claimed by some that the concept of intrinsic and integrative motivation and the concept of extrinsic and instrumental motivation are basically interchangeable (e.g. Soh, 1987). According to that view, the concepts of intrinsic and integrative motivation capture the concept that the language and culture are studied for their own value and that language learning is not conducted to obtain an external incentive (a monetary reward, or a particular profession). On the other hand, the concepts of extrinsic and instrumental motivation capture all those reasons that are extraneous to 
the learning process. However, Gardner (1985) himself points out the underlying theoretical problems posed by such a conflation of terminology: intrinsically motivated learners engage in a learning activity without any external incentive, they derive pleasure from the learning activity itself. In contrast, integrative as well as instrumental orientation are motivated by an external purpose, a goal, and would thus have to be called extrinsic according to self-determination theory. In a similar vein, Schmidt and Savage (1994) have pointed out that language learners might have a strong integrative orientation yet derive little intrinsic pleasure from learning the language. In addition, although extrinsic motivation is conceptualised as a continuum which may over time become internally regulated and synthesised with the self (Ryan and Deci, 2000), extrinsic motivation is usually seen as inferior to intrinsic orientation in terms of the quality of learning engagement (Deci and Moller, 2005). Gardner originally held that an instrumental orientation is inferior to an integrative orientation in terms of achievement and learning engagement (Gardner, 1979), but, as discussed above, both concepts might be called extrinsic in self-determination theory. Conflating extrinsic and instrumental motivation and intrinsic and integrative motivation is therefore clearly problematic on a theoretical level.

While they reject the notion of two parallel constructs, researchers like Noels similarly stress the similarity between integrative and intrinsic motivation: "the integrative orientation is similar to intrinsic motivation in that it refers to positive attitudes towards the activity and the learning process" (2001b:51). This interpretation, the author argues, is supported by the findings of a questionnaire study on 322 students studying Spanish (Noels, 2001a). However, a closer scrutiny of the study reveals that significant correlations were found between integrative orientation and both intrinsic and extrinsic orientations. Admittedly, strong correlations were only found between Gardner's integrative orientation and the more self-determined form of 
extrinsic motivation, identified regulation, but the author does not report whether the statistical significance of the difference between correlation coefficients was tested, and no effect sizes for the differences were provided. One should further note that the attitudes towards learning Spanish scale included a statement that taps into intrinsic motivation ("I enjoy learning Spanish"). A full list of questionnaire items is not included in the appendix.

The motivational framework subsequently proposed by Noels (2003) distinguishes between three interrelated categories: intrinsic reasons inherent in the language learning process, that is language learning is seen as fun, engaging etc., extrinsic reasons for language learning, which might include curricular/parental pressure; and integrative reasons relating to positive contact with L2 group and possible identification with L2 group. She argues that students who learn a language because they enjoy it also learn the language because it gives them an opportunity to interact with the language community, and that students who have more internalised reasons for L2 learning, are also more persevering. In a recent article she hypothesised that

more internalised reasons for learning a language are linked to increased identification with target language group [... learners] increasingly feel a sense of belonging to that ethnolinguistic community (2009:304).

The study which seeks to support this notion, however, has produced contradictory results. Goldberg and Noels (2006) conducted a study with 91 graduates of French immersion and intensive language programs to see whether students who opted for the French immersion programme had internalised the language to a greater degree and adopted a more Francophone identity. No difference between immersion and nonimmersion students was found in the quantitative data, evidence was found in the qualitative data only as students on the French immersion programmes described their 
orientations and reasons for continuing to study in a more self-determined style. One may assume that the special Canadian research background needs to be taken into account in interpreting the qualitative findings.

To sum up, while there are reasons to suggest that the concept of intrinsic motivation can shed light on motivated engagement with language learning, the attempts to match self-determination theory to the socio-psychological view on language learning are not convincing. There is also no sound empirical evidence to corroborate the thesis that higher levels of intrinsic motivation lead to identification with the people and the country of the target language.

\subsubsection{The L2 Motivational Self System}

The recently developed L2 Motivational Self System (Dörnyei, 2005, 2009b) represents the latest stage in Dörnyei's elaboration of a framework for L2 motivation; it has attracted considerable attention in recent years and inspired a number of empirical studies looking at the self in foreign language learning contexts (Al-Shehri, 2009, Csizér and Kormos, 2009, Csizér and Lukács, 2009, Ryan, 2009, Taguchi, Magid and Papi, 2009). The following section will explore the model itself as well as the empirical evidence based on the L2 Motivational Self in some detail. I will argue that the ideal self component of the L2 Motivational Self System is a very promising area for exploring students' motivations for studying a foreign language. However, both the theoretical framework and the empirical evidence to support the framework merit close scrutiny.

The L2 Motivational Self System draws on possible selves theory as articulated in mainstream motivational research (Dunkel and Kerpelman, 2006, Higgins, 1987, Markus and Nurius, 1986, Oyserman, Terry and Bybee, 2002, see also section 3.3.3), according to which people have the capacity to motivate themselves by conjuring up a future visions of themselves: the person they would like to become, they could 
become, or are afraid of becoming. The L2 Motivational Self System has three components, the ideal L2 self and the ought-to self and the L2 learning experience. The model draws on self-discrepancy theory (Higgins, 1987), as motivated behaviour is hypothesised to emerge from people's desire to bridge the gap between their actual self and a desired future self, i.e. the person one would like to become. If a language learner has a future vision of himself which entails speaking a foreign language, this so-called ideal L2 self serves as a motivator to learn this language as the student desires to reduce the discrepancy between the actual and ideal self states. Its counterpart, the ought-to self, is an externally imposed self-image, shaped by the attributes that a person feels he or she ought to possess in order to meet expectations or to avoid negative consequences. The third component, the L2 learning experience, relates to the learning environment in which the self is situated and which exerts influence on both self states.

It is hypothesised that in particular the first component of the system, the ideal self, plays an important role in language learning motivation. It is important to note in this respect that on the basis of self-discrepancy theory, the concept of the self is understood by Dörnyei $(2005,2009 c)$ as dynamic and oriented towards future states, in contrast to the theory of self-concept (see 3.3.2.1), which is relatively stable and orientated towards past experience. However, similarly to Erikson (2007) and somewhat in contrast to Higgins (1987), Dörnyei (2009b) stresses the difference between the concept of goals and the concept of possible selves: that is, a possible self such as the ideal L2 self is not merely seen as a subset of goals; in forming an ideal L2 self, a complex set of imagery, dreams and emotions play a part, forming learners' visions and their ability to conjure up an ideal L2 self. This point is important, as Dörnyei thereby addresses the emotional dimension of motivation, which had largely been neglected in the cognitive phase of motivational research (3.4.2). 
Dörnyei's theoretical thinking has been motivated by empirical findings showing an extraordinary resilience of the integrativeness factor and its close relationship with motivated behaviour even in the foreign language learning context, as revealed by a large-scale survey of over 13,000 language learners in Hungary (Dörnyei, Csizér and Németh, 2006). Accounting for this influence of integrativeness in the FL learning context, the L2 Motivational Self System was driven by the desire to embrace the influential concept of integrativeness from a broader self perspective, and thereby make it applicable to the foreign language learning context

Integrativeness was found to play a key role in L2 motivation [...] After some consideration I came to the conclusion that the possible selves approach [...] offered a good account of the data. Looking at "integrativeness" from the self perspective, the concept can be conceived of as the L2-specific facet of one's ideal self: if our ideal self is associated with the mastery of an L2 [...] we can be described in Gardner's (1985) terminology as having an integrative disposition. Thus, the central theme of the emerging new theory was the equation of the motivational dimension that has traditionally been interpreted as "integrativeness/ integrative motivation" with the Ideal L2 Self. (2009b:27)

This approach has had considerable influence on motivational research in recent years; and empirical evidence appears to show that reinterpreting the concept of integrativeness from a broader self perspective is especially promising for research on FL learning motivation as stronger links are observed between the ideal self and motivated behaviour than integrativeness and motivated behaviour. Results, however, are not straightforward, and I will discuss empirical studies in more detail at a later stage (3.5.4.2.2). Dörnyei holds that the integrative component of the socialpsychological model can play a role in the concept of the ideal self: language learners whose future vision is to be fluent in a language could also be said to have an integrative disposition. In contrast to the socio-psychological view, this does not mean that students identify with a particular native L2 speaker community; rather students 
may envision themselves as members of an imagined cosmopolitan community of international L2 speakers:

Our idealized L2-speaking self can be seen as a member of an imagined L2 community whose mental construction is partly based on our real-life experiences of members of the community/communities speaking the particular L2 in question and partly on our imagination (Dörnyei, 2005: 102).

In summary, one may say that approaching L2 motivation from a self perspective is forward looking as it offers the potential to amplify the L2 motivation research agenda beyond the integrativel instrumental dichotomy and narrowly conceived linear causal relationships. It takes insights from motivational processes (3.4.3) into account, as well as insights from research on the self and personal visions as offered by mainstream psychological research, the latter of which offers the potential to embrace both the affective and the cognitive dimensions of motivation. There are, however, some conceptual as well as empirical challenges that merit further attention. I will first turn to conceptual issues before exploring existing empirical evidence.

\subsection{Conceptual challenges}

Drawing on self-discrepancy theory, Dörnyei defines the central construct of the L2 Motivational Self System as the wish to bridge the gap between a current and a possible self. The actual self is, however, is not clearly articulated in the L2 Motivational Self System. As pointed out previously (3.3.3), not all future visions lead to motivated behaviour. Whether or not mental imagery can unfold one's motivational potential also depends on the beliefs about the actual self, and one may assume that a student's self-efficacy beliefs (see 3.3.2) will influence whether that student perceives a possible self within her realistic potential and decides to invest effort into pursuing that possible self. As Dunkel and Kerpelman (2006) stress, possible selves need to be attainable and to be situated within a person's realistic potential. By not taking account 
of the actual self in the L2 Motivational Self System, Dörnyei excludes important components such as self-efficacy beliefs, without which only limited insight can be gained into the process of the motivational unfolding of possible selves. The link between mental imagery, motivation and self-efficacy as suggested by studies in mainstream motivational psychology (e.g. Beauchamp et al., 2002, Cumming, 2008, Munroe-Chandler et al., 2008, Wesch et al., 2006, see section 3.4.3) therefore merits further theoretical and empirical consideration in L2 motivational research.

Secondly, it should be pointed out that whereas there is a very clear and convincing conceptualisation of the ideal L2 self, far less is said about the constructs of the ought-to self and the L2 learning experience. In particular, the latter is not clearly conceptualised. For the L2 learning experience, Dörnyei (2009b) refers to his previous publication for a review (Dörnyei, 2001, see also Dörnyei's 1994 framework as discussed in section 3.4.2.1). However, a close scrutiny of empirical studies set in the L2 Motivational Self System show very different definitions of the L2 learning experience, ranging from a set of classroom attitudes (Csizér and Kormos, 2009:108), through one's history of learning successes and evaluation of past learning successes (MacIntyre, Mackinnon and Clément, 2009), to the experience of language learning as a communication tool (Yashima, 2009). This suggests that the component of L2 learning experience remains somewhat hazy for researchers, which may consequently be the reason why the role of the L2 learning experience is largely ignored in empirical studies. The self literature already discussed (3.3) suggests that it may be difficult to conceptualise the L2 learning experience as a third component of a model along with two self-beliefs, without further indications on the relationship between self and environment. A clearer conceptualisation of the relationship between the individual (within whom self-beliefs are situated) and context - the L2 learning experience - is needed. In particular, it needs to become clearer that different self- 
beliefs - which may include, among other factors, the actual self's wish for selfdetermination, self-efficacy beliefs, but also emerging or already existing ideal self beliefs, and ought-to self beliefs - are situated within a real-life individual, who is shaped by a given context but who also acts upon and shapes the context in turn (Järvelä, 2001, Ushioda, 2009, Volet, 2001, Volet et al., 2009, see section 3.4.3.4).

To sum up, I would argue that the L2 Motivational Self System has much potential for the exploration of FL learning motivation, but that there is a need to elaborate on the relationship between the three variables that constitute the system at present, in particular on the relationship between the two self-beliefs and the L2 learning experience; further, there is a need to include the dimension of the actual self; in particular, the importance of competence beliefs to unfold the motivational potential of a future self needs to be acknowledged.

\subsection{Empirical Validation}

I will now discuss the empirical validation of the model. In 2009, an edited volume was published jointly by Dörnyei and Ushioda which comprised several studies set within the framework of the L2 Motivational Self System. According to Dörnyei (2009b) these studies test and validate the L2 Motivational Self System. In this section, a close scrutiny of the relevant studies will reveal that although the research reported offers important insights, the L2 Motivational Self System cannot claim to have been validated as a whole. Concomitant with the focus on the ideal self concepts in Dörnyei's theoretical work, existing empirical work has paid considerably less attention to the ought-to self construct, and the L2 learning experience in particular has largely been neglected. Furthermore, empirical evidence for a reinterpretation of the concept of integrativeness through the ideal self has been not yet been convincingly presented, due to methodological inconsistencies. 
Al-Shehri's (2009) study reveals that students' visual learning style and their capacity for imagination is related to a pronounced ideal L2 self. In a two-phase crosssectional study with 200 Arab students of English in England and Saudi Arabia, Shehri found that a preference for visual learning was highly correlated with a vivid ideal self, which in turn was linked to increased language learning motivation. The study provides support for Dörnyei's (2009b) emphasis on imagination/ imagery in students ideal L2 selves. The other two components of the L2 Motivational Self System were not the foci of investigation in this study.

Csizér and Kormos's (2009) study explored the motivations of 432 Hungarian students of English from secondary schools and universities. They found significant correlations between the ideal L2 self and motivated learning behaviour, in particular for university students. No significant correlation between the ought-to L2 self and motivated learning behaviour for secondary school students and only a weak correlation for university students was found. The authors reported strong correlations between the L2 learning experience and motivated behaviour. However, the L2 learning experience scale was not reported, therefore rendering it unclear what it consisted of. It appears that the L2 learning experience was equated with "positive attitudes to the learning context and the teacher as well as motivating activities, tasks and teaching materials" (Csizér and Kormos, 2009:108), and the authors' conclusion that teachers are the most important motivational factor appears to suggest that the scale measured students' attitude to their teachers.

Similarly to Al-Shehri's study, Ryan's (2009) investigation of 2397 learners of English from secondary and tertiary Japanese institutions did not address the ought-to self dimension or the L2 learning experience. He found, however, strong significant correlations between integrativeness and the ideal L2 self. Supporting Dörnyei's (2009) theoretical considerations of the reinterpretation of integrativeness through a 
self perspective, he suggests that the two concepts might be tapping into the same pool of emotional identifications. It is worth pointing out, however, that Ryan's questionnaire equated integrativeness with a positive attitude to the L2 community, and only one item of the scale measured learners' sense of identification. The stronger correlations between the ideal L2 self and intended learning effort than between integrativeness and intended learning effort is seen as further support for the assertion that the ideal L2 self is a better measure of motivated behaviour than integrativeness and that integrativeness can be reinterpreted through the ideal self. This assertion can be challenged, however. Firstly, Ryan does not appear to have tested whether the differences between correlations were statistically significant. Secondly, the assertion ignores the significant correlation between integrativeness and effort: if the scale indeed measured what it intended to measure, the existing correlation between integrativeness/ attitude and effort cannot simply be discarded. A clear distinction between integrativeness and positive attitude might have given further insights here, clarifying the extent to which emotional identification is related to motivated behaviour.

The largest study to be conducted on the L2 Motivational Self System is the one by Taguchi, Magid and Papi (2009) which looks at 4943 students of varying ages. Both the ideal self and ought-to self scales were included, but again the L2 learning environment was neglected. The only scale in their questionnaire that appears to look at the L2 learning experience to some extent is the scale attitudes to learning English.

The study revealed medium to strong correlations between the ideal L2 self and integrativeness for most sub-samples, which led the authors to draw a similar conclusion to Ryan's (2009), stating that the two concepts can be equated. It should be noted, however, that the three-item integrativeness scale had only one item looking at identification ("How much would you like to become similar to the people who speak 
English?"). Also, the Cronbach Alpha was below the recommended value of .7, ranging from .64 (Japan) to .63 (China) to .56 (Iran), rendering the scale less than reliable. The average variance in intended effort explained by integrativeness was 29\%, whereas the ideal L2 self explained 34\%. Their conclusion that "these findings justify the replacement of integrativeness with the ideal L2 self' (Taguchi et al., 2009:78) is reminiscent of Ryan's interpretation, but is questionable for the reasons pointed out.

Interestingly, Taguchi et al. (2009) also found evidence for two different types of instrumental motivation: promotion-oriented, corresponding to the ideal L2 self, and prevention-oriented, corresponding to the ought-to L2 self, which ties in with Dörnyei's theoretical considerations of instrumental orientations (2009b). A problem that may need to be pointed out, however, is that the same items sometimes appear in different scales for different sample populations, for example, an item ("The things I want to do in the future require me to use English") in the instrumentality-promotion scale for China (item 28), and in the ideal self scale for Japan (item 66).

Lastly, a recent study by Csizér and Lukács (2009) with 237 Hungarian school pupils needs to be mentioned. The study is not in the Dörnyei and Ushioda (2009) volume, but similarly works with the L2 Motivational Self System and is innovative, as it sets out to see whether there are perceived differences in students' ideal and oughtto selves when learning English and German as foreign languages simultaneously. The study showed that for learners who are engaged in the study of both English and German, the ideal self images show interference. Students have on the whole more favourable attitudes towards English than German, and the ideal self for English is better developed than that for German. Using multiple stepwise regression analysis, the ideal L2 self was found to contribute significantly to students' motivated behaviour. However, a developed ideal L2 self for German had a negative effect on 
motivated behaviour to engage with English. The authors interpret their result by drawing on dynamic system theory (see section 3.4.3.3) stating that students' initial choice of learning a language has an effect on their motivation in the long run, and that the ideal self can either serve as a attractor (in the case of a developed English ideal self and motivated behaviour to engage in learning English) or repeller (in the case of a developed German ideal self and motivated behaviour to engage in learning English). This study's results are interesting, as they suggest that an already developed ideal L2 self is likely to have an effect on a developing ideal L3 self and on students' engagement with the L3.

While the Csizér and Lukács (2009) study provides further evidence for the importance of the ideal self for interpreting students' motivated engagement with learning German, the other two dimensions of the L2 Motivational Self System are again neglected: the ought-to self dimension was included in the questionnaire but had to be excluded from the analysis as the Cronbach alpha value did not reach an acceptable level. The L2 learning experience was also included in the questionnaire, but was not linked to motivated learning behaviour in this study. Scrutiny of the scale was not possible as it was not included in the appendix, but according to the authors it consisted of a 9-item scale with newly developed questions including items such as "I like our English/ German course-book", that is, the L2 learning experience was equated with a positive attitude towards the language class and teaching materials.

\subsection{Summary of the L2 Motivational Self System research}

To sum up: The L2 Motivational Self System and the research it has inspired have made a very important contribution to the field by showing the potential of exploring motivated language learning behaviour in the context of FL learning from a self perspective. The consistent correlation between the ideal self and motivated learning 
behaviour in many different foreign language learning contexts shows that research on FL learning motivation can benefit from exploring students' visions of the future.

Nevertheless, the literature review above indicates that the L2 Motivational Self System faces various conceptual and empirical challenges. While the conceptual challenges have already been outlined, the empirical challenges discussed in this section show that the conceptual difficulties are to some extent reflected in the empirical evidence: while studies found reliable evidence of the ideal self, and the relationship between the ideal self and motivated behaviour, the ought-to self has received considerably less attention, and the third component, the L2 learning experience, was clearly neglected, an impression that may be aggravated by the inconsistent terminology used in different studies to refer to this dimension. The overview of empirical evidence shows that, contrary to assertions that the model has been tested and validated as a whole (Dörnyei, 2009b), the studies analysed reveal very little about the relationship between ideal self, ought-to self and L2 learning experience. Furthermore, the empirical evidence for the theoretical assumption that the ideal self can replace the concept of integrativeness is not conclusive; as there was a consistent - though weaker - link between integrativeness and effort. The measurements chosen also do not unravel to what extent a positive attitude vs. a sense of emotional identification with an ethnolinguistic group is part of the concept of the ideal self.

Lastly, as the overview of research evidence has shown, the bulk of empirical research is based on learning English (with the exception of Csizér and Lukács, 2009, and a master's dissertation by Eid, 2008) and not much is said about the motivation of students of other languages. Little is known therefore about the extent to which the ideal self can play a part in learning a foreign language other than English. 


\subsection{Implications for the Current Approach to Motivation}

This literature review has tried to convey a picture of the multifaceted perspectives on motivation that have shaped the L2 research agenda. It needs to be pointed out that the purpose of the present study is not to test or validate any of the motivational theories discussed. Rather, this study is exploratory in nature, and the literature reviewed is used to inform the approach taken to pursuing the three overall aims of the research: firstly, to explore students' motivations for studying German at university level; secondly, to explore changes in students' motivation over the course of the first year; and thirdly, to explore the interplay between students' motivation and the learning environment. I will here describe how the literature reviewed helped me to shape my theoretical thinking on motivation, before clarifying and specifying how the insights gained have informed the approach to exploring the three overall aims of the study.

My theoretical thinking is informed by literature in mainstream motivation, in particular, by self-determination theory (3.3.1), self-efficacy theory (3.3.2), and possible selves theory (3.3.3). The project particularly draws on the L2 Motivational Self-System (3.4.4.2) developed for the foreign language learning context, but takes into account insights gained by early L2 motivational research, as well as recent theoretical explorations on the relationship between motivation, time and context.

By drawing on the literature discussed in this chapter on the whole, the following broad assumptions about motivation are made:

1. motivation is a state of arousal situated in an individual.

2. this state of arousal is in flux.

3. motivation is not to be seen as independent of the context where it occurs: the learning environment can influence and shape motivational thought processes. While some motivational thought processes may be subconscious, as stressed by early motivational theories (2.1), there are 
also conscious motivation thought processes through which the learner can act as an agent of his motivation, thereby also influencing the learning environment itself.

4. motivation usually displays itself in motivated behaviour, either immediately or over time (e.g. possible selves have long-term motivational potential as highlighted in section 3.3 .3 while self-efficacy beliefs exert influence on more immediate action as pointed out in section 3.3.2).

Motivation is therefore here defined as a contextually situated dynamic state of arousal, which manifests itself in immediate or future motivated engagement in (language learning) activity. It is conceded that knowing all factors involved in initiating and sustaining motivated behaviour is impossible and that describing motivation in terms of cause-effect relationships has limitations. While the shortcomings of approaching motivation through correlation studies are thus acknowledged, the thesis cannot ignore the substantial body of research that has already provided valuable insights into important motivational factors that have been consistently linked to sustained motivated behaviour. The thesis therefore also employs statistical methods which postulate the existence of causal relationships, as discussed in the methods chapter (Chapter 4), to detect and measure these motivational factors and their changes over time. However, the theoretical insights gained through the exploration of the dynamics of motivational processes and in particular the insights gained by the person-in-context relational view on motivation (Ushioda, 2009) has informed the analysis of the interviews conducted with students and the exploration of the relationship between learners and learning context. The multilayered and interlinked motivational narratives generated in the results chapter acknowledge the complexity of the phenomena under investigation. 


\subsection{Defined Research Aims}

\section{Exploring students' motivations for studying German at university level}

This thesis explores students' motivation for studying German at university level, by exploring in particular: the role of the ideal L2 self and the ought-to L2 self, of integrative and instrumental orientations, and intrinsic motivation for studying German. It further explores relationships between these five motivational concepts. By drawing on preliminary results already gained in the DipLATHE exploration (Busse and Meyer-Beining, 2007), it also aims to find out whether and to what extent students are driven in their decision to embark on a German degree course by the wish to achieve language proficiency, and which skills in particular students' seek to improve. The thesis further explores students' self-efficacy beliefs in more depth, and their relationship with the other six motivational constructs. Lastly, the role of all seven motivational constructs for students' self-perceived motivated engagement with language learning is explored.

\section{Exploring changes in students' motivation over the course of the first year} In addition, this thesis explores changes in students' motivation, by exploring in particular whether and to what extent the seven motivational variables singled out (wish for language proficiency, integrative and instrumental reasons, intrinsic motivation, the ideal L2 self and ought-to L2 self, self-efficacy) undergo any changes over time. The thesis also explores changes in students' motivated engagement with language learning over the course of the year.

\section{Exploring the interplay between students' motivation and the learning environment}

Finally, this thesis explores the interplay between students' motivation and the learning environment by trying to identify contextual factors in the university learning environment that bring about changes in students' motivations, in particular with regard to the seven motivational constructs discussed. The focus of the thesis filters 
the complexity of the context variable, in that the study looks at the learning environment of the university and the context of language classes only. The macro dimension of societal factors is not explicitly addressed, a decision based on the particular educational focus of this thesis. 


\section{Methodology and Procedures}

As laid out in the rationale (Chapter 1), and in the literature review (Chapter 3), there are three broad research aims of this project. Pursuant to these three research aims, there are two main methodological considerations that have led me to adopt the current design of this study, and these will be discussed separately. I then turn to providing an in-depth description of the current research design.

\subsection{Considerations on the nature of the research aims: towards a combined use of qualitative and quantitative methods}

The exploratory nature of the research aims led me to adopt a mixed methods approach with a qualitative focus. I will outline this decision in more detail below.

Research on L2 motivation - similarly to research on motivation in mainstream educational psychology - has mainly been conducted within a quantitative paradigm. The initial influence of the social psychological approach to L2 motivation had a strong influence in this respect, as has been pointed out by Ushioda (1996a). That is to say, L2 motivational researchers have traditionally targeted the more general and stable aspects of L2 motivation by employing survey methods. In contrast, this study is exploratory in nature; it aims to gain a better understanding of students' motivational experience during the course of the first year at university. Survey methods have severe limitations if such an in-depth understanding of the contextual and temporal variability of motivation is sought. As Dörnyei notes:

Interpretive techniques such as in-depth interview or case studies are in many ways better suited to explore the internal dynamics of the intricate and multilevel construct of student motivation than quantitative methods. (2001b: 50)

That is to say, a qualitative approach is firstly useful if the relationship between factors is to be explored: omnibus questionnaires usually provide more limited insight into relationships between and coexistence of factors; in particular they are rather 
insensitive to the reasons behind these relationships (Dörnyei, 2007, Punch, 1998). In addition, qualitative research methods are needed if one is to pay attention to the dynamics of motivation (Shoaib and Dörnyei, 2005, Ushioda, 1998). A qualitative approach may therefore be particularly suitable for this study.

Yet there are good reasons for making use of quantitative methods in this research: in general, mixing methods can "increase the scope, depth and power of research" (Punch, 1998: 243). In this study, some insights into the motivational processes of this cohort were initially gained through extensive exploratory interviews in the pilot phase of this study (see Chapter 1). The exploratory interviews suggested that the following theories could be helpful in shedding light on the changes students' motivation undergoes over the course of the year: the L2 Motivational Self System (Dörnyei, 2009b), self-determination theory and the concept of intrinsic motivation (Deci and Ryan, 1985), and self-efficacy theory (Bandura, 1997). In the literature review I pointed out that studies relating language learning motivation to self-efficacy have been scarce and are frequently compromised by methodological difficulties. Research conducted on self-determination in language learning has mainly been carried out in second language learning settings such as Canada, whose bilingual status makes it markedly different from foreign language learning contexts where there is little contact with the target language or speakers of the target language, while research conducted on the L2 Motivational Self System has mainly explored students' motivations for studying English as a foreign language.

Apart from providing an overview of the cohort, quantitative methods can investigate whether and to what extent these motivational concepts are indeed useful for exploring the foreign language learning context in this study, as the exploratory interviews suggested.

Lastly, quantitative methods can be useful if a researcher is not to rely on 
convenience sampling, which can pose threats to the credibility of the study (Miles and Huberman, 1994). Quantitative methods such as questionnaires enable the researcher to choose participants for the qualitative data collection by means of purposive sampling (this is discussed in detail in 4.5.2)

The considerations outlined above led me to adopt a mixed-methods approach. For mixed methods research to be principled, three basic purposes have been identified: triangulation, explanation, and exploration (Creswell and Plano Clark, 2007). This study aims for a triangulation design, where qualitative and quantitative data are collected and interpreted, and findings are checked against each other, although the main focus is on the qualitative data. In the typology provided by Morse (2003), this makes for a $Q U A L+$ quan design where qualitative and quantitative data are collected simultaneously, but priority is given to the qualitative data (the abbreviations appear in either upper case or lower case to indicate the priority given to each approach).

\subsubsection{Conceptual Implications of the Chosen Approach}

As mentioned above, research on motivation in language learning has traditionally tended to put a stronger focus on quantitative research than on qualitative research, and has relied principally on survey methods. The traditionally strong focus on quantitative methods in L2 motivational research, however, is not only a matter of methodological preference, but also a conceptual issue. Motivational research has mainly been driven by a desire to seek to explain motivation; it has aimed to uncover and generalise its underlying rules. That is to say, motivational research has been firmly situated in a positivist paradigm, which is based on the assumption that an objective reality exists and that the rules of this reality can be uncovered (Bryman, 2008, Creswell, 2008).

This study, on the other hand, is conducted with the aim of understanding 
human action rather than explaining it, which situates this research within an interpretive research paradigm (Von Wright, 1971). It is also concerned with the individual's subjective world, in other words, with the subject's making meaning of the outer world (Creswell, 2007). This also has important consequences as to how motivation is approached on a conceptual level. Ushioda (2001: 96) stresses:

A qualitative research approach, however, is not simply a question of methodology. It is defined by the nature of its theoretical focus and empirical purpose. [...] As a quantitative variable, motivation may be equated with a conceptualization of measurable activity that involves energy and persistence [...] As a qualitative variable, on the other hand, motivation may be defined not in terms of observable and measurable activity, but rather in terms of what patterns of thinking and beliefs underlie such activity and shape students' engagement in the learning process. (Ushioda, 2001: 96)

In line with a qualitative approach to motivation, the analytical focus of this study is to explore the intricate net of thought processes that shape students' motivation during the first year at university. At the same time, however, quantitative methods will be used to analyse self-reports of motivational concepts, effort and the relationships between variables in these areas. One may argue that this poses a potential problem. If Ushioda's call for conceptual transparency is taken to heart, does a mixed methods approach not inevitably lead the research into the murky waters of a conceptual quagmire?

While I reject the notion of qualitative vs. quantitative methods as two opposing ends of a binary system, I would still argue that an overall positioning of a mixed methods approach in the proximity of both of these two approaches is beneficial to enhance conceptual transparency. I will explain this conclusion in more detail below before turning to my own paradigmatic stance.

Qualitative and quantitative methods have been viewed by some researchers as mutually exclusive rather than complementary, although the difference between them is at first glance a merely technical one: quantitative data is primarily concerned with 
the objective analysis of numerical data while qualitative research interprets nonnumerical data (Sandelowski, 2003), which in the area of L2 motivational research usually implies attitudinal questionnaires vs. learner interviews. Yet, this difference may only scratch the surface of more profound ontological and epistemological differences, as the so-called paradigm war between the 1970s and 1990s suggests (Datta, 2006 , Hammersley, 2006). That is, social science research done in the positivist spirit usually chooses to engage in survey research and employs quantitative methods of statistical analysis, while research done in the constructivist or subjectivist stance usually employs qualitative methods such as interviews.

However, the dichotomy that has subsequently been evoked between the two approaches has increasingly been questioned by many researchers:

this divide - objectivist research associated with quantitative methods over against constructionist or subjectivist research associated with qualitative methods - is far from justified. We should accept that, whatever research we engage in, it is possible for either qualitative methods or quantitative methods, or both, to serve our purposes. Our research can be qualitative or quantitative, or both qualitative and quantitative, without this being in any way problematic (Crotty, 1998: 15)

What is more, on closer inspection opinions regarding the nature of qualitative research are rather disparate (Denzin and Lincoln, 2005, Sandelowski, 2003), and the lines between qualitative and quantitative research often seem blurred. The view of qualitative and quantitative research as matters of degrees or a continuum instead of a binary dichotomy has gained ground (Dörnyei, 2007). Moreover, research reality may have already overtaken conceptual disagreements as, in the field of L2 motivation, mixed methods have increasingly proved to be very useful for gaining new insights (e.g. Ryan, 2008).

However, I would still like to go back one step and turn to the question of conceptual clarity. While the combined use of qualitative and quantitative methods in 
itself may not be in any way difficult or contradictory, it is true that it would be "problematic [...] to be at once objectivist and constructionist (or subjectivist)" (Crotty, 1998: 15). Similarly, Tashakkori and Teddlie point out (2003:107):

By attending too little to philosophical ideas and traditions, mixed methods inquirers are insufficiently reflective and their practice is insufficiently unproblematized.

Along with the researchers cited above, I would argue that underlying assumptions about human knowledge and reality are of importance with regard to any research conducted, as they influence research aims, research design and ultimately also the claims the study seeks to make. Also, making explicit the assumptions of the researcher is essential for all research, and in particular for mixed methods research which, as has so vividly been depicted by Johnson and Onwuegbuzie (2004: 15), sits "in a new third chair, with qualitative research sitting on the left side and quantitative research sitting on the right”. Bringing underlying epistemological and ontological assumptions into consciousness - just like other beliefs of the researcher that may affect the research - is, to keep to the metaphor, to position this chair firmly; or, in other words, to ensure the rigour of the research.

\subsubsection{Epistemological Beliefs}

This research approaches motivation from a qualitative perspective; it is situated in the interpretative research paradigm which is concerned with the process of understanding human action. The focus of the present research is on reaching a better understanding of students' motivation during the course of their first year at university. I would be remiss were I not to acknowledge that my own epistemological beliefs play a role in my interest.

Teaching German language and literature for almost eight years now has influenced my stance as a researcher. My personal and professional history plays a part in my approach to this research: cultivating the ability to understand things from 
somebody else's point of view has for a long time been an integral part of my teaching, such that I retain an almost intuitive distrust of research on real people which is stripped bare of the individual and levels out personal differences to averages and numbers. I also believe that research cannot discover a single objective reality (Lincoln and Guba, 2000), rather, that the researcher plays an important part in interpreting reality.

However, I am by no means opposed to the general idea that statistics can provide valuable insight into a phenomenon, in particular when a great deal of research already exists which a study can build on. I also believe that through a mixed methods approach a more accurate and multidimensional picture of learners and learning processes can be achieved, a conviction increasingly found in educational research (Gorad and Taylor, 2004, Mertens, 2009), as well as applied linguistics and language learning research (Dörnyei, 2007, Johnson, 1992, Larsen-Freeman and Long, 1991).

At the same time, I agree that an overall decision regarding the empirical purpose of each study needs to be taken. Approaching a phenomenon with preconceived concepts which are then "tested" through surveys is usually linked to an objectivist stance on reality. Qualitative studies situated in the interpretative paradigm, on the other hand, usually explore the phenomenon under investigation and then generate theory.

With regard to the present research, I would argue that the overall purpose of statistics for this study is not principally deductive theory-testing, although it does seek to explore some pre-set concepts derived from existing theories. The need for such a theoretical base in the present research context is obvious given the vast amount of research that has already been conducted in the field of language learning motivation. The theoretical base as elaborated on in the literature review has therefore provided an important starting point to achieve the aim of exploring first year students' 
motivational experiences.

In addition, the epistemological beliefs formed through my professional and personal background imply that even though quantitative data are collected, these cannot be mistaken for "objective" facts, neither can they be taken at face value. Rather, statistical analysis needs to be questioned, just like qualitative data.

Moreover, the study is not concerned with obtaining (statistical) generalisability. Its purpose rather lies - in line with my ontological and epistemological stance - in providing additional information so as ultimately to better understand the individuals in this cohort. This is particularly important in a field that has so far paid little attention to individual variability in motivation, and where quantitative methods such as surveys have largely excluded learners' perspectives and interpretations of motivation (Ushioda, 2009).

\subsection{Considerations on the nature of the research aims: towards a longitudinal design}

As mentioned in the rationale, my interest in motivation was triggered by my curiosity about gaining a better understanding of the motivational changes modern language students seem to experience during their first year at university. Although studies in mainstream motivational research have revealed the usefulness of longitudinal approaches to motivation (see Chapter 3), empirical investigations looking at the temporal aspect of motivation in L2 learning, which could have guided my study, were, surprisingly, scarce. My interest in motivational change made it imperative that the methods used in this study had to be able to trace possible changes in students' motivation, so as to shed light on the interplay between students' motivation and their perception of the learning environment over time. Only a longitudinal approach allows for an in-depth exploration of the temporal dimension of this complex interplay. As Menard concludes: 
longitudinal research can, in principle, do much that cross-sectional research cannot, but that there is little or nothing that cross-sectional research can, in principle, do that longitudinal research cannot (2002:80).

The advantages of adopting a longitudinal approach to this research are selfexplanatory; in particular the problem of retrospective data collection where researchers have to rely solely on students' accurate reflection on past motivational changes can be avoided (see discussion of the study by Shoaib and Dörnyei, 2005, Chapter 3, section 3.5.3.2). There are some pitfalls, however, that need to be taken into consideration: firstly, there are drawbacks if participants are not questioned with great frequency. The quality of the data diminishes the further back in time the interviewee is asked to go; for instance, literature speaks of the difficulties of omission effects - events are not revealed because they are not remembered - and telescope effects, when the time at which the event took place is not remembered accurately (Ruspini, 2002: 96).

Another possible risk that all longitudinal studies face is sample attrition. Students might drop out from the course or be unwilling to participate in the second questionnaire or the follow-up interviews. While attrition is a concern usually linked to quantitative studies as it threatens generalisability, it may also be worrying from a validity perspective in qualitative studies where the original sample is very small (see discussion of Ushioda, 1996b in the literature review), because the reduction may not be random: in fact, it might be especially interesting to get to know the reasons of those students who drop out of the course.

\subsubsection{Practical Implications of Chosen Approach}

Based on the considerations discussed above, this study explored students' motivation from a longitudinal perspective with a mixed-methods approach. I have already pointed out that there are still very few longitudinal studies in the field of L2 motivational research. This is all the more striking as longitudinal studies have been at 
the top of many a researcher's wish list for quite some time (Dörnyei, 2009d, Oxford and Shearin, 1996). Obvious reasons for this absence are limited time and financial resources, which are especially prevalent in longitudinal designs, and set certain constraints for this research as well. The current project should be considered as a first step towards future longitudinal studies which might look at the entire undergraduate motivational trajectory in order to gain insights into how the motivational experience of the first year affects students' motivational trajectories in the long run. Due to financial and time constraints, this study can focus on the first year only.

The practical implications of the chosen approach were the following: a combination of self-report questionnaires and semi-structured interviews was employed, that is, a questionnaire was administered at the beginning of the academic year (Time Point 1) and at the end of the academic year (Time Point 2). To reduce the potential peril of the telescope effect as discussed above, interviews were conducted at shorter intervals, that is, five times over the course of the academic year.

In order to reduce the potential danger of student attrition, a number of attrition prevention measurements were taken (see Procedures, section 4.5). However, while sample attrition could be avoided in the interviews, it could unfortunately not be avoided in the questionnaire administered at Time Point 2.

\subsection{Participants and Setting}

In the rationale (Chapter 1), my interest in students studying German from University A has been explained and linked to my analytical focus. I have already outlined why University B is a suitable comparison university for University A (Chapter 2). I will here summarise the four main reasons.

Firstly, both universities have very large and strong German language departments. Secondly, although University A is a long-established and highly reputable university and University B is a more recently established university, the 
latter has a similarly high academic reputation. Thirdly, the two universities have comparable Research Assessment Exercise (RAE) results, with University A scoring slightly higher in category four (publications with international impact), and with University B scoring slightly higher in the Teaching Quality Assessment subject review. Lastly, both universities have a similar student intake, and students can study German either as a single subject or in combination with another language or another subject. The respective sampling procedures and participant characteristics for the quantitative and qualitative components are presented below.

\subsubsection{Sampling for Questionnaire}

The whole first-year German cohort of both universities $(n=142)$ at the beginning of the academic year (72 students at University A and 70 students at University B) was invited to participate in the questionnaire study. 97 (56 at University A and 41 at University B) accepted the invitation, giving a response rate of $68.3 \%$ overall $(77.8 \%$ from University A and $58.6 \%$ from University B; the reasons for the disparity in response rates will be discussed below). There is no evidence to suggest that the profile of responders differed systematically from the profile of non-responders. Of the original 97, three students (all from University A) were native speakers of German and their reasons for studying German were considerably different from those of the other students. The respondents' ages ranged from 18 to 20 years. Participants had studied German for an average of 6.46 years (SD 2.18). There were slightly more females in the sample $(\mathrm{f}=53 ; \mathrm{m}=36)$; however, five students did not indicate their gender. The majority of students were of British nationality (71 students), and English was the mother-tongue of most of the students (81 students).

The overwhelming majority of the student sample had attended state schools before and whilst studying for A-levels. However, there were considerably more students from the private sector at University A than at University B, a distribution 
which was to be expected, as University A has traditionally been a university attracting students from the private/ independent sector. At University A, there were 30 students from state schools and 22 students from independent/ private schools, and one student did not indicate his school education. At University B, there were 34 students from state schools and 5 students from private/independent schools, with one student from another kind of school, and one who did not indicate his school education.

At Time Point 2, sample attrition reduced the cohort to 59 students, 38 students from University A and 21 students from University B. The reasons for sample attrition (and for the proportionately greater attrition at University B) will be elaborated in the description of the procedures. Therefore, all statistical procedures exploring motivational change (Chapter 6, Chapter 7) are based on the reduced sample of 59 students.

Table 2 Overview of Participants

\begin{tabular}{lcc}
\hline \hline \multirow{2}{*}{ University } & \multicolumn{2}{c}{ Number of participants } \\
\cline { 2 - 3 } & Time Point 1 & Time Point 2 \\
\hline A & 53 & 38 \\
B & 41 & 21 \\
\hline Total & 94 & 59 \\
\hline \hline
\end{tabular}


Table 3 Overview of gender and school background at Time Point 1

\begin{tabular}{lllllll}
\hline \hline & \multirow{2}{*}{ University } & Gender & & & \multicolumn{2}{l}{ School Background } \\
\cline { 5 - 7 } & & Male & Female & Missing & State & Private Other \\
& 24 & 28 & 1 & 30 & 22 & 1 \\
A & 12 & 25 & 4 & 34 & 5 & 1
\end{tabular}

Table 4 Overview of gender and school background at Time Point 2

\begin{tabular}{lllllll}
\hline & \multirow{2}{*}{ University } & Gender & & & \multicolumn{2}{l}{ School Background } \\
\cline { 5 - 7 } & & Male & Female & Missing & State & Private Other \\
\hline A & 13 & 24 & 1 & 25 & 12 & 1 \\
B & 7 & 13 & 1 & 16 & 4 & 1
\end{tabular}

\subsubsection{Sampling for Interviews}

Questionnaire respondents were invited to volunteer for follow-up interviews. Respondents were purposively chosen for the interview on the basis of balance of gender (three female and three male students from each university) and so as to represent a range of perceived levels of motivation and self-efficacy as operationalised by the questionnaire. At University A, two students from private/ independent schools were chosen to reflect the larger number of students from the private/ independent schools at University A. These were both young women, as no male student from a private school volunteered for an interview at University A. At University B, none of the students who had attended a private/ independent school volunteered for interview. Given that there are only five students from private/ independent schools in the German undergraduate cohort at University B in total, the bias on interviewees from state schools at University B is reflective of students' school background at University B. An overview of the interviewees organised by university is given in Table 5 . 
Table 5 Overview of Interviewees

\begin{tabular}{lllll} 
University & Name, Course of Study & School & \multicolumn{2}{l}{ Motivational Profile Time Point 1 } \\
A & Jane, German single subject & private & Motivation & $\begin{array}{l}\text { Self-Efficacy } \\
\text { quite high most items }\end{array}$ \\
\hline A & Tom, German and Portuguese & comprehensive & so-so & diverse* \\
\hline A & Jebedee, German and Arabic & comprehensive & quite high & so-so (speaking high) \\
\hline A & Jayanthy, German and French & comprehensive & so-so & diverse \\
\hline A & Valda, German single subject & private & very high & quite high most items \\
\hline A & Samuel, German and French & comprehensive & so-so & very high most items \\
\hline B & Marc, German and French & grammar & very high & quite high most items \\
\hline B & Susan, German and History & comprehensive & very high & quite high most items \\
\hline B & Peter, German and Italian & comprehensive & quite high & quite high (writing low) \\
\hline B & Richard, German single subject & comprehensive & quite high & diverse \\
\hline B & Heather, German and French & comprehensive & very high & so-so most items \\
\hline B & Lindsey, German and French & comprehensive & so-so & diverse \\
\hline Total & $\mathbf{1 2 ~ I n t e r v i e w e e s ~}$ & & & \\
\hline \hline & & & & \\
\hline
\end{tabular}

* Diverse means that students showed very diverse levels of self-efficacy ranging from not confident to very confident depending on tasks

\subsection{Instruments}

The study was informed by the exploratory interviews and existing research on motivation, as discussed in the literature review. The study could therefore draw on existing research instruments, as will be outlined below.

\subsubsection{Questionnaire}

The construction of the questionnaires was informed by the ideal self framework (Dörnyei, 2009b), and by research conducted on intrinsic motivation (Noels, 2001b, 2009), and by research carried out on self-efficacy beliefs (Bandura, 1997). The draft questionnaire was piloted by asking 10 former students of Universities A and B to complete it and think aloud while filling it in. Potentially problematic items were reworded. The questionnaire was then piloted with a third university in the UK $(\mathrm{N}=30)$ and further adjustments were made. The final questionnaire (Appendix 1) contained eight categories of items; the items were taken from existing research or developed for 
the present study, as explained in detail below.

\section{Wish for Language Proficiency}

Following from the literature review and the results of the explorative DipLATHE study, five items $(1.1 ; 1.2 ; 1.5 ; 1.10 ; 1.17)$ were designed which targeted the general wish to gain language proficiency and the wish to become proficient in the four language skills of speaking, listening, reading, and writing.

\section{Intrinsic Reasons}

Five items $(1.3 ; 1.22 ; 1.18 ; 1.11 ; 1.5)$ were designed to capture enjoyment of the language itself, drawing on work looking at intrinsic orientations in L2 learning (Noels, 2001b, 2009, Noels et al., 2000). Following the literature review the explorative DipLATHE study, I designed four items to measure students' general enjoyment of learning German and their enjoyment of the challenges of learning German. On the grounds of the pilot study, I added the item I like the challenges that learning German poses as participants felt that this item captured their motivation to learn German well.

\section{Ideal Self}

Four items $(1.28 ; 1.15 ; 1.8 ; 1.6)$ were adapted from Ryan (2008). Following the literature review, the items focused on the clarity and intensity of learners' visions of themselves as proficient users of German (Dörnyei, 2009b, 2009d). There was evidence to conclude from the pilot study that the concept of the ideal self in learners of German may work slightly differently from learners of English as some items adapted from Ryan received low scores and others very high scores. E.g. the item: The things I want to do in the future require me to speak German received between 1 to 2 points, while the item I can imagine myself as someone who is able to use German well received by the same students 4 or 5 points. When asked about this difference, students stressed in their answer that in most jobs there were often no real requirements to speak different languages. The item was therefore replaced by Whenever I think of my future, I imagine myself being able to use German.

\section{Instrumental Reasons}

Four items $(1.14 ; 1.27 ; 1.4 ; 1.24)$ were taken from Ryan $(2008)$ to capture the utilitarian benefits of studying German. Items such as whether participants thought that 
German would help them to travel or whether it was important these days had to be excluded as German was not considered useful in this respect. Following the literature review, possible aspiration to gain financial benefits as well as job-prospects were targeted. One item had to be slightly rephrased following the pilot study. Studying German will help me get a good job was rephrased to My German ability will help me to obtain a better job.

\section{Integrative Reasons}

Four items $(1.26 ; 1.9 ; 1.12 ; 1.19)$ were adapted from Gardner's Attitude/Motivation Test Battery (Gardner, Tremblay and Masgoret, 1997) to assess the extent to which students seek to learn German for integrative reasons. Following the discussion in the literature review, in particular the findings discussed in section 3.4.4.2.2, two items were chosen which tap into a sense of identification (e.g. I would like to become more like people from German-speaking countries) and two items which tap into a positive attitude (e.g. I like meeting people from German-speaking countries).

\section{Ought-to Self}

Four items $(1.16 ; 1.13 ; 1.21 ; 1.7)$ were taken from Taguchi, Magid and Papi's (2009) ten-item measure of the ought-to self construct. Following the literature review, the items measure to what extent students feel pressure to study German because of social/ familiar expectations, or a possible sense of obligation. One item had to be rephrased: $I$ have to study German, because, if I do not study it, I think my parents will be disappointed with me proved to be difficult for its syntax as well as its content. It was rephrased with: My parents believe that I ought to study German at Time Point 1 of the study and with People I respect believe that I ought to study German at Time Point 2 of the study in order to amplify the item and to capture whether other people of importance (such as tutors) triggered the ought-to self dimension at the end of the academic year.

\section{Effort}

With the help of insights gained through the DipLATHE exploration and the interviews conducted in the pilot phase of the project, 14 items $(2.1 ; 2.4 ; 2.5 ; 2.6 ; 2.7$; $2.10 ; 2.11 ; 2.13 ; 2.14 ; 2.16 ; 2.17 ; 2.19 ; 2.20 ; 2.21)$ were designed to measure the effort students perceive themselves as exerting on language learning. The effort items 
included items targeting at perceived general effort (e.g. I am working hard at learning German) to perceived effort for course specific tasks (e.g I try to learn as many new words as possible during language classes). The effort items tap in the different learning activities students may engage in during the first year at university.

\section{Self-Efficacy}

14 items (3.1-3.14) were designed to measure students' perceived self-efficacy for tasks. In the literature review (3.4.2.3), I pointed out that existing measurements are problematic, as they do not enable the researcher to gain specific insights into students' perception of their ability. A more task-sensitive approach is needed here, as this research is interested in the development of students' capability perceptions with regards to the tasks that form part of course requirements. The items were therefore designed to tap into the course specific tasks that students have to engage in during their first year at university. They comprise task-specific self-efficacy beliefs for listening (3 items), speaking (3 items), reading ( 3 items) and writing ( 3 items) tasks, as well as for grammar (1 item) and translation into German (1 item) and translation into English (1 item). Some items were slightly reworded after the pilot phase, but no bigger changes had to be made. Exploratory factor analysis used in the main study suggested the use of four self-efficacy scales, consisting of three items each with the exception of one six-item scale (self-efficacy for listening and speaking).

\section{Motivational State}

2 items $(4.1,4.2)$ were designed to measure students' perceived state of motivation ( $I$ would describe my present state of motivation for studying German as high at the moment and I would describe my present state of motivation for studying German as somewhat low at the moment). These two items were designed for sake of purposive sampling. They do not form part of the motivational scales.

The final questionnaire consisted of three sections with 55 items. These were eventually structured into eight main scales. Note that three effort items were excluded, which reduces the item pool statistical procedures are carried out with to 52 items. The first two sections are presented briefly in the table below (the full scales with all items appears as Appendix 1). The last section of the instrument (background information) 
collected details about gender, school background, the number of years participants had studied German for, and their language background. Except for the background information, scales consisted of summative Likert scales. The scales rendered satisfactory reliability coefficients given the small sample size as presented in Table 6 . Note that exploratory factor analysis suggested two effort scales and four self-efficacy scales, and that not all items from the questionnaire were retained in the effort factors.

Table 6 Questionnaire scales with item examples and internal consistency coefficients at Time Point $1(\mathrm{~N}=94)$ and Time Point $2(\mathrm{~N}=59)$

\begin{tabular}{|c|c|c|}
\hline Scale & $\begin{array}{l}\text { (Number of items) } \\
\text { Examples of items }\end{array}$ & $\begin{array}{l}\text { Internal } \\
\text { consistency } \\
\text { (Cronbach's } \alpha \text { ) }\end{array}$ \\
\hline $\begin{array}{l}\text { Wish for Language } \\
\text { Proficiency }\end{array}$ & $\begin{array}{l}\text { (5) I study German because I want to improve } \\
\text { my German }\end{array}$ & $\begin{array}{l}.90(\text { Time } 1) \\
.87(\text { Time } 2)\end{array}$ \\
\hline Intrinsic Reasons & (5) Learning German is a challenge which I enjoy & $\begin{array}{l}.82(\text { Time } 1) \\
.83(\text { Time } 2)\end{array}$ \\
\hline Ideal Self & $\begin{array}{l}\text { (4) Being able to converse in another language } \\
\text { is an important part of the person I want to } \\
\text { become }\end{array}$ & $\begin{array}{l}.79(\text { Time } 1) \\
.81(\text { Time } 2)\end{array}$ \\
\hline Instrumental Reasons & $\begin{array}{l}\text { (4) Studying German is important to me because } \\
\text { with a high level of proficiency in a foreign } \\
\text { language I will be able to earn more money }\end{array}$ & $\begin{array}{l}.75(\text { Time 1) } \\
.73(\text { Time } 2)\end{array}$ \\
\hline $\begin{array}{l}\text { Integrative } \\
\text { Reasons }\end{array}$ & $\begin{array}{l}\text { (4) I feel an affinity with the people who live in } \\
\text { German-speaking countries }\end{array}$ & $\begin{array}{l}.64(\text { Time } 1) \\
.77(\text { Time } 2)\end{array}$ \\
\hline Ought-to Self & $\begin{array}{l}\text { (4) I study German because people surrounding } \\
\text { me expect me to do so }\end{array}$ & $\begin{array}{l}.70(\text { Time } 1) \\
.84(\text { Time } 2)\end{array}$ \\
\hline $\begin{array}{l}\text { Self-Efficacy } \\
\text { Reading }\end{array}$ & $\begin{array}{l}\text { (3) How confident are you that you can read and } \\
\text { understand the main ideas of a German novel? }\end{array}$ & $\begin{array}{l}.74(\text { Time 1) } \\
.77 \text { (Time 2) }\end{array}$ \\
\hline $\begin{array}{l}\text { Self-Efficacy } \\
\text { Writing }\end{array}$ & $\begin{array}{l}\text { (3) How confident are you that you can write an } \\
\text { essay in German? }\end{array}$ & $\begin{array}{l}.81(\text { Time } 1) \\
.85(\text { Time } 2)\end{array}$ \\
\hline $\begin{array}{l}\text { Self-Efficacy } \\
\text { Listening and Speaking }\end{array}$ & $\begin{array}{l}\text { (6) How confident are you that you listen to and } \\
\text { understand a German native speaker in a } \\
\text { tutorial? }\end{array}$ & $\begin{array}{l}.91(\text { Time } 1) \\
.88(\text { Time } 2)\end{array}$ \\
\hline $\begin{array}{l}\text { Self-Efficacy } \\
\text { Grammar and } \\
\text { Translation }\end{array}$ & $\begin{array}{l}\text { (3) How confident are you that you can do well } \\
\text { when translating a short prose passage from } \\
\text { German into English? }\end{array}$ & $\begin{array}{l}.75 \text { (Time 1) } \\
.85 \text { (Time 2) }\end{array}$ \\
\hline Effort 1 & (7) I am working hard at learning German & $\begin{array}{l}.86(\text { Time 1) } \\
.91(\text { Time } 2)\end{array}$ \\
\hline Effort 2 & $\begin{array}{l}\text { (4) I try very hard to read more than just set texts } \\
\text { in newspapers/magazines }\end{array}$ & $\begin{array}{l}.72(\text { Time } 1) \\
.68(\text { Time } 2)\end{array}$ \\
\hline
\end{tabular}




\subsubsection{Interviews}

The interview schedule was determined by the three overall aims of the study and the defined research aims, and was developed over time. This process was not straightforward but cyclical: first, some questions were generated by a retrospective scrutiny of the DipLATHE data from 2007. I then turned to Ushioda's (1996a) qualitative study on Irish university students studying French and to qualitative studies exploring possible selves (Chapter 3) to further devise my interview guide. Some of the interview questions developed were adapted or even eliminated on the basis of the exploratory interviews conducted thereupon with students from University A and B. The developed interview guide was piloted on three first year students at Queen Mary, University of London.

Second, during the course of the five interviews with each interviewee, questions followed up issues that emerged during the interviews. In line with the aim of qualitative research (Hammersley, 1992), the broad focus of the questions was to capture motivation and motivational change from the point of view of the students. I therefore constructed questions loosely based around the theoretical framework and the emerging themes, rather than trying to find proof for a hypothesis.

All interviews were semi-structured, an approach advocated within an interpretive research tradition (Radnor, 2001). The interview protocols can be found in Appendix 2 and Appendix 3. Two examples of a transcribed interview can be found in Appendix 6. Students were allowed to express their views freely, yet the semistructured format allowed me to elicit responses that were pertinent to the research aims. Also, the semi-structured format allowed for a better comparison of students' answers. I followed the lead of the students to probe further into what they felt was important, which made interviews longer than anticipated, varying between 1 to 2 hours. 
I will now turn to the first interviews that were conducted (see Appendix 2 for the interview protocol). The opening questions used in the interview were based on Ushioda's (1996a) study. Interview questions were open enough to allow for students' own conceptualisation of motivation to emerge, and care was taken not to prime interviewees with motivational concepts.

After initial remarks thanking students for participation and asking whether students had any questions about the study, the content and structure of the first interviews were dictated by the participants' own personal conception of their reasons for studying a language. Open questions such as, "Why do you want to study German?" were followed up by set prompts to probe whether motivational concepts looked at in the questionnaire played a part in the students' decision making processes, e.g. career goals etc. At the end of each interview, students were asked to rate their motivation on a scale from 1-5, with 5 being the highest and 1 being the lowest. Finally, questions were asked about individual items of the questionnaire to illuminate findings from the quantitative data.

In the interviews that followed, questions were asked to probe and explore whether students felt that they had undergone any motivational changes. Also, students were asked to elaborate on their perception of the learning environment. A list of specific aspects that had emerged from the DipLATHE interviews and the exploratory interviews guided me in this respect. Topics that had emerged in one interview, e.g. career plans, were followed up in the next interview to see whether career plans had been developed further or changed.

\subsection{Procedures}

The heads of department at both universities were contacted prior to the study. The head of department at University A had already been informed about the research project through private conversation, and verbal consent had been obtained when the 
study was still in its preliminary phase. An official letter was sent out once the details of the project were clarified, and written consent was obtained.

The head of department at University B was contacted by email and then by telephone. After obtaining verbal consent, an official letter was sent out with the details of the study. Written consent from the head of department was obtained prior to data collection. Data collection took place from November 2008 to June 2009.

\subsubsection{Questionnaire}

An information leaflet about the research project was sent out via email before the date of data collection at both universities. At University A, I invited the students to take part in the questionnaire study myself immediately after a compulsory lecture for firstyear students. The lecturer had shortened his talk to enable me to conduct my research. All students present at the lecture opted to participate. Although the lecture was compulsory, not the whole cohort was present. An assistant - a former student helped me to collect the completed questionnaires. She was briefed well in advance about the aims and procedures of the project. It was explained to students that a paper version of the questionnaire would be administered, but that there would also be an electronic version sent around on the same day for information.

The questionnaire administration, including the instructions and explanations, took approximately 30 minutes. Students who wanted to remain anonymous were asked to write their mother's date of birth on the questionnaire, so that the first questionnaire could later be matched to the second questionnaire. Those who wanted to take part in the follow-up interview left an email address on the questionnaire. Immediately after administration, every questionnaire was assigned a unique identification code for reasons of confidentiality and for data back-up purposes. The same day, I also sent out an electronic version of the questionnaire for those who may 
have missed the lecture, but still wanted to participate. None of those students who were not present opted to fill in the electronic questionnaire.

The second questionnaire could not be administered in the same way as there are no compulsory lectures which all students have to attend in their third term at University A. I therefore distributed the questionnaires in the various language seminars that students have to attend. However, fewer students attend language seminars towards the end than towards the beginning of the academic year, which led to sample attrition.

I had intended to administer the questionnaire at University B in a similar manner to University A. The correspondence to prepare the administration of the questionnaire had been with a fellow German lecturer at University B, with whom I am wellacquainted. However, she unexpectedly left the department at University B for a tenured position in Germany. The new lecturer, who had to fill in for her on short notice, was quite apprehensive of the project. She was not willing to give up teaching time for the administration of the questionnaire. I suspected that she was afraid that the questionnaire was geared to evaluate her teaching, which she, being newly appointed, felt threatened by. I travelled to the University to meet her in person and to try and to allay her doubts, but found her adamant on this topic. A conversation with the head of department to find an alternative solution failed after the only other lecture that all students had to attend had to be suspended due to the lecturer falling sick. The head of the German department decided that the new German lecturer would distribute the questionnaires to students, and that those students who agreed to participate would then return the completed questionnaires to the department's secretary by the end of the day. Although I pointed out that this procedure would probably lead to a low return rate, the head of department did not see any alternative to this procedure. I decided to offer a small monetary reward of two pounds for each questionnaire returned, but I 
was still doubtful whether this measure would be sufficient to lead to a satisfactory return rate. A last attempt to appeal to the head of department failed and I received the following email:

[the language lecturer] has done a great deal to encourage the students to fill them out. Since, I gather, you are also proposing to reward the students who do so to the tune of $£ 2.00$, I suspect you will get a good return and I suggest that you now leave things to take their course (private email correspondence, 27.11.2008).

I then sent an email via the department's secretary to inform all students about the procedure and the purpose of the study, and I deposited the monetary reward with the secretary. Along with the questionnaires, I also sent envelopes so that students could seal their questionnaires immediately when returning it to the lecturer. I also sent out an electronic version of the questionnaire. After the administration through the lecturer, I wrote an email to remind students to return the questionnaire. Unfortunately, however, the return rate was lower than at University A.

Although the disadvantages of administering the questionnaire in this way were repeatedly discussed with the gatekeepers at University B, the second questionnaire had to be administered in a similar way. This time, five pounds were offered for each questionnaire returned to avoid further sample attrition, yet even fewer students returned the second questionnaire.

As discussed previously, sample attrition poses a threat to longitudinal research as it may not be random. In the case of University A, one may assume that it is the more motivated students who attend language classes towards the end of the year, while less motivated students may be less likely to attend. This may be a bias the research has to take into account. At University B, a similar bias could be in place. It could also be, however, that students simply did not think it important enough to complete the questionnaire in their own time, or that they just forgot to return the questionnaire. 


\subsubsection{Interviews}

In line with purposive sampling, interviews were conducted slightly after the administration of the questionnaire, that is, in December 2008, with the last interview conducted towards the end of the third term, May 2009 (University B) and June 2009 (University A). At both universities, quiet facilities were available for confidential discussions. Also, tea and biscuits were provided which made the discussion appear rather informal. All students could choose a pseudonym so that their names would not appear in the transcripts. Students clearly felt at ease when conversing and interviews were often much longer than the anticipated hour. I also stayed in regular email contact with interviewees over the course of the year by sending them short emails informing them about the progress of my study, which may explain why no student dropped out of the interview study. Only one interviewee, Samuel, missed one interview during the course of the year. He did also not respond to my emails at this point. At the next interview, he apologized for his absence, and explained that he had had a very difficult time at university and serious problems with his tutor, which prevented him from attending the interview.

The primary research purpose was to gain an understanding of students' motivation over the course of the first academic year; therefore the study did not incorporate pre- or post-testing of L2 proficiency. That is, the focus was on the interrelatedness of factors contributing to students' motivation to learn, rather than finding motivational component that co-vary with achievement. This did not mean, however, that it was not of interest to this study to gain an impression of their levels of competence, especially given that competence beliefs for academic tasks are part of the enquiry. Students were therefore asked to bring in pieces of their writing, which allowed me to gain some insight into their proficiency level of written German, and to track their development in this respect. I also had an informal chat in German with each 
student at the end of each interview to gain an impression of their ability to express themselves in German. Also, as it emerged from the interviews that students were unhappy with the feedback they received from their tutors, students were asked to bring in the feedback. This enabled me to compare students' comments and feelings about the feedback with the actual feedback itself. Assignments and feedback were scanned and stored together with students' interview transcripts.

\subsection{Data Analysis}

\subsubsection{Questionnaire}

The quantitative data were analysed with SPSS version 14.0. The answers to the questionnaire were coded according to the scale 1 (very much), 2 (quite a lot), 3 (soso), 4 (not really), 5 (not at all). The polarities of negatively worded items were reversed.

The self-reported data were treated as continuous data in this study. It should be pointed out, however, that this classification is not entirely unproblematic. Self-rating data have been described as "grey area" between ordinal and continuous data (Kinnear and Gray, 2008:2). Yet one would be hard-pressed to find any study on motivation conducted on self-reported Likert scales using the self-report data as ordinal (see for instance Al-Shehri, 2009, Ryan, 2008, Taguchi et al., 2009, Yashima, 2009). The reason for this is that parametric tests are at the heart of motivational research. In line with the stance adopted in motivational research as well as social science in general (Agresti and Finlay, 1997, Pallant, 2005, Sharma, 1996), self-reported data were regarded as continuous and therefore parametric tests were used.

The principal statistical procedures used for analysis of the data were factor analysis, correlation analysis, and t-tests. Reliability analysis was used to confirm the reliability of the scales that were based on established questionnaires. Exploratory 
factor analysis was used to explore the internal structure of the scales particularly designed for this study (Effort and Self-Efficacy).

T-tests were performed to explore significant change over time on the individual item level. In order to explore change on the factor level, multi-item scale scores (using the mean) were calculated to be able to perform t-tests between the factors. Aggregated regression scores were obtained by factor analysis in order to be able to test correlations between the factors.

\subsubsection{Interviews}

The analysis of qualitative data is a continuous and cyclical process. In addition, analysis is not a separate phase as it is in quantitative research, where the data have to be collected in their entirety before the analysis can begin. Interviews were fully recorded and transcribed immediately after they were conducted. The transcripts were sent to interviewees to give them the opportunity to read the transcriptions and to rectify any points that they did not feel accurately reflected what they wanted to say. Each transcript was carefully re-read before the next interview was conducted with the respective student. Themes that should be followed up were annotated: e.g. if a student mentioned a possible future career path, each follow-up interview probed whether and to what extent it became concretised or whether/why it became dismissed over the course of the year. This procedure enabled me to keep close track of qualitative changes in students' motivational development and represents a novel element in L2 motivational research. The procedure also meant that although the overall interview guide was the same for all students, I had a separate guide with additional themes and questions for each individual student. I also kept a research log, where I noted any additional remarks of the students after the digital recorder was switched off.

To keep the internal coherence of the narratives, short vignettes based on the longer transcripts were created. The analysis of interview transcripts was informed by 
the six steps guide analysis discussed by Radnor (2001) consisting of topic ordering, category constructing, reading for content, completing coded sheets, generating coded transcripts, analysis and interpretation of the data. The qualitative software programme MAXQDA was used for step four and five. The process will be described in more detail below.

Each transcript was identified by the pseudonym of the interviewee and the date it was conducted. All transcripts were stored in separate files for backup purposes, as well as in the qualitative software programme MAXQDA for the analysis. Interviews were re-read several times as whole texts. This preliminary step allowed descriptive categories to emerge. Based on these, I made a list of topics that emerged on reading the whole texts. For instance, enjoyment of learning German, career plans, feedback etc. I then looked through the data in more depth and linked each statement to the descriptive categories. I then proceeded to write sub-headings for each topic, e.g. enjoyment of learning German, school experience, etc. The main quotes were highlighted in MAXQDA for quick reference for the writing up process. Appendix 16 shows an example as to how interviews were coded in MAXQDA.

A number of the categories were pre-determined by the interview questions, but care was taken to include additional themes that emerged. A thematic analysis was performed to explore conceptual overlap of the categories. Finally, the descriptive categories were compared and matched (where appropriate) to the categories focused on in the questionnaire. As Radnor (2001) points out, this procedure is not always straightforward, and some pieces of data did not fit into any category, or could be added to more than one category. In the data, I highlighted all the different categories this comment could be assigned to. After re-reading these codes, I would then analyse to what extent a comment belonged more to one than another category. This main category 
was highlighted by bold letters while the other categories were kept in small letters. The organisation of the results chapter is organised according to these categories.

In addition, frequencies were counted to identify the most frequent recurrent themes. Note that such quantifications were not seen as an end in themselves, but rather as additional tools to for a systematic approach to analysing the data (Huberman and Miles, 1994), a tool to help detect the emphasis that interviewees placed on certain factors.

\subsection{Ethical Considerations}

The research design was guided by ethical considerations, for which The British Educational Research Association (BERA, 2004) was used as a guideline. The study is therefore set within the overall ethical conditions and parameters of research in education, which can be described as follows: "All education research should be conducted within an ethic of respect for the person, knowledge, democratic values, quality of [...] research and academic freedom” (BERA, 2004:5). These general parameters can be subdivided into responsibility to participants, to sponsors of research and to the community of educational research. As this research is not sponsored by any organisation, the following considerations focus on the issue of responsibility to participants and responsibility to the educational research community.

The guiding principle regarding the first point is that the research should not inflict any mental or physical harm to the participants. In practice, responsibility to participants manifests itself in various steps that researchers have to go through prior to undertaking the research. One of them is that voluntary informed consent needs to be obtained from potential participants. "Informed" means that researchers must take the steps necessary to ensure that all participants in the research understand the process in which they are engaged, including why their participation is necessary, how it will be used and how and to whom it will be reported (BERA, 2004:6). In summary, 
researchers need to disclose "as much as possible about the aims of the investigation and the purpose for which the data will be used, the tasks the participants will be expected to perform during the study, the possible risks and the potential consequences of participating in the research, the extent to which answers will be held confidential, the basic right of the participants to withdraw from the study" (Dörnyei 2007:69). On the other hand, one needs to be aware that too much information on the purpose may bias or influence the results; a careful balance needs to be achieved in this respect. Therefore, all participants were informed by email of the purpose of the study prior to administering the questionnaire (see Appendix 4). The interest of the researcher in motivation was explained, however, the focus on changes in motivation was not elaborated on so as not to bias students' answers. The questionnaire was accompanied by the same information leaflet that had been sent out via email before the date of data collection. The leaflet also informed students of their right not to participate. All interviewees signed an informed consent form prior to undertaking the first interview, and this can be found in Appendix (5).

Another point that refers back to the question of responsibility towards the participant is the issue of privacy: "the confidential and anonymous treatment of participants' data is considered the norm for the conduct of research" (BERA, 2004:8). To ensure anonymity, it is obligatory to employ proper data storing techniques, a point to be remembered when collecting and evaluating data. Given the number of students and the nature of the study, the identity of the individual students was not revealed when the data was eventually written up for the thesis, and pseudonyms were used instead. Participants themselves chose their pseudonyms. A dilemma, however, was posed by the fact that although the individual names of the students did not matter for this study, a form of identification was needed in order to match the data from the first questionnaire to the second questionnaire. Therefore, students could opt to leave out 
their name and provide only the date of birth of their mother so as to make the second questionnaire identifiable. Only those students who wanted to participate in follow-up interviews were asked to provide their email addresses. In addition, all participants were informed that the information provided would be treated with discretion; and that no one except the researcher would have access to the stored data. Students would not be identifiable once the results of the study were made public. It was stressed that the provision of the name/ email address was voluntary, and only necessary for those students who wanted to participate in the follow-up interviews. These students could tick a box on the questionnaire to indicate that they wanted to be contacted for a follow-up interview. Each student was provided with a questionnaire and an envelope where they themselves could store and seal the questionnaires as to ensure that no one except the researcher saw the questionnaire. Participants were number-coded for the statistical evaluation.

The last point that needs to be discussed is the research setting. As mentioned before, I had been working for the German department at University A as a German language lecturer. This provided me with valuable inside knowledge of the University itself, the organisation of the course and the way tutorials and lectures are held, in addition to a familiarity with first year students of German. On the other hand, it posed a different situation from that of most researchers:

People considering embarking on insider research have to think very carefully about what taking on the role and identity of researcher can mean and involve in a setting where they are normally seen as someone else with particular responsibilities and powers. (Sikes, 2006:112)

Thus, special care was taken to separate the role of the researcher from that of the lecturer. Special attention was also paid to ensuring the trust of the department for the project, and permission was asked from all people involved in the research, that is, not only the Head of the German Subfaculty but also departmental lecturers. Genuine 
interest and support was found on this side. In addition, during the year of data collection, I abstained from giving lectures to first year students so that I would not be known in my function as a lecturer to students. No interviewee was selected that I was familiar with, had taught or would teach in the future.

Lastly, in line with my researcher's duty of reciprocity, I reported every step of my project to both universities, and published results (Busse and Williams, 2010) have already been made available to both departments as well as to the participants.

\subsubsection{Quality Criteria and Limitations of Chosen Approach}

Quality criteria in quantitative research are usually associated with the terms validity and reliability. A common definition of the former is an instrument's ability to measure what it is supposed to measure. The latter, on the other hand, is concerned with consistency of data, that is, the extent to which the instrument produces consistent results in a given population (Bryman, 2008, Dörnyei, 2007). There are also more finely tuned classifications in use: for instance, distinguishing between internal validity and external validity (Bryman, 2008). Internal validity is present if the outcome is a function of the variables that are measured, while external validity refers to the extent to which findings are generalisable.

In quantitative research, an instrument's reliability is usually measured by the internal consistency coefficient of a scale. As discussed earlier, the Cronbach's $\alpha$ of the scales of $>.7$ suggests that the questionnaire instrument is reliable. The questionnaire's content validity, i.e. the extent to which the research instrument tests the relevant domains of the concepts being investigated (Punch, 1998), was ensured by systematically drawing on the relevant motivational literature and existing research on L2 motivation. Naturally, measuring students' engagement with language learning through an effort scale which quantifies engagement with language learning in terms of frequency of action is not without controversy. Note, however, that this is a common 
way of measuring motivated behaviour in motivational studies (e.g. Ryan, 2009, Taguchi et al., 2009) and that interviews were used in this study to gain a more indepth insight into the quality of students' engagement with language learning.

The limitations of small-scale studies as these are obvious, however, if a quality criterion such as external validity is aspired to. The small sample size and the relative stronger sample attrition experienced at University B at Time Point 2 means that caution has to be taken to generalise findings on motivational change to all German first-year university learners in Russell group universities in England. Naturally, neither can results be generalised which are generated by qualitative data analysis.

This limitation, however, does not mean that the study has no intrinsic value, especially given that qualitative research is per se not about generalisations, but rather about an in-depth understanding of a phenomenon, more concerned with “"trustworthiness" (Dörnyei, 2007, Lincoln and Guba, 2000). I will not attempt to go any further into a debate that would lead me eventually to another discussion of the different epistemic cultures with one more rooted in a positivist, scientific understanding of education, and the latter rooted in a humanistic understanding of educational research (see 4.1.2 ). Rather, I will point out why the quality criteria for qualitative research are met, and show that the data elicited are trustworthy.

Great care was taken to ensure the data's trustworthiness at all stages of the project, as I elaborated in the procedures section. While it cannot be ruled out that students' involvement in the research study and their interactions with the researcher may have had an effect on their motivational thought processes, I minimised the threat of social desirability bias (Dörnyei, 2007) by introducing myself to students as a research student and not as lecturer; great care was also taken not to disclose too much information about the project (section 4.7.). I also made sure to provide transparency of the data collection and analysis process, in particular the development of coding 
frames and the emergence of the themes. In addition, a fellow D.Phil. student working in the same area of research continuously read and commented on my analysis (peer checking, Dörnyei, 2007). This, last but not least, helped ensure that findings represent a critical analysis of all the data rather than anecdotal incidents (threat of anecdotalism, Silverman, 2004). Also, I chose participant feedback for the interpretation to check on the trustworthiness of my qualitative data. Students not only read the transcriptions of their interviews but also read and discussed findings with me. Students also commented on and shaped the published article. Possible alternative interpretations of an observation were always pointed out. Ethical considerations and the focus on students' individual experience of motivation excluded teacher interviews as data used in the thesis, but the knowledge gained through my informal and professional interaction with staff at both universities has helped me to look at the data from a comprehensive vantage point.

The fact that quantitative findings and qualitative findings were largely in harmony with each other underlines the trustworthiness of the data. It also suggests that the methods chosen were adequate for the phenomenon under investigation.

To sum up, although caution has to be taken when generalising results to firstyear students of German at Russell group universities, the research methods have generated insights which are trustworthy; they may also offer what has been termed "internal generalizability" (Maxwell, 1992), this is, they are generalisable to the particular universities concerned. The results may later be used as a starting point for broader statistical analysis. 
5 Why German? - Students' motivation to study German at university level at the beginning of the academic year

This chapter is not available via ORA. 
6 The Motivational Rollercoaster: Students' motivational changes over the course of the first academic year

This chapter is not available via ORA. 


\section{Exploring Effort and Efficacy}

This chapter is not available via ORA. 


\section{Discussion}

This study contributes to the knowledge of language learning motivation, but also bridges the gap between theory and practice. This concluding chapter is therefore divided into two parts. The first part addresses the ways in which the present study has contributed to the field of L2 motivational research. I will first provide an overview of the main results; sections 8.1.1-8.1.5 outline in more detail how the findings can inform future studies. The second part of the chapter explores how the theoretical insights gained about students' motivation(s) may improve established teaching practice at the two universities in question. Notably, it is clear that closer cooperation between modern foreign language departments and applied linguistics/ educational departments is desirable to this end. Pedagogical suggestions focus on a) more content and language integrated learning (CLIL) (section 8.2.1) and b) stronger support of autonomous forms of learning (section 8.2.2). To conclude, possible measures to enhance motivation on a micro-level are outlined (section 8.2.3). The chapter closes with final reflections on adjusting students' expectations of the higher education experience (section 8.2.4).

\subsection{What Contribution does the Study make to the Field?}

Naturally, the small scale and exploratory nature of the present study poses limitations and it would be incautious to presume that the results generalise even across first year university learners of German in Russell group universities in England, given that the majority of students in the sample came from a university that is, arguably, exceptional. However, the new theoretical focus and the innovative empirical approach taken in this study provide forward-looking insights that future L2 motivational research may build on. Before turning to a more in-depth discussion of 
empirical findings, I will summarise three main insights that may be of interest for future studies:

\section{1) Theoretical Focus}

This study is the first to apply theories of self to student motivation for studying modern foreign languages in the UK. The results suggest that this perspective clearly throws new light on the motivation of these students. On the basis of this study, one can infer that a different picture would emerge if larger scale studies moved beyond the traditional concepts of integrative/ instrumental orientations for studying, to which studies such as Coleman (1996) are confined. I discussed in Chapter 7 why integrative motivation in particular may not be the key to understanding modern foreign language students' engagement in language learning, and why, therefore, concerns about a low level of emotional identification with the target culture may be unfounded. The longitudinal data convincingly illustrate that possible selves theory and the concept of the ideal L2 self as developed in the L2 motivational context, self-determination theory and the concept of intrinsic motivation, and self-efficacy theory with the concept of task-specific self-efficacy offer a much better basis for understanding students' immediate and their sustained motivated engagement in language learning.

2) Empirical Approach: The Time Variable

Isolating individual motivational differences in learners' profiles can generate important insights into learning behaviours. However, learning behaviour is everchanging and motivational attributes are dynamic rather than static, an aspect that much of the existing body of L2 motivational research with its dominance of one-off surveys has failed to pay attention to. This study illustrates the considerable changes students' motivational profiles undergo even during the course of one academic year: students' intrinsic motivation significantly decreased over the course of the year and so did their self-efficacy beliefs for speaking and listening, a decline concomitant with 
decreasing effort to engage with language learning. The ought-to self dimension significantly increased over the course of the year yet it did not appear to be related to students' engagement with language learning. The implications of these findings will be discussed in more depth at a later stage; here, the methodological aspect should be highlighted: while avoiding student attrition in longitudinal designs is a challenge, the study bears evidence of the usefulness of longitudinal approaches to exploring L2 motivation.

3) Empirical Approach: The Context Variable

In order to interpret changes in motivational profiles and to gain an understanding of the underlying reasons for them, the influence of the learning context has to be considered. The interviews painted a detailed picture of the motivational changes experienced by twelve students. By interviewing these students repeatedly over the course of the year, the dynamics in the interplay between motivation and learning context were traced. Qualitative approaches have considerable potential in this respect: the qualitative data illustrated well how various contextual factors, such as, for instance, the challenge of language learning tasks or the feedback practices, came to affect the individual's motivational profile. At the same time, the data illuminated how gradual changes in students' motivational thinking came to shape students' perception of the given learning context.

\subsubsection{Exploring the Concept of the Ideal L2 Self and the Ought-to L2 Self in the English-speaking context}

The ideal L2 self

Possible selves research in L2 motivation is still in its preliminary phase, and the recently developed ideal L2 self concept has mainly been applied to the learning of English as a foreign language. This calls into question whether drawing on possible selves theory is useful at all for L2 motivational research and whether the ideal L2 self 
concept in particular is applicable to the learning of other languages than English. This study suggests that drawing on possible selves theory is valuable for a motivational enquiry into fl learning. It also suggests that the ideal L2 self concept is not restricted to learning English only and that exploring whether students' imagined future self is tied to using a language is important to understanding their engagement with language learning. I will first discuss the quantitative results before elaborating on the salient qualitative results.

The consistent results obtained from Time Point 1 as well as Time Point 2 from the questionnaire underline that the ideal L2 self is valuable for exploring students' motivation to study German and that it offers a much better conceptualisation of students' motivation for studying German than the concept of integrative orientation. Recall that students placed significantly more importance on the dimension of the ideal L2 self than on integrative reasons for studying. This is despite the fact that there is an existing and clearly defined target culture with which students could potentially identify.

Furthermore, the clear and consistent link between the ideal L2 self and students' effort at both time points underlines the interpretation that the ideal L2 self is a useful concept for understanding students' engagement with language learning over time. Note that the observed relationship between the ideal L2 self and effort contrasted with a missing link between the concept of integrativeness and students' effort. In other words, the results of this study strongly suggest that the ideal L2 self is a better concept for explaining students' engagement with language learning than the concept of integrativeness. In the literature review, I pointed out that authors such as Ryan (2009) and Taguchi et al. (2009) have already made a similar claim based on data obtained by large-scale studies on learning English as a foreign language. However, I criticised that their data were not conclusive (Chapter 3, section 3.5.4.2.2): 
strong correlations were observed between the ideal L2 self and the effort variable, but also significant moderate correlations between students' sense of integrativeness and effort. To interpret these results, one may recall that the integrative scales used in these studies focused more on a positive attitude and less on the dimension of emotional identification with the target culture.

In order to clarify to what extent emotional identification played a role for the students in this study, a more fine-grained measurement was needed. The integrativeness scale was divided into two integrative sub-scales, with one subscale measuring a positive attitude and with the other subscale measuring emotional identification. No correlation was found between emotional identification and the two effort factors, suggesting that emotional identification with German-speaking people played no role for these students' engagement with language learning. A positive attitude towards German-speaking people/countries was only linked to one effort factor, effort expended on unpopular language learning tasks. This study is therefore the first in which the concept of the ideal L2 self proved a better measurement for exploring students' effort for foreign language learning than the concept of integrativeness.

The qualitative data supported and enriched this interpretation confirming that students' ideal L2 selves were not linked to a sense of identification with Germanspeaking people. Their ideal L2 selves did not even appear to be particularly tied to German as a language. Rather, these students pictured themselves as future multilinguals: one may recall Heather's statement in this respect 
And I realised it's part of who I am, the fact that I can do languages [...] Yeah. I think that's sort of my - I think it sounds a bit weird but sort of my identity for the future. That'll be part of my life sort of thing.

Becoming multilingual may have a particular appeal for these students, who - being native speakers of English - consider multilingualism as an intellectually appealing exception from the monolingual norm; almost an elite attribute among native speakers of English. Becoming multilingual then becomes equated with becoming an educated person, with becoming someone who has access to the higher spheres of society and also to higher career-paths. The latter aspect may be echoed in the moderate correlations found between the ideal L2 self and instrumental reasons for studying. The qualitative data suggest that the proposed distinction between instrumental orientations with a promotion vs. a prevention focus (Dörnyei, 2009b, Taguchi et al., 2009, see Chapter 6, section 6.2.4), with the former being part of the ideal L2 self and the latter forming part of the ought-to L2 self, may indeed be helpful to steer away from the traditional classification of instrumentally motivated students, a concept less suitable for capturing the relationship between notions of self, identity and emerging career orientations: if a student's imagined future self entails being professionally successful, and speaking different languages is seen as an integral part of being professionally successful, career orientations have a promotion focus and the imagined future career may be a powerful motivator to learn languages. In contrast, students who study in order to prevent negative outcomes, as, for instance, not to disappoint the tutor, may not show the same engagement with learning. The motivational impact of the ought-to self will be discussed in more depth at a later stage: attention here is drawn to the promotion focus. Recall in this context Samuel's statement which illustrates the positive interplay between the ideal L2 self and evolving career orientations, as present at the beginning of the year: 
I can kind of envisage myself as part of my career, whether, I don't know, whether I will be a kind of diplomat or - well, probably be something higher than that, an ambassador or something. Or foreign secretary would be pretty good. I can see myself as kind of bilingual no, not bilingual, but bicultural as well.

To sum up, the study is pioneering in that the results imply that the ideal L2 self is a useful and versatile concept not restricted to the foreign language learning context of English. By using the concept of the ideal L2 self, a better picture of students' motivation for studying German and their sustained motivation to continue to engage with German has been gained.

Future research may want to draw on these results and explore to what extent insights based on students from high-profile universities are generalisable to first year modern foreign languages students in England. More research is also warranted to further explore to what extent a pronounced ideal L2 self plays a role in students' continued engagement with the target language over the whole course of study.

\section{The ought-to L2 self}

While the data provided convincing evidence for the importance of considering the concept of the ideal L2 self in students' motivation for studying German, it was less conclusive with regard to the ought-to L2 self. The data suggested that the ought-to L2 self component does not play a role in students' decision to study modern foreign languages at university level, in other words, students do not feel that they are expected to study German and nor do they seem to feel any external pressure to study German. I commented on possible implications for the school sector in Chapter 5.

It needs to be pointed out that students' ought-to L2 self also appeared to be unrelated to the other motivational variables, and that its impact on students' motivated engagement with language learning was not clear: recall that the ought-to L2 self only showed a moderate correlation (.30) with effort for unpopular language tasks at Time Point 1 . This indicates that the ought-to L2 self dimension may exert 
some influence when students face tasks they find less intrinsically motivating. I suggested that students come to believe that they are expected to improve their language skills during the year abroad instead of within the framework of university teaching (see Chapter 6, section 6.2.3.3), which reduces the pressure of the ought-to L2 self dimension, and this may explain why the ought-to L2 self was not correlated with effort for unpopular learning tasks at Time Point 2.

Recall, however, that the ought-to L2 self dimension increased significantly over the course of the year. The qualitative data suggested that ought-to L2 self beliefs may have prevented individuals from dropping the degree course and ceasing to engage with the activity of studying German.

That is, while ought-to L2 self beliefs did not appear to play a role in initiating the motivated behaviour (starting to study German), they may have been a factor in sustaining already initiated actions (continuing to study German), albeit without exerting much influence on actual language learning behaviour. Future studies would certainly have to explore these tentative insights further.

\subsubsection{Exploring Students’ Intrinsic Motivation}

In the literature review, it was pointed out that self-determination theory and the concept of intrinsic motivation has found a particularly strong echo in the Canadian research context. The data obtained in the present study highlights the usefulness of paying attention to the concept of intrinsic motivation for understanding students' motivation for studying a modern foreign language in the UK. Addressing students' level of intrinsic motivation is also important in order to gain a better understanding of students' engagement with language learning over the course of the year: recall the strong correlation between intrinsic motivation and students' effort observed at both time points. 
The study further revealed that students' level of intrinsic motivation does not remain stable over time and that students feel less intrinsically motivated towards the end of the academic year than towards the beginning of the academic year. Selfdetermination theory offers a useful theoretical framework for interpreting the motivational changes observed. Among other factors, the influence of task-challenge and feedback on students' level of intrinsic motivation could be traced. These contextual variables will be discussed at a later stage. I will here focus attention on an interesting development apparent in both the qualitative and quantitative data: the increasingly close relationship between intrinsic motivation and students' self-efficacy beliefs. Note that students' enjoyment of language learning was relatively independent from self-efficacy for language learning tasks at the beginning of the year, as intrinsic motivation was not correlated with self-efficacy except for a moderate correlation with self-efficacy for writing tasks at Time Point 1. Over time, however, the two motivational dimensions became linked; and intrinsic motivation was moderately correlated with all four self-efficacy factors at Time Point 2. In the qualitative data as well, there were ample references that capability beliefs interacted with students' enjoyment of language learning. These findings are in line with self-determination theory, which stresses the close relationship between competence beliefs and intrinsic motivation (see Chapter 3, section 3.4.1).

Lastly, I would like to draw special attention to the consistent and strong relationship found between intrinsic motivation and the ideal L2 self. Waterman (2004) emphasises the link between intrinsically motivated behaviour and identity, he proposes that intrinsic motivation may over time become deeply rooted in a person's identity. For instance, a child who enjoys writing stories might later form an identity as a writer. In the Canadian L2 motivational research context, Noels (2009) similarly argues that attention has to be paid to the role of volitional engagement in the 
language learning process for the internalisation of language learning into self and identity. In this vein, she also hypothesises that a higher level of intrinsic motivation for learning a language brings about a feeling of identification with the ethnolinguistic group speaking this language. However, note in this respect that there is no firm empirical evidence; see Chapter 3, section 3.5.4.1. The data of the present study does not support Noels's hypothesis. Firstly, there was a consistent strong correlation between the ideal L2 self and intrinsic reasons for studying observed at both time points, while there was only a moderate correlation between integrative reasons for studying and intrinsic reasons. A t-statistic was computed in order to test the statistical significance of the difference between correlation coefficients (comparing dependent rs according to Field, 2009). The relationship between ideal L2 self and intrinsic reasons for studying was significantly stronger than the correlation between integrative and intrinsic reasons for studying at both time points (t-distribution Time Point $1=2.38$; Time Point $2=1.89$ ).

Second and importantly, when the relationship between intrinsic motivation and the two integrative subscales was examined, no correlation could be found between intrinsic motivation and integrative subscale B measuring emotional identification.

The results of the present study do therefore not support the hypothesis that intrinsically motivated students have or develop a higher level of emotional identification with German-speaking people. Rather, the findings of this study indicate that highly intrinsically motivated students who enjoy the challenges of learning a language may be better able to conjure up the vision of a linguistically proficient future self.

On the grounds of the qualitative data one may further hypothesise that lower levels of intrinsic motivation, i.e. decreasing enjoyment of learning a language, can curb a further elaboration of an existing future L2 self, probably in concert with 
decreasing self-efficacy beliefs (addressed below). These results may be an important step forward in understanding the gradual internalisation process of language learning into self and identity.

To sum up, self-determination theory and the concept of intrinsic motivation proved useful for a) exploring students' motivation for studying German at university, b) students' engagement with language learning and c) students' motivational ups and downs during the course of the year. It is further suggested that intrinsic motivation together with self-efficacy beliefs play a role in the internalisation of language learning and the elaboration of students' ideal L2 selves.

\subsubsection{Exploring Students' Self-Efficacy Beliefs}

In the literature review, I lamented that there is a general scarcity of studies looking at self-efficacy beliefs in the L2 motivational field. It was also pointed out that existing studies are not very reliable, as they tend to measure self-efficacy too broadly and not in a task-specific manner (see Chapter 3, section 3.5.2.3).

This study suggests that if measured in a task-sensitive manner, self-efficacy is an important variable to interpret motivated engagement with language learning in an institutional learning context. Note that all self-efficacy factors were either moderately or strongly correlated with the two effort factors at Time Point 2. The study further suggests that students are highly motivated by a vivid ideal L2 self and a high level of intrinsic motivation at the beginning of the academic year, but they do not feel secure about their capability for dealing with the specific language learning requirements at the university. Recall the average level of self-efficacy for university language learning tasks in the area of writing, listening, speaking, grammar and translation at the beginning of the year; at both time points $<3$, where $3=$ so-so. Already existing self-efficacy beliefs may therefore be taken into account when trying to understand 
why students come to struggle with a particular language learning activity at university level.

However, as the analysis of the Time Point 2 data indicated, the university environment does not help to improve students' self-efficacy beliefs; on the contrary, over the course of the year, self-efficacy for speaking and listening tasks significantly decreased. It was hypothesised that this trend was linked to the lack of regular practice provided within the framework of the curriculum, a topic which will be revisited at a later stage. Students' sense of self-efficacy for the other university tasks did not undergo any significant changes, and more input was provided in the areas of reading, writing, grammar and translation. The results therefore suggest that the university environment has an influence in lowering students' self-efficacy in the areas of speaking and listening; it is not successful, however, in raising first-year students' self-efficacy beliefs in the other areas. Given the correlation between self-efficacy and effort in the present study and the general importance of self-efficacy beliefs for motivated engagement with academic tasks (e.g. Schunk and Pajares, 2005, see Chapter 3, section 3.4.2), these findings are not only valuable for the universities in question but also for studies seeking insights into the particular challenges of the firstyear experience of modern foreign languages students.

In the literature review, it was further highlighted that the newly developed $L 2$ Motivational Self System ignores the role of competence beliefs for the formation of possible selves. I pointed out evidence suggesting a close link between self-efficacy beliefs and people's capacity to conjure up successful self-images (e.g. Beauchamp et al., 2002, see Chapter 3, section 3.4.3). To my knowledge, no study has as yet explored the links between self-efficacy beliefs and the ideal L2 self. The finding that task-specific self-efficacy for different areas such as reading, writing, listening, speaking, grammar and translation is consistently linked to students' ideal L2 selves is 
therefore pioneering. I suggested above that self-efficacy beliefs and intrinsic motivation may have a say in whether students further elaborate an existing ideal L2 self.

More empirical research is certainly warranted to explore the relationship between intrinsic motivation, self-efficacy beliefs and ideal L2 self beliefs. Studies based on a larger sample may explore the predictive power of intrinsic motivation and self-efficacy beliefs for students' ideal L2 selves. Importantly, more attention has to be paid to the relationship between self-efficacy beliefs, intrinsic motivation and the ideal L2 self on a theoretical level.

\subsubsection{Exploring Motivational Change and the Role of Context}

The quantitative data revealed changes in students' motivational profiles over the course of the first academic year; the interviews explored reasons for these changes. By scrutinizing individual motivational trajectories in the qualitative data, some important contextual factors within the university environment could be identified. The relationship between students' motivation, specific tasks (reading, writing and grammar tasks) and the level of challenge posed by these tasks was explored. Following from this, the interaction between motivation, students' sense of progress and regular practice was investigated. The links between motivation and feedback were followed up, and the role of the language teacher was examined. Contextual factors that appeared to have affected students' ideal L2 self beliefs were then investigated. For instance, the function of role models for developing and elaborating ideal L2 self beliefs was explored. I also pointed out an interaction between the university environment, decreasing self-efficacy beliefs and a decreasing level of intrinsic motivation and weakening ideal L2 self beliefs. Lastly, I explored the role of the university environment in forming beliefs about language learning that are detrimental to the formation of the ideal L2 self. 
To sum up, one may say that the interviews provided a rich description of the various contextual factors which came to influence learners' motivational characteristics over time. At the same time, the data illustrated how a particular motivational characteristic can shape the way an individual perceives and interprets a given learning context. Note that Jayanthy in particular, who had a low level of selfefficacy for grammar tasks, perceived grammar classes as extremely demotivating. The longitudinal data allowed her motivational trajectory to be traced, and it was interesting to see that her increasingly self-directed approach to learning not only affected her motivation positively but also altered her perception of the learning environment.

I took a new - they've been...well, not the lessons themselves have been different, but I've taken a new approach [...] It made it more enjoyable because it was more understandable. There's nothing worse than coming out of an hour's lesson and not having understood anything.

Dörnyei rightly points out that "the role of learner characteristics can only be evaluated with regard to their interaction with specific environmental and temporal factors or conditions." (2009a:232). Previous empirical studies, however, have paid little attention to this interaction. In Chapter 3, I commented critically on the neglect of the learning environment variable in existing studies conducted within the framework of the L2 Motivational Self System (see Chapter 3, section 3.5.4.2.2). The data generated by this study clearly suggest that more attention has to be paid to how motivation is formed over time through individual and contextual variables.

To conclude: as stated in the literature review, motivation was defined in this study as a contextually situated dynamic state of arousal, which manifests itself in immediate or future motivated engagement in (language learning) activity. This study illustrates some of the ways in which contextual factors interacted with an individual's present and possible future self-beliefs, and manifested themselves in changing levels 
of motivated behaviour, conceptualised as effort for language learning. In line with the educational focus of this study, the interviews explored the motivational impact of the context variable by limiting it to the learning environment of the university. While this was a necessary narrowing-down process for the feasibility of the present project, there are naturally various other layers of contextual sources which may also be worth considering. In order to guide future studies in their investigation of the context variable, I will in the following section propose a four-layered conceptualisation of the context variable. The present study generated insights with regard to three contextual levels, the micro, meso and exo-level; the fourth level, the macro sphere, was not directly addressed. More research is warranted to explore all four contextual levels, to investigate how these interact with each other and how they, in turn, interact with the motivational characteristics of the individual in question.

\subsubsection{Towards an Expanded L2 Motivational Self System}

In the literature review I have already commented in detail on both the benefits and the shortcomings of the L2 Motivational Self System developed by Dörnyei (2009b, see Chapter 3, section 3.5.4.2). My criticism tackled two aspects in particular, the exclusion of present self-beliefs and the vague conceptualisation of the L2 learning environment in the current model. In the following, I will propose an expanded $L 2$ Motivational Self System (Figure 1) which draws on insights derived from selfefficacy theory (Bandura, 1997) and self-determination theory (Deci and Ryan, 1985, explored in the L2 context by Noels, see Chapter 3, section 3.5.4.1), and could produce a synergy of two important strands in L2 motivational research, Dörnyei's L2 Motivational Self System (2009b), and Ushioda's person-in-context approach to motivation (2009).

The individual is placed at the centre of the model. Present and possible future self-beliefs are embedded in the individual. The correlations observed in the empirical 
data support the thesis that present self-beliefs (e.g. self-efficacy beliefs) and present motivational attributes (level of intrinsic motivation) are linked to possible future selfbeliefs (e.g. ideal L2 self) and must therefore be connected in the model. Note, however, the dashed lines leading to ought-to L2 self beliefs to indicate that data was not conclusive in the present study and that more attention will have to be paid to this motivational dimension.

The context variable is depicted as multi-layered spheres surrounding the individual. In the L2 Motivational Self System by Dörnyei, the context variable is conceptualised as the L2 learning environment, which is the third variable of the tripartite self system (ideal L2 and ought-to L2 self, L2 learning environment). This conceptualisation is somewhat misleading; although the context variable interacts with self-beliefs, it is not strictly speaking part of the self.

I will now elaborate in more detail how the context variable is conceptualised here, to enable a better exploration of the relationship between motivation and learning environment. The four-layered context construct proposed draws on a model developed by Gurtner, Monnard and Genoud (2001). Although many more contextual layers could be added, the model of Gurtner et al. appeared useful for enquiries into institutional learning contexts, as it identifies and distinguishes gradually widening spheres of educational influence: the four strata consist of (1) the micro level, which comprises the school subject and type of lesson or work (2) the meso level, which entails classroom level or school, but also teacher attitudes, classroom environments; classroom goal structure, classroom norms and practices. The exo level (3) refers to the school, and the macro level (4) is termed outside school, and refers to familial, cultural, economic and political factors.

In order to make the distinction used by Gurtner et al. applicable to a range of L2 motivational research settings, the following amendments need to be made: the 
meso-level (2) needs to include teacher-specific motivational components as specified in the learning situation level in the 1994 framework developed by Dörnyei (2001 see Chapter 3, section 3.5.2.1), i.e. a classification of the teacher (controlling vs. autonomy supporting), feedback and task-presentation. On the exo level (3), educational institution is substituted for school. Based on the insights of the present study, the curricular framework is also included. The macro level (4) refers explicitly to societal factors. These need to be differentiated from familial/parental influences, a point that may be of particular importance when researching adult learners. 
Figure 1 Expanded L2 Motivational Self System

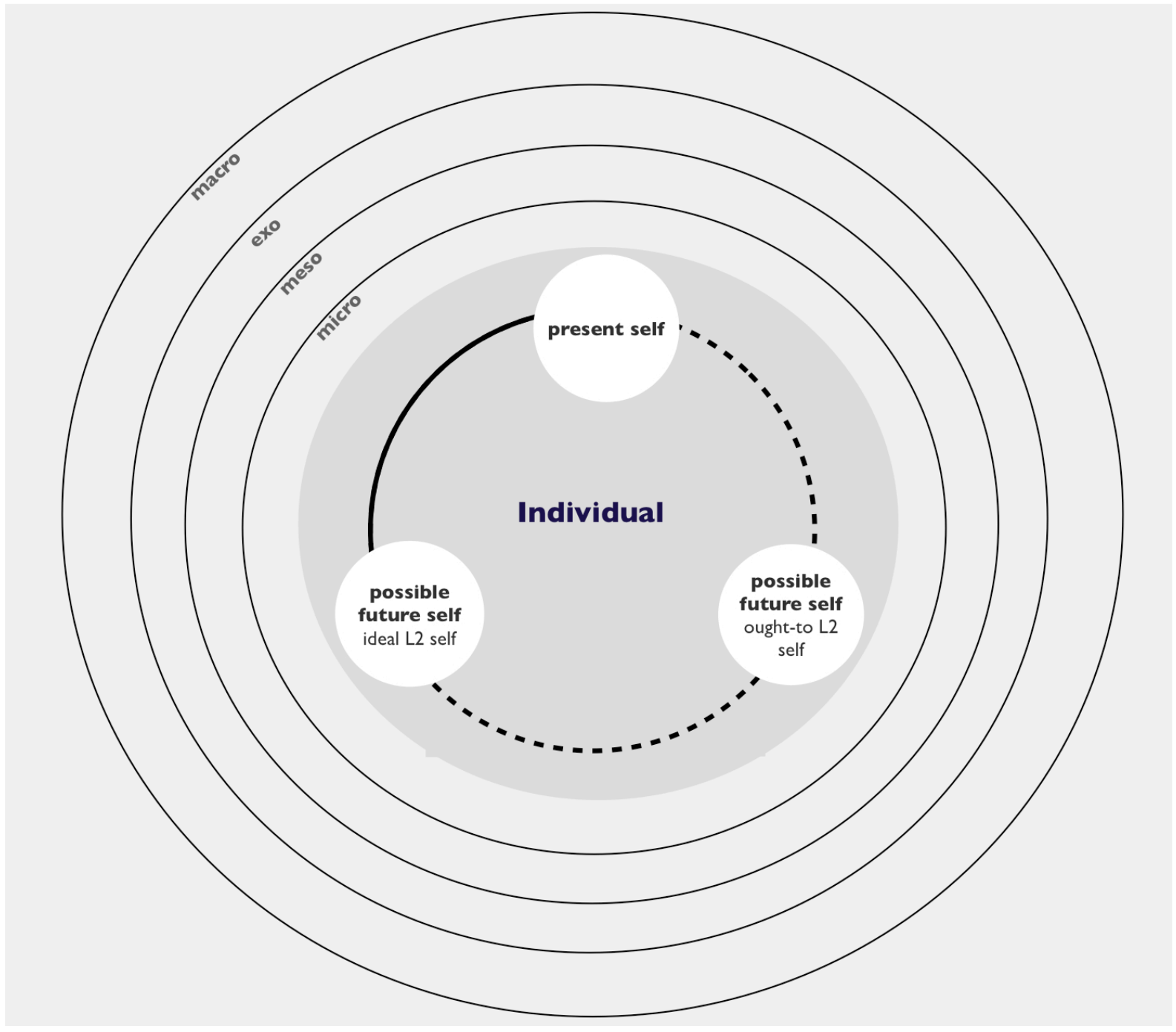

\section{Present self}

e.g. students' self-efficacy beliefs, students' sense of self-determination and their level of intrinsic motivation

Possible future self (desired by individual)

e.g. students' ideal L2 self

Possible future self (expected by others)

e.g. students' ought-to L2 self

\section{Micro context :}

subject, type of lesson or work

Meso context:

classroom level, teacher-specific motivational components,

school/ university/ college year

Exo context:

educational institution/ curricular framework

Macro context:

outside the educational institution:

I: familial/parental influences,

II: societal factors

III cultural/ political/ economic factors 


\subsection{Pedagogical Implications for Universities}

Tracing students' motivational trajectories over the course of the year has revealed some of the motivational challenges of the first year of the German degree course. Drawing on the findings of this study, I will here explore ways in which the transition from school to university may be improved, and through which the university environment may counteract the worrying decline in students' effort to engage with language learning. I would like to stress that the propositions outlined below tackle only those issues that emerged as salient points in this motivational analysis. They cannot and are not intended to be exhaustive, nor do they pretend to be a novel approach to teaching first-year language students. Such an undertaking would not only lie outside of the motivational focus of this project but would also demand a study on its own. Rather, pedagogical suggestions follow from the findings discussed; they are geared towards this specific cohort and draw on the four main insights gained from the present study. They seek to answer the following questions: how can the university environment

1. better respond to first year students' wish for gaining language proficiency?

2. nourish students' ideal L2 self beliefs?

3. counteract decreasing levels of intrinsic motivation and self-efficacy for speaking and listening over the course of the year?

4. enhance students' self-efficacy beliefs for language learning tasks in the area of reading, writing, grammar and translation?

With reference to Figure 1 and the discussion in section 8.1.5, adjustments on the micro and meso level may well tackle some of these questions and positively affect first-year students' language learning experience. Areas that may be worth considering are summarised in section 8.2.3 and include better scaffolding of tasks, more attention to the importance of feedback for students' motivation and 
interventions to nourish students' ideal L2 self beliefs. However, the study suggests that more profound changes on the exo-level may be needed to tackle all four central questions and to address the root of the underlying problems.

An important issue to consider in this context is the limited amount of contact time with the language (recall that students have only three hours of formal language instruction per week; German is used as a means of communication in only one of these three classes and it is not used as a means of communication in any other class). An increase in contact time would not only respond to students' wish for language proficiency, but also address the other three central questions: an increase in contact time is likely to affect students' sense of progress. In Chapter 6 it was suggested that perceived lack of progress negatively affected students' enjoyment of language learning (section 6.2.1.2). Perceived slow progress was then linked to lack of regular practice within the framework of university teaching (6.2.1.3). Of course, feedback (section 6.2.1.4, revisited in this Chapter in section 8.2.3) also plays a role in students' perceived progress. However, one may hypothesise that without regular practice it is unlikely for students to experience a genuine sense of progress. Perceived progress, in turn, is linked to motivation (Schunk, 1989, see Chapter 6, section 6.2.1.2).

Clearly, without regular practice, there are also fewer opportunities for students to stretch their skills and master difficult language tasks. Note that both selfdetermination theory (see Chapter 3, section 3.3.1) and self-efficacy theory (see Chapter 3, section 3.4.2) stress the importance of mastering the learning task. Given that mastery experiences are the most powerful source of influence on self-efficacy beliefs (e.g. Fantuzoo and McWayne, 2002, Klassen, 2004, see Chapter 3, section 3.4.2), self-efficacy beliefs may not increase without opportunities for regular practice. 
To summarise, there is reason to suggest that an increase in contact time and more opportunities for practice can affect students' motivation directly (mastering learning tasks influences self-efficacy and intrinsic motivation); as well as indirectly (more opportunities for regular practice enables students to become more skilful in the different language learning tasks and provides them with a sense of progress, which then affects motivation positively).

Lastly, given the consistent correlations in the present study between intrinsic motivation and the ideal L2 self and between self-efficacy beliefs and the ideal L2 self, interventions to increase intrinsic motivation and self-efficacy beliefs are bound to have an impact on the ideal L2 self as well.

An increase in contact time and more opportunities to practise German is thus very important from a motivational perspective. It may also be worth noting in this context that engaging regularly in speaking and writing activities is hypothesised to be necessary for processing language input and for the gradual build-up of more complex language structures, i.e. not only language input but also opportunities for language output are important pillars of L2 learning (Swain, 1995, 2005).

While few may quibble with the notion that regular language practice is important for any modern language student, financial constraints are usually voiced as a reason for reduction in contact time within the framework of the curriculum. Suggestions as to how to improve opportunities for regular practice inevitably have to take these financial constraints into account if they want to find their manifestation in the curriculum.

I will argue that in order to ensure regular practice in a financially feasible way a) the existing separation of target-language use and content teaching has to be challenged and b) autonomous forms of language learning have to be more strongly supported and more firmly anchored on a curricular level. I will argue that these two 
approaches also address the dimension of task-challenge, the mainstay of intrinsic motivation. I am aware that top-down changes like these, i.e. structural and curricular changes, are not easy to bring about, needing time and careful consideration to be put into practice. There are, however, good arguments for reconsidering established practice. Table 22 summarises how the two proposed approaches address the four central questions posed at the beginning of this section. In sections 5.2.1 and 5.2.2 I will elaborate on these points in more detail.

Table 22 Overview of motivational impact of proposed approaches

\begin{tabular}{|l|l|l|}
\hline $\begin{array}{l}\text { How can the university } \\
\text { environment }\end{array}$ & $\begin{array}{l}\text { More Content and } \\
\text { Language Integrated } \\
\text { Learning }\end{array}$ & $\begin{array}{l}\text { Extension and Support } \\
\text { of Autonomous Forms of } \\
\text { Learning }\end{array}$ \\
\hline $\begin{array}{l}\text { respond to students' wish } \\
\text { to gain language } \\
\text { proficiency? }\end{array}$ & $\begin{array}{l}\text { increase in contact time } \\
\text { with language }\end{array}$ & $\begin{array}{l}\text { increase in contact time } \\
\text { with language }\end{array}$ \\
\hline $\begin{array}{l}\text { counteract decreasing } \\
\text { levels of } \text { intrinsic } \\
\text { motivation and (b) self- } \\
\text { efficacy for speaking and } \\
\text { listening over the course } \\
\text { of the year? }\end{array}$ & $\begin{array}{l}\text { provides intellectual } \\
\text { challenge } \\
\text { may stimulate sense of } \\
\text { progress } \\
\text { provides opportunities for } \\
\text { mastery experience }\end{array}$ & $\begin{array}{l}\text { provides challenge geared } \\
\text { to individual } \\
\text { provides learner choice, } \\
\text { may stimulate sense of } \\
\text { progress } \\
\text { provides opportunities for } \\
\text { mastery experience }\end{array}$ \\
\hline $\begin{array}{l}\text { enhance students' self- } \\
\text { efficacy beliefs for } \\
\text { language learning tasks } \\
\text { in the areas of reading, } \\
\text { writing, grammar and } \\
\text { translation? }\end{array}$ & $\begin{array}{l}\text { provides opportunities for } \\
\text { mastery experience }\end{array}$ & $\begin{array}{l}\text { provides opportunities for } \\
\text { mastery experience }\end{array}$ \\
\hline $\begin{array}{l}\text { nourish existing } \text { ideal } \text { L2 } \\
\text { self beliefs? }\end{array}$ & $\begin{array}{l}\text { (indirectly) may enhance } \\
\text { self-efficacy and intrinsic } \\
\text { motivation } \\
\text { (directly) may offer } \\
\text { literature tutors as } \\
\text { linguistic role models } \\
\text { (directly) may counteract } \\
\text { beliefs about year abroad }\end{array}$ & $\begin{array}{l}\text { (indirectly) may enhance } \\
\text { self-efficacy and intrinsic } \\
\text { motivation } \\
\text { (directly) may offer peers } \\
\text { as linguistic role models } \\
\text { (directly) may counteract } \\
\text { beliefs about year abroad }\end{array}$ \\
\hline
\end{tabular}

\subsubsection{Addressing the Exo-Level: Content and Language Integrated Learning}

At both universities investigated in this study, English is used as the only medium of instruction and communication for the study of academic "content", i.e. the literature, 
linguistics or culture of the target-language. While students are expected to read set texts in the German original, they write their assignments and essays on the set texts in English only. In other words, German is not used as a medium of learning, and the content covered in literature, linguistics or culture seminars/tutorials and lectures is transmitted through English only. This separation between language teaching and academic content is not unique to the two universities in question (Coleman, 2005). In the following, I will align myself to those voices advocating a stronger use of the target-language as a medium of learning and teaching in modern foreign language degree courses (Barrette, Paesani and Vinall, 2010, Coleman, 2005, McBride, 2000, McBride, 2003), and draw on literature on content and language integrated learning (CLIL).

CLIL is here defined as a dual-focused approach in which the target language is used for the learning and teaching of both content and language (Coyle, Hood and Marsh, 2010). While the underpinnings of CLIL cannot be covered here in detail (see, for instance, Coyle, 2007, Coyle et al., 2010, Gajo, 2007, Ruiz De Zarobe and Jimenez Catalan, 2009), this section provides a scrutiny of empirical evidence that may be useful to evaluate the potential of CLIL for the present research context. Note that in contrast to traditional CLIL approaches where an academic subject as, for instance, mathematics, is taught through the target language, the academic content usually associated with a modern foreign language degree course is already strongly intertwined with language learning. A stronger use of the target language for teaching and communicating about the literature, linguistics and culture of the target-language is therefore doubly advisable.

However, Coleman (2005:6) summarises the various arguments brought forward for maintaining the current situation in the UK. The view that "intellectually challenging material is beyond learners' competence in the target language" is worth 
highlighting in this respect, as it has almost taken on the function of a thoughtterminating cliché. It would go beyond the scope of this section to comment on the complex picture painted by existing research evidence, but in summary one can note that studies looking at performance evidence tentatively suggest that CLIL has a positive effect on language performance and is not necessarily detrimental to content learning (Admiraal, Westhoff and de Bot, 2006, Campo, Grisaleña and Alonso, 2007, Cenoz, 2009, Jimenez Catalan and Ruiz De Zarobe, 2009, Lasagabaster, 2008, Ruiz De Zarobe, 2008, Sylvén, 2004).

For instance, it appeared that lack of vocabulary was a problem when reading and writing in the foreign language (Chapter 6, sections 6.2.1.1.1 and 6.2.1.1.2), and CLIL may be one way of improving students' vocabulary: a longitudinal study conducted over a period of two years based on 363 secondary school students in Sweden suggests that CLIL may have a positive effect on students' vocabulary acquisition (Sylvén, 2004). Although the CLIL learners already had a slightly better vocabulary to start with, the observed effect was substantial over the course of the years. Note that extracurricular reading also had a significant positive effect on lexical richness, which underlines the importance of reading in the target language as stressed in this study. A related study involving 130 female students in sixth grade of primary education similarly found a positive effect of CLIL on receptive vocabulary (Jimenez Catalan and Ruiz De Zarobe, 2009). It is worth mentioning that in both studies CLIL students had more exposure to the language than non-CLIL students, that is, it is not yet clear whether CLIL or the fact that it is usually associated with more contact time, causes the positive effect. However, given that CLIL would also bring about more contact time in the present research context, one may hypothesise that students' vocabulary may be improved by introducing CLIL. 
An interesting evaluation of Dutch bilingual secondary schools drawing on a total sample of 1305 students suggests that CLIL enhances also other aspects of language proficiency such as oral proficiency, pronunciation and reading comprehension (Admiraal et al., 2006). While this study failed to detect a positive effect on receptive word knowledge, it is important to point out that no negative effect of CLIL on the content knowledge of subjects taught through the foreign language could be found.

A study involving 198 secondary students in the Basque country learning English through CLIL even showed a positive relationship between content gain and CLIL instruction in addition to a positive correlations with writing and speaking skills (Lasagabaster, 2008). The authors concede that given the voluntary basis of the CLIL programme this result could also be a reflection of the learner profile of those students, i.e. more motivated or more gifted students may be more likely to opt for the CLIL programme. On the other hand, no effect of sociocultural status could be found, suggesting that CLIL programmes may indeed be a successful teaching approach for a wide range of students. A longitudinal study set in the Basque country involving 161 school students revealed a positive long-term relationship between CLIL and pronunciation, grammar, fluency (Ruiz De Zarobe, 2008). Interestingly, CLIL also seemed to have a positive effect on content knowledge. Cenoz (2009) reports on the longitudinal data obtained from a study carried out over a one-year period by the Basque Institute for Research and Evaluation in Education (ISEI-IVEI, 2007). The study looked at 229 secondary students who were taught through the medium of English. Similarly to the study mentioned above, the CLIL groups did not only perform better in listening, reading, writing, speaking and grammar tasks but also in content knowledge. The qualitative data revealed that teachers felt that their students paid better attention to difficult concepts, which may explain this result. 
Admittedly, results are not yet conclusive and more research is certainly warranted for the specific university context. Airey (2004) has already criticised the lack of empirical evidence regarding the effectiveness of CLIL in the higher education sector, and not much seems to have changed in recent years. (Note that an ongoing research project in the Italian higher education sector is described by Costa and Coleman, 2010, however, at the point of writing, there have not been any results regarding the effectiveness of CLIL in this setting.). It also needs to be highlighted that in evaluations of CLIL school programmes it is difficult to control for all variables. As Coyle et al. (2010) rightly point out, future studies need to ensure methodological rigour by sample matching and by addressing the units of measurement of language proficiency and content knowledge. However, it is fair to say that the picture painted by existing research on CLIL is not a bleak one at all.

On the basis of the present study, one may suggest the following reasons for developing a curriculum which includes - at least to some extent - the teaching of literature, linguistics and culture through target language German.

Firstly, this approach would respond to students' strong wish for language proficiency, as observed in the quantitative analysis, and to students' wish for more opportunities to practise their German, as expressed in the interviews. One may note in this context that eight of the twelve interviewees had expected the language degree course to be taught entirely or partly in German (see Final Reflections, section 8.2.4).

Secondly, self-determination theory stresses the importance of stimulating and challenging material which is personally relevant to students (Deci and Ryan, 1985, Ryan, 1982). CLIL may be one way to counteract students' perception of language exercises as intellectually unchallenging and to make learning material more relevant to students. The interviews suggest that linking writing exercises to content modules/ papers on literature/ linguistics/ culture is particularly desired by students (Chapter 6, 
section 6.2.1.1.2). In this respect it may be worth pointing out a study conducted by Preece (2009) on a cohort of first-year BME students from a wide range of linguistic and social backgrounds taking part in an English writing programme at a London University. The framework outlined by the author for approaching academic writing practice at university level seems useful also in the present context. Her in-depth ethnographic exploration of students' experience revealed that students objected to writing courses, as they perceived them to be remedial. She argues that more attention has to be paid to the process-like nature of writing and its role in deepening the understanding of a subject, and proposes to embed writing practice firmly in curricular content to counteract lack of engagement in supplementary writing classes. A special emphasis is set on developing disciplinary-specific writing expertise. One may hypothesise that in this context, too, embedding writing practice in disciplinary content and developing writing expertise for linguistic/literature/ and culture studies may make students perceive writing activities as more age-appropriate and more intellectually challenging.

Thirdly, increased contact time through CLIL provides more opportunities for practice. At present, students have few opportunities to practise their language skills. One may recall in this respect that students were particularly dissatisfied with grammar tuition: apart from the problems related to the lecture format (section 8.2.3), one may also hypothesise that grammar lectures (imparted in the first year only) do not enable students to process the information acquired in them, given that students have few opportunities to actually use the grammatical structures taught. It might be worth highlighting Klapper's (2005) reflections on the teaching of German grammar at university level in this context. This author maintains that more attention has to be paid to the developmental character of grammatical competence at university level. The curriculum has to respond to this procedural character by providing opportunities 
to practise structures in meaning-based activities. Coyle et al. point out that CLIL is precisely useful because it offers more language input but also more opportunities for language practice, which is needed to support this developmental process:

The language classroom is essential for the learner to understand the "nuts" and "bolts" of language - the grammar, vocabulary and so on. But [...] learners need time to build things with these "nuts" and "bolts" - to put into practice the things which they see in theory on paper. CLIL can offer learners [...] a natural situation for language development. (2010:11)

In this respect, CLIL may provide students with the opportunity for mastering the learning task as stressed in self-efficacy theory and self-determination theory, or, to stay with the metaphor, the opportunity to put the "nuts and bolts" of language to use.

Fourthly, students commented on their close relationship to their literature tutors, which was in contrast to their somewhat indifferent relationship with their language tutors (Chapter 6, section 6.2.1.5). Given that literature tutors also seemed to function as academic role models, one may hypothesise that by using German more as a means of communication in seminars/ tutorials on literature/ linguistics/ culture, literature tutors could also take on the role of linguistic role models. Note that literature staff at the two universities are mostly native speakers of English with a high level of proficiency, whereas language tutors are mostly native speakers of German. With reference to existing studies (Murphey and Arao, 2001, Yashima, 2009) I have suggested that students may find it more difficult to identify with native speakers of the language than with non-native speakers (see Chapter 6, section 6.2.3.1).

Lastly, one may assume that, in particular at University A, content and language integrated learning would enhance the perceived value placed on language learning within the framework of the curriculum. Coleman's (2005:6) hypothesises that "the separation of target-language use and content teaching through English must tend to devalue the former". I would like to draw attention to one of Jane's statements 
to illustrate this point. This may also serve as a reminder that lack of engagement in language learning can also be a reflection of the perceived value placed on language learning by the curriculum:

It's odd because the focus of tutes [tutorials] is on the literature side and the analysis and it's almost like sometimes the important side of learning a language is given a backseat. And that mentality can be reflected in how you view your work and how you structure your time. Like, I would leave myself a lot more time to do a literature essay and spend much more time going to the library and getting books than I would on a [...] summary and [language assignments] (Jane)

One the basis of this study, one may well hypothesise that CLIL could be a way of tackling students' gradually forming belief that language learning should take place during the year abroad and that proficiency can only be reached by living in the targetcountry (see Chapter 6, section 6.2.3.3).

Naturally, moving genuinely towards more content and language integrated learning in the German degree course would imply more than using German as the vehicle language to teach and learn about German literature, linguistics and culture. CLIL would involve the close cooperation between language and literature staff to define language and content specific goals, moreover, questions of curricular coherence and alignment of curriculum, content, teaching methods and, particularly, assessment would have to be addressed (for CLIL in particular see Coyle et al., 2010, for alignment in the curriculum in the higher education sector in general see Biggs, 1999 and Knight, 2001).

Last but not least, a close cooperation between modern language departments and applied linguistics/ educational departments is crucial not only to make researchinformed choices about how and to what extent CLIL is implemented on a curricular level but also to train staff in the new teaching methodology required by CLIL. 


\subsubsection{Addressing the Exo-Level: Supporting Autonomous Forms of Language Learning}

Students criticised the amount of language tuition they received at their respective universities. At the same time, it appeared that the actual language tuition they received had a negative impact on their motivation. One may recall in this respect that fewer students were available for the follow-up questionnaire, as fewer students attended language classes towards the end of the academic year. I have argued that a sub-optimal level of challenge in language classes contributed to the paradoxical situation where students complained about the scarcity of language tuition, but started to avoid existing language classes or began engaging less fully with language tasks. Recall in this respect that students' general effort for language learning also decreases over the course of the year.

It would go beyond the scope and the focus of this thesis to explore all of the issues emerging from the interviews, but I would like to draw attention to the observed problems from a broader motivational angle: unless tuition is delivered in one-on-one or one-on-two tutorials (as in the case of literature tutorials at University A), language seminars/ classes have to meet the needs of many. Providing the heterogeneous student body with optimal challenging tasks for each individual is therefore difficult. Developing learner autonomy and supporting autonomous forms of language learning is therefore a promising avenue to pursue. Following Benson (2001), supporting learner autonomy is here meant developing students' capacity to control their own learning.

From a motivational perspective such an approach is beneficial, as it supports the need for autonomy postulated by self-determination theory (e.g. Deci and Ryan, 1985, see Chapter 3, section 3.4.1). Given that supporting autonomy in the language learning process has been advocated for some time (an overview is provided by Benson, 2009), that it has been related to other important applied linguistic areas such 
as strategy research (e.g. Macaro, 1997, 2008b), and that the interface between motivational research and learner autonomy has convincingly been explored elsewhere (e.g. Ushioda, 1996b), I will in what follows focus on the question of how more autonomous forms of language learning can be implemented in these specific institutional settings.

Taking the lessons from self-determination theory on board implies supporting students' need for autonomy from the very beginning of their course and developing their self-directed learning abilities. This is important not only from a motivational and educational point of view but also when considering the increasing financial constraints under which universities are forced to operate. It cannot imply, however, that language input is reduced from three weekly language classes, leaving the students to make use (or not) of the language learning opportunities offered by language centres. In other words, caution needs also to be taken so that autonomous forms of language learning are not seen as synonymous with self-instruction and therefore as a (cheap and therefore attractive) substitute for language tuition. In the following discussion, supporting student autonomy in language learning is not meant as an alternative to existing language tuition: rather, I will argue for more guidance and a better integration of autonomous forms of language learning into the curricular framework.

It is curious to note that the interviewees did not report making much use of the various opportunities offered by universities to pursue language learning on their own; time constraints, I would argue, are not the only reasons for lethargy in this area. When asked about the language learning pursued - apart from set homework and set reading texts - interviewees mentioned the occasional activity such as watching a German film or reading a newspaper, but none of the interviewees at University A had used the language institute for private studies or the computer assisted language 
learning programme (CALL) in place for private study. At University B, the picture was slightly different, as three interviewees reported having used the CALL programme. Students at University B reported that they were encouraged by various tutors (language and literature tutors) to engage with these programmes in their spare time, demonstrating the importance all departmental staff place on promoting them. However, although the picture therefore looked somewhat better at University B than at University A, interviewees at University B did not seem to use CALL facilities to the desired extent. As Lindsey explained:

We're encouraged to do a lot on our own. We have computer programs that they want us to use.

Do you use them?

Occasionally when I have time but usually I don't during the week.

The low mean values for students' engagement with reading anything other than set texts, grammar exercises and independent vocabulary learning were also apparent in the quantitative data. It therefore seems that first-year students may need to be supported better to make full use of the language facilities in place. They have also to come to see these facilities as relevant and meaningful for pursuing their personal learning aims. Moreover, given the many other compulsory learning tasks during the first year, autonomous forms of learning need to be firmly embedded in the first-year curriculum and be linked to other components of the course. As Thompson (2005:151) states:

Successful integration depends on a small number of key elements. The most important of these [...] is the relevance of CALL materials to learners' needs. Unless they are directed towards specific modules in specific programs, which relate in a meaningful way to their general language learning programme, learners will soon dismiss CALL as a waste of time.

A very good example of a way of gearing the level of challenge through autonomous forms of language learning appears to be the student-led group project in 
place at University B. To recall, students felt the project to be very motivating and reported to put a lot of effort into it. Apart from the project's motivational potential learner autonomy and learner choice stimulates intrinsic motivation (e.g. Moller et al., 2006, Zuckerman et al., 1978) - three aspects in particular appeared to have contributed to the success of the programme.

Firstly, it was supported by a language tutor at all stages. The literature stresses the importance of teaching staff for accompanying students on their way towards autonomy; teachers or mentors need to provide guidance where needed and to facilitate negotiation (Dam, 2003, 2009, Wright, 2005).

Secondly, the language project was integrated within the wider curricular framework and thematically linked to the media module. This aspect is particularly important as Wright (2005:140) points out:

Of the $[\ldots]$ elements that make for successful independent learning, it is the integration of independent learning with the curriculum that is the most important. A curriculum that values the development of learner independence [...] is most likely to be successful. If not, only the most dedicated of learners will prioritize it and succeed in taking charge of their own learning.

Thirdly, and this aspect should not be overlooked given the many competing assignments in the first year, the importance of student-led project was given emphasis in that it counted towards the overall assessment of the year.

Drawing on the insights of the present study, an introductory programme appears to be needed which provides learner choice and thereby the background for students' exploration and differentiation of their intrinsic interest. Note, for instance, that at both universities the first year poses the lowest level of learner choice within the three years of the taught degree. Self-directed learning opportunities and studentled group projects have great potential but they need to be firmly embedded in the curriculum and thematically linked to other modules/ papers, supported by teaching 
staff and need to count towards the overall assessment. According to one of Peter's statements from the final interview, more guidance is needed to help students to work out what they need to help their learning.

In retrospect, what were the biggest challenges in the first year for you?

I'd say self-directed learning. You know, there's not a lot of contact time, so making sure you organise your time and you keeping up on the computers. There's, like, grammar exercises that you should do an hour a week. Just keeping, like, doing things outside of it. So, you know, reading newspapers, reading books extra to your course. Just keeping up with the work, which you might not have done at A level because a lot of the time, you know, you would get set work for home every week. Whereas here you are obviously expected to do a bit more, which, you know, you have to work out what's gonna benefit you the most. You have to sort of work out what you need to do to help you learn.

Given the importance students placed on gaining speaking proficiency in particular, tandem projects may be another useful supplement to traditional tuition. In their original form, face-to-face tandem sessions usually involve two native speakers of different languages conversing with each other alternately in one or the other language, although the new media have brought about different forms of web-based tandem projects (Appel and Mullen, 2000). In order to for all tandem projects to work, pedagogical and organisational support is needed (Esch, 1996, Lewis, 2005), e.g. projects need to be coordinated and learner counselling needs to accompany students in the learning process. Organisational challenges in the UK include finding enough interested native speakers, a problem that may not easily be overcome. On the basis of the present study, one may hypothesise that discussion groups in the target-language across different year groups may also be effective from a motivational perspective. In Chapter 6 it was suggested that learners find it easier to identify with other L2 users (Murphey and Arao, 2001, Yashima, 2009, see section 6.2.3.1). Samuel's story also pointed towards the healthy motivational effect of engaging in debates with students across different year groups in the target-language (Chapter 6, section 6.2.1.3). More 
mature students may act as linguistic role models but may also be better able to help first-year students in overcoming embarrassment when speaking in German.

Last but not least, if oral skills are not assessed towards the end of the year as in the case of University A (see Chapter 2, section 2.1), a signal is given that improving oral skills is to happen during the year abroad only, which may counteract the success of the suggestions made.

\subsubsection{Addressing the Micro- and Meso-Levels}

There are various ways in which contextual factors on the micro and meso levels may improve the current situation and strengthen language work in a bottom-up approach. It will become clear in the following that stimulating exchange and encouraging close cooperation between staff in the modern foreign language departments and staff in the educational/ applied linguistics department is particularly important towards this end in order to better inform teaching practice by research evidence.

\section{Scaffolding}

On the basis of this study, issues to be considered by teachers may include a better scaffolding of first-year tasks. For instance, the data suggest that students perceived reading German literature as particularly challenging and that some students resorted to reading the translated versions instead of the original versions. At the same time, reading had an invigorating motivational effect once students rose to the challenge and read the literature in the original version (Chapter 6, section 6.2.1.1.1). These findings tie in with a larger study involving 601 undergraduate students studying various modern foreign languages including German: Gallagher-Brett (2006) found that reading was perceived by students as very difficult, in particular by first-year students, and lack of vocabulary was identified as the main source of difficulty. At the same time, students saw reading as a positive challenge and felt it to be gratifying once accomplished. Implications for the present context may include adjusting the reading 
syllabus by progressing from less complex to more complex reading tasks to enable students to read the original versions instead of translated version of set texts. A stronger focus on widening vocabulary in the target language should also be high on universities' agendas to better support first-year students' reading process.

Scaffolding measures may also address grammar tuition. The interviews suggested that the lecture format for grammar tuition may not be suitable for first-year students, as it failed to engage students actively (Chapter 6, section 6.2.1.1.3). Replacing grammar lectures with grammar workshops may be one way of avoiding students' passivity. One may also consider spreading these grammar workshops over the first two years of the degree course to give students time to process the information acquired (see section 8.2.2).

\section{Feedback}

The data suggests that feedback is important for first year students' continued motivation to engage with language learning. The data also revealed that students want feedback on their written work, and that the absence of feedback is detrimental to students' motivation, as it negatively affects students' self-efficacy for writing. Recall that there is evidence to suggest that feedback can influence intrinsic motivation (e.g. Ryan, 1982, see also Chapter 3, section 3.4.1) and self-efficacy beliefs (e.g. Britner and Pajares, 2006, see also Chapter 3, section 3.4.2). The importance of informational feedback for intrinsic motivation and the detrimental effect of controlling feedback were discussed in Chapter 3. Particularly harmful is feedback which implies incompetence, a point similarly stressed by self-determination theory (Deci and Ryan, 1985). In addition, it is worth pointing out the hypothesis that existing self-efficacy beliefs may be more easily destroyed by negative feedback than restored by positive feedback (Bandura, 1997). The data suggest that there is a need to implement insights generated by motivational research and to raise university 
teachers' awareness in this respect. In particular, the data suggest that too little attention was paid to informing students about progress, to increasing students' confidence for writing tasks, and to giving clear suggestions how to improve performance.

In addition, the data indicates that there is still a gap between institutional practice and recommended practice based on existing SLA research, especially in the area of error correction. In Chapter 6 I pointed out that researchers differ in their views regarding error correction, and I aligned myself to those strands of research suggesting systematic and selective in-depth feedback (e.g. Ferris, 2003, see also Chapter 6, section 6.2.1.4). However, researchers would concur that the teaching practice of just correcting all language mistakes is not effective. This strongly supports the argument for strengthening the cooperation and enhancing the flow of information between applied linguistics departments and modern foreign language departments as mentioned above.

Nourishing the ideal L2 self

Research on possible selves in language learning is still in its preliminary phase and there are no developed pedagogical guidelines to follow. Preliminary suggestions as to how to nourish students' ideal L2 selves have been made (Dörnyei, 2008, 2009b), among them suggestions for the exploration of imagery enhancement techniques in the classroom. While this appears an exciting avenue to pursue, it needs to be pointed out that a more thorough didactic scrutiny is needed to determine how imagery enhancement techniques as explored in therapeutic settings (e.g. Berkovits, 2005, Hall, Hall, Stradling and Young, 2006) can be used in the foreign language classroom in general, and in university settings in particular.

For this particular setting, I would suggest that offering theatre workshops in the target-language as extra-curricular activities may be particularly useful: the 
potential of theatre in education in general (e.g. Jackson, 1993) and for language learning in particular (e.g. Bräuer, 2002, Mattevi, 2005, Neglia, 1982) has already attracted quite some attention. Given that acting is a popular spare-time activity of modern foreign languages students at these universities and also given that acting involves the use of mental imagery and requires identification with characters, one may hypothesise that using drama for language learning may also be a useful tool for stimulating these students' ideal L2 self.

In addition, career orientation meetings organised by the university as mentioned by Susan (Chapter 6, 6.2.4), are also important, as they make students aware of the different careers open to language students. Inviting successful alumni to these events may then help students visualise themselves in these careers.

Moreover, short trips to target countries during the first year are beneficial not only to maintaining fluency but also to keeping the vision of becoming a future multilingual alive. The German society at University B offered two trips to Germany during the first year, an initiative which was well received by students.

At the same time, the data suggest that students' emerging beliefs about language learning have to be addressed. On the one hand, students have to become aware that language learning is a slow process, in order to avoid the inevitable motivational low if the perceived progress does not live up to the individual's expectations. On the other hand, it is counterproductive to give students the feeling that language proficiency can be reached only through living abroad. It impairs first year students' ability to visualise themselves as proficient in the language, and negatively affects their engagement with language learning within the framework of the curriculum. Literature and language staff share the responsibility for transmitting the importance of regular engagement with language learning for reaching proficiency in the target language. They also share the responsibility for pointing out the benefits 
of using autonomous forms of language learning for achieving proficiency in the particular area the individual places most importance on.

Last but not least, I would argue that in view of possible pedagogical suggestions for this specific setting, it is particularly important to bear in mind that possible selves only unfold a self-regulatory function when linked to the present (Oyserman, 2008).

Imagining becoming a doctor can only improve the chances of actually becoming one [...] if this distal possible self is linked to current steps and more proximal possible selves (Oyserman and James, 2009:391)

I have already commented on measures to increase self-efficacy and intrinsic motivation, which, as the study suggests, are important for nourishing the ideal L2 self. Furthermore, general insights derived from motivational research on how to maintain and protect motivation (e.g. Dörnyei, 2001, Schunk et al., 2008) should not be ignored: in particular, the setting of proximal subgoals is an important measure to provide clear and accessible proximal steps towards reaching the more distant ideal L2 self.

\subsubsection{Final Reflection: Adjusting Students' Expectations}

The important factor of students' expectations of higher education was not explicitly tackled in this study, as it lay outside the theoretical focus; yet models of learning in higher education stress that students' presage, which comprises their experience with learning prior to university as well as their expectations of learning in higher education, influences the way they engage with their subject at university level (Prosser and Trigwell, 1999).

The present study similarly suggests that the influence of expectations on motivation needs to be acknowledged. Of course, interviewees had differing expectations of studying German at university level: some of them had detailed 
expectations, while others had only vague ideas of what to expect. Some of students' expectations were directly linked to the university they were studying at or were concerned with the particular language degree offered at that university:

At University A, I thought it would be quite intense, which appealed to me, quite challenging. [...] There was a conception of University A before that it did not place so much emphasis on language work, they have been criticised for it, because they put pretty much emphasis on the literature side, but now it is 50/50, they balanced it up, and my intentions ultimately were to improve rapidly in the language. (Jebedee)

Other expectations were linked to general beliefs about language learning in higher education or to teaching in higher education. As one of Heather's statements illustrates, future motivational studies may also investigate students' existing conceptions of learning and teaching in this respect:

Yeah. I kind of expected that it'd be sort of, I dunno, in small groups or something and you'd be, I dunno, taught it all and explained it all, I think.

Note that in the higher education context, much attention has been paid to students' conceptions of learning, which are hypothesised to be linked to the quality of engagement in the learning process (see the proposed surface vs. deep learning distinction in Marton and Saljo, 1976).

In many instances, a particular disparity between expectations and the actual language learning environment was felt by the interviewee to influence enjoyment and motivation negatively.

It would be beyond the scope of this discussion to explore all interviewees' expectations in depth. However, it needs to be pointed out that in the areas discussed above - language activities, progress, regular practice and feedback - interviewees on the whole had very high expectations. Interviewees had expected a) university language classes to be more effective than school classes b) progress to be much more rapid than at school c) to practise their German every day and d) to receive high 
grades and the kind of supportive feedback they received at school. In addition, as mentioned above, eight of the twelve interviewees had expected the language degree course to be different from what it was, e.g. they expected the course to be taught entirely or partly in German. Students' motivational changes could be linked to dissatisfaction in this respect, particularly towards the beginning and middle of the academic year

On the one hand, the points raised imply that creating realistic learner beliefs is an issue that has to be addressed. More knowledge about the slow nature of L2 learning and expected progress could help in this respect. On the other hand, one cannot help but notice the discrepancy between the advertisement of the degree course in the prospectus and website and the actual set-up (see Chapter 2), in particular at University A. I would argue that this dimension may also be taken into account when explaining why interviewees from University A appeared to undergo stronger motivational turbulence than interviewees from University B.

Therefore, either the organisation of degree courses has to change or attention has to be paid to making sure that official websites, modern foreign language prospectuses and German open days are explicit about both the amount and the nature of the language teaching students are to receive during the first year. Specifying language learning aims for the first year course and making these aims transparent to students from the very beginning is important not only to avoid building up wrong expectations but also to help students to better judge their progress within these parameters. In this regard, students' apparent confusion with the marking system in place at the two universities is also worth mentioning. I will not question the marking system itself, although students' comments may indeed tap into wider problems inherent in the marking schemes, but the data indicate that the marking schemes have to become more transparent to students, a recommendation also highlighted in the 
literature on teaching in higher education (Ashwin, 2003, 2006). This, last but not least, is an important point in adjusting students' expectations to the new learning environment. 


\section{References}

Admiraal, W., Westhoff, G. \& de Bot, K. (2006) Evaluation of bilingual secondary education in the Netherlands: students' language proficiency in English. Educational Research and Evaluation: An International Journal on Theory and Practice, 12, 75-93.

Agresti, A. \& Finlay, B. (1997) Statistical methods for the social sciences. Upper Saddle River, NJ, Pearson Education.

Airey, J. (2004) Can you teach it in English? Aspects of the language choice debate in Swedish higher education. IN Wilkinson, R. (Ed.) Integrating content and language; meeting the challenge of a multilingual higher education. Maastrich, Maastrich University.

Al-Shehri, A. (2009) Motivation and vision: the relationship between the ideal L2 self, imagination and visual style. IN Dörnyei, Z. \& Ushioda, E. (Eds.) Motivation, language identity and the L2 self. Bristol, Multilingual Matters.

Ames, C. (1992) Achievement goals and the classroom motivational climate. IN Schunk, D. \& Meed, J. (Eds.) Research and Motivation in Education. New York, Academic Press.

Ames, C. \& Archer, J. (1988) Achievement goals in the classroom: students' learning strategies and motivation processes. Journal of Educational Psychology, 80, 260-267.

Anderman, E. M., Anderman, L. H. \& Griesinger, T. (1999) The relation of present and possible academic selves during early adolescence to grade point average and achievement goals. The Elementary School Journal, 100, 3-17.

Anderman, E. M. \& Wolters, C. A. (2006) Goals, value, and affect. IN Alexander, P. \& Winne, P. H. (Eds.) Handbook of Educational Psychology. 2nd ed. Mahwah, NJ, Lawrence Erlbaum.

Anderson, R., Manoogian, S. T. \& Reznick, J. S. (1976) The undermining and enhancing of intrinsic motivation in preschool children. Journal of Personality and Social Psychology, 34, 915-922.

Appel, C. \& Mullen, T. (2000) Pedagogical considerations for a web-based tandem language learning environment. Computers \& Education, 34, 291-308.

Arts and Humanities Research Council (2006) AHRC Review of research in modern languages. Available from: http://www.llas.ac.uk/projects/2498. Accessed 14 June 2009.

Ashwin, P. (2003) Can traditional final examinations assess and encourage in-depth understandings of disciplinary knowledge? A literature review. Oxford, Institute for the Advancement of University Learning, University of Oxford.

Ashwin, P. (2005) Variation in students' experiences of the 'oxford tutorial'. Higher Education 50, 631-644.

Ashwin, P. (Ed.) (2006) Changing higher education: the development of learning and teaching. New York, Taylor \& Francis.

Atkinson, J. (1964) An introduction to motivation. Princeton, Van Nostrand.

Bandura, A. (1969) Principles of behavior modification. New York, Holt, Rinehart and Winston.

Bandura, A. (1986) Social foundations of thought and action: a social cognitive theory. Englewood Cliffs, N.J., Prentice-Hall.

Bandura, A. (1995) Self-efficacy in changing societies. Cambridge, Cambridge University Press.

Bandura, A. (1997) Self-efficacy: the exercise of control. New York, W.H. Freeman.

Bandura, A. \& Cervone, D. (1986) Differential engagement of self-reactive influences in cognitive motivation. Organizational Behavior and Human Decision Processes, 38, 92-113. 
Barling, J. \& Abel, M. (1983) Self-efficacy beliefs and tennis performance. Cognitive Therapy and Research, 7, 265-272.

Barling, J. \& Beattie, R. (1983) Self-efficacy beliefs and sales performance. Journal of Organizational Behavior Management, 5, 41-51.

Barrette, C. M., Paesani, K. \& Vinall, K. (2010) Toward an integrated curriculum: maximizing the use of target language literature. Foreign Language Annals, 43, 216230.

Bassi, M., Steca, P., Fave, A. \& Caprara, G. (2007) Academic self-efficacy beliefs and quality of experience in learning. Journal of Youth and Adolescence, 36, 301-312.

Bavendiek, U. (2008) Keeping up the good work: the motivational profiles of students in secondary and higher education. The Higher Education Academy LLAS, Languages, Linguistics Area Studies. Available from: http://www.llas.ac.uk/resources/paper/3229. Accessed 1 February 2009.

Beal, S. J. \& Crockett, L. J. (2010) Adolescents' occupational and educational aspirations and expectations: Links to high school activities and adult educational attainment. Developmental Psychology, 46, 258-265.

Beauchamp, M. R., Bray, S. R. \& Albinson, J. G. (2002) Pre-competition imagery, selfefficacy and performance in collegiate golfers. Journal of Sports Sciences, 20, 697 705.

Becker, L. J. (1978) Joint effect of feedback and goal setting on performance: A field study of residential energy conservation. Journal of Applied Psychology, 63, 428-433.

Benson, P. (2000) Teaching and researching learner autonomy in language learning. London, Longman.

Benson, P. (2001) Teaching and Researching Autonomy in Language Learning. Harlow, Longman.

Benson, P. (2009) Making sense of autonomy in language learning. IN Pemberton, R., Toogood, S. \& Barfield, A. (Eds.) Maintaining Control: Autonomy and Language Learning. Hong Kong, Hong Kong University Press.

BERA (2004) Revised Ethical Guidelines for Educational Research. BERA. Available from: http://www.bera.ac.uk/publications/guides.php. Accessed 12 December 2009.

Berkovits, S. (2005) Guided imagery with children: successful techniques to improve school performance and self-esteem. Duluth, MN, Whole Person Associates.

Biggs, J. (1999) Teaching for quality learning at university. Buckingham, SRHE\&Open University Press.

Bitchener, J. \& Knoch, U. (2009) The contribution of written corrective feedback to language development: a ten month investigation. Applied Linguistics, 31, 193-214.

Blumenfeld, P. C., Pintrich, P. R. \& Hamilton, L. V. (1986) Children's concepts of ability, effort, and conduct. American Educational Research Journal, 23, 95-104.

Boggiano, A. K., Main, D. S. \& Katz, P. A. (1988) Children's preference for challenge: the role of perceived competence and control. Journal of Personality and Social Psychology, 54, 134-141.

Bräuer, G. (2002) Body and language. Intercultural learning through drama. Westport, CT, Ablex Publishing.

Britner, S. L. \& Pajares, F. (2006) Sources of science self-efficacy beliefs of middle school students. Journal of Research in Science Teaching, 43, 485-499.

Brophy, J. (2009) Connecting with the big picture. Educational Psychologist, 44, 147-157.

Brown, H. D. (1981) Affective factors in second language learning. IN Alatis, J. E., Altman, H. B. \& Alatis, P. M. (Eds.) The second language classroom: directions for the eighties. New York, Oxford University Press. 
Brown, H. D. (1990) M \& Ms for language classrooms? Another look at motivation. IN Alatis, J. E. (Ed.) Georgetown University round table on language and linguistics. Washington, DC, Georgetown University Press.

Brown, H. D. (1994) Teaching by principles. Englewood Cliffs, NJ, Prentice Hall.

Bruton, A. (2009a) Designing research into the effects of grammar correction in L2 writing: Not so straightforward. Journal of Second Language Writing, 18, 136-140.

Bruton, A. (2009b) Improving accuracy is not the only reason for writing, and even if it were... System, 37, 600-613.

Bruton, A. (2010) Another reply to Truscott on error correction: improved situated designs over statistics. System, In Press, Corrected Proof.

Bryman, A. (2008) Social research methods. Oxford, Oxford University Press.

Busse, V. \& Meyer-Beining, J. (2007) Re-aligning Paper I. Unpublished DipLaTHE Dissertation; Oxford Learning Institute.

Busse, V. \& Williams, M. (2010) Why German? Motivation of students studying German at English universities. Language Learning Journal, 38, 67-85.

Campo, A., Grisaleña, J. \& Alonso, E. (2007) Trilingual students in secondary school: a new reality. Bilbao, Basque Institute of Educational Evaluation and Research.

Catell, R. B. (1966) The scree test for number of factors. Multivariate Behavioral Research, $1,245-276$.

Cenoz, J. (2009) Towards multilingual education: Basque educational research from an international perspective. Bristol, Multilingual Matters.

Chambers, G. N. (1999) Motivating language learners. Clevedon, Multilingual Matters.

Chandler, J. (2003) The efficacy of various kinds of error feedback for improvement in the accuracy and fluency of L2 student writing. Journal of Second Language Writing, 12, 267-296.

Chemers, M. M., Hu, L.-t. \& Garcia, B. F. (2001) Academic self-efficacy and first year college student performance and adjustment. Journal of Educational Psychology, 93, $55-64$.

Cheng, Y. (2002) Factors associated with foreign language anxiety. Foreign Language Annals, 35, 647-656.

Clément, R. (1980) Ethnicity, contact and communicative competence in a second language. IN Gildes, H., Robinson, W. P. \& Smith, P. M. (Eds.) Language: Social psychological perspectives. Oxford, Pergamon.

Cohen, J. (1988) Statistical Power Analysis for the Behavioral Sciences. New York, Psychology Press, Taylor \& Francis Group.

Coleman, J. A. (1996) Studying languages: a survey of British and European students: the proficiency, background, attitudes and motivations of students of foreign languages in the United Kingdom and Europe. London, CILT.

Coleman, J. A. (1997) Residence abroad within language study. Language Teaching, 30, 120.

Coleman, J. A. (2001) What is residence abroad for? Intercultural competence and the linguistic, cultural, academic, personal and professional objectives of students' residence abroad. IN Di Napoli, R., Polezzi, L. \& King, A. (Eds.) Fuzzy Boundaries? Reflections on modern languages and the humanities. London, CILT.

Coleman, J. A. (2005) Modern Languages as a university discipline. IN Coleman, J. A. \& Klapper, J. (Eds.) Effective learning \& teaching in Modern Languages. London, Routledge.

Coleman, J. A. (2009) Why the British do not learn languages: myths and motivation in the United Kingdom. Language Learning Journal, 37, 111-127. 
Coleman, J. A., Galaczi, A. \& Astruc, L. (2007) Motivation of UK school pupils towards foreign languages: A large-scale survey at Key Stage 3. Language Learning Journal, $35,245-280$.

Costa, F. \& Coleman, J. A. (2010) Integrating content and language in higher education in Italy: ongoing research. International CLIL Research Journal, 1, 19-29.

Covington, M. V. (1976) Self-worth and school learning. New York, Holt, Rinehart \& Winston.

Covington, M. V. (1992) Making the grade: A self-worth perspective on motivation and school reform. New York, Cambridge University Press.

Covington, M. V. (1998) The will to learn: A guide to motivating young people. New York, Cambridge University Press.

Coyle, D. (2007) Content and language integrated learning: towards a connected research agenda for CLIL pedagogies. International Journal of Bilingual Education and Bilingualism, 10, 543-562.

Coyle, D., Hood, P. \& Marsh, D. (2010) CLIL: Content and Language Integrated Learning. Cambridge, Cambridge University Press.

Creswell, J. W. (2007) Qualitative inquiry and research design: choosing among five approaches Thousand Oaks, CA, Sage.

Creswell, J. W. (2008) Research design: Qualitative, quantitative and mixed methods approaches. Thousand Oaks, CA, Sage.

Creswell, J. W. \& Plano Clark, V. L. (2007) Designing and conducting mixed methods research. Thousand Oaks, CA, Sage.

Crookes, G. \& Schmidt, R. W. (1991) Motivation: Reopening the Research Agenda. Language Learning, 41, 469-512.

Cross, S. \& Markus, H. (1991) Possible selves across the life span. Human Development, 34, 230-255.

Crotty, M. (1998) The foundations of social research : meaning and perspective in the research process. London, Sage.

Csikszentmihalyi, M. \& Nakamura, J. (1989) The dynamics of intrinsic motivation: A study of adolesents. IN Ames, C. \& Ames, R. (Eds.) Research on motivation in education. San Diego, CA, Academic Press.

Csizér, K. \& Kormos, J. (2009) Learning Experiences, Selves and Motivated Learning Behaviour: A Comparative Analysis of Structural Models for Hungarian Secondary and University Learners of English. IN Dörnyei, Z. \& Ushioda, E. (Eds.) Motivation, Langauge Identity and the L2 Self. Bristol, Multilingual Matters.

Csizér, K. \& Lukács, G. (2009) The comparative analysis of motivation, attitudes and selves: The case of English and German in Hungary. System, 38, 1-13.

Cumming, J. (2008) Investigating the relationship between exercise imagery, leisure-time exercise behavior, and self-efficacy. Journal of Applied Sport Psychology, 20, 184198.

Cumming, J. \& Hall, C. (2002) Deliberate imagery practice: the development of imagery skills in competitive athletes. Journal of Sports Sciences, 20, 137-145.

Cumming, J., Hall, C., Harwood, C. \& Gammage, K. (2002) Motivational orientations and imagery use: a goal profiling analysis. Journal of Sports Sciences, 20, 127-136.

Czsikszentmihalyi, M., Rathunde, K. \& Whalen, S. (1993) Talented teenagers. Cambridge, UK, Cambridge University Press.

Dam, L. (2003) Developing learner autonomy: the teacher's responsibility. IN Little, D., Ridley, J. \& Ushioda, E. (Eds.) Learner autonomy in the foreign language classroom: teacher, learner, curriculum and assessment. Dublin, Authentik. 
Dam, L. (2009) The use of logbooks - a tool for developing learner autonomy. IN Pemberton, R., Toogood, S. \& Barfield, A. (Eds.) Maintaining control. Autonomy and language learning. Hong Kong, University Press.

Danner, F. W. \& Lonky, E. (1981) A cognitive-developmental approach to the effects of rewards on intrinsic motivaiton. Child Development, 52, 1043-1052.

Datta, L. (2006) Paradigm wars: a basis for peaceful coexistence and beyond. IN Bryman, A. (Ed.) Mixed methods. London, Sage.

Davies, A. \& Elder, C. (2004) The handbook of applied linguistics. Malden, MA ; Oxford, Blackwell.

Deci, E. L. (1971) Effects of externally mediated rewards on intrinsic motivation. Journal of Personality and Social Psychology, 8, 105-115.

Deci, E. L. (1972) Intrinsic motivation, extrinsic reinforcement, and inequity. Journal of Personality and Social Psychology, 22, 113-120.

Deci, E. L., Koestner, R. \& Ryan, R. M. (1999) A meta-analytic review of experiments examining the effects of extrinsic rewards on intrinsic motivation. Psychological Bulletin, 125, 627-668.

Deci, E. L. \& Moller, C. (2005) The concept of competence: a starting place for understanding intrinsic motivation and self-determined extrinsic motivation. IN Elliot, A. J. \& Dweck, C. S. (Eds.) Handbook of competence and motivation. London, Guilford Press.

Deci, E. L. \& Ryan, R. M. (1985) Intrinsic motivation and self-determination in human behaviour. New York, Plenum.

Deci, E. L. \& Ryan, R. M. (2008) Self-determination theory: A macrotheory of human motivation, development, and health. Canadian Psychology/Psychologie canadienne, 49, 182-185.

Denzin, N. K. \& Lincoln, Y. S. (2005) Introduction: the discipline and practice of qualitative research. IN Denzin, N. K. \& Lincoln, Y. S. (Eds.) The sage handbook of qualitative research. Thousand Oaks, CA, Sage.

Diener, C. I. \& Dweck, C. S. (1978) An analysis of learned helplessness: Continuous changes in performance, strategy, and achievement cognitions following failure. Journal of Personality and Social Psychology, 36, 451-462.

Diener, C. I. \& Dweck, C. S. (1980) An analysis of learned helplessness: II. The processing of success. Journal of Personality and Social Psychology, 39, 940-952.

Dörnyei, Z. (1994a) Motivation and motivating in the foreign language classroom. Modern Language Journal, 78, 273-284.

Dörnyei, Z. (1998) Motivation in second and foreign language learning. Language Teaching, 31, 117-135.

Dörnyei, Z. (2001) Teaching and researching motivation. Harlow, Longman.

Dörnyei, Z. (2001b) New themes and approaches in L2 motivation research. Annual Review of Applied Linguistics, 21, 43-59.

Dörnyei, Z. (2005) The psychology of the language learner: individual differences in second language acquisition. Mahwah, NJ, Lawrence Erlbaum.

Dörnyei, Z. (2007) Research methods in applied linguistics. quantitative, qualitative and mixed methodologies. Oxford, Oxford University Press.

Dörnyei, Z. (2008) New ways of motivating foreign language learners: Generating visions. Links, 38, 3-4.

Dörnyei, Z. (2009a) Individual differences: interplay of learner characteristics and learning environment. Language Learning, 59, 230-248.

Dörnyei, Z. (2009b) The L2 motivational self system. IN Dörnyei, Z. \& Ushioda, E. (Eds.) Motivation, language identity and the L2 self. Bristol, Multilingual Matters. 
Dörnyei, Z. (2009c) The L2 Motivational Self System. IN Dörnyei, Z. \& Ushioda, E. (Eds.) Motivation, Language Identity and the L2 self. Bristol, Multilingual Matters.

Dörnyei, Z. (2009d) The psychology of second language acquisition. Oxford, Oxford University Press.

Dörnyei, Z. (2010) The relationship between language aptitude and language learning motivation: Individual differences from a dynamic systems perspective. IN Macaro, E. (Ed.) Continuum companion to second language acquisition. London, Continuum.

Dörnyei, Z., Csizér, K. \& Németh, N. (2006) Motivation, language attitudes and globalisation: a Hungarian perspective. Clevendon, Multilingual Matters.

Dörnyei, Z. \& Ottó, I. (1998) Motivation in action: A process model of L2 motivation. Working Papers in Applied Linguistics (Thames Valley University, London), 4, 43-69.

Dörnyei, Z. \& Skehan, P. (2003) Individual differences in second language learning: Advances in theory, research, and applications. IN Dörnyei, Z. (Ed.) Attitudes, orientations and motivation in language learning. Amsterdam, John Benjamins.

Dörnyei, Z. \& Ushioda, E. (Eds.) (2009) Motivation, language identity and the L2 self. Bristol, Multilingual Matters.

Dunkel, C. \& Kerpelman, J. (2006) Possible selves: theory, research and applications. New York, Nova Science.

Dunkel, C. S. \& Anthis, K. S. (2001) The role of possible selves in identity formation: a short-term longitudinal study. Journal of Adolescence, 24, 765-776.

Dunlap, W. P., Cortina, J. M., Vaslow, J. B. \& Burke, M. J. (1996) Meta-analysis of experiments with matched groups or repeated measures designs. Psychological Methods, 1, 170-177.

Dweck, C. S. (2000) Self-theories. New York, Psychology Press.

Dweck, C. S. \& Leggett, E. L. (1988) A social-cognitive approach to motivation and personality. Psychological Review, 95, pp. 256-273.

Eccles, J. S. (1984) Grade-related changes in the school environment: effects on achievement motivation. IN Nicholls, J. (Ed.) Advances in motivation and achievement: The development of achievement motivation. Greenwich, CT, JAI Press.

Eccles, J. S., Adler, T. F., Futterman, R., Goff, S. B., Kaczala, C. M., Meece, J. L. \& Midgley, C. (1983) Expectancies, values and academic behaviors. IN Spence, J. T. (Ed.) Achievement and achievement motivation. San Francisco, W.H. Freeman.

Eccles, J. S., Wigfield, A., Flanagan, C. A., Miller, C., Reuman, D. A. \& Yee, D. (1989) Selfconcepts, domain values, and self-esteem: relations and changes at early adolescence. Journal of Personality, 57, 283-310.

Ehrman, M. (1996) An exploration of adult language learner motivation, self-efficacy, and anxiety. IN Oxford, R. (Ed.) Language learning motivation: pathways to the new century. Honolulu, HI, Second Language Teaching \& Curriculum Centre, University of Hawai'i.

Eid, J. (2008) Determining the relationship between visual style, imagination, the L2 motivational self system, and the motivation to learn English, French and Italian. University of Nottingham, School of English Studies.

Erez, M. (1977) Feedback: A necessary condition for the goal setting-performance relationship. Journal of Applied Psychology, 62, 624-627.

Erikson, M. G. (2007) The meaning of the future: toward a more specific definition of possible selves. Review of General Psychology, 11, 348-358.

Ertl, H., Hayward, G., Wright, S., Edwards, A., Lunt, I., Mills, D. \& Yu, K. (2008) The student learning experience in higher education. Literature review report for the higher education academy: higher education academy. Available from: http://www.heacademy.ac.uk/assets/York/documents/ERTL_HAYWARD_LR.pdf. Accessed 1 May 2010. 
Esch, E. (1996) Promoting learner autonomy: criteria for the selection of appropriate methods. IN Pemberton, R., Li, E. S. L., Or, W. W. F. \& Pierson, H. D. (Eds.) Taking control, autonomy in language learning. Hong Kong, Hong Kong University Press.

Fantuzoo, J. \& McWayne, C. (2002) The relationship between peer-play interactions in the family context and dimensions of school readiness for low-income preschool children. Journal of Educational Psychology, 94, 79-87.

Fazey, D. M. A. \& Fazey, J. A. (2001) The potential for autonomy in learning: perceptions of competence, motivation and locus of control in first-year undergraduate students. Studies in Higher Education, 26, 345-361.

Ferris, D. (1999) The case for grammar correction in L2 writing classes: a response to Truscott (1996). Journal of Second Language Writing, 8, 1-11.

Ferris, D. (2002) Treatment of error in second language student writing. Michigan, MI, University of Michigan Press.

Ferris, D. (2003) Response to student writing. Implications for second language students. London, Lawrence Erlbaum Associates.

Ferris, D. \& Roberts, B. (2001) Error feedback in L2 writing classes: How explicit does it need to be? Journal of Second Language Writing, 10, 161-184.

Ferris, D. R. (2004) The "grammar correction" debate in L2 writing: where are we, and where do we go from here? (and what do we do in the meantime ...?). Journal of Second Language Writing, 13, 49-62.

Field, A. (2005) Discovering statistics using SPSS. London, Sage.

Field, A. (2009) Discovering statistics using SPSS (3rd edition). London, Sage.

Fisher, C. D. (1978) The effects of personal control, competence, and extrinsic reward systems on intrinsic motivation. Organizational Behavior and Human Performance, 21, 273-288.

Fisher, L. (2001) Modern foreign languages recruitment post-16: the pupils' perspective. Language Learning Journal, 23, 33-40.

Freud, S. (1934) A general introduction to psychoanalysis. New York, Washington Square.

Gajo, L. (2007) Linguistic knowledge and subject knowledge: how does bilingualism contribute to subject development? International Journal of Bilingual Education and Bilingualism, 10, 563-581.

Gallagher-Brett, A. (2004) Seven hundred reasons for studying languages. Southampton, Subject Centre for Languages, Linguistics and Area Studies. Available from: http://www.llas.ac.uk/700reasons/orderform.html. Accessed 10 May 2010.

Gallagher-Brett, A. (2006) Hard going but worth it: a snapshot of attitudes to reading among language undergraduates. Southhampton, Subject Centre for Languages, Linguistics and Area Studies. Available from: http://www.llas.ac.uk/publications/reading.html. Accessed 11 October 2010.

Garcia, J. N. \& De Caso, A. M. (2006) Changes in writing self-efficacy and writing products and processes through specific training in the self-efficacy beliefs of students with learning disabilities. Learning Disabilities: A Contemporary Journal, 4, 1-27.

Gardner, R. C. (1979) Social psychological aspects of second language acquisition. IN Giles, H. \& R.St.Clair (Eds.) Language and social psychology. Oxford, Blackwell.

Gardner, R. C. (1985) Social psychology and second language learning : the role of attitudes and motivation. London, E. Arnold.

Gardner, R. C. (2001) Integrative motivation and second language acquisition IN Dörnyei, Z. \& Schmidt, R. (Eds.) Motivation and second language acquisition. Honolulu, HI, University of Hawai'i Press

Gardner, R. C. \& Lambert, W. E. (1972) Attitudes and motivation in second language learning. Rowley, MA, Newbury House 
Gardner, R. C., Tremblay, P. F. \& Masgoret, A.-M. (1997) Towards a full model of second language learning: an empirical investigation. The Modern Language Journal, 81, 344-362.

Gibbs, G. \& Simpson, C. (2004) Conditions under which assessment supports students' learning. Learning and Teaching in Higher Education, 1, 1-31.

Godding, P. R. \& Glasgow, R. E. (1985) Self-efficacy and outcome expectations as predictors of controlled smoking status. Cognitive Therapy and Research, 9, 583-590.

Godsland, S. (2010) Monolingual England. The crisis in foreign language enrollments from elementary schools through college. Hispania, 93, 113-118.

Goldberg, E. \& Noels, K. A. (2006) Motivation, ethnic identity and post-secondary education language choices of of graduates of intensive French language programs. Canadian Modern Language Review, 62, 423-447.

Gorad, S. \& Taylor, C. (2004) Combining methods in educational and social research. Maidenhead, UK, Open University Press.

Gorham, J. \& Christophel, D. M. (1992) Students' perceptions of teacher behaviors as motivating and demotivating factors in college classes. Communication Quarterly, 40, 239-252.

Gould, D., Damarjian, N. \& Greenleaf, C. (2002) Imagery training for peak performance. IN Van Raalte, J. L. \& Brewer, B. W. (Eds.) Exploring sport and exercise psychology. 2 ed. Washington, DC, American Psychological Association.

Graham, S. (2007) Learner strategies and self-efficacy: making the connection. Language Learning Journal, 35, 81-93.

Graham, S. \& Weiner, B. (1996) Theories and principles of motivation. IN Berliner, D. C. \& Calfee, R. C. (Eds.) Handbook of educational psychology. New York, Simon \& Schuster Macmillan.

Gregg, M. \& Hall, C. (2006) Measurement of motivational imagery abilities in sport. Journal of Sports Sciences, 24, 961-971.

Gurtner, J.-L., Monnard, I. \& Genoud, P. A. (2001) Towards a multilayer model of context and its impact on motivation. IN Volet, S. \& Järvelä, S. (Eds.) Motivation in learning contexts: theoretical advances and methodological implications. Amsterdam, Pergamon.

Hall, C. R., Munroe-Chandler, K. J., Cumming, J., Law, B., Ramsey, R. \& Murphy, L. (2009) Imagery and observational learning use and their relationship to sport confidence. Journal of Sports Sciences, 27, 327-337.

Hall, E., Hall, C., Stradling, E. \& Young, D. (2006) Guided imagery: creative interventions in counselling and psychotherapy. London, Sage.

Hammersley, M. (1992) What's wrong with ethnography? Methodological explorations. London, Routledge.

Hammersley, M. (2006) The Paradigm Wars: Reports From the Front. IN Bryman, A. (Ed.) Mixed Methods. London, Sage.

Hampton, N. Z. (1998) Sources of Academic Self-Efficacy Scale: An assessment tool for rehabilitation counselors. Rehabilitation Counseling Bulletin, 41, 260-277.

Harter, S. (1974) Pleasure derived by children from cognitive challenge and mastery. Child Development, 45, 661-669.

Harter, S. (1990) Causes, correlates, and the functional role of self-worth: A life-span perspective. IN Suls, J. \& Greenwald, A. C. (Eds.) Competence considered. New Haven, CT, Yale University Press.

Harter, S. (1999) The construction of the self: A developmental perspective. New York, Guildford Press. 
Hartshorn, K. J., Evans, N. W., Merrill, P. F., Sudweeks, R. R., Strong-Krause, D. \& Anderson, N. J. (2010) Effects of dynamic corrective feedback on ESL writing accuracy. TESOL Quarterly, 44, 84-109.

Harvey, L., Drew, S. \& Smith, M. (2006) The first-year experience: a review of literature for the Higher Education Academy. York, Higher Education Academy.

Hattie, J. A. (1987) Identifying the salient facets of a model of student learning: a synthesis of meta-analyses. International Journal of Educational Research, 11, 187-212.

Heider, F. (1958) The psychology of interpersonal relations. New York, Wiley.

Higgins, E. T. (1987) Self-discrepancy: a theory relating self and affect. Psychological Review, 94, 319-340.

Higgins, R., Hartley, P. \& Skelton, A. (2001) Getting the message across: the problem of communicating assessment feedback. Teaching in Higher Education, 6, 269-274.

Hirsh, D. \& Nation, P. (1992) What vocabulary size is needed to read unsimplified texts for pleasure? Reading in a Foreign Language, 8, 698-696.

Horwitz, E. K. (1988) The beliefs about language learning of beginning university foreign language students. The Modern Language Journal, 72, 283-294.

Huberman, A. M. \& Miles, M. B. (1994) Data managment and analysis methods. IN Denzin, N. K. \& Lincoln, Y. S. (Eds.) Handbook of qualitative research. London, Sage.

Hull, C. L. (1951) Essentials of behavior. New Haven, CT, Yale University Press.

Hunt, J. M. (1966) The epigenesis of intrinsic motivation and early cognitive learning. IN Haber, R. N. (Ed.) Current research in motivation. New York, Holt, Rinehart\&Winston.

Hunt, J. M. (1975) Implications of sequestional order and hierarchy in early psychological development. IN Friedlander, B. Z., Sterritt, G. M. \& Kirk, G. E. (Eds.) Exceptional infant. New York, Brunner/Mazel.

Jackson, T. (Ed.) (1993) Learning through theatre. New perspectives on theatre in education. London, Routledge.

Järvelä, S. (2001) Shifting research on motivation and cognition to an integrated approach on learning and motivation in context. IN Volet, S. \& Järvelä, S. (Eds.) Motivation in learning contexts. Theoretical advances and methodological implications. Amsterdam, Pergamon.

Järvelä, S., Volet, S. \& Järvenoja, H. (2010) Research on motivation in collaborative learning: moving beyond the cognitive-situative divide and combining individual and social processes. Educational Psychologist, 45, 15-27.

Jimenez Catalan, R. M. \& Ruiz De Zarobe, Y. (2009) The receptive vocabulary of EFL learners in two instructional contexts: CLIL versus non-CLIL instruction. IN Ruiz De Zarobe, Y. \& Jimenez Catalan, R. M. (Eds.) Content and language integrated learning: evidence from research in europe. Bristol, Multilingual Matters.

Johnson, D. (1992) Approaches to research in second language learning. New York, Longman.

Johnson, R. B. \& Onwuegbuzie, A. J. (2004) Mixed methods research: a research paradigm whose time has come. Educational Researcher, 33, 14-27.

Kaiser, H. F. (1970) A second-generation little jiffy. Psychometrika, 35, 401-415.

Kemp, S. R. \& Lang, B. (2005) Literature and language teaching in modern languages with particular reference to German and French. Learning Institute. Oxford, University of Oxford.

Kern, R. G. (1995) Students' and teachers' beliefs about language learning. Foreign Language Annals, 28, 71-92.

Kerpelman, J. (2006) Using Q methodology to study possible selves. IN Dunkel, C. \& Kerpelman, J. (Eds.) Possible selves: theory, research and application. New York, Nova Science. 
Kerpelman, J., Eryigit, S. \& Stephens, C. (2008) African American adolescents' future education orientation: associations with self-efficacy, ethnic identity, and perceived parental support. Journal of Youth and Adolescence, 37, 997-1008.

Kerpelman, J. L. \& Pittman, J. F. (2001) The instability of possible selves: identity processes within late adolescents' close peer relationships. Journal of Adolescence, 24, 491-512.

Kinnear, P. R. \& Gray, C. D. (2008) SPSS 15 made simple. Hove, UK, Psychology Press.

Kitsantas, A. \& Zimmerman, B. (2009) College students' homework and academic achievement: The mediating role of self-regulatory beliefs. Metacognition and Learning, 4, 97-110.

Klapper, J. (2005) Teaching grammar. IN Coleman, J. A. \& Klapper, J. (Eds.) Effective learning \& teaching in Modern Languages. London, Routledge.

Klassen, R. (2004) A cross-cultural investigation of the efficacy beliefs of South Asian immigrant and Anglo non-immigrant early adolescents. Journal of Educational Psychology, 96, 731-742.

Knight, P. T. (2001) Complexity and curriculum: a process approach to curriculum-making. Teaching in Higher Education, 6, 369-381.

Koch, S. (1956) Behavior as "intrinsically" regulated: work notes toward a pre-theory of phenomena called "motivational". IN Jones, M. R. (Ed.) Nebraska symposium on motivation. Lincoln, University of Nebraska Press.

Koestner, R., Ryan, R. M., Bernieri, F. \& Holt, K. (1984) Setting limits on children's behavior: The differential effects of controlling versus informational syles on intrinsic motivation and creativity. Journal of Personality and Social Psychology, 52, 233-248.

Lafford, B. (2007) Second language acquisition reconceptualized? The impact of Firth and Wagner (1997). (Focus Issue) Modern Language Journal, 91, 733-942.

Lamb, T. \& Reinders, H. (Eds.) (2008) Learner and teacher autonomy: concepts, realities and responses. Amsterdam, John Benjamins Publishing Company.

Larsen-Freeman, D. (1997) Chaos/ complexity science and second language acquisition. Applied Linguistics, 18, 141-165.

Larsen-Freeman, D. \& Cameron, L. (2008) Complex systems and applied linguistics. Oxford, Oxford University Press.

Larsen-Freeman, D. \& Long, M. (1991) An introduction to second language research. New York, Longman.

Lasagabaster, D. (2008) Foreign language competence in content and language integrated courses. The Open Applied Linguistics Journal, 1, 31-42.

Latham, G. P. \& Locke, E. A. (2006) Enhancing the benefits and overcoming the pitfalls of goal setting. Organizational Dynamics, 35, 332-340.

Latham, G. P. \& Locke, E. A. (2007) New developments in and directions for goal-setting research. European Psychologist, 12, 290-300.

Lea, M. \& Street, B. V. (2000) Student writing and staff feedback in higher education: an academic literacies approach. IN Lea, M. \& Stierer, B. (Eds.) Student writing in higher education: new contexts. Buckingham, SRHE and Open University Press.

Lent, R. W., Brown, S. D., Gover, M. R. \& Nijer, S. K. (1996) Cognitive assessment of the sources of mathematics self-efficacy: a thought-listing analysis. Journal of Career Assessment, 4, 33-46.

Lent, R. W., Brown, S. D. \& Larkin, K. C. (1984) Relation of self-efficacy expectations to academic achievement and persistence. Journal of Counseling Psychology, 31, 63-84.

Lewis, T. (2005) The effective learning of languages in tandem. IN Coleman, J. A. \& Klapper, J. (Eds.) Effective Learning \& Teaching in Modern Languages. London, Routledge. 
Lincoln, Y. S. \& Guba, E. G. (2000) Paradigmatic controversies, contradictions, and emerging confluences. IN Denzin, N. K. \& Lincoln, Y. S. (Eds.) Handbook of qualitative research. 2 ed. Thousand Oaks, Sage.

Lindseth, M. U. (2010) The development of oral proficiency during a semester in Germany. Foreign Language Annals, 43, 246-268.

Linnenbrink, E. A. \& Pintrich, P. R. (2000) Multiple pathways to learning and achievement. The role of goal orientation in fostering adaptive motivation, affect and cognition. Intrinsic and extrinsic motivation: The search for optimal motivation and performance San Diego, Academic Press.

Llanes, À. \& Muñoz, C. (2009) A short stay abroad: Does it make a difference? System, 37 , 353-365.

Locke, E. A. (1996) Motivation through conscious goal-setting. Applied \& Preventive Psychology, 5, 117-124.

Locke, E. A. \& Latham, G. P. (1990) A theory of goal setting \& task performance. Englewood Cliffs, NJ, Prentice Hall.

Luenberg, D. G. (1979) Introduction to dynamic systems: theory, models, and applications. New York, John Wiley and Sons, Inc.

Macaro, E. (1997) Target language, collaborative learning and autonomy. Clevedon, Multilingual Matters.

Macaro, E. (2008a) The decline in language learning in England: Getting the facts right and getting real. Language Learning Journal, 36, 101-108.

Macaro, E. (2008b) The shifting dimensions of language learning autonomy. IN Lamb, T. \& Reinders, H. (Eds.) Learner and teacher autonomy: concepts, realities and responses. Amsterdam, John Benjamins Publishing Company.

Macaro, E. \& Wingate, U. (2004) From sixth form to university: motivation and transition among high-achieving state-school language students. Oxford Review of Education, 30, 467-489.

MacIntyre, P. D. (1995) How does anxiety affect second language learning? A reply to Sparks and Ganschow. Modern Language Journal, 79, 1-32.

MacIntyre, P. D., Baker, S. C., Clément, R. \& Donovan, L. A. (2002a) Motivation, anxiety and emotion in second language acquisition. IN Robinson, P. (Ed.) Individual differences and instructed language learning Amsterdam, John Benjamins.

MacIntyre, P. D., Baker, S. C., Clément, R. \& Donovan, L. A. (2002b) Sex and age effects on willingness to communicate, anxiety, perceived competence, and L2 motivation among junior high school French immersion students. Language Learning, 52, 537564.

MacIntyre, P. D., Clément, R., Dörnyei, Z. \& Noels, K. A. (1998) Conceptualizing willingness to communicate in a L2: A situated model of confidence and affiliation. Modern Language Journal, 82, 545-562.

MacIntyre, P. D. \& Gardner, R. C. (1994) The subtle effects of language anxiety on cognitive processing in the second language. Language Learning, 44, 283-305.

MacIntyre, P. D., Mackinnon, S. P. \& Clément, R. (2009) The baby, the bathwater, and the future of language learning motivation research. IN Dörnyei, Z. \& Ushioda, E. (Eds.) Motivation, language identity and the L2 self. Bristol, Multilingual Matters.

MacIntyre, P. D., MacMaster, K. \& Baker, S. C. (2001) The convergence of multiple models of motivation for second language learning: Gardner, Pintrich, Kuhl, and Mccroskey. IN Dörnyei, Z. \& Schmidt, R. (Eds.) Motivation and second language acquisition. Manoa, HI, University of Hawai'i Press.

Magogwe, J. M. \& Oliver, R. (2007) The relationship between language learning strategies, proficiency, age and self-efficacy beliefs: A study of language learners in Botswana. System, 35, 338-352. 
Manning, M. M. \& Wright, T. L. (1983) Self-efficacy expectancies, outcome expectancies, and the persistence of pain control in childbirth. Journal of Personality and Social Psychology, 45, 421-431.

Manzi, C., Vignoles, V. L. \& Regalia, C. (2010) Accommodating a new identity: Possible selves, identity change and well-being across two life-transitions. European Journal of Social Psychology, 40, 970-984.

Markus, H. \& Nurius, P. (1986) Possible selves. American Psychologist, 41, 954-969.

Markus, H. \& Nurius, P. (1987) Possible selves: the interface between motivation and the self-concept. IN Yardley, K. \& Honess, T. (Eds.) Self and identity: psychosocial perspectives. Chichester, UK, Wiley.

Markus, H. \& Ruvolo, A. P. (1989) Possible selves: personalized representations of goals. IN Pervin, L. A. (Ed.) Goal concepts in personality and social psychology. Hillsdale, NJ, Lawrence Erlbaum.

Marsh, H. W. (1986) The self-serving effect in academic attributions: its relation to academic achievement and self-concept. Journal of Educational Psychology, 78, 190-200.

Marsh, H. W. (1987) The big-fish-little-pond effect on academic self-concept. Journal of Educational Psychology, 79, 280-295.

Marsh, H. W. (1989) Age and sex effects in multiple dimensions of self-concept: Preadolescence to early adulthood. Journal of Educational Psychology, 81, 417-430.

Marsh, H. W. (1993) Academic self-concept: theory, measurement, and research. IN Suls, J. (Ed.) Psychological perspectives on the self. Hillsdale, NJ, Lawrence Erlbaum.

Marsh, H. W. (2006) Self-concept theory, measurement and research into practice : the role of self-concept in educational psychology. Leicester, British Psychological Society.

Marsh, H. W. \& Hau, K.-T. (2003) Big-fish-little-pond effect on academic self-concept: a cross-cultural (26-country) test of the negative effects of academically selective schools. American Psychologist, 58, 364-376.

Marsh, H. W., Kong, C.-K. \& Hau, K.-T. (2000) Longitudinal multilevel models of the bigfish-little-pond effect on academic self-concept: counterbalancing contrast and reflected-glory effects in Hong Kong schools. Journal of Personality and Social Psychology, 78, 337-349.

Marsh, H. W., Seaton, M., Trautwein, U., Lüdtke, O., Hau, K. T., O'Mara, A. J. \& Craven, R. G. (2008) The big-fish-little-pond-effect stands up to critical scrutiny: implications for theory, methodology, and future research. Educational Psychology Review, 20, 319350.

Marton, F. \& Saljo, R. (1976) On qualitative differences in learning: 1 - outcome and process.

Matsui, T., Matsui, K. \& Ohnishi, R. (1990) Mechanisms underlying math self-efficacy learning of college students. Journal of Vocational Behavior, 37, 225-238.

Mattevi, Y. (2005) Using drama in the classroom: The educational values of theatre in second language acquisition. Unpublished Doctoral Thesis. State University of New York. Available from: http://gradworks.umi.com/31/89/3189394.html. Accessed 1 October 2010.

Maxwell, J. A. (1992) Understanding the validity in qualitative research. Harvard Educational Review, 62, 279-300.

McBride, N. (2000) Studying culture in language degrees in the UK: target culture - target language? A survey. IN Mcbridge, N. \& Seago, K. (Eds.) Target culture - target language? London, AFLS/CILT.

McBride, N. (2003) The role of the target language in cultural studies: two surveys in UK universities. Language, Culture and Curriculum, 16, 298-311.

McDonough, S. H. (1986) Psychology in foreign language teaching. London, George Allen \& Unwin. 
McInnis, C. (2001) Researching the first year experience: where to from here? Higher Education Research \& Development, 20, 105-114.

McIntosh, C. N., Cameron, N. \& Noels, K. A. (2004) Self-determined motivation for language learning: The role of need for cognition and language learning strategies. Zeitschrift für Interkulturellen Fremdsprachenunterricht 9, 19-47.

McQuillan, J. (2000) Attribution theory and second language acquisition: an empirical analysis. AAAL Conference (paper presented). Vancouver.

Meara, P. (1994) The year abroad and its effects. Language Learning Journal, 10, 32-38.

Meece, J. L., Wigfield, A. \& Eccles, J. S. (1990) Predictors of math anxiety and its influence on young adolescents' course enrollment intentions and performance in mathematics. Journal of Educational Psychology, 82, 60-70.

Menard, S. (2002) Longitudinal research. Thousand Oaks, CA, Sage.

Mertens, D. M. (2009) Research and evaluation in education and psychology: Integrating diversity with quantitative, qualitative and mixed methods. Thousand Oaks, CA, Sage.

Miles, M. B. \& Huberman, A. M. (1994) Qualitative data analysis: an expanded sourcebook. London, Sage.

Millar, J., Davis, S., Rollin, H. \& Spiro, J. (2010) Engaging feedback. Brookes eJournal of learning and teaching. Avaiable from: http://bejlt.brookes.ac.uk/article/engaging feedback/. Accessed 16 June 2010.

Miller, G. A., Galanter, E. \& Pribram, K. H. (1960) Plans and structure of behavior. New York, Holt, Rinehart \& Winston.

Mills, N. (2004) Self-efficacy of college intermediate French students: relation to motivation, achievement and proficiency. French and Educational Studies. Unpublished Doctoral Thesis; Emory University.

Mills, N., Pajares, F. \& Herron, C. (2007) Self-efficacy of college intermediate French students: relation to achievement and motivation. Language Learning, 57, 417-442.

Moller, A. C., Deci, E. L. \& Ryan, R. M. (2006) Choice and ego-depletion: the moderating role of autonomy. Personality and Social Psychology Bulletin, 32, 1024-1036.

Moore, W. G. (1968) The tutorial system and its future. Oxford, Pergamon Press.

Mori, S. (2002) Redefining motivation to read in a foreign language. Reading in a Foreign Language, 14, 91-110.

Mori, Y. (1999) Epistemological beliefs and language learning beliefs: what do language learners believe about their learning? Language Learning, 49, 377-415.

Morse, J. M. (2003) Principles of mixed methods and multimethod research design. IN Tashakkori, A. \& Teddlie, C. (Eds.) Handbook of mixed methods in social and behavioural research. Thousand Oaks, CA, Sage.

Multon, K. D., Brown, S. D. \& Lent, R. W. (1991) Relation of self-efficacy beliefs to academic outcomes: A meta-analytic investigation. Journal of Counseling Psychology, 38, 30-38.

Munroe-Chandler, K., Hall, C. \& Fishburne, G. (2008) Playing with confidence: the relationship between imagery use and self-confidence and self-efficacy in youth soccer players. Journal of Sports Sciences, 1539-1546.

Murphey, T. \& Arao, H. (2001) Reported belief changes through near peer role modeling. TESL-EJ, 5. Available from: http://tesl-ej.org/ej19/a1.html. Accessed 11 June 2010.

Neglia, E. G. (1982) A dramatic approach to theatre and language learning. Canadian Modern Language Review, 38, 694-98.

Noels, K. A. (2001a) Learning Spanish as a second language: learners' orientations and perceptions of their teachers' communication style. Language Learning, 51, 107-144.

Noels, K. A. (2001b) New orientations in language learning motivation: towards a model of intrinsic, extrinsic and integrative orientations and motivation. IN Dörnyei, Z. \& 
Schmidt, R. (Eds.) Motivation and second language acquisition. Honolulu, HI, University of Hawai'i.

Noels, K. A. (2003) Learning Spanish as a second language: Learners' orientations and perceptions of their teachers' communication style. IN Dörnyei, Z. (Ed.) Attitudes, orientations, and motivations in language learning Oxford, Blackwell.

Noels, K. A. (2009) The internalisation of language learning into the self and social identity. IN Dörnyei, Z. \& Ushioda, E. (Eds.) Motivation, language identity and the L2 self. Bristol, Multilingual Matters.

Noels, K. A., Clément, R. \& Pelletier, L. G. (1999) Perceptions of teachers' communicative style and students' intrinsic and extrinsic motivation. The Modern Language Journal, 83, 23-34.

Noels, K. A., Pelletier, L. G., Clément, R. \& Vallerand, R. J. (2000) Why are you learning a second language? Motivational orientations and self-determination theory. Language Learning, 50, 57-85.

Nowak, A., Vallacher, R. R. \& Zochowski, M. (2005) The emergence of personality: dynamic foundations of individual variation. Developmental Review, 25, 351-385.

Owens, R. G. (1981) Organizational behaviour in education. Englewood Cliffs; London, Prentice-Hall.

Oxford, R. (1994) Where are we with language learning motivation? Modern Languages Journal, 7, 512-514.

Oxford, R. \& Shearin, J. (1994) Language learning motivation: expanding the theoretical framework. The Modern Language Journal, 78, 12-28.

Oxford, R. L. (1996) Language learning motivation: pathways to the new century. Manoa, HI, Second Language Teaching \& Curriculum Center, University of Hawai'i.

Oxford, R. L. \& Shearin, J. (1996) Language Learning Motivation in a New Key. IN Oxford, R. L. (Ed.) Language Learning Motivation: Pathways to the New Century. Manoa; Hawaii, University of Hawaii.

Oyserman, D. (2008) Possible selves: identity-based motivation and school success. IN Marsh, H. W., Craven, R. G. \& Mcinerney, D. (Eds.) Self-processes, learning and enabling human potential dynamic new approaches. Charlotte, NC, Information Age Publishing.

Oyserman, D., Bybee, D. \& Terry, K. (2006) Possible selves and academic outcomes: how and when possible selves impel action. Journal of Personality and Social Psychology, 91, 188-204.

Oyserman, D. \& James, L. (2009) Possible selves: from content to process. IN Markman, K. D., Klein, W. M. P. \& Suhr, J. A. (Eds.) Handbook of imagination and mental simulation. New York, Psychology Press.

Oyserman, D. \& Markus, H. R. (1990) Possible selves and delinquency. Journal of Personality and Social Psychology, 59, 112-125.

Oyserman, D., Terry, K. \& Bybee, D. (2002) A possible selves intervention to enhance school involvement. Journal of Adolescence, 25, 313-326.

Pajares, F. (1994) Self-Efficacy Beliefs in Academic Settings. Review of Educational Research, 66, 543-578.

Pajares, F. (1996) Self-efficacy beliefs in academic settings. Review of Educational Research, 66, 543-578.

Pajares, F. \& Schunk, D. (2002) Self and self-belief in psychology and education: a historical perspective. IN Aronson, J. (Ed.) Improving academic achievement. New York, Academic Press.

Palfreyman, D. e. (2001) The oxford tutorial: 'Thanks, you taught me how to think'. Oxford, Oxford Centre for Higher Education Policy Studies. 
Pallant, J. (2005) SPSS survival manual. A step by step guide to data analysis using SPSS version 12. New York, Open University Press.

Pemberton, R., Toogood, S. \& Barfield, A. (Eds.) (2009) Maintaining control: autonomy and language learning. Hong Kong, Hong Kong University Press.

Pintrich, P. R. (2000a) Educational psychology at the millenium: a look back and a look forward. Educational Psychologist, 35, 221-226.

Pintrich, P. R. (2000b) The role of goal orientation in self-regulated learning. IN Boekaerts, M., Pintrich, P. R. \& Zeidner, M. (Eds.) Handbook of self-regulation. San Diego, CA, Academic Press.

Pintrich, P. R. (2003a) A motivational science perspective on the role of student motivation in learning and teaching contexts. Journal of Educational Psychology, 95, 667-686.

Pintrich, P. R. \& DeGroot, E. V. (1990) Motivational and self-regulated learning components of classroom academic performance. Journal of Educational Psychology, 82, 33-40.

Pintrich, P. R. \& Garcia, T. (1991) Student goal orientation and self-regulation in the college classroom. IN M.Maehr \& P.R.Pintrich (Eds.) Advances in motivation and achievement: goals and self-regulatory processes. Greenwich, CT, JAI Press.

Pintrich, P. R. \& Schrauben, B. (1992) Students' motivational beliefs and their cognitive engagement in classroom academic tasks. IN Schunk, D. \& Meece, J. (Eds.) Student perceptions in the classroom: Causes and consequences. Hillsdale, NJ, Erlbaum.

Preece, S. (2009) Posh talk. Language and identity in higher education. Basingstoke, Palgrave Macmillan.

Prosser, M. \& Trigwell, K. (1999) Understanding learning and teaching: the experience in higher education. Buckingham, SRHE \& Open University Press.

Punch, K. (1998) Introduction to social research: quantitative and qualitative approaches. London, Sage.

Radnor, H. (2001) Researching your professional practice: doing interpretive research. Buckingham, Open University

Reeve, J. \& Jang, H. (2006) What teachers say and do to support students' autonomy during a learning activity. Journal of Educational Psychology, 98, 209-218.

Reeve, J., Jang, H., Carrell, D., Jeon, S. \& Barch, J. (2004) Enhancing students' engagement by increasing teachers' autonomy support. Motivation and Emotion, 28, 147-169.

Reeve, J., Nix, G. \& Hamm, D. (2003) Testing models of the experience of self-determination in intrinsic motivation and the conundrum of choice. Journal of Educational Psychology, 95, 375-392.

Research Assessment Exercise (2008) Available from: http://www.rae.ac.uk/. Accessed 14 April 2010.

Rifkin, B. (2000) Revisiting beliefs about foreign language learning. Foreign Language Annals, 33, 394-408.

Rose, J. \& Ziman, J. (1964) Camford observed. London, Victor Gollancz.

Rotter, J. (1966) Generalized expectancies for internal versus external control of reinforcement. Psychological Monographs, 80, 1-28.

Ruiz De Zarobe, Y. (2008) CLIL and foreign language learning: a longitudinal study in the Basque country. International CLIL Research Journal, 1, 60-73.

Ruiz De Zarobe, Y. \& Jimenez Catalan, R. M. (Eds.) (2009) Content and language integrated learning: evidence from research in Europe. Bristol, Multilingual Matters.

Ruspini, E. (2002) Introduction to longitudinal research. London, Routledge.

Ruvolo, A. P. \& Markus, H. (1992) Possible selves and performance: The power of selfrelevant imagery. Social Cognition, 10, 95-124.

Ryan, R. M. (1982) Control and information in the intrapersonal sphere: An extension of cognitive evaluation theory. Journal of Personality and Social Psychology, 43, 450461. 
Ryan, R. M. \& Deci, E. L. (2000) Intrinsic and extrinsic motivations: classic definitions and new directions. Contemporary Educational Psychology, 25, 54-67.

Ryan, S. (2008) The ideal L2 selves of Japanese learners of English Applied Linguistics. Nottingham, University of Nottingham.

Ryan, S. (2009) Self and identity in L2 motivation in Japan: the ideal L2 self and Japanese learners of English. IN Dörnyei, Z. \& Ushioda, E. (Eds.) Motivation, language identity and the L2 self. Bristol, Multilingual Matters.

Sandelowski, M. (2003) Tables of tableaux? The challenges of writing and reading mixed methods studies. IN Tashakkori, A. \& Teddlie, C. (Eds.) Handbook of mixed methods in social and behavioral research. Thousands Oaks, CA., Sage.

Sansone, C. \& Morgan, C. (1992) Intrinsic motivation and education: competence in context. Motivation and Emotion, 16, 249-270.

Schmidt, R. \& Savage, W. (1994) Challenge, skill and motivation. University of Hawai'i Working Papers in ESL, 12, 1-25.

Schunk, D. (1989) Self-efficacy and cognitive skill learning. IN Ames, C. \& Ames, R. (Eds.) Research on motivation in education. San Diego, CA, Academic.

Schunk, D. H. (1991) Self-efficacy and academic motivation. Educational Psychologist, 26, 207-231.

Schunk, D. H. \& Pajares, F. (2005) Competence perceptions and academic functioning. IN Elliot, A. J. \& Dweck, C. S. (Eds.) Handbook of competence and motivation. New York; London, Guilford Press.

Schunk, D. H., Pintrich, P. R. \& Meece, J. L. (2008) Motivation in education: theory, research, and applications. Upper Saddle River, N.J, Pearson-Merrill, Prentice-Hall. .

Schwarzer, R., Bäßler, J., Kwiatek, P., Schröder, K. \& Zhang, J. X. (1997) The assessment of optimistic self-beliefs: comparison of the German, Spanish, and Chinese versions of the general self-efficacy scale. Applied Psychology, 46, 69-88.

Shapira, Z. (1976) Expectancy determinants of intrinsically motivated behavior. Journal of Personality and Social Psychology, 43, 1235-1244.

Sharma, S. (1996) Applied multivariate techniques. New York, Wiley.

Shell, D. F. \& Husman, J. (2008) Control, motivation, affect, and strategic self-regulation in the college classroom: a multidimensional phenomenon. Journal of Educational Psychology, 100, 443-459.

Shoaib, A. \& Dörnyei, Z. (2005) Affect in life-long learning: exploring L2 motivation as a dynamic process. IN Benson, P. \& Nunan, D. (Eds.) Learners'stories: difference and diversity in language learning Cambridge, Cambridge University Press.

Short, S. E., Tenute, A. \& Feltz, D. L. (2005) Imagery use in sport: mediational effects for efficacy. Journal of Sports Sciences, 23, 951-960.

Sikes, P. (2006) On dodgy ground? Problematics and ethics in educational research. International Journal of Research \& Method in Education, 29, 105-117.

Silverman, D. (2004) Qualitative research : theory, method and practice. London; Thousand Oaks, Calif., Sage Publications.

Skehan, P. (1991) Individual differences in second-language learning. Studies in Second Language Acquisition, 13, 275-298.

Soh, K. C. (1987) Language use: A missing link. Journal of Multilingual and Multicultual Development, 8, 443-449.

Speier, C. \& Frese, M. (1997) Generalized self efficacy as a mediator and moderator between control and complexity at work and personal initiative: a longitudinal field study in East Germany. Human Performance, 10, 171-192.

Strauss, R. \& Goldberg, W. A. (1999) Self and possible selves during the transition to fatherhood. Journal of Family Psychology, 13, 244-259. 
Swain, M. (1995) Three functions of output in second language learning. IN Cook, G. \& Seidlhofer, B. (Eds.) Principles and practice in applied linguistics. Oxford, Oxford University Press.

Swain, M. (2005) The output hypothesis: theory and research. IN Hinkel, E. (Ed.) Handbook on research in second language teaching and learning. Mahwah, NJ, Lawrence Erlbaum.

Sylvén, L. K. (2004) Teaching in English or English teaching? On the effects of content and language integrated learning on Swedish learners' incidental vocabulary acquisition. Unpublished Doctoral Thesis. Göteborg University, Department of English.

Tabachnick, B. G. \& Fidell, L. S. (2007) Using multivariate statistics. 5th ed. Boston, MA, Pearson Education.

Taguchi, T., Magid, M. \& Papi, M. (2009) The L2 Motivational Self System among Japanese, Chinese and Iranian learners of English: a comparative study. IN Dörnyei, Z. \& Ushioda, E. (Eds.) Motivation, language identity and the L2 self. Bristol, Multilingual Matters.

Tapper, E. \& Palfreyman, D. (2000) Oxford and the decline of the collegiate tradition. London, Woburn Press.

Tashakkori, A. \& Teddlie, C. (2003) Handbook of mixed methods in social and behavioral research. Thousand Oaks, CA, Sage.

The Guardian (11 June 2009) Threat of closure for university language departments. Available from: http://www.guardian.co.uk/education/2009/jun/11/universitieslanguage-departments-close. Accessed 17 April 2010.

The Guardian (13 March 2007) Chattering classes. Modern Languages are increasingly becoming an elite subject, dominated by the middle classes and concentrated at the top universities. Available from:

http://www.guardian.co.uk/education/2007/mar/13/highereducation.cutsandclosures. Accessed 17 April 2010.

The Guardian (22 September 2009) Auf Wiedersehen, dept? Available from: http://www.guardian.co.uk/education/2009/sep/22/german-university-departmentsclosure. Accessed 18 April 2010.

The Times (27 May 2005) The Times university guide table. Available from: extras.timesonline.co.uk/gooduniversityguide2005/20german.pdf. Accessed 17 March 2010.

The Times (27 May 2010) The Times: 2011 University League Table. Available from: http://registrarism.wordpress.com/2010/05/27/the-times-2011-university-league-table/. Accessed 18 April 2010.

Thomas, S. \& Oldfather, P. (1997) Intrinsic motivations, literacy, and assessment practices: 'That's my grade. That's me.' Educational Psychologist, 32, 107-123.

Thompson, J. (2005) Computer-assisted language learning (CALL). IN Coleman, J. A. \& Klapper, J. (Eds.) Effective learning and teaching in modern languages. London, Routledge.

Tremblay, P. F. \& Gardner, R. C. (1995) Expanding the motivational construct in language learning. Modern Language Journal, 79, 505-520.

Truscott, J. (1996) The case against grammar correction in L2 writing classes. Language Learning, 46, 327-369.

Truscott, J. (1999) The case for "the case against grammar correction in L2 writing classes": A response to Ferris. Journal of Second Language Writing, 8, 111-122.

Truscott, J. (2004a) The effectiveness of grammar instruction: Analysis of a meta-analysis. English Teaching \& Learning, 28, 17-29.

Truscott, J. (2004b) Evidence and conjecture on the effects of error correction: A response to Chandler. Journal of Second Language Writing, 13, 337-343. 
Truscott, J. (2010) Some thoughts on Anthony Bruton's critique of the correction debate. System, 38, 329-335.

Tsai, Y.-M., Kunter, M., Lüdtke, O., Trautwein, U. \& Ryan, R. M. (2008) What makes lessons interesting? The role of situational and individual factors in three school subjects. Journal of Educational Psychology, 100, 460-472.

Tse, L. (2000) Student perceptions of foreign language study: a qualitative analysis of foreign language autobiographies. The Modern Language Journal, 84, 69-84.

Turner, J. C. (2001) Using context to enrich and challenge our understanding of motivational theory. IN Volet, S. \& Järvelä, S. (Eds.) Motivation in learning contexts. Theoretical advances and methodological implications. Amsterdam, Pergamon.

Usher, E. L. \& Pajares, F. (2008) Sources of self-efficacy in school: critical review of the literature and future directions. Review of Educational Research, 78, 751-796.

Ushioda, E. (1996a) Language learners' motivational thinking: a qualitative study. Unpublished Doctoral Thesis. Dublin, Trinity College.

Ushioda, E. (1996b) The role of motivation. Dublin, Authentik Language Learning Resources. Ushioda, E. (1997) The role of motivational thinking in autonomous language learning. IN Little, D. \& Voss, B. (Eds.) Language centres: Planning for the new millennium.

Ushioda, E. (1998) Effective motivational thinking: A cognitive theoretical approach to the study of language learning motivation. IN Soler, E. A. \& Espurz, V. C. (Eds.) Current issues in English language methodology. Castelló de la Plana, Spain, Universitat Jaume I.

Ushioda, E. (2001) Language learning at university: exploring the role of motivational thinking. IN Dörnyei, Z. \& Schmidt, R. (Eds.) Motivation and second language acquisition. Manoa, HI, University of Hawai'i.

Ushioda, E. (2009) A person-in-context relational view of emergent motivation, self and identity. IN Dörnyei, Z. \& Ushioda, E. (Eds.) Motivation, language identity and the L2 self. Bristol, Multilingual Matters.

Ushioda, E. (2010) Socialising students' motivation and autonomy in the English language classroom IETEFL Conference. Harrogate, Available from: http://iatefl.britishcouncil.org/2010/sessions/2010-04-10/plenary-session-ema-ushioda. Accessed 10 October 2010.

Vallerand, R. J. (1997) Towards a hierarchical model of intrinsic and extrinsic motivation. Advances in Experimental Social Psychology, 29, 271-360.

Volet, S. (2001) Understanding learning and motivation in context: a multi-dimensional and multi-level cognitive-situated perspective. IN Volet, S. \& Järvelä, S. (Eds.) Motivation in learning contexts. Theoretical advances and methodological implications. Amsterdam Pergamon.

Volet, S., Vauras, M. \& Salonen, P. (2009) Self- and social regulation in learning contexts: an integrative perspective. Educational Psychologist, 44, 215-226.

Von Wright, G. H. (1971) Explanation and understanding. London, Routledge.

Waterman, A. S. (2004) Finding someone to be: studies on the role of intrinsic motivation in identity formation. Identity: An International Journal of Theory and Research, 4, 209 228.

Watson, J. B. (1913) Psychology as the behaviorist views it. Psychological Review, 20, 158177.

Watts, C. \& Pickering, A. (2005) Some reasons behind the drop-out from German foreign language study between AS and A2 levels. Language Learning Journal, 32, 18-26.

Weaver, M. R. (2006) Do students value feedback? Student perceptions of tutors' written responses. Assessment \& Evaluation in Higher Education, 31, 379-394.

Weiner, B. (1969) Motivation. IN Ebel, R. L. (Ed.) Encyclopedia of educational research. 4 ed. New York, Macmillan. 
Weiner, B. (1985) An attributional theory of achievement motivation and emotion. Psychological Review, 92, 548-573.

Weiner, B. (1990) History of motivational research in education. Journal of Educational Psychology, 82, 616-622.

Weiner, B. (1992) Human motivation. Metaphors, theories and research. New York ; London, Holt, Rinehart \& Winston.

Weiner, B. (2005) Motivation from an attributional perspective and the social psychology of perceived competence. IN Elliot, A. J. \& Dweck, C. S. (Eds.) Handbook of competence and motivation. London, Guilford Press.

Weiner, B., Russell, D. \& Lerman, D. (1979) The cognition-emotion process in achievement related contexts. Journal of Personality and Social Psychology, 37, 1221-1230.

Wesch, N. N., Milne, M. I., Burke, S. M. \& Hall, C. R. (2006) Self-efficacy and imagery use in older adult exercisers. European Journal of Sport Science, 6, 197-203.

Wigfield, A., Eccles, J. S. \& Pintrich, P. R. (1996) Development between the ages of 11 and 25. IN Berliner, D. C. \& Calfee, R. C. (Eds.) Handbook of educational psychology. New York, Wiley.

Wigfield, A., Eccles, J. S. \& Rodriguez, D. (1998) The development of children's motivation in school contexts. Review of Research in Education, 23, 73-118.

Williams, M. (1994) Motivation in foreign and second language learning: An interactive perspective. Education and Child Psychology, 11.

Williams, M. \& Burden, R. (1999) Students' developing conceptions of themselves as language learners. The Modern Language Journal, 83, 193-201.

Williams, M., Burden, R. \& Al-Baharna, S. (2001) Making sense of success and failure: the role of the individual in motivation theory. IN Dörnyei, Z. \& Schmidt, R. (Eds.) Motivation and second language acquisition. Manoa, HI, University of Hawai'i.

Williams, M., Burden, R., Poulet, G. \& Maun, I. (2004) Learners' perceptions of their successes and failures in foreign language learning. Language Learning Journal, 30, 19-29.

Williams, M. \& Burden, R. L. (1997) Psychology for language teachers: a social constructivist approach. Cambridge, Cambridge University Press.

Wolters, C. A. \& Yu, S. L. (1996) The relation between goal orientation and students' motivational beliefs and self-regulated learning. Learning \& Individual Differences, 8, 211-238.

Wright, V. (2005) Independent learning. IN Coleman, J. A. \& Klapper, J. (Eds.) Effective learning and teaching in Modern Languages. London, Routledge.

Wurf, E. \& Markus, H. (1991) Possible selves and the psychology of personal growth. IN Ozer, D. J., Healy Jr., J. M. \& Stewards, A. J. (Eds.) Perspectives in personality. London, Kingsley.

Yashima, T. (2009) International posture and the ideal L2 self in the Japanese EFL context. IN Dörnyei, Z. \& Ushioda, E. (Eds.) Motivation, language identity and the L2 self. Bristol, Multilingual Matters.

Yorke, M. (2001) Formative assessment and its relevance to retention. Higher Education Research \& Development, 20, 115-126.

Yorke, M. \& Longden, B. (2008) The first-year experience of higher education in the UK. Available from: www.heacademy.ac.uk. Accessed 1 May 2010.

Zimmerman, B. J. \& Kitsantas, A. (2007) Reliability and validity of self-efficacy for learning form (SELF) scores of college students. The Journal of Psychology, 215, 157-163.

Zuckerman, M., Porac, J., Lathin, D. \& Deci, E. L. (1978) On the importance of selfdetermination for intrinsically-motivated behavior. Personality and Social Psychology Bulletin, 4, 443-446. 


\section{Appendix 1 Questionnaire Items}

\section{LANGUAGE PROFICIENCY AS REASON FOR STUDYING GERMAN}

1.1 I study German because I want to improve my German

1.2 By studying German I hope to gain more competence in speaking German

1.5 By studying German I hope to gain more reading fluency in German

1.10 By studying German I hope to improve my written German

1.17 By studying German I hope to better my listening comprehension in German

INTEGRATIVE REASONS FOR STUDYING

1.26 I feel an affinity with the people who live in German-speaking countries

1.9 I like to travel to German-speaking countries

1.12 I like meeting people from German-speaking countries

1.19 I would like to become more like people from German-speaking countries

OUGHT-TO L2 SELF

1.16 I study German because people surrounding me expect me to do so

1.13 My parents / People I respect believe that I ought to study German

1.21 If I fail to learn German, I'll be letting other people down

1.7 I consider learning German important because the people I respect think that I should do so

\section{INSTRUMENTAL REASONS FOR STUDYING}

1.14 I think knowing German will help me to become a more knowledgeable person

1.27 I think German will help in my future career

1.4 My German ability will help me to obtain a better job

1.24 Studying German is important to me because with a high level of proficiency in a foreign language I will be able to earn more money

INTRINSIC REASONS

1.3 I really enjoy learning German

1.22 Learning German is a challenge which I enjoy

1.18 I find learning German really interesting.

1.11 Learning German is one of the most important aspects in my life

1.5 I like the challenges that learning German poses

IDEAL L2 SELF

1.28 Whenever I think of my future, I imagine myself being able to use German

1.15 I can imagine myself as someone who is able to use German well

1.8 If my dreams come true, I will use German effectively in the future

1.6 Being able to converse in another language is an important part of the person I want to become 


\section{EFFORT}

2.1 I invest much time and effort on all written language assignments, such as German essays, etc.

2.4 I am working hard at learning German

2.5 I can honestly say that I put a lot of effort into German language classes.

2.6 RC I often feel that it takes too much effort to really engage with a piece of translation (not retained in the factors after exploratory factor analysis)

2.7 I put as much effort as possible into language assignments

2.10 RC I think it would be too much effort to read anything other than set texts in German (not retained in the factors after exploratory factor analysis)

2.11 I spend a lot of time on translations

2.13 I am the kind of person who makes great efforts to learn German

2.14 I try very hard to read more than just set texts in newspapers/ magazines

2.16 I spend a lot of time on improving my grammar where I feel it to be necessary

2.17 RC Honestly, I do not have much time to spend on language work

(not retained in the factors after exploratory factor analysis)

2.19 I spend as much time as possible on language learning

2.20 I try to learn as many new words a possible during language classes

2.21 I can honestly say that I am really doing my best to learn German

\section{SELF EFFICACY}

How confident are you that by the end of this academic year you will be able to

3.1 write an essay in German?

3.2 write a short summary of a newspaper article in German?

3.3 write a your opinion about an article in German?

3.4 read and understand the main ideas of a German poem?

3.5 Read and understand a newspaper article?

3.6 Listen to and understand a lecture in German?

3.7 Listen to and understand a German native speaker in a tutorial?

3.8 Listen to and understand a German film?

3.9 Engage in a conversation with a native speaker about a novel?

3.10 Speak about a film with a native speaker?

3.11 Discuss a newspaper article with a native speaker?

3.12 Do well in the grammar part of the classes?

3.13 Do well when translating a short prose passage from German into English?

3.14 Do well when translating a short prose passage from English into German?

PRESENT MOTIVATION

4.1 I would describe my present state of motivation for studying German as high at the moment

4.2 I would describe my present state of motivation for studying German as somewhat low at the moment 


\section{Appendix 2 Interview Guide, Time Point 1}

- Why do you want to study German?

Follow-ups (depending on opening statement):

- Do you have any other reasons for studying German?

- Do you relate your reasons for studying to any long-term plans that you might have?

- Did job considerations play a role for you?

- Many people think about their future and imagine what they will probably be like in the future. Do you have a picture or a sort of vision of yourself with regard to German?

- If so, what does it look like? Does it affect your motivation?

- Do you envisage using German in the future?

- Can you imagine being fluent in German?

- What do you hope to gain from studying German at university level?

- Any other kind of expectations?

- How is your language learning going at the moment?

- How are the grammar classes/ Lektorinnen classes/ translation classes (University A) and large/ small/ oral classes going?

- How would you describe your engagement in grammar/ Lektorinnen/ translation class (University A) large language class/ small language class/ oral class (University B).

- How confident do you feel about the following tasks (tasks mentioned in the questionnaire)?

- Follow-up from questionnaire. 


\section{Appendix 3 Interview Guide, Time Point, 2,3,4,5}

- How would you describe your present state of motivation for learning German?

- Have you experienced any motivational changes during the term?

- If so, to what factors would you attribute these changes?

- Have you experienced any changes in your ideas about future career plans? If so, do you think these have had any impact on the way you feel about studying German?

- Has anything happened in your personal life that has influenced the way you feel about your studies?

- Questions about vision/ ideal self depending on what students had stated earlier.

- How is your language learning going at the moment?

- How are the grammar classes/ Lektorinnen classes/ translation classes (University A) and large/ small/ oral classes going?

- How would you describe your engagement in grammar/ Lektorinnen/ translation class (University A) large language class/ small language class/ oral class (University B).

- To what factors would you attribute that classes are going well/ that you made good/ hardly any progress?

- Anything that you found particularly motivating/ demotivating in these classes?

- Are there any particular tasks/ conditions where you feel that your motivation is low?

- Why?

- (Depending on the previous interviews) Do you feel your confidence about any of the tasks discussed has changed? If yes, why?

- Follow-up on feedback depending on what students had stated in the first interview.

- (Students and I looked at writing tasks and the feedback received.) How do you feel about this piece? Did the feedback you received affect the way you feel about it? 
Additional Questions at Time Point 5

- In the first interviews you mentioned your teacher's influence: how would you evaluate your teacher's influence in retrospect?

- In retrospect, what were the biggest challenges of the first-year for you?

- Is there anything within the university environment that could be done to change your motivation?

- Follow-up from questionnaire. 


\title{
Appendix 4 Participant Information Sheet
}

\author{
Participant Information Sheet
}

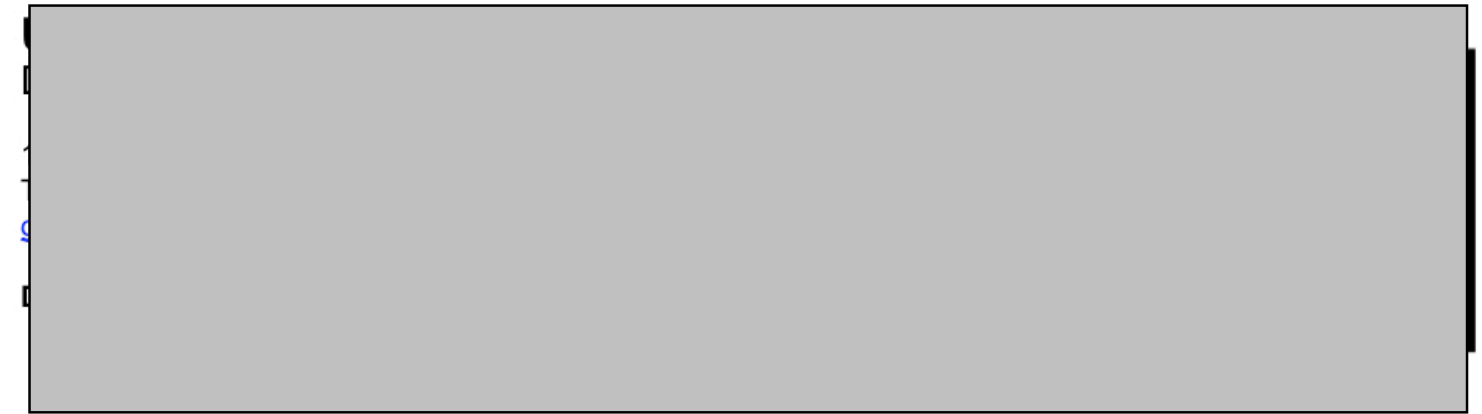

\section{Invitation}

Dear student,

I am a research student in applied linguistics at the educational department o

University. My research is on language learning motivation and I am particularly interested in motivational processes of first year students studying German, which is why I would like to invite you to take part in this research project. Before you decide to participate, please take the time to read the following information carefully. Please ask if there are any aspects of the project that are unclear or if you would like more information.

\section{How is the research being conducted?}

The project consists of two stages, with a questionnaire being distributed now and another one towards the end of the academic year. There are also follow-up interviews for voluntary students. The questionnaire will take approximately $15 \mathrm{~min}$. while the interviews would take up to $30 \mathrm{~min}$.

\section{Do I have to take part? What are the risks and benefits of taking part?}

It is your decision to take part in this study. The research will be conducted in accordance with the ethical requirements of University and participation is fully voluntary; you have the right to withdraw at any time and to refuse to participate. You do not need to answer questions that you do not wish to. Your responses to the questionnaire are confidential. Data will be stored by the researcher personally, and of course you will remain anonymous in the evaluation of the study. If you would like to take part in follow-up interviews, please provide me with your name/ details so that I will be able to contact you. Note that your name and details of the questionnaire/ interviews will not be disclosed to anyone else besides the researcher. Alternately, if you wish to remain completely anonymous, you may write down your mother's date of birth, which would still enable me to match this questionnaire to the questionnaire distributed towards the end of the academic year. By participating in this study you are helping to create a picture of first year students' motivational processes for learning German and will benefit those interested in understanding the demanding transitional process from secondary school to university. 


\section{Who is funding and organizing the research?}

The research is funded and organized as an independent doctoral research project in conjunction with the Department of Educational Studies, $\square$ University.

What will happen to the results of this research?

The results of this research will form the basis of an doctoral dissertation. Some results maybe published in academic journals concerned with exploring foreign language learning motivation. I will be happy to provide you with some results of this project or a copy of the published results, and please feel free to ask me any questions about this study either before or during your participation or contact me throughout the academic year (

Yours

Vera Busse

Contact for further information or follow-up

Should you have any further questions about this research, please feel free to also contact: further information, insight into these issues, or questions your inquires are most welcome.

Thank you for taking the time to read this information sheet! 


\section{Appendix 5 Interview Consent Form}

\section{Informed Consent}

Foreign Language Learning Motivation in Higher Education: A Longitudinal Study of German Language Motivation among First Year University Students Interview Consent Form

This research study seeks to explore motivational processes of first year university students of German. This is a studv undertaken by Vera Busse, doctoral student at that Department of Education,

1. I have read and understood the information about this study and have had the opportunity to ask questions. I have considered all the risks involved with this research.

2. I understand that I can withdraw from the study without consequences at anytime simply by informing the researcher of my decision.

3. I understand who will have access to identifying information provided and what will happen to the data at the end of the project.

4. I am aware of who to contact should $I$ have questions following my participation in this study.

5. I give my permission to the researcher to use recordings and any notes taken during the interview for research purposes.

6. I understand that this project has been reviewed by and received ethical clearance through the University of Research Ethics Committee.

I agree to participate in this study.

NAME

SIGNATURE:

DATE: 


\section{Appendix $6 \quad$ Examples of Transcribed Interviews}

\section{Interview Transcript, Samuel (University A)}

V.: Would you like to know anything about my study to begin with?

S.: No, no, I've read the sheet on the front of the questionnaire.

V.: Good, let's start then. Why do you want to study German?

S.: I like German a lot, I have always liked it. I wouldn't go so far as to say I have an aptitude for it, but I've always enjoyed it. I mean at first, I changed between my different degree courses: initially I was going to apply for law with a language here, because I thought I would make quite a good lawyer, everyone used to say, and I also liked that profession. But I can only do law with one language. But when I was applying, it never entered my head that I could do German at university level, I only taught myself German from a book, so it never entered my head, so I never had any idea as to how good I was.

V.: So you didn't take German as an A-level?

S.: Yes, I did it as an A-level, but I had only a year worth of... I wasn't taught properly, I didn't have classes in my school. Because my school didn't offer German, but there was another school in Liverpool, called [...] that offered German, so every few weeks, I would get a taxi during my lunch break to that girl school and would have like an hour of German and then come back and then just read in my own time. And then I obviously had to get that school to mark my course work, because I needed that. So when I was applying, I thought I would apply for law and French, but then I decided that I liked German a lot, so I thought, if they take me - I wanted to do see if they let me do it ab initio, and see, but then I thought: Well, I have got an A-level, and I thought I had done quite well in the exams, so I thought I would go in for French and German. Well, I think it is like - I suppose I had thought of all the courses it would 
give me like the most transferable skills. Because I know that everyone just classifies languages as "arts", but that kind of gets me a bit angry, because they box it off and say: all sciences are great! The thing that people don't understand about languages is that when you go to a university to do languages you learn how to speak in English you know what I mean, you learn just like long lists of vocabulary and let alone how to translate so I get very angry when people say: Oh, what do you want to do with that, you just want to be a translator or a languages teacher? So I just feel like saying: Oh, if you think of all the careers that languages can get you into! I mean, I was reading somewhere that in the cabinet, most of the PPs, most of the ministers have done is languages. When you do languages you get to - given that you're kind of fluent already, have the grammar when you get here, because they don't really teach you the grammar that much, they just like fiddle with the details - so you are getting to do the history, the literature, the linguistics, the politics, the philosophy of it, you are getting to appreciate the film- it is [close?] to so many different subjects. So that's why I wanted to do it. Because within that actual discipline of language it allows you to do what you want to do.

V.: So is that sort of a long term plan - going into politics?

S.: Possibly, yes. I wanted to be a lawyer first. Because I actually wanted to make a difference. Because I think everyone is given a talent. And I can do other stuff - music but I think my main kind of thing is communication. And - yes, I want to make an impact. I could go into politics, and I could make more of a change there than through law. But - I have got this kind of ambition, but I am a bit hesitant to tell it to other people, because it sounds a bit weird, because everyone else here is kind of - oh, I will be a [?] or I am going to be this, and, I don't have an actual job title, but I think that with languages, you can view the world from so many viewpoints, from different perspectives, we are not just confined to our island mentality that we have got. And 
what I kind of like to do is like working in the public, be like a public figure... I don't know. Have you ever heard of Michel de Montaigne?

V.: Yes.

S.: We do have him in first year French. He is - was - mayor in a town called Montaigne, in France. He was a great public figure, he would make these speeches, and these treatises, and negotiated (long description of Motaigne's life. Emphasis is on his writing late in live). He is kind of looked upon as: he founded the essay format, so I think my ambition would probably be like: not like to be an academic but to be a public figure and than write something that is looked upon when I die. And I think languages best prepare you for that, nothing else can (speaks with great conviction). Not politics, not philosophy, because there are all too specific, just one track.

V.: Can you say that you have a picture or a sort of vision of yourself with regard to German?

S.: Yes, although, at first, it is quite difficult to actually imagine yourself just walking in a room and speaking differently from all your life. And I know - I have seen through all other disciplines that at first, that even if you are not particularly skilled for it, after a certain time that you have done it; you get to the level. So, yes, I can kind of envision myself as part of my career: whether, I don't know, whether I will be a kind of diplomat or - well, probably be something higher than that, an ambassador or something. Or foreign secretary would be pretty good. I can see myself as kind of bilingual - no, not bilingual, but bicultural as well.

V.: Does this vision affect your motivation?

S.: Yes, very much so! This is what keeps you going.

V.: What do you hope to gain from studying German at university level?

S.: I want to become fluent, but yes, I thought it would be - I thought it would be a little bit more like my French was at school, at A-level and how I imagine a lot of 
other people's experience was with German at school. I mean, I am not saying that it would be broken down to speaking classes, reading classes, etc. I just mean: I didn't think we wouldn't get much exposure to the actual spoken language at all! I mean, other than the $[\ldots]$ lectures, we don't really get any German spoken at us much. I mean the only chance where we ourselves get to speak German, as opposed to just listening to, is in the [...] seminars [combined Paper I/ oral class] they are only every second week and the environment of those is - (pause) is such that people actually loathe to speak. I don't know that's because at this level everyone is sort of competitive, and no one wants to be the one who makes the mistake or says something that sounds stupid, and you would think that people would have gone past by that at this level. Because they have already displayed a lot of ability, the fact that they are at [University A] shows that they make fewer mistakes than many. But, erm, my particular seminar is with Ms [...]; she is really hospitable, friendly and personal, but once she speaks, she speaks German, it feels really awkward because it is only ever me who is offering answers. I mean, I have got no problem, I have got no shame, so to speak. But even I get conscious of the fact that it is just me speaking all the time. So I thought there would be a lot more speaking at university, I thought there would be a lot more listening exercises, I don't know - because we get here translation and stuff but maybe if they gave us some kind of clips from the news or some kind or radio abstract or songs to interpret or something like that, just to expose us to the different kind of media a bit more.

V.: So your expectations of German learning at university was that you would get all sorts of different language activities, and that you would be exposed to the language more?

S.: Yes, yes.

V.: Any other kind of expectations? 
S.: I don't think I really had any high expectations, hadn't thought of or conceived an idea, or a manner in which they would make us fluent; I just entrusted that to them that they would make us fluent somehow. I can't really think of a fashion other than it is taught. I don't know, I just doesn't seem great, because my class is quite big, there are like 20 people in it -

V.: You feel that is too big?

S.: Yes, definitely!

V.: Can you tell me a bit more about how your language learning is going at the moment?

S.: At the moment it is just like a translation a week, translation into German every fortnight, a commentary a week and than a few kinds of twiddly seminar questions and so - I thought there would be more required of us, and more stuff that would inspire us and get us thinking a bit more. Because at the moment it does seem a bit more like ticking boxes. And I think the actual writing, I think the emphasis is on how you say it and not necessarily on what you say and that is the kind of thing that affects my motivation. Also in the literature classes. I think this is quite a demotivating, quite a demoralizing thing. What you have got to say they don't really care as much, they just care about how you elucidate your thoughts and how eloquent you are. I mean, I can do that, I can dance the academic dance, and I can write frivolously and frilly, but I am more concerned with the what it actually means: the essay. I think that is a bit demotivating, because other people are getting a better mark than you and when you mention what they have said and you have said more, but you have said it in a certain way - but it says the exact same thing, just prettier to read, but what I have to say might be slightly more coarse that what they have to say.

V.: That is the feedback in literature - is that similar for language? 
S.: For language, we never get to write anything. We would write a couple of definitions, like Texterläuterungen and stuff, but they are all so short - and the feedback is: you could use that word instead, so I don't suppose there is so much on with those, with the feedback we get - for the language stuff and the seminars. It is only, as I said, because the work is so short and so sparse. But I would like more essays to be written in German. The focus is supposed to be on academic writing, on academic standard, and I know that we are supposed to be working towards that in the seminars, but I think we are going towards that a bit too slowly. I expected more on kind of linguistic inventions and more morphology and etymology. And - I don't know whether you can have a lecture on that - but sort of on the use of idioms. In the grammar classes it is sort of hinted at, but more on actually how lots of people would speak in Germany. That would be quite interesting.

V.: That's something that you missed?

S.: Yes, when I applied, my first sentence was: Language is at the centre of everything I do. And I think it is fundamental, it is crucial to all academic study. And I think that still stands, whatever the discipline is: maths, law - although their language is English, your notions, your thoughts, the way you express yourself, what you understand, is all done in a language that you have accumulated so the actual study of language itself would be a bit more interesting than what happened in a play and why. Language is not theatre, not theatre studies.

V.: And with respect to the actual language classes, how are the language classes going?

\section{S.: Language classes?}

V.: Yes, you have prose, translation, grammar, DGK lectures and seminars, language tutorials with your Lektor, for Paper I.

Ah, I suppose... 
V.: And you have Paper I.

S.: Yes, I think for me Prose and Paper I is the same thing. Because it is one session and it is one hour that Mrs [...] taught. And we do Paper I.

V.: But you don't have prose - translation into German?

S.: Er...

V.: Students have translation usually from English into German and German into English

S.: Ah, yes, we have them in college every fortnight.

V.: English into German or German into English?

S.: Yes, it kind of alternates. We do it only every second week so we only do two translations into German. I like them. I would like a lot more of that.

V.: Why do you like them?

S.: They are really good, they are sort of challenging. To make it sound more English or more German. Yes, although it takes me quite a long time to look up all the words. Because my vocabulary, I don't really know a lot of vocabulary so I have to look up a lot of things. But I really enjoy them.

V.: Let's turn to Paper I classes then, how are they going?

S.: I don't think they have lived up to my expectations. Just because they are so slow going and the material is so dull. I don't think that it has anything to do with the teaching. Because Mrs $[\ldots]$ is like really good, but I think it is the atmosphere of the class. The class is unwilling to respond. It goes slow and we go through awful silences it is almost like - and if we also have to wait for everyone to turn up we have really only 15 minutes. It is just not sufficient I think.

V.: You are saying that they are not sufficient, do you use opportunities provided by the university to engage in language work outside of these classes? 
S.: We haven't really been told about them at all. I know that there is a pronunciation clinic by Dr. [...], but I don't need to build that up, because I have been told it is just about pronunciation. I know some of my college have been referred to it. But I don't know of anything else. Oh, yes, I know that there is a German society. I went to like a debate of that once, that was interesting.

V.: Is there something like computer assisted language learning here, like grammar programmes you could use on the computer?

S.: No.

V.: And how are the grammar classes going?

S.: Uh, my grammar class, is in a really small room. It is like having a lecture even though we are not having a lecture, we have a grammar book and a note book/ work book and she keeps flicking between the two. So we are constantly throwing everything everywhere. And the way it is taught: they don't really exemplify enough, it is not really that difficult, they just show you the answer: They give you like a minute and then they give you the answer and then she just moves on. I mean, this is not great, is it? We get through lots of stuff in the actual lessons so we have to do stuff at home, and then I think: hey, wait a minute, that is how I taught myself German in the first place, what is the point of coming to this grammar class? I could just read it from the book. Maybe that is just me, I can learn from a book and other people just can't. It's just, because I am doing German, because I am doing languages full time, there wouldn't be as much having to go and work on grammar and all that stuff, I thought most of the actual homework we would be doing would be the actual reading and writing essays, broadening our horizons, filling in the gaps, culturally also.

V.: How would you describe your engagement in these language classes?

S.: Er - I am not sure. (Silence). I suppose I could be putting more effort in. I prioritise literature at the moment. But it is also because a lot of the stuff we do, however hard 
you... whatever effort you put into it, you will get the same feedback, in the seminar work or your prose work or Paper I, however hard I try is not going to make a difference. They just going to give it back to you and then just move on. I think there are constraints on time as well which make it actually difficult to put as much effort into it as you would like to. Something might be due at 4 pm, let's say a translation, so would get up at 9 o'clock and because the way the lectures are set a lot of them are at 10 so you when you get back you have til 4 to do it. Minus a break for lunch. So you have that kind of pressure, so you have to rush it. So, you just feel you can't put any effort in, so you are so tired from everything else, you are just glad to get it done. And even though that makes you kind of get worse, morally, then, because your turning something in when normally you wouldn't - I am the kind of person who would not hand it in until I thought, this is exactly how it should be, I have nailed it. But if you don't, you get shouted at, so just giving in work that you know you could do better on. You know you could get a better mark, you feel like saying: hang on, I can do better than that. But of course they expect everyone to say, oh, I can do better. But you actually can. It is frustrating, it is depressing, it is tiring. And it is so unfulfilling.

V.: Can we go over some of the questions from your questionnaire? For instance, you said that you like German, and in the questionnaire you also said that you enjoy learning German very much, can you elaborate on that a bit?

S.: Yes, I enjoy German, I like speaking it. I don't know, for instance, I applied for this competition, it was by the British council, and I won a scholarship in a gymnasium in Berlin, and it was like, Student des Jahres [Student of the Year]. And you had to write a proposal for research and collect the data while you were there. I don't know how but I happened to win and it was on the kind of politics and the difference between Britain and Germany. And it was basically on politics that 17-18 year olds involved themselves with at school. At our school there was [describes 
different groups that he was involved in at school, that are democratically elected and self-organised etc.]. While I was there, it was when I was speaking to them, that I realised that my efforts had come to a head, it was, it miled you forward, it is like: hey, I am speaking German, I speaking with someone I would have never had the opportunity to speak, speaking about something that is interesting and carrying out research, that is great. And then this summer I went back to the family that I had stayed with. They had a lot of relatives around and then the uncles and aunts were from Russia and they didn't speak any English, but she learnt German so we both shared German as a second language. So the amazing thing for us was that we were both able to speak in German, in ways - I think she taught herself as well, but she was also enrolled in some kind of night classes as well - we were able to share our experience, of doing language, but just the fact that we could speak to each other: I was kind of pinching myself, this women speaks Russian and she speaks in German and I am English but I speak in German so I would have never been able to speak to this woman. I think that is kind of the most amazing things about languages, that contact with people who speak it, not just natives but as a second language, that is great just for morale as well. And it just really inspires you to do more.

V.: So this interchange has also positively affected your motivation to study German? S.: Yes, yes!

V.: In the questionnaire, there are two items: "I feel an affinity with people who live in German-speaking countries", and you said "so-so", and the same to "I would like to become more like people from German-speaking countries". So you are sort of sitting on the fence there, can you explain that a bit more?

S.: I mean, I don't really know many people from German-speaking countries. I went on my scholarship to Germany, I told you, but that was very short. Yeah, I don't think I have an affinity to German-speaking people. 
V.: Yes, you said you said in the questionnaire that you would very much like to meet people from German-speaking countries and to travel to German-speaking countries, is that still right?

S.: Yes, exactly, yes, I would like to travel!

V.: Now, there are some items like "I study German because people surrounding me expect me to do so", and "people surrounding me believe that I ought to study German". You felt that was not at all applicable to your situation, can you tell me a bit about that?

S.: My mother is not really happy about it, about studying at university in general. She just thinks I'm gonna spend the rest of my life paying off the student loan.

V.: Yeah, it is quite a lot of money, isn't it?

S.: Yeah. Yeah, and, I mean, her boyfriend was kind of - even when I started doing A level when I was sixteen, he was saying that I should've had a job then, and he was saying I should've been paying rent to my mum and stuff. You know, none of my friends did that. But when he grew up, his parents died really early when he was young, so he had to pay rent and stuff. I think it's a bit selfish that they expect me to do that just 'cause they did it.

V.: Now she has come to accept it, that you've made a choice to study at university?

S.: No, I think she just tries not to talk about it. So when I come home - because, I mean, I've sort of got back in contact with my dad again, who I haven't seen in, like, twelve years - so I went back to Liverpool for a few days. And while I was there, I think she wanted to avoid arguments and things. She tried not to talk about it. She just asked me how I was and what I was up to. I think it's because I'm quite stubborn, and I get that from my mum, so she doesn't want to kind of admit defeat. That's probably how she'd see it. So she doesn't approve of the fact that I study, you know. She's 
probably reserving judgment. And then if in the future I can't get a really good graduate-level job, that's when she'll dart off the old "I told you so".

V.: That sounds familiar. And your mother's boyfriend, does he go on about it?

S.: He stopped, yeah. He stopped after A levels. He knew I wasn't gonna give up my education. Because I mean, like, my little brother, I mean, it's probably good that he's not going on to education because that's not where his area of expertise lies. And he is quite good; he is kind of the best in his class. He got a kind of, not like a scholarship, almost an apprenticeship to a kind of catering college just out of town, and so, I mean, it's good that he's doing that, but you couldn't expect me to do something else because my expertise lies in kind of academia.

V.: Yeah, I can understand that. If that's okay, I would like to ask another question: the item "I put a lot of effort into all German language assignments" gets "so-so", so you are sorting of sitting on the fence, can you elaborate on that?

S.: Time-constraints. Enthusiasm, yes, but not enough time.

V.: You also put: "I am working hard at learning German": "so-so".

S.: Yes, I didn't want to like - it's not like enthusiasm is missing.

V.: Is this the same for grammar - "so-so". Are there other reasons why you don't put much effort into grammar?

S.: Well, it is mostly time-constraints, but - I mean - it is not the most interesting thing. I mean, I actually enjoy learning grammar, it is just the way that it is taught, and when you go through it, at such a high level, it gets a bit annoying, because you think you nailed a rule: a rule that's maybe ten pages long and then you just learn a long list of things that don't follow that rule. But it is satisfying when you actually know that you have learnt it. Yes, when you compare it to the French one, I mean the French grammar is like that and German is like that -

V.: So when you put "so-so" for "I am really doing my best to learn German"... 
S.: I have no time, or not the right scope for showing your ability. They don't offer as many resources or ways of learning.

V.: Anything else?

S.: The curriculum, the classes, the feedback that you do get, it is obviously more for literature, obviously also the comments you get, and the facts that all your tutorials are held in literature, there is really none of that: minimal contact, minimal feedback, minimal time. Possibly, because literature is taught by your college tutor, the university employs a lot more people who are proficient in literature, not in language, but in things that concern the language. It makes you wish they would employ someone for German language. The tutors are obviously not involved in any of the language things.

V.: Can we talk a bit more about your engagement in the different language learning aspects of the course? How much effort do you put in the language learning modules?

S.: It is difficult, because I have got German and French as well. I get up at about 9 every day, and on Monday I have got a lecture and after that lecture I stay in the [library] and do some reading for the literature on Friday. When I come back I work on my German grammar. And I do the exercises that we are supposed to do. Read the chapters. And on Wednesday I do in the evening the things we have to do for Paper I on Thursday morning. And on a Tuesday morning, when I have to get up at 8 , I do the translation that I probably got the evening before. So I do like a rough draft of that. So in total, I try to do six hours of academic work every day. I also work on Saturdays but I keep Sundays free. But if I don't get enough reading done, I make sure that I read. But I think you have to allow yourself time to do other things as well. Because I sing in a choir and also act in plays, so I think in terms of enthusiasm, I am as high as you can possibly be, but in terms of effort you also have to think of what matters: because 
you can spend two hours on a translation and do it half-heartedly but if you really want to convey the meaning and if you really want to get the register right, then -

V.: Then how long does it take you to prepare a translation?

S.: Probably about three and a half hours, maybe four, because what I tend to do is: I write it out all the different possible meanings and examples of translations of a word. But then I play around with the sentence and look at the way it all works together and what wants to be stressed and then through the course of that, I might choose a word in German that isn't the same as the one in English but might sound better. And to try... so I don't necessarily go for a clinical kind of translation, I don't think of what is the exact word, I look for a translation that is really tight but also is on the right level and contains the right and appropriate kind of register - to the best of my ability.

V.: Can you tell me a bit about the tasks you are enjoying? Seems like you like translation?

S.: Translation. Yes!

V.: Any other things?

S.: I think grammar is not one of the things I like the most. I don't think there is anything that I really detest.

V.: What about Paper I?

S.: I enjoy it in principle but the actual things we do aren't as enjoyable because they are so - language-wise they are demanding, a fierce training for the prelims. But the topics are, I don't know, dull, and - we only ever get to write 240, 300 words to write it is so small you don't feel like - 'cause when you start and you get into the flow of writing it is already finished. I mean you can probably tell from the way I am talking right now I have got a lot to say. Or we read through an article that is just not very long and than we talk about what is important and we look at the questions and she says: what is that? So people don't answer because it is obvious in a way, and most 
people don't prepare at home so you don't get as much out of it. And you are losing time. Yes, because when people come late, and a class is only 60 minutes and people come 15 minutes late than it's only 45 minutes. What is good, though, in those classes, is when you hand in something beforehand and she would write down five sentences on the board from your essays and you run through them and at first you think there is nothing wrong with them, but then she points out the mistakes we hadn't realised, it's like a mistake that all people make. And then she might suggest a few stylistic things, so in one sense: you look at five different sentences and you look at how they could be improved. So, I suppose these are sort of mild achievements. But that doesn't necessarily help me when I am writing the next essay. I might help you when you want to write that same sentence in the future.

V.: How could the situation be improved?

S.: Yes, more classes, more reading, more everything, more trips. You would think that there were trips to Germany organised by the university, I don't know. I had never been to Germany before I send off my application for [University A]. And then when I went it was after that. I still haven't been to France in my entire life. People will say: how can you be doing French, you have never been there! How did you manage to get in for that? And I just say: I don't know. Well, I completed more exercises than I would have done for A-level, but that doesn't make me feel that I have been improving. It is also the feedback that you get on them. Well, and I think when you get to a certain level anyway I think you need more feedback to get better, because you have already learnt something and you are doing it pretty well but to get that extra bit of data input and so on, they got to tell us. I am not moaning but... So, in my literature, this morning, for example, we are discussing something, and she compared me to - and she said that my essays are kind of like that, she said I have got all the amazing ideas kind of bubbling over. So that means I have to think of that first 
when I write an essay, get one idea write one paragraph, then turn to the next idea. So she wasn't much bothered with my ideas, but she was bothered with how I expressed them. I think it is the same all across the language and the literature, they can see that you have got all these amazing things to say, but they are not helping you to get them out they just let you know that you need to get them out. But I am aware that I need to get them out but my essay might lack a little bit of structure or I might need to just cut some things out of it - although I don't approve because I think you should say what you have to say - but I just think she should tell us how, they should give us more focus because we are supposed to learn and not just constantly submit things and then have them assessed and then not get back to them. We need to be told, ok then, if this is a not the gold standard, how to get better then, how? They say, because that is not difficult right, have less ideas and say them better. That is not helpful, how is this going to be better? How should I do this, what should I focus on? And how should I draw together my arguments and present them in a pretty little bundle?

V.: I can imagine that must be frustrating. This is for literature though, isn't it? Is the feedback same for language assignments?

S.: No, for language assignments there is hardly any feedback.

V.: Can I ask, in the questionnaire you said that you felt confident that you could deal with the different language learning tasks, such as reading, writing, listening, speaking, grammar and translation, is that right or has that changed?

S.: Hm, we don't really do any speaking or listening tasks, and I am not very pleased with my writing at the moment.

V.: Would you mind me looking at some of the tasks that you work on next time we meet, maybe some tasks that you feel really pleased with and something you are not so pleased with, and at the feedback?

S.: I don't think I am pleased with any of them. I have one here. 
[We look at the assignments.]

That one was where the feedback was very good, I mean what it actually said. That was like when I actually felt like I want to kick myself because very many are actually typos, I think I will actually shift to writing stuff out instead of typing it now, because I type it and sometimes I correct something but sometimes you just type something in that you didn't mean to, typing errors, and also I find it hard to concentrate looking at the screen, I find it harder to find the mistakes. And I think they mark pretty harshly. I mean it looks like everyone gets poor marks. Well, I think that's a bit - I don't think it has the desired effect. I think they mark you low because they want you to think: oh, I will be so much better the next time. But you actually think - oh no, I can't bother. They say that: they say you should be spending that much time, blah, blah, blah, but I spend that, I spend that much time. But you just don't get - I mean, I came here to get firsts. I know everyone here is pretty good, and everyone thinks: I am great and stuff, but - like when you have friends at other universities and they got miles better results than that, they are all getting firsts and I am getting like 64\%.

V.: That is not bad...

S.: I know, for [University A]. But everyone else, I mean, I can't say: oh, a 2.1 from [University A] is just like a first at other universities. They will go: no, no, no, that is awful, you can't just say that. That's like really bigotted. I think the university has to make a decision, it has to either say: we mark harsher than other universities, but then make distinct categories or else mark more fairly compared to other universities.

V.: Does that demotivate you?

S.: A bit.

V.: So what happens when you get your work and the mark back? 
What I do is I look at the actual feedback itself and see what is wrong. But then I do not really get down to thinking, oh no, this is a $64 \%$, what can I possibly do to get a first?

V.: You don't?

S.: No, I don't. I look at the actual comments. I look at the comments and see: tick, tick, tick, there are actually lots of ticks and a few mistakes, she often puts good. You know how to use phrasal verbs, etc. [reads feedback], so she wants me to feel good about this. There are morphological errors. So there is just a grammar mistake, I open the grammar book and the page and see - oh, ok. So hopefully I won't make the mistakes again.

V.: Does the feedback affect your confidence for writing at all?

S.: I think it depends how you are thinking of confidence, right. It would take a lot to make $m e$ think: oh, no, I am so not confident that I am actually giving in or crumble to pieces. I will still always write confidently and actually have the faith to hand it in. But it does give you a niggle in the back of your mind thinking: am I completely sure about this? Is this really going to be any good? But it's not enough a knock on my confidence to make me doubt that - to reconsider, I still go with my first instinct.

V.: Thanks a lot for sharing this with me. To conclude, would you mind rating your motivation for studying German on this scale?

[We look at the scale]

S.: Probably here, "so-so": just because this first term wasn't really great.

V.: Thank you. 


\section{$\underline{\text { 1. Interview Transcript, Lindsey (University B) }}$}

V.: Ok: first of all, thank you very much for participating. As you know my study is about motivation, foreign language learning motivation, focusing on German. Is there anything else that you would like to know about my study?

L.: No, I think I know it well from the information leaflet.

V.: So can we start then, good. Can I ask you: why are you studying German?

L.: Yep, erm, I've just always enjoyed it in school and I was always good at it, it's one of my favourite subjects. Yes. Well I've always enjoyed studying it at school and I always got good marks in it, so, I don't know, I never thought about doing anything else.

V.: So you've always thought that you were going to be studying German?

L.: Yes.

V.: Were there any other reasons that were important for you studying German?

L.: Hmm, no -

V.: Do you relate your reasons for studying to any long-term plans that you might have?

L.: Hmm, no, not really.

V.: What about job reasons, did job considerations play a role for you at all?

L.: Well, I suppose it's a good degree to have to get into a wide range of jobs. You have a lot of opportunities when you've got a language degree.

V.: How important was that for you?

L.: I would say it was in the back of my mind, but that is not why I am studying German, I've always enjoyed it, yes, I really enjoyed it at school.

V.: Why was that? 
L.: Because the teaching was really good, yeah, I really liked the lessons because it was quite a small class so if we needed any help we could just ask, we didn't have to wait for the teacher to go round the class.

V.: Oh, ok, so you really liked German at school?

L.: Yes, although I was good at other subjects, too, but German was my favourite subject.

V.: Oh, ok, I see. Now many people think about their future and imagine what they will probably be like in the future. Do you have a picture or a sort of vision of yourself with regard to German?

L.: Erm, I don't know, I'd like to be fluent. I've never had a picture of myself being fluent, I don't know, I never thought I was good enough I always wanted to get better at it. That's why I stuck with it.

V.: So you don't think too much ahead, you kind of think: my next step is to become a bit better, would that be right?

L.: Yeah, I want get better, fluent, hopefully.

V.: So you want to become fluent in German?

L.: Yes, I want to speak German fluently.

V.: Do you envisage using German in the future?

L.: I would like to, yes. But yeah, I don't know how, I would just like to.

V.: What do you hope to gain from studying German at university level?

L.: Well, I expected my language skills to improve a bit more than they probably have done because you don't get much speaking practice or anything. But I think my grammar's come on, there's a lot of focus on that rather than on the speaking. I expected more focus on becoming orally fluent which there isn't really until the year abroad.

V.: Any other kinds of expectations? 
L.: Well, I chose [University B] because it's got a good reputation, it's got a good German department and I liked the campus. I liked the feel of the campus when I visited, more than being in a city.

V.: And do you live on campus as well?

L.: Yes.

V.: So you said you hoped to gain fluency, sort of speaking proficiency, is that right?

L.: Yes.

V.: Was there anything else that you hoped to gain from studying German at university level?

L.: I suppose a better knowledge about culture, literature and things, I suppose. And history as well. I didn't know much about history before. But yes, I feel a bit disappointed, my expectations haven't really been fulfilled, sort of. Not really on the language side but I enjoy the literature side a lot more than I thought I would. I was quite worried about that.

V.: And what on the language side has not been fulfilled?

L.: The amount of oral practice that we get but there's not a lot of time for it, so. Yeah I expected to be speaking a lot more German and be using it a lot more. And when I was first looking into the courses I thought that things like essays and that would be in German, like we'd be writing German a lot more. I suppose because it's at degree level, language is more - it's not spoon-fed really but, you know, there's still... you can be sat there and the teacher will just tell you how to do the grammar but the literature - it's a higher level.

V.: More adult work?

L.: Yeah. I think because you have to do so much more on your own, you have to research.

V.: So you are disappointed that you don't have that in the language side? 
L.: Yes, I guess.

V.: But the rest of it you're happy with?

L.: Yep, with the literature side I'm really happy.

V.: Did you have any sort of expectations with regard to the language classes?

L.: Not really, I didn't really know what to expect. I thought, I suppose because it's classes I thought it would be quite similar to school really, just being taught the grammar as well. But I thought the classes'd be in German. All my German language classes are in English. My French ones are in French but German ones are in English. V.: Oh the French ones are in French? French language classes are taught in French?

L.: Yes, but I think that's the individual teachers, they choose to do it in French, but German's in English. Maybe because the grammar's so complicated that they can get it across easier in English.

V.: Do you have a feeling that because you do it in French and you have more classes in French, language classes in French; does that sort of have an effect on your motivation at all?

L.: Yes, I suppose I feel like they're more productive. I feel like I'm practising my listening skills as well as my speaking if I have to answer a question in French. But German it's just purely learning the grammar. No listening and speaking practice.

V.: So do you like one way or the other better?

L.: I always liked German more than French, it has always been my favourite subject, but I think the way French is taught here is better.

V.: And why is that, that you always liked German more than French?

L.: I think I prefer German as a language.

V.: Why is that?

L.: I think I find German harder and I think it's because it's more challenging that I enjoy it more. 
V.: But French is difficult, isn't it, for instance the pronunciation is very difficult, isn't it?

L.: Yeah, that side of it is difficult but I find the grammar easier to grasp in French because it's quite similar to English grammar I suppose.

V.: So you think German grammar is quite tough?

L.: Yes, very.

V.: And you like that?

L.: Yes, I mean, I have now noticed that French grammar is getting a lot harder, all the exceptions to rules that they're telling us now that I didn't know before. So that is interesting, but German was much harder at school.

V.: Oh, ok. So can I come back to your French course? Do you think if they taught more through German in your German degree course, would you feel, would that give you a motivational boost as well in German?

L.: Yes, definitely, yes, I would feel like I was being challenged more.

V.: Oh I see, because in French it's more of a challenge at the moment?

L.: Yes.

V.: I see. Can we now talk about the German side of your course? How is your language learning going at the moment?

L.: Er, on the whole, I think so-so. But it's more, like, not as in depth as it was in school. But, we'll focus on things for one lesson and then move on, the pace is a lot quicker. You're expected to do a lot more on your own. I find that difficult, although I'm getting used to it now. But it's still difficult though. Yeah, I suppose my motivation probably went down at the start of term when everything was so difficult and the workload was a lot but I'm getting used to it and getting more into it again, because now I know what's expected of me. 
V.: So how do you feel about learning German at the moment? Would you say you feel still keen to go on?

L.: I'm keen to go on because I know that at the end of the four years I'll have a really good standard of German. That spurs me on.

V.: So you said, you're expected to do a lot on your own: do you do a lot on your own then?

L.: Yes, quite a bit, we're encouraged to do a lot on our own. We have computer programmes that they want us to use.

V.: Do you use them?

L.: Occasionally when I have time but usually I don't during the week.

V.: Do you think they're helpful?

L.: They are, because they're like grammar exercises and things that are useful because you can't learn grammar by reading it.

V.: But you haven't yet used them much?

L.: No, not really. I probably put more work into the literature side because of all the reading that we have to do.

V.: Why is that?

L.: Because I have to do a lot of research for the essays, yes.

V.: But you also get language assignments, is that right?

L.: Yes, we have grammar exercises and things. Translations, things like that.

V.: And how would you describe your engagement in these classes?

L.: I spend probably two or three hours a week on language work.

V.: How would that compare to the hours you spend on literature?

L.: Probably about four or five on the literature. But that depends whether we've got an essay or not.

V.: So when you have an essay it will probably be even more, right? 
L.: Erm, yes, probably a lot of hours. Probably more nearer ten when we've got an essay.

V.: Do you also have to write essays or things like that for language classes?

L.: For language classes we haven't had to so far. We've just had things like short translations or write a passage about a description of someone. So you don't really spend much time on that.

V.: Can we talk a bit more about the language classes, how are they going?

L.: I'm enjoying grammar, small grammar, more, probably because we've got quite a small seminar group. So we'll work on grammar exercises together instead of being quite a solitary thing to do.

V.: This is the small language class you are taking about?

L.: Yeah, exactly.

V.: Yeah, I like to talk a little bit about these classes because obviously I don't really know these classes. So, I know you've got the large language class, the small language class, and the oral class. What's the class of all of these that you look most forward to?

L.: The small language class.

V.: The small language class. Can you tell me a bit about that one?

L.: There's about eight of us in it, and we just sit in an office like this, sit around a small table with the tutor. At the start of the lesson, we'll go over each lesson will have a particular theme, so, like, the subjunctive or the passive. We also do translations. And first of all, we'll go over the homework from last week. We go around the room so, like, everybody has to answer a question in turn. So everybody gets a go with saying one answer and being corrected if they're wrong. And anytime you can ask, like, questions if you don't understand or you've got it wrong. And then we'll usually be given a sheet explaining a new grammar rule. So we have to, like, we 
read that out, and she answers any questions on it. And then we'll do an exercises. The exercises are which we do going around the class again. So everybody answers a question in turn. But it's really, really useful. And it's just a really nice class as well. The tutor's really easy to get along with. It's quite intense with all the grammar 'cause you do have to think on the spot, but it really makes you rack your brain, and, like, you're putting the grammar into practice rather than being told it in a lecture.

V.: And that's something you enjoy?

L.: Yeah, it is really challenging. You really feel like you've worked hard when you come out the class. It makes you really, really tired. 'Cause you have to think so hard about the answers. I think that's a good thing. I always feel I have learned something when I come out. Even if I've got all the answers wrong, I know what I'm doing wrong.

V.: So could you say that it is a motivator, then, that it is difficult?

L.: Yeah, it is, definitely. Because then - if I find that I can't do part of the subjunctive, I'll have to go back and read over it and do more exercises on it. If everything was too easy, I'd probably never do anything like that.

V.: So, and there is the oral class, what is that like?

L.: The oral class? I find it a bit uncomfortable because there are 8 of us in the group but no one really wants to speak that much. So it's a bit awkward and the conversation doesn't seem to flow very well.

V.: Why is that? because most students seem to think that there are very few speaking classes but when they have a class no one wants to speak. Why would you think that is?

L.: I think everyone's just a bit shy. No one wants to be worse than everyone else, no one wants to be better than everyone else. And also because there are 8 of you in the 
group, it'd be quite easy to dominate the conversation and no-one wants to speak too much.

V.: So you would say that this is a confidence problem?

L.: Yeah, partly, and sometimes it's just difficult to think of something to say when the teacher gives you a topic to talk about if you don't know anything about that. Then it's quite hard.

V.: You are saying that sometimes you just don't know anything about the topics?

L.: Usually we get given an article that we have to read over during the week and there are questions on it which we'll discuss in the class. But the topics are sort of random. Usually we get given a vocab list with it which we're supposed to learn. And I think sometime the main problem is just knowing what to say.

V.: And you said you're supposed to learn the vocabulary list, and do you find the time to do that?

L.: Never.

V.: Yeah, it is difficult to find time, isn't it?

L.: Yeah it's really hard to find enough time to learn vocab because that's an extra thing to do, like it's not necessarily a set homework so I don't usually find the time to do that.

V.: So do you have a feeling that the others feel similar to you?

L.: I think so.

V.: So people won't sit down beforehand and study the vocab list?

L.: No, not usually.

V.: This is why people find it difficult to say something?

L.: Yes, I think so.

V.: Well, is there another reason why it is difficult to find something to say? 
L.: Probably partly for the vocabulary but then sometimes if you can't think of anything to say in English, then it's even harder in German. It also has to do with the topics: they are not very interesting.

V.: Ok, I see. And what about the large language class?

L.: I hate that.

V.: Why is that?

L.: I feel like it's out of focus. Like, in small language class we'll deal with a particular topic every lesson. In the large language class - I just feel like I don't know what I'm supposed to be getting from it. We just go over - we usually have - at the moment we're doing sort of comprehensions and things and grammar, like the kind of thing we're gonna have to do on the exam. I suppose I'll learn on a scale, but I just don't feel like I come out of it knowing anything. And it's quite a long hour, really. V.: So it's a sense of progress that's missing from this class?

L.: Yeah, it definitely is. I don't feel like I'm getting anything from it. I just don't really feel like I've learned that much from it. Like, whatever we do in the class, it's a lot of stuff I could do at home. You know, we do the comprehension in class; we could just do that for homework.

V.: And to get an idea, what's the main difference between the large language class and the small language class then, because you do grammar in both classes, don't you?

L.: I think the small one is more like practising the actual grammar rules and doing practice on it specifically. The large language class tends to be more like - it's not like a lecture, but we're more passive. Like, we don't have to say that much. The tutor, she tends to just stand up there and talk us through something, so we don't have as much input as the small languages. Probably why I don't feel like I get much from it, 'cause 
I don't have to use my brain. I can just sit there for an hour and then ask a few questions if I don't get something but generally just listen for an hour.

V.: Yeah, I can see that. What's the class you least look forward to? Is it this one then?

L.: Yeah.

V.: And the small one's the one you most look forward - ?

L.: Yeah.

V.: Yeah, I can see that. We were touching a bit on confidence. In those different skills, listening, speaking, reading, writing, translation, and grammar skills, where do you think you're most confident?

L.: I think probably reading at the moment. 'Cause I have to do so much of it, it's probably the thing that I practise the most. Like, I don't have to write in German very often. Like translation, we've only started to do that in the last few weeks. But listening, we don't do any. I started doing that by listening to the news reports on the radio, 'cause I did sort of realise a week ago that we really don't do any listening or speaking very often, so I need to start doing that myself instead of waiting for it to be done. German. And then yeah, writing: we don't have to write much. And obviously we don't speak very often. So, definitively reading.

V.: Do you think when we meet next time, could we have a look at the things you have written or some of the exercises that you've got, and maybe also at the feedback? L.: Yeah I'll bring my folder if you want.

V.: That would be lovely because it's sort of difficult for me to imagine what the tasks look like. Ok, is that ok if we just have a look at your questionnaire?

L.: Yes, that's fine. 
V.: I would like to check on a couple of items. For instance, there is "I consider learning German important because the people I respect think that I should do so". "So, so". You are sort of sitting on the fence there.

L.: Well, because I want to learn German because I want to do it but then when I was deciding which course to do obviously what my mum and dad thought and my teachers thought was important as well, like I took on board everybody's advice before I made a decision but ultimately it was my choice to study German.

V.: What did you parents and your teacher think?

L.: My teacher encouraged me to study German and my parents were not against it, I mean they think that a language degree in general is a good thing to have.

V.: "If my dreams come true, I will use German effectively in the future" gets a "very much", and the item "I often imagine myself as someone who is able to use German well" gets a "so-so".

L.: Because I always think I can improve on something, like I don't think I'm bad at German for the level I'm at but I can always improve and get better.

V.: But can you imagine yourself being able to use German?

L.: I sort of did before coming here but then I got bombarded with so many new things that I realised there's quite a lot that I don't know and I have to learn. It's a confidence thing really.

V.: Can we just for a second dwell on that? So you are saying that you could imagine yourself being fluent or becoming fluent in German and then you came here and you've sort of realised that it takes a lot to get there, would that be correct?

L.: Yeah, because in school I had good grades in German so I was one of the best in my class but then, I don't know, because I find it a lot more challenging here and there's so much that I have to improve on so I can get to the level of fluency at the end. 
V.: So the vision has kind of faded away?

L.: Well, I think it's just a lot more realistic now. I realise I have to put in a lot of work to get to that level.

V.: So you thought it would be easier to obtain the level of fluency?

L.: Yep.

V.: Ok, this item, "I would like to become more like people from German speaking countries." I felt that was interesting because it gets a "not really".

L.: I wouldn't like to become more German.

V.: Why doesn't the item get a "not at all" then?

L.: Yeah, maybe in terms of language I would like to become more German. I'd obviously like to have native-speaker fluency in the future. But apart from that I'm quite happy being English! I would say I have quite an English identity, yeah, yeah! [Laughing]

V.: Ok, fluent in German but with an English identity, I understand.

L.: Yes because I haven't got any German family or anything, no-one in my family's ever done German before.

V.: But can I ask, has doing German for quite a long time affect in some way what you call your English identity?

L.: Yeah, I suppose so.

V.: And how?

L.: Not sure. [Laughing]

V.: And then, "Learning German is a challenge which I enjoy": "very much", why is that?

L.: Yeah, learning a language is a challenge, because sometimes if it is too difficult and I'm making a lot of mistakes it can be demoralising but then if I don't make any mistakes then I'm not going to learn anything if everything's too easy. 
V.: Ok, I see, and this item: "Honestly I do not have much time to spend on language work": "Quite a lot". Why is that?

L.: Things like, the reading that I have to do for my other two modules and I sort of don't have - I have 14 hours of lectures a week which I suppose isn't that many but when they're spread out during the day it reduces the amount of time I can spend on language work when... you know if I have an hour between two lectures then by the time I get back it's time to go out again and stuff like that.

V.: Is it also because you're prioritising the literature work?

L.: Yes, just because it takes longer and there's more of it. The research and the reading as well because the books, they're usually about 150 pages long but it takes me quite a while.

V.: Do you read the original versions?

L.: I try to, I have not read all of them in the original, but I have managed to read some of them and understand them so far even if I've not understood everything. I think I've understood the gist of it.

V.: "I try to learn as many new words as possible during language classes": "Not really".

L.: Just because...I do write them down but I don't usually get round to learning them. If I do hear a new word I do write it down with the intention of going back and learning it but something always gets in the way. Like in school when we were doing something we'd have time to repeat things, repeat vocabulary, so it would be drummed in more but now we'll have one lesson on each grammar point or something so it's not... well, I suppose it's efficient with time and we'll get through a lot more but I don't know whether I'm absorbing it quite as well as in school.

V.: So you expected classes to be more like at school? 
L.: I'm not sure. Really I didn't really know what to expect because I knew it wouldn't be like school where we got spoon-fed but then I thought whether, I don't know, I thought... our grammar lessons in school it was the teacher stood at the front just teaching us, you know, telling us how you do each grammar point but now it's a lot more... we'll get a grammar exercise or something and we'll have to answer a question each rather than just being taught how. I don't know. There's not as much explanation of things, I think. That's more on you to go and read explanations and then ask questions if you don't understand something.

V.: So you were a bit disappointed with that to start with?

L.: A bit but then... I suppose I was a bit disappointed but a lot of people come out of 4th year and they have a really high standard of German, so I'm not too worried; if I do everything that they tell me to do, I think we will learn during our year abroad.

V.: Is that something that the other students tell you?

L.: I suppose in the curriculum in that we only have one hour of oral a week, so it's definitely expected that you improve your oral skills when you're abroad because there's obviously a lot more opportunity to do that. That's just the impression I get from not having many hours on language really.

V.: But the professors or the lecturers as well tell you that because sometimes they comment on that?

L.: They've never said it explicitly but I think on the open day people did ask questions about the language because half of the course is literature and people were asking how do you improve your language and they said well that's why you have the year abroad, to do that. And I spoke to a 2nd year student about what their German's like now. They said they didn't improve that much between first and second year in speaking, I don't know about grammar. I think it'll definitely be the year abroad to improve it. 
V.: So you think the university places more emphasis on literature classes than on language classes?

L.: Well, sort of, we don't have that many language classes. So if there was more importance on it we'd have more contact hours. But then again they do emphasise that it's really important to go and if you don't go your work will suffer. And they do try and pack in as much as possible so we do get the benefit from them.

V.: Sorry, I don't quite follow, go where?

L.: The year abroad.

V.: Ah, ok, I see.

V.: "I spend as much time as possible on language learning" Why's there a "so-so" here?

L.: There are a lot of opportunities but it's just having the time really. There are societies where you can go and speak German.

V.: What kind of...?

L.: It's called LipSoc, it's the Linguistics Improvement and Practice Society.

V.: In the language centre?

L.: No, it's just a society, they have several groups a week for German and they run lots of languages. So you go and you meet up with the same people every week and a group leader and you have a conversation in German for an hour. And the group leader's there to sort of prompt you and move the conversation along a bit so you make sure you speak in German. That's an hour a week.

V.: Do you go there sometimes?

L.: Not at the moment but yeah I want to try and go every week but I suppose it's more like every week to every other week that I'll go. It sort of depends because it's on a Friday and Friday's quite a busy day so it depends really. 
V.: Good, let's move to the confidence items: confidence-wise, you felt least confident about writing an essay in German?

L.: Yes, we didn't write long essays at school and so far we have written only short pieces here.

V.: Listen to and understand a lecture in German and listen to and understand a German film?

L.: Yes, we don't practise that much either.

V.: With regard to speaking you've put "so-so".

L.: I don't really feel like I've done that much speaking since I've been here so I don't think my confidence has improved really. I doubt there's been an improvement.

V.: Thanks a lot, this is it. To conclude, would you mind rating your motivation for studying German on this scale?

L.: It's "so-so" or maybe, maybe a bit better.

V.: Why is that?

L.: I think I am a bit more motivated, but because there's such a big reliance on the year abroad really, it's easy to put things off a bit and be like, well it will improve later on.

V.: And that has not really helped your motivation?

L.: Not really.

V.: And that's why you say that your state of motivation was "so-so".

L.: Yes, but is has improved a bit, so maybe here [indicates "quite high"].

V.: Thanks a lot. 


\section{Appendix $7 \quad$ Example of Feedback (Jebedee)}

Binnen Sekunden war aus dem verdächtigen Ausländer der Gefreite Hagi geworden, ein guter Deutscher! $!^{2}$

Die Laster des Rassenvorurteils und der Personen, die besonders heutzutage in vielen Westköpfen existieren, werden in diesem Satz ins Blickfeld gebracht. Der Satz verkörpert die wachsende, misstrauische Einstellung zu den Ausländern, die aus dem Nahen Osten stammen. Wir wissen, dass der Schreiber wörtlich ist, indem er die Phrase „Binnen Sekunden“ benutzt. Wegen Hagis Rassenverteilung wurde er sofort ein Verdächtiger. Jedoch wurde er sofort akzeptiert, als er den Bundeswehrausweis in den Augen des Türstehers verwandelt hatte. Weiterhin gibt es eine radikale, ironische Einstellungsveränderung zu Hagi, da er sich aus einen Verdächtiger (oder eigentlich ein verdächtigen Selbstmordattentäter) in einen Soldat des Vaterlands verwandelte. Der Hauptpunkt des Satzes besteht darin, dass wir uns Bildnisse von unseren Mitmenschen machen und sie dadurch in Rollen zwingen, die ihrem Wesen nicht gemäß sind.

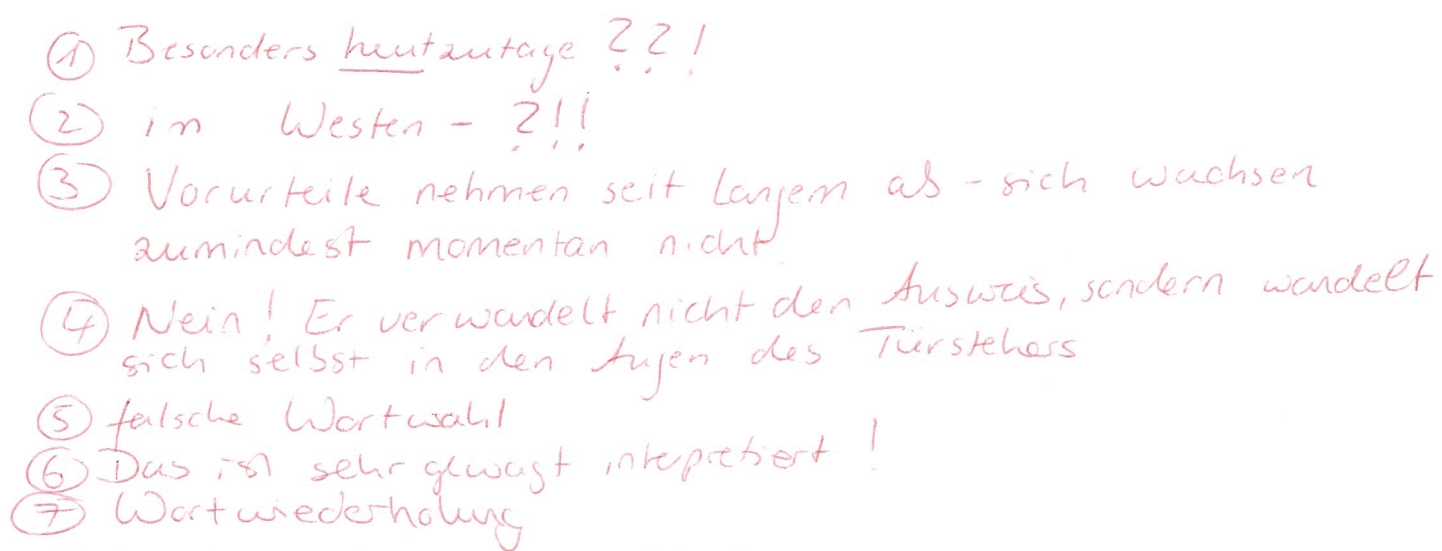

The lecturer's summarising comment says: "Your first lines sound like a cliché [verbatim: cliché-ed] and tendentious."

\footnotetext{
${ }^{2}$ Note that the original feedback was typed up and the lecturer's handwritten comments were copied by the researcher to guarantee anonymity.
} 


\section{Appendix 8 Example of Feedback (Richard)}

Mausklick für Bücherwürmer

$2 / 31$. Wenn man die Internet-Seite von 'Bookstacks' eröffnet, wird man von einer

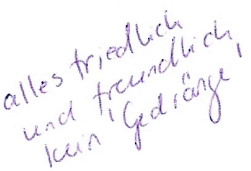
Suchmaschine und einer Tafel die Zahl der umsehenden Kunden angezeigt,(begrüßt.)

2. Man bekommt in einigê Sekundé eine große Auswahl von vielen Titeln, die auf den finish one clanse Wunsch des Kundes abstimmte ist.

3. Die beste Vorteile von 'Bookstacks `sind, dass vor allem die Kunden auf die Buchhandlung zu Hause zugreifen können, der Prozess ist ganz schnell, und das virtuelle Geschäft ist rund um die Uhr geöffnet. Das ist auch für die Buchhändler vorteilhaft, weil sie längere Geschäftszeit haben, und wegen der weltweiten Art der Web-Site, können die Buchhändler viele Kunden auf der Welt erreichen.

4. Wegen des Booms des Internet-Geschäfts, glaubten viele Leute, dass Bücher überflüssig werden würden, um Platz für elektronische Alternative machen.

5. Der Verkauf von echten Büchern ist erfolgreicher, aber Bücher auf CD-Rom sind attraktiv zu den kleineren Marktnischen.

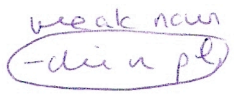

Man braucht nicht das Produkt an- oder auszuprobieren, im Internet ist es möglich, eine Vorstellung des Buch zu bekommen, z.B. durch Abbildungen, Leseproben und Inhaltsangaben. Man kann auch eine Meinung des Buchs entwickeln durch viele Buchbesprechunge und der Preis ins Netz sehen.

7. Meiner Meinung nach werden wir immer Bücher haben, sie sind ein sehr wesentlicher Teil unsers Lebens. Zuerst wird die Nachfrage für etwas Echtes immer da sein, weil man eine physische Verbindung mit den Figuren und der Handlung machen möchte. Vielleicht wäre es leichter für die Leser, wenn man alles hören kann, weil die Hände freigelassen sind, aber mit Hörbüchher usw. bekommt man nur eine Interpretation, die von dem Erzähler. Wenn ich Zeit habe lese ich sehe gern. Ich finde es sehr entspannend und ich kann mich für einige Stunde in einer anderen Welt verlieben, aber manchmal ist es schwierig zwei oder drei Stunden zu finden, darin ich lesen kann, wegen Unterbrechungen und beschäftigter Lebensstil. Natürlich benutze ich andere Medien, weil manchmal sie lohnend sind, ein Buch zum Beispiel ins Netz

6. lesen. Aber die wird hur für praktische Grunde, weil sie eine Dringlichkeit haben. 2
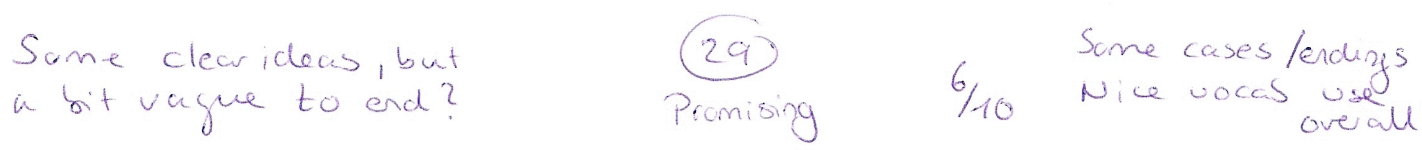

\footnotetext{
${ }^{1}$ Note that the original feedback was typed up and the lecturer's handwritten comments were copied by the researcher to guarantee anonymity.
} 


\section{Appendix 9 Screeplot for Effort Components}

Scree Plot

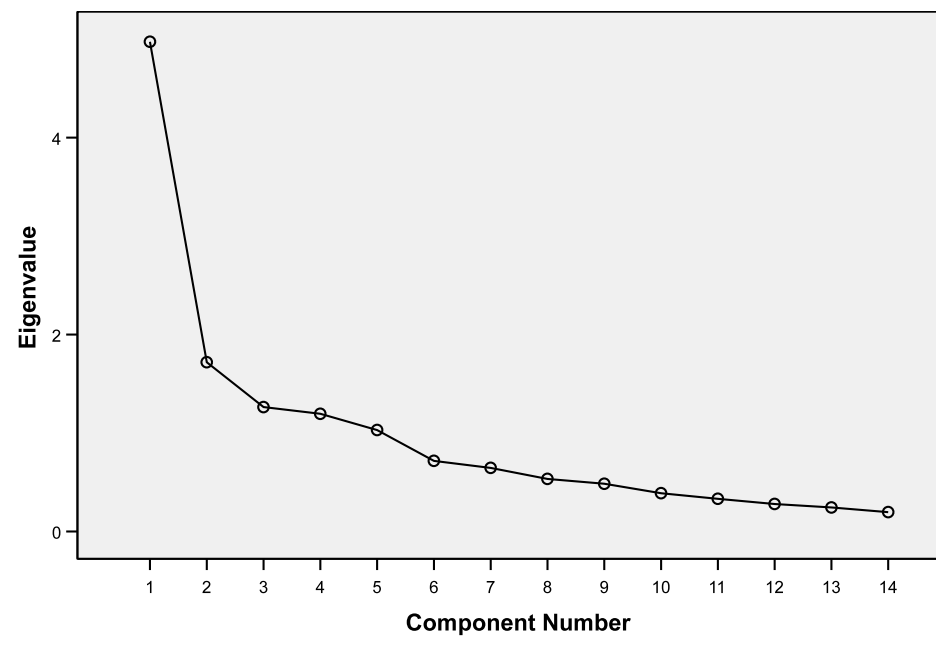




\section{Appendix 10 Pattern/Structure for Effort Coefficients}

\begin{tabular}{|c|c|c|}
\hline & \multicolumn{2}{|c|}{ Component } \\
\hline & 1 & 2 \\
\hline $\begin{array}{l}\text { I invest much time } \\
\text { and effort on all } \\
\text { written language } \\
\text { assignments, such } \\
\text { as German essays, } \\
\text { etc. } \\
\text { I am working hard at } \\
\text { learning German } \\
\text { I am the kind of } \\
\text { person who makes } \\
\text { great efforts to learn } \\
\text { German } \\
\text { I put as much effort } \\
\text { as possible into } \\
\text { language } \\
\text { assignments } \\
\text { I can honestly say } \\
\text { that I am really doing } \\
\text { my best to learn } \\
\text { German } \\
\text { I can honestly say } \\
\text { that I put a lot of } \\
\text { effort into German } \\
\text { language classes } \\
\text { I spend a lot of time } \\
\text { on translations } \\
\text { RC Honestly. I do } \\
\text { not have much time } \\
\text { to spend on } \\
\text { language work } \\
\text { RC I often feel that it } \\
\text { takes too much effort } \\
\text { to really engage with } \\
\text { a piece of translation } \\
\text { I try to learn as many } \\
\text { new words as } \\
\text { possible during } \\
\text { language classes } \\
\text { I spend a lot of time } \\
\text { on improving my } \\
\text { grammar where I feel } \\
\text { it to be necessary } \\
\text { I try very hard to read } \\
\text { more than just set } \\
\text { texts in German. e.g. } \\
\text { German newspapers/ } \\
\text { magazines } \\
\text { I spend as much time } \\
\text { as possible on } \\
\text { language learning } \\
\text { RC I think it would be } \\
\text { too much effort to } \\
\text { read anything other } \\
\text { than set texts in } \\
\text { German }\end{array}$ & .771 & $\begin{array}{l}.717 \\
.656\end{array}$ \\
\hline
\end{tabular}




\section{Appendix 11 Sreeplot for Self-Efficacy Components}

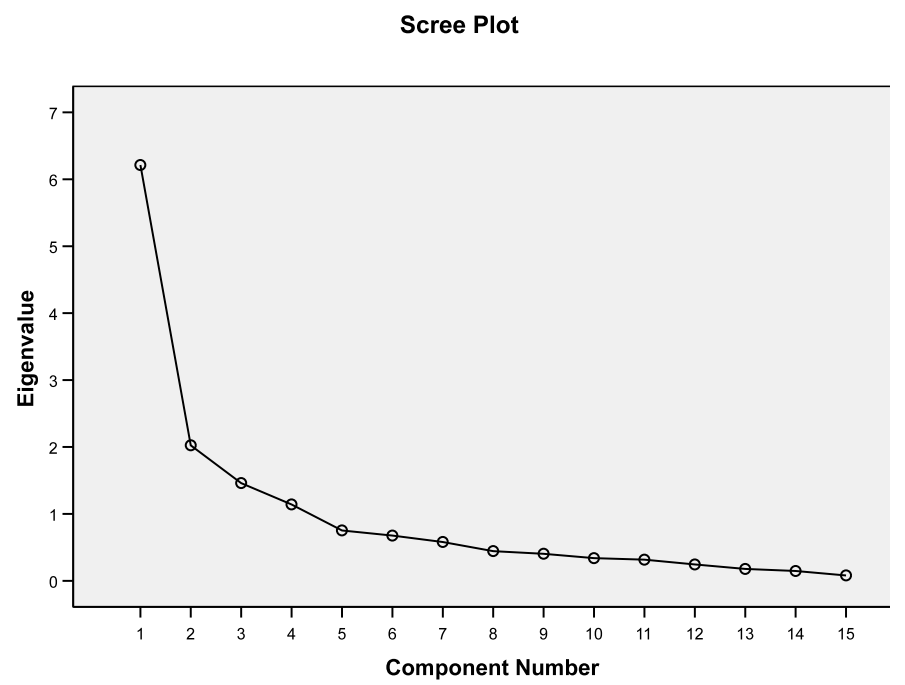

\section{Appendix 12 Component Correlation Matrix for Self- Efficacy}

Component Correlation Matrix

\begin{tabular}{|l|r|r|r|l|}
\hline Component & \multicolumn{1}{|c|}{1} & \multicolumn{1}{|c|}{2} & \multicolumn{1}{|c|}{3} & \multicolumn{1}{c|}{4} \\
\hline 1 & 1,000 &, 312 &, 406 &,- 251 \\
2 &, 312 & 1,000 &, 178 &,- 331 \\
3 &, 406 &, 178 & 1,000 &,- 268 \\
4 &,- 251 &,- 331 &,- 268 & 1,000 \\
\hline
\end{tabular}

Extraction Method: Principal Component Analysis.

Rotation Method: Oblimin with Kaiser Normalization. 


\section{Appendix 13 Rotated Self-Efficacy Component Matrix}

\begin{tabular}{|c|c|c|c|c|}
\hline \multicolumn{5}{|c|}{ Rotated Component Matrix } \\
\hline & \multicolumn{4}{|c|}{ Component } \\
\hline & 1 & 2 & 3 & 4 \\
\hline $\begin{array}{l}\text { How confident are you } \\
\text { that in the course of this } \\
\text { academic year you can } \\
\text { write an essay in } \\
\text { German? }\end{array}$ & & 700 &, 309 & \\
\hline $\begin{array}{l}\text { How confident are you } \\
\text { that you can write a short } \\
\text { summary of a newspaper } \\
\text { article in German? }\end{array}$ & & 811 & & \\
\hline $\begin{array}{l}\text { How confident are you } \\
\text { that you can write your } \\
\text { opinion about an article in } \\
\text { German? }\end{array}$ & & 903 & & \\
\hline $\begin{array}{l}\text { How confident are you } \\
\text { that you can read and } \\
\text { understand the main } \\
\text { ideas of a German novel? }\end{array}$ & & & & 834 \\
\hline $\begin{array}{l}\text { How confident are you } \\
\text { that you can read and } \\
\text { understand the main } \\
\text { ideas of a German } \\
\text { poem? }\end{array}$ & & & & 842 \\
\hline $\begin{array}{l}\text { How confident are you } \\
\text { that you can read and } \\
\text { understand a newspaper } \\
\text { article? }\end{array}$ & 380 & & &, 543 \\
\hline $\begin{array}{l}\text { How confident are you } \\
\text { that you can listen to and } \\
\text { understand a lecture in } \\
\text { German? }\end{array}$ & .648 & & &, 331 \\
\hline $\begin{array}{l}\text { How confident are you } \\
\text { that you can listen to and } \\
\text { understand a German } \\
\text { native speaker in a } \\
\text { tutorial? }\end{array}$ & ,735 & & & \\
\hline $\begin{array}{l}\text { How confident are you } \\
\text { that you can listen to and } \\
\text { understand a German } \\
\text { film? }\end{array}$ & .535 & &, 377 & 399 \\
\hline $\begin{array}{l}\text { How confident are you } \\
\text { that you can engage in a } \\
\text { conversation with a native } \\
\text { speaker about a novel? }\end{array}$ & 869 & & & \\
\hline $\begin{array}{l}\text { How confident are you } \\
\text { that you can speak about } \\
\text { a film with a native } \\
\text { speaker? }\end{array}$ & 884 & & & \\
\hline $\begin{array}{l}\text { How confident are you } \\
\text { that you can discuss a } \\
\text { newspaper article with a } \\
\text { native speaker? }\end{array}$ & 899 & & & \\
\hline $\begin{array}{l}\text { How confident are you } \\
\text { that you can do well in } \\
\text { German grammar } \\
\text { classes? }\end{array}$ & & .511 &, 551 & \\
\hline $\begin{array}{l}\text { How confident are you } \\
\text { that you can do well in } \\
\text { translation classes where } \\
\text { you translate a short } \\
\text { prose passage from } \\
\text { German into English? }\end{array}$ & & & 843 & \\
\hline $\begin{array}{l}\text { How confident are you } \\
\text { that you can do well in } \\
\text { translation classes where } \\
\text { you translate a short } \\
\text { prose passe from English } \\
\text { into German? }\end{array}$ & & &, 830 & \\
\hline
\end{tabular}

Extraction Method: Principal Component Analysis.

Rotation Method: Varimax with Kaiser Normalization.

a. Rotation converged in 6 iterations 


\section{Appendix 14 Students' Test Results}

\begin{tabular}{|l|l|l|}
\hline Name & Grammar Diagnostics & Language Assignments \\
\hline $\begin{array}{l}\text { Jayanthy } \\
\text { A })\end{array}$ & 6.8 (points out of 10) & $\begin{array}{l}\text { Paper I: 60\% } \\
\text { Paper II: 63\% }\end{array}$ \\
\hline $\begin{array}{l}\text { Tom } \\
\text { (A) }\end{array}$ & 8.4 (points out of 10) & $\begin{array}{l}\text { Paper I: 70\% } \\
\text { Paper II: 65\% }\end{array}$ \\
\hline $\begin{array}{l}\text { Valda } \\
\text { (A) }\end{array}$ & 5.1 (points out of 10) & $\begin{array}{l}\text { Paper I: 63\% } \\
\text { Paper II: 55\% }\end{array}$ \\
\hline $\begin{array}{l}\text { Jebedee } \\
\text { (A) }\end{array}$ & 4.9 (points out of 10) & $\begin{array}{l}\text { Paper I: 70\% } \\
\text { Paper II: 57\% }\end{array}$ \\
\hline $\begin{array}{l}\text { Samuel } \\
\text { (A) }\end{array}$ & 5.6 (points out of 10) & $\begin{array}{l}\text { Paper I: 60\% } \\
\text { Paper II: 54\% }\end{array}$ \\
\hline $\begin{array}{l}\text { Jane } \\
\text { (A) }\end{array}$ & 7.3 (points out of 10) & $\begin{array}{l}\text { Paper I: 39\% } \\
\text { Paper II: 65\% }\end{array}$ \\
\hline $\begin{array}{l}\text { Lindsey } \\
\text { (B) }\end{array}$ & 51 (points out of 100) & $\begin{array}{l}\text { Language Exam I 79\% } \\
\text { Language Exam II 71\% }\end{array}$ \\
\hline $\begin{array}{l}\text { Heather } \\
\text { (B) }\end{array}$ & 38 (points out of 100) & $\begin{array}{l}\text { Language Exam I 71\% } \\
\text { Language Exam II 64\% }\end{array}$ \\
\hline $\begin{array}{l}\text { Susan } \\
\text { (B) }\end{array}$ & 49 (points out of 100) & $\begin{array}{l}\text { Language Exam I 72\% } \\
\text { Language Exam II 71\% }\end{array}$ \\
\hline $\begin{array}{l}\text { Marc } \\
\text { (B) }\end{array}$ & 32 (points out of 100) & $\begin{array}{l}\text { Language Exam I 68\% } \\
\text { Language Exam II 63\% }\end{array}$ \\
\hline $\begin{array}{l}\text { Peter } \\
\text { (B) }\end{array}$ & 55 (points out of 100) & $\begin{array}{l}\text { Language Exam I 66\% } \\
\text { Language Exam II 64\% }\end{array}$ \\
\hline $\begin{array}{l}\text { Richard } \\
\text { (B) }\end{array}$ & 34.5 (points out of 100) & $\begin{array}{l}\text { Language Exam I 53\% } \\
\text { Language Exam II 63\% }\end{array}$ \\
\hline
\end{tabular}




\title{
Appendix 15 Example of Interviews coded in MAXQDA
}

\section{Example:}

Code: Reasons For Studying German $\backslash$ School ExperiencelSchool Teacher

Coded across interview points 1 and 2.

\author{
Text: Interview WSusan_15.12.2008 \\ Gewicht: $\quad 0$ \\ Position: $\quad 13-13$ \\ Code: Reasons For Studying GermanlSchool ExperiencelSchool Teacher
}

S.: Because I found that A level, I found my teachers very good. I mean, I've seen and compared maybe to some other people's teachers. He was German himself, so he taught us very well.

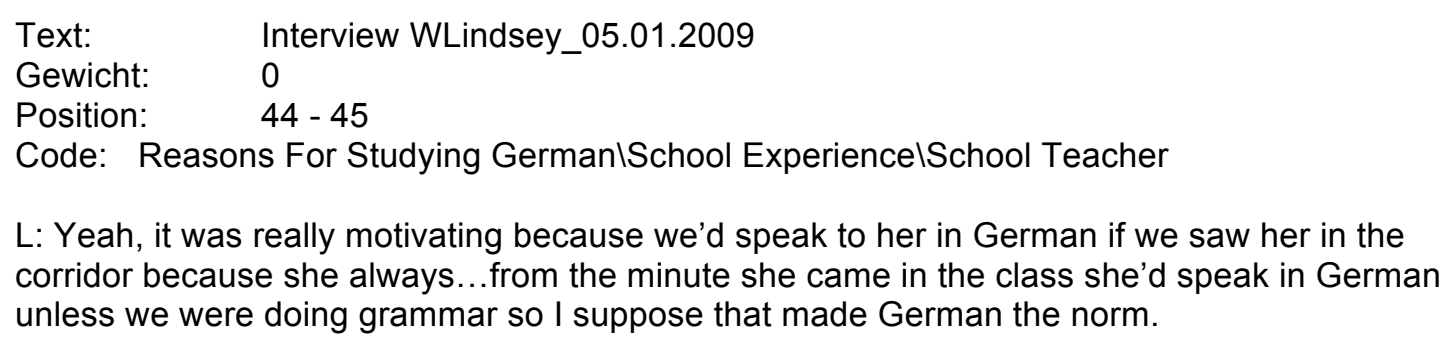

$\mathrm{H}$. : I just really enjoyed learning the language really it was my favourite subject at school. I think I was quite inspired by my teachers as well because I had really good teachers for it and I just enjoy learning it so I wanted to carry on doing it really. 
Text: Interview WHeather_05.01.2009

Gewicht: $\quad 0$

Position: $\quad 34-40$

Code: Reasons For Studying GermanISchool ExperiencelSchool Teacher

$\mathrm{H} .:$ I think one thing was I had good teachers and I think because I enjoyed languages I concentrated on them probably more than my other subjects.

$\mathrm{V}$ :: So you put in a lot of work?

H.: A fair bit of work, yeah, and, I dunno, I suppose just because I did them...because we did them so often, I mean it was pretty much everyday at school, I think just the constant learning and going over stuff, it just kind of...all the rules and things stick in your brain.

V.: Did you have a German German teacher? I mean was he a native speaker?

H.: No. They were all English, teaching us German.

$\mathrm{V}$.: Was that sort of a motivating factor or not a motivating factor?

$\mathrm{H}$.: Motivating, definitely, and it's less intimidating as well because if you have a teacher who is German I think you feel almost more guilty about making mistakes because it's their language whereas when it's an English teacher they also understand how you're learning the language because they've learnt it to start with as well. I think that is quite motivating and gives you more confidence really. And my teacher's German was very good, yeah, I hope I can become that good, too.

Text: $\quad$ Interview WRichard_12.12.2008

Gewicht: $\quad 0$

Position: 22 - 22

Code: Reasons For Studying GermanISchool ExperiencelSchool Teacher

R.: Well, I say, I really enjoyed it throughout school, and, excelled, well, I say excelled, I got $A^{*}$ at GCSE and then did well at A-Level as well. I always got on really well with my teachers I suppose, yeah they encouraged me to apply to go for it at university, and I mean, I enjoyed the other, the rest of my A-levels, but none as much as this one, none as much as German I suppose.

Text: $\quad$ Interview WRichard_05.01.2009

Gewicht: $\quad 0$

Position: $25-30$

Code: Reasons For Studying GermanISchool ExperiencelSchool Teacher

V.: Was your teacher German?

R.: One of them was German, um, the other was English, but um, it was always taught in German, um, everything was taught in German, except when we couldn't grasp something. $\mathrm{V}$.: And did that affect you positively or negatively in your motivation?

R.: Um, I think positively because she regularly went back, she was able to bring back magazines and newspapers and stuff, so I guess in that way it benefitted us, um, she would have had more of a knowledge of the language and the culture than an English speaking teacher would.

$\mathrm{V}$ :: And the English teacher?

R.: Um, yeh he was good, because he was a stickler for grammar, so he was uh, he was very up on hammering it in to us, um, and I enjoyed his method of teaching, um I guess you could say it was someone to look up to, but I don't really have any desires to become a German teacher. Yes, I think we all looked up to him, he was very good, he spoke German fluently, you see. 


\author{
Text: Interview OJebedee_16.01.2009 \\ Gewicht: $\quad 0$ \\ Position: $\quad 28-33$ \\ Code: Reasons For Studying GermanlSchool ExperiencelSchool Teacher
}

V.: You told me, I think, that your teacher was English?

J.: He was English, yes, but he had a first degree in German. He was the best teacher - I mean I like the language classes here - but I think he was the best language teacher I have ever come across, not just German, but also compared to other subjects. And I think he always got the best grades as well, like at GCSE everyone in my year, got A stars or As, so yes, he was a good teacher. I think that does help someone to be - someone who is so interested in the subject, they dedicate time to you to make you just as interested in that subject.

V.: To what factors would your attribute your success at school then?

J.: To him.

V.: Any others?

J.: Yes, I attribute almost all of it to my teachers, just the way it was at school, my teachers I find that the subject I did was very interesting, I think that is the key. If you find something interesting then you are more likely to put work into it and go home and revise, because you find it interesting anyway. When it is interesting it does not feel like a chore. But I would definitely place - I think - a teachers' motivation and a teachers' input and the way they teach, I think contributes a great deal to the way a person views a subject and the way that a person works at it.

Text: Interview OJayanthy_16.01.2009

Gewicht: $\quad 0$

Position: $\quad 18-20$

Code: Reasons For Studying GermanlSchool ExperiencelSchool Teacher

J.: I think I had a very good teacher. She was quite experienced and she knew what it took to get in here, just because she had coached so many people, she had taught so many people to get into here so she was quite experienced -

V.: Was she German or was she English?

J.: She was English, actually, I never had a German native-speaker. Which is a shame, I would have quite liked to have to - no, she was English, but I just think that she was - she was quite old, she was near her retirement, and she had a lot of experience, she had been to Germany a lot, so she kind of knew the culture and everything. And she arranged exchanges for us to go over, like in the holidays and stuff, and that was really useful and that was something not many teachers do, so that gave us the opportunity to go abroad. Because I think, going abroad, if you can do it quite cheaply as well it is just an opportunity, it is really good fun. This is a good way to practise. So I think I greatly improved because of that, I think it is part of the reason that I got in, because that gave me a boost. Cause I was able to directly - because I was able to do a week's work experience in a Kindergarten near Frankfurt which was good fun, it was really difficult because the children obviously didn't speak English, but it was really good practice. Because obviously I was forced to speak German, that was really useful, I enjoyed that. So that - so I was able to talk about that in my interview here, so that, altogether I think that is what attributed to it, my teacher, the experience abroad - because I couldn't go abroad to Germany now, I wouldn't know where to start, how to arrange a work experience, because I think that is quite tricky, because you have to approach the company and send in an application, because my teacher set it up with students over the years, she just did it for us, so that was really convenient.

V.: So the teacher was good, you think?

J.: Yes, very, yes, quite experienced and very dedicated. 
$\begin{array}{ll}\text { Text: } & \text { Interview OTom_03.12.2008 } \\ \text { Gewicht: } & 0 \\ \text { Position: } & 2-2 \\ \text { Code: } & \text { Reasons For Studying GermanISchool ExperiencelSchool Teacher }\end{array}$

T.: And I think, I had a really good German teacher for a start, she was really enthusiastic about it.

Text: $\quad$ Interview OTom_03.12.2008

Gewicht: $\quad 0$

Position: 22 - 24

Code: Reasons For Studying GermanISchool ExperiencelSchool Teacher

T.: I would like to be fluent, but ultimately that's want I want to be.

$\mathrm{V}$.: That influences your motivation?

T.: Yes, and possibly, my English teacher she was Portuguese, the other language I do, and her English was just amazing. I suppose this is also a motivation, you see like other people, their English is awful, but others are amazing, her English was really, really good. I perceived it that it is really a possibility, a real possibility to be like that - you can definitely write with almost a $100 \%$ accuracy. I suppose that has really motivated me as well.

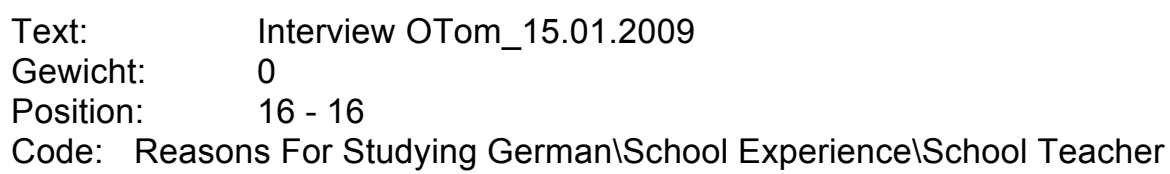

T.: So there is that, perhaps more enthusiastic as well. They had to be more enthusiastic. And probably less academic as well. We also had tea and toast in the lesson, less formal,

Text: Interview OTom_15.01.200

Gewicht: $\quad 0$

Position: 22 - 24

Code: Reasons For Studying GermanISchool ExperiencelSchool Teacher

T.: - well, in the first three years, it was ok, I hardly enjoyed it, I was one of the best, but it was like really basic level that we did. Actually I had of teachers, my teacher went on maternity leave and we had a teacher who could not control the class, so it was not one of the most pleasant experiences. And then for GCSE more out of just because I thought, I should do it, I think a language is important, it was something I was good at, I was one of the best at school, not that I was very good, but I thought: yes, I will do that and when it got to German GCSE I got a new teacher and I don't think I have ever met anyone so enthusiastic about it, the classroom was just plastered in German stuff, in tourism Kitsch as it were, and she was just really friendly, she is just crazy [affectionate], her enthusiasm just kind of rubbed off. So partly, my success is down to the teacher, because if you have a bad teacher you are not going to enjoy the subject. 


\section{Example}

Code: Possible Selves\Marc

Coded across all interviews (individual trajectory, Marc).

Text: Interview WMarc_12.12.2008

Gewicht: $\quad 0$

Position: $14-18$

Code: Reasons For Studying German|Possible Selflldeal Self Abstract Fluency

V.: Many people think about their future and imagine what they will probably be like in the future. Do you have a picture of a sort of vision of yourself with regard to German?

M.: Yeah, I want to be fluent in German, yeah, speak fluently, that is my ultimate goal.

$\mathrm{V}$ :: Mm-hmm. Is that something that drives you, you'd say?

M.: Yes, yeah, very much

V.: Do you envisage using German in the future?

M.: Hmm, not sure, I would like to use it, yes. Obviously speaking another language is quite an asset, not many people can do that, yeah.

Text: $\quad$ Interview WMarc_12.12.2008

Gewicht: $\quad 0$

Position: $14-18$

Code: Reasons For Studying German|Possible Selfldeal Self Abstract Fluency

V.: Being able to converse in another language is an important part of the person I want to become, "quite a lot", can you elaborate on that?

M.: Yes, yeah, I would like to become fluent, to be able to converse in another language, it's an educational thing, isn't it? speaking other languages. It's ignorant to just speak one language, people in top jobs [?], top positions, they usually speak more than one language.

Text: Interview WMarc_12.12.2008

Gewicht: $\quad 1$

Position: $\quad 178-181$

Code: Reasons For Studying GermanIInterest in Country/Attitude towards Germans/ldeal L2 self

V.: I would like to become more like people from German-speaking countries, "so-so"', why is that?

M.: Well, I would like to become more like them in the aspect of being fluent in German, but I also...yeah, I don't pretend in any way to be German. I am still myself; I just want to be myself, who can speak German fluently, yeah, no, I don't want to become more German, but I would like to see myself as an Englishman fluent in another language.

Text: Interview WMarc_05.01.2009

Gewicht: $\quad 0$

Position: $\quad 88$ - 92

Code: Reasons For Studying German\Possible Selflldeal Self Abstract Fluency

V.: So do you feel that you're getting closer to your ultimate goal then?

M.: Um, I think it's still very early. I think I have improved, not as much as I wanted. I wouldn't say I'm anywhere close to being fluent yet, but I'm just driving for fluency - obviously l'm not going to achieve anytime soon - but that is still basically my motivation. 


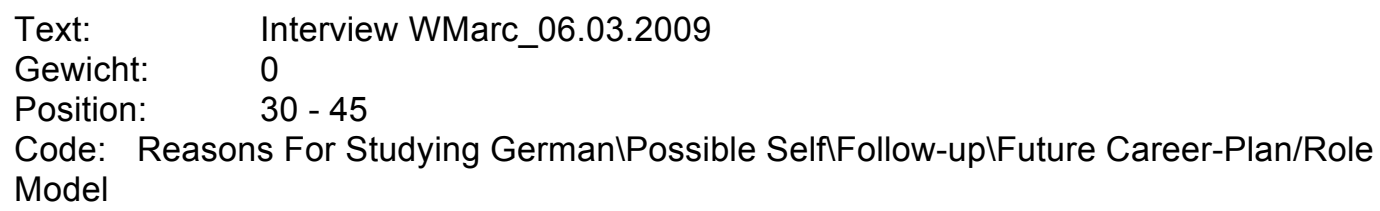

V.: I wonder, have you experienced any changes in your ideas about future career plans over the holidays?

M.: No, I am still looking at, like translating but I wouldn't say l'm any more definite or have thought of any other careers over the holidays than where I was before.

Text: Interview WMarc_17.04.2009

Gewicht: $\quad 0$

Position: $\quad 88-92$

Code: Reasons For Studying GermanIPossible SelffFollow-up/Future Career-Plan

V.: And we spoke last time about your sort of future a little bit, and you said that your future life sort of involves someone who uses German in some way, probably translating, is that correct?

M.: Sill the same, yeah. Yeah, it's still driven as part of the job that I will eventually get, and I will be fluent in it hopefully.

$\mathrm{V}$.: Do you think that you can reach this?

M.: Yeah, I'm confident. 


\author{
Text: $\quad$ Interview WMarc_17.04.2009 \\ Gewicht: $\quad 0$ \\ Position: $\quad 88-92$ \\ Code: Reasons For Studying German|Possible SelffFollow-up/Questionnaire
}

V.: If my dreams come true, I will use German effectively in the future has moved up from "quite a lot" to "very much", do you feel using German effectively has become more important to you?

M.: Yes, I told you about translating, this is what I want to do, I told you about my neighbour, XX, didn't I? Yes, I would quite like to do something similar to her, maybe have my own translation company, yes. 


\section{Appendix $16 \quad$ Example of Motivational Profile}

$\underline{\text { Jane }}$

Jane links her motivation to study German to the enjoyment she felt when engaging with German at school level. She also mentions a school exchange which she enjoyed:

the main reason I decided to study German was because I'd done it at school since I was about eleven, and I really enjoyed it, always felt I had a thing for it. I wouldn't call myself a natural linguist, but it was always a language that I associated well with, um, and my whole way through school I really enjoyed it. I went on an exchange to Germany and I met people there and I liked them and aspect, there are aspects about the German culture that I just really, really like, um, it was just I wanted to study that and the literature, especially here.

She stresses that she does not have a German background, but that she has always been interested in German and that her brother also studies German and French at University A. She says that "seeing him study" really made her "interested" as well. She explains: "It was something I always wanted to take part in as well. I'd say that's probably why I decided to study it". She feels that her whole family is supportive, as they feel that languages are "wide-based" subjects. She hopes to get a "lot better at the speaking side of it" by studying German. She hopes that by the time she finishes the course, she will "have achieved a good, solid level of fluency". She stresses: "that's something that I would really, really like to achieve and I hope that I can do it”.

When asked why she enjoyed learning German at school, Jane explains that before A-levels, German classes were "a little dry" and "very centred around passing the exam". However, she felt she was "very, very lucky" at A-level, because she "had a really motivating teacher". She explains:

I had a really motivating teacher who saw how dull the curriculum was and instead of just doing that added for of little extra modules and gave us some books, we like read Sansibar oder der letzte Grund and three other books and things that were quite difficult but pushed us instead of just plodding through language exercises, 
this was tacked on the side to make us interested in it and I don't know that was good for me, that was what I was interested in, but it was quite centered around the curriculum. And I think that is the main difference: because here, it is not about teaching you to pass exams, we have a curriculum but then it is whatever you decide what to do after that.

She attributes her success to her "really, really good teachers". She explains that "they were not just doing their job, they were interested in the pupils". She also felt that "the general ethos" at her school was that students got "pushed" quite a lot.

In retrospective she feels that the school experience was very important for her decision to study German, she describes it as "a huge, huge fostering influence". She feels that her teacher "brought out the best in people". She explains that three students out of a class of five are now studying either at University A or another League Table university. She then explains that job prospects are not as important for her:

I don't see university as just a vehicle for getting a job because I think, I think you could probably spend your time better, spend your time getting a job as opposed to studying for one. That's why I started German because of the love of the language and I wanted to become better and to immerse myself in the language.

\begin{tabular}{|c|c|c|c|c|c|}
\hline \multicolumn{4}{|c|}{ 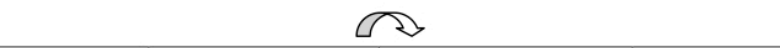 } & \multicolumn{2}{|c|}{ R } \\
\hline Quotation & $\begin{array}{l}\text { at school }(\ldots) \text { I } \\
\text { really enjoyed it }\end{array}$ & $\begin{array}{l}\text { I went on an } \\
\text { exchange to } \\
\text { Germany and I } \\
\text { met people there } \\
\text { and I liked them } \\
\text { and aspect, there } \\
\text { are aspects about } \\
\text { the German } \\
\text { culture that I just } \\
\text { really, really like, } \\
\text { um, it was just I } \\
\text { wanted to study } \\
\text { that and the } \\
\text { literature, } \\
\text { especially here }\end{array}$ & $\begin{array}{l}\text { seeing } \\
\text { him study } \\
\text { really } \\
\text { made me } \\
\text { interested } \\
\text { as well } \\
\text { (...) It was } \\
\text { something } \\
\text { I always } \\
\text { wanted to } \\
\text { take part } \\
\text { in as well. }\end{array}$ & $\begin{array}{l}\text { really } \\
\text { motivating } \\
\text { teacher }\end{array}$ & $\begin{array}{l}\text { added little extra } \\
\text { modules and gave } \\
\text { us some books, } \\
\text { we like read } \\
\text { Sansibar oder der } \\
\text { letzte Grund and } \\
\text { three other books } \\
\text { and things that } \\
\text { were quite } \\
\text { difficult but } \\
\text { pushed us instead } \\
\text { of just plodding } \\
\text { through language } \\
\text { exercises }\end{array}$ \\
\hline Category & $\begin{array}{l}\text { Intrinsic: } \\
\text { Enjoyment } \\
\text { School } \\
\text { Experience: } \\
\text { Enjoyment }\end{array}$ & $\begin{array}{l}\text { School } \\
\text { Experience: } \\
\text { student exchange } \\
\text { Integrativeness } \\
\text { (?): } \\
\text { likes German } \\
\text { people and } \\
\text { culture }\end{array}$ & $\begin{array}{l}\text { Family } \\
\text { Influence: } \\
\text { brother } \\
\text { studies } \\
\text { German }\end{array}$ & $\begin{array}{l}\text { School } \\
\text { Experience: } \\
\text { teacher }\end{array}$ & $\begin{array}{l}\text { School } \\
\text { Experience: } \\
\text { teaching } \\
\text { Intrinsic: } \\
\text { feelings of } \\
\text { accomplishment } \\
\text { when mastering } \\
\text { difficult tasks }\end{array}$ \\
\hline
\end{tabular}

